\title{
Abstract \\ Three Essays on the Politics of American Social Programs
}

\author{
Baobao Zhang
}

2020

This dissertation presents experimental and quasi-experimental studies that examined the drivers of Americans' attitudes toward social programs. The first and second essays sought to understand how benefiting social programs (e.g., Medicare and governmental scholarships) affected voters' political attitudes and behavior, a process termed policy feedback. The third essay investigated how expert forecasts about automation's potential impact shaped Americans' beliefs about the future of work and preferences for governmental response.

The first essay, "Hands Off My Medicare? Self-Interest and Conditional Policy Feedback," examined how Medicare affects American seniors' political attitudes and behavior. Seniors citizens, compared with other age groups, have consistently expressed the lowest level of support for the Affordable Care Act (ACA). This observation has led some to hypothesize that seniors oppose the ACA because they perceive that the policy threatens Medicare. Lerman and McCabe's (2017) regression discontinuity design study produces a surprising finding: receiving Medicare increases support for the ACA. My research tackles the methodological problems of the original study and expands the analysis to include four additional datasets. Contrary to Lerman and McCabe (2017), I find that acquiring Medicare has almost no impact on one's support for the ACA and limited impact on one's support for Medicare. My study suggests that evidence for policy feedback through changes in public opinion is weak, and where it exists, respondents' shift in attitudes reflects their self-interest.

The second essay "Scientists' Political Participation is Not Motivated by Government Benefits" (with Matto Mildenberger, University of California, Santa Barbara) examined the relationship between government funding for science education and political activism by scientists. Some political critics of scientists argue that scientists have become partisan 
political actors with self-serving financial agendas. However, most scientists strongly reject this view. While social scientists have explored the effects of science politicization on public trust in science, little empirical work directly examines the drivers of scientists' interest in and willingness to engage in political advocacy. Using a natural experiment involving the U.S. National Science Foundation Graduate Research Fellowship (NSF-GRF), we causally estimate for the first time whether scientists who have received federal science funding are more likely to engage in both science-related and non-science-related political behaviors. Comparing otherwise similar individuals who received or did not receive NSF support, we find that scientists' preferences for political advocacy are not shaped by receiving government benefits. Government funding did not impact scientists' support of the 2017 March for Science, nor did it shape the likelihood that scientists donated to either Republican or Democratic political groups. Our results offer empirical evidence that scientists' political behaviors are not motivated by self-serving financial agendas. They also highlight the limited capacity of even generous government support programs to increase civic participation by their beneficiaries.

The third essay, "No Rage Against the Machines: Threat of Automation Does Not Change Policy Preferences," examined whether the threat of workplace automation changes political preferences. Labor-saving technology has already decreased employment opportunities for middle-skill workers. Experts anticipate that advances in artificial intelligence (AI) and robotics will cause even more significant disruptions in the labor market over the next two decades. This paper presents three experimental studies that investigate how this profound economic change could affect mass politics. Recent observational studies suggest that workers' exposure to automation risk predicts their support not only for redistribution but also for right-wing populist policies and candidates. Other observational studies, including my own, find that workers underestimate the impact of automation on their job security. Misdirected blame towards immigrants and workers in foreign countries, rather than concerns about workplace automation, could be driving support for right-wing populism. To correct American workers' beliefs about the threats to their jobs, I conducted three survey experiments in which I informed workers about the existent and future impact of workplace automation. While these informational treatments convinced workers 
that automation threatens American jobs, they failed to change respondents' preferences on welfare, immigration, and trade policies. My research finds that raising awareness about workplace automation did not decrease opposition to globalization or increase support for policies that will prepare workers for future technological disruptions. 


\title{
Three Essays on the Politics of American Social Programs
}

\author{
A Dissertation \\ Presented to the Faculty of the Graduate School \\ of \\ Yale University \\ in Candidacy for the Degree of \\ Doctor of Philosophy
}

\author{
by \\ Baobao Zhang \\ Dissertation Director: Jacob S. Hacker
}

May 2020 
Copyright (C) 2020 by Baobao Zhang All rights reserved. 


\section{Contents}

\begin{tabular}{|l|l}
\hline Acknowledgements & xiv
\end{tabular}

1 Introduction: When Policy Struggles to Remake Mass Politics 1

1.1 Building Nuance into Policy Feedback . . . . . . . . . . . . . . . . . . . . . 2

$1.2 \quad$ Limitations of the Quantitative Causal Inference Approach . . . . . . . . . 3

1.3 Policy Feedback Competes with Politics . . . . . . . . . . . . . . . . . . 4

2 Hands Off My Medicare? How Government Benefits Fail to Change Po-

$\begin{array}{ll}\text { litical Attitudes } & 9\end{array}$

2.1 Introduction and Background $\ldots \ldots \ldots \ldots$

2.2 Research Design and Hypotheses $\ldots \ldots \ldots$. . . . . . . . . . . 10

2.3 Results $\ldots \ldots \ldots \ldots \ldots \ldots$

2.4 Discussion and Conclusion . . . . . . . . . . . . . . . . 17

3 Scientists' Political Behaviors Are Not Driven By Individual-level Gov$\begin{array}{ll}\text { ernment Benefits } & 19\end{array}$

3.1 Overview . . . . . . . . . . . . . . . . . . . . . . . . . . . . . . . 19

3.2 Materials and Methods . . . . . . . . . . . . . . . . . . . . . 21

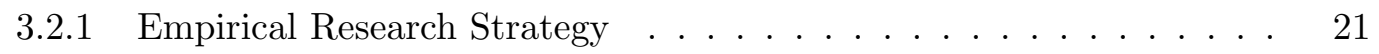

3.2 .2 Data . . . . . . . . . . . . . . . . . . . . . 22

3.2 .3 Balance Tests . . . . . . . . . . . . . . . . . . . . . . . . . . 23

3.2 .4 Analysis of Main Outcomes . . . . . . . . . . . . . 25

3.3 Results. . . . . . . . . . . . . . . . . . . . . . . . . . . . . . . 27 
3.4 Discussion $\ldots \ldots \ldots \ldots \ldots$

4 No Rage Against the Machines: Threat of Automation Does Not Change

$\begin{array}{ll}\text { Policy Preferences } & 31\end{array}$

$4.1 \quad$ Introduction $\ldots \ldots \ldots \ldots \ldots \ldots$

4.2 Literature Review $\ldots \ldots \ldots \ldots$. . . . . . . . . . . . . . . . . . 32

4.2 .1 Impact of Automation on the Labor Market . . . . . . . . . . . . . . 33

4.2 .2 Impact of Automation on Mass Politics . . . . . . . . . . . . . 34

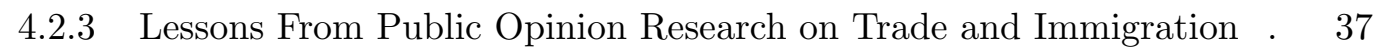

4.3 Hypotheses and Outcome Measures . . . . . . . . . . . . . . . . . . . 39

4.3 .1 Hypotheses $\ldots \ldots \ldots \ldots$

4.3 .2 Outcome Measures $\ldots \ldots$. . . . . . . . . . . . . . . . . . . . . 40

4.4 Three Empirical Studies . . . . . . . . . . . . . . . . . . . . . . . . 41

4.4.1 Study 1: The Impact of Expert Forecasts on Factual Beliefs and Policy Preferences . . . . . . . . . . . . . . . . . 44 41

$4.4 .2 \quad$ Study 2: Survey Experiment Studies Workers Highly Affected Automation ......................... 52

4.4.3 Study 3: Survey Experiment Investigates Policy Responses to Workplace Automation . . . . . . . . . . . . . . . . . 57

4.5 Discussion $\ldots \ldots \ldots \ldots \ldots \ldots \ldots$

4.5.1 Changing Political Preferences Is Harder than Changing Factual Beliefs 60

4.5 .2 Uncertain Future, Uncertain Workers . . . . . . . . . . . . . . 61

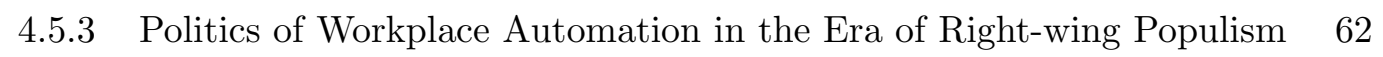

4.6 Conclusion $\ldots \ldots \ldots \ldots$

A Appendix for "Hands Off My Medicare? How Government Benefits Fail to Change Political Attitudes"

A.1 Critique of Previous Research . . . . . . . . . . . . . . . . . . 65

A.2 Survey Text . . . . . . . . . . . . . . . . . . . . 67

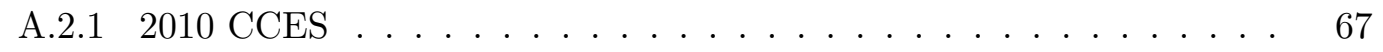

A.2.2 $2012 \mathrm{CCES} \ldots \ldots \ldots \ldots \ldots$ 
A.2.3 2014 CCES . . . . . . . . . . . . . . . . . . 70

A.2.4 Questions from the 2010/2012/2014 CCES Panel Study . . . . . . . 73

A.2.5 Placebo Outcome Questions . . . . . . . . . . . . . 75

A.3 Additional Figures $\ldots \ldots \ldots \ldots$. . . . . . . . . . . . . . . . 79

A.4 Balance Tests . . . . . . . . . . . . . . . . . . . . 85

A.5 Robustness Checks . . . . . . . . . . . . . . . . . . . . . . . . . . 90

A.5.1 Placebo Outcomes . . . . . . . . . . . . . . . . . . 90

A.5.2 OLS Estimates . . . . . . . . . . . . . . . . . . . . . 92

A.5.3 Those Who Did Not Have a Job in the Past Five Years . . . . . . . 95

A.5.4 Placebo Treatment Using Placebo Age Cutpoints . . . . . . . . . . . 97

B Appendix for "Scientists' Political Behaviors Are Not Driven By Individual-level Government Benefits" $\quad 101$

B.1 Replication Materials . . . . . . . . . . . . . . . . . . . . . . 101

B.2 Procedure to Match Subjects with Political Donation Records . . . . . . . 101

B.3 Main Results Tables . . . . . . . . . . . . . . . . . . . . . . . . . . . 102

B.4 Further Details About the Subjects . . . . . . . . . . . . . . . . 105

B.5 Additional Results . . . . . . . . . . . . . . . . . . . . . 107

B.6 Additional Survey Experimental Results . . . . . . . . . . . . . . . . . 110

B.6.1 Partisan Cues Survey Experiment . . . . . . . . . . . . . . . 110

B.6.2 Domain Expertise Survey Experiment . . . . . . . . . . . . . . 111

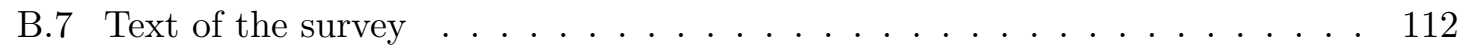

C Appendix for "No Rage Against the Machines: Threat of Automation Does Not Change Policy Preferences" $\quad 124$

C.1 Text of Study 1 . . . . . . . . . . . . . . . . . . . . . . . . 124

C.1.1 Instructions . . . . . . . . . . . . . . . . . . . . 124

C.1.2 Control . . . . . . . . . . . . . . . . . . . . . . . . . . 124

C.1.3 Treatment 1: General Forecast - Frey and Osborne . . . . . . . . . . 124

C.1.4 Treatment 2: General Forecast - OECD . . . . . . . . . . . . . . . . 125

C.1.5 Treatment 3: Individual Forecast - Frey and Osborne . . . . . . . . 126 
C.1.6 Treatment 4: Individual Forecast - OECD . . . . . . . . . . . . . . 126

C.1.7 Outcome Measures . . . . . . . . . . . . . . . . . . . . . . . . . . . 127

C.2 Text of Study 2 . . . . . . . . . . . . . . . . . . . . 134

C.2.1 News Article Informational Treatment . . . . . . . . . . . . . . . . . 134

C.2.2 Outcome Measures . . . . . . . . . . . . . . . . . . . 135

C.3 Text of Study $3 \ldots \ldots \ldots \ldots$. . . . . . . . . . . . . . . . 137

C.3.1 News Article Informational Treatment . . . . . . . . . . . . . . . . . 137

C.3.2 Outcome Measures . . . . . . . . . . . . . . . . . . . . . . . . . 138

C.4 Additional Figures and Tables . . . . . . . . . . . . . . . . . . . . . . . . 140

C.4.1 Study 1 . . . . . . . . . . . . . . . . . . . . . . . . . . 140

C.4.2 Study 2 . . . . . . . . . . . . . . . . . . . 153

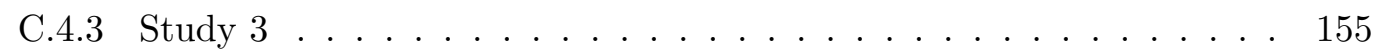




\section{List of Figures}

2.1 Effects of Acquiring Medicare on Respondents' Attitudes: Evidence from 2010, 2012, 2014, and 2016 Cross-Sectional CCES Surveys . . . . . . . . . . 15

2.2 Effects of Acquiring Medicare on Respondents' Attitudes: Evidence from the $2010 / 2012 / 2014$ CCES Panel Study $\ldots$. . . . . . . . . . . . . . . . . 16

$3.1 \quad$ Comparing Differences in Background Characteristics Between Winners and Non-winners . . . . . . . . . . . . . . . . . . . . . . . 25

3.2 Comparing Differences in Contact Information Between Winners and Nonwinners . . . . . . . . . . . . . . . . . . 26

$3.3 \quad$ Effect of Being Awarded the NSF Graduate Research Fellowship on Political Attitudes and Behavior f . . . . . . . . . . . . . . . . . . 28

3.4 Effect of Being Awarded the NSF Graduate Research Fellowship on Political

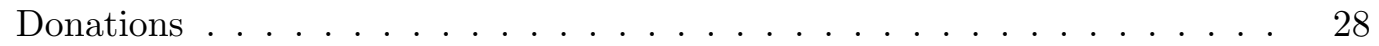

$4.1 \quad$ Study 1 Survey Experiment Flowchart . . . . . . . . . . . . . . . . . . . . . 43

4.2 Study 1 Results: Beliefs About the Future of Work . . . . . . . . . . . . . . 48

4.3 Study 1 Results: Policy Preferences . . . . . . . . . . . . . . . . . . . . . . . 51

4.4 The Informational Treatment News Article Displayed in Study 2 . . . . . . 53

4.5 Study 2 Results: Beliefs About the Future of Work . . . . . . . . . . . . . . 55

4.6 Study 2 Results: Policy Preferences . . . . . . . . . . . . . . . . . . 56

4.7 Study 3 Results: Manipulation Check and Policy Preferences . . . . . . . . 58

A.1 Support of the Affordable Care Act (ACA) by Age . . . . . . . . . . . . . . 79

A.2 Support of the Affordable Care Act (ACA) by Age Group Across Time . . 80 
A.3 Percent of Respondents Who Gained Government Health Insurance Between Waves of the 2010-2014 CCES Panel Study . . . . . . . . . . . . . . 81

A.4 Effects of Acquiring Medicare on Respondents' Attitudes: Evidence from 2010, 2012, 2014, and 2016 Cross-Sectional CCES Surveys . . . . . . . . . 82

A.5 Effects of Acquiring Medicare on Respondents' Attitudes: Evidence from the CCES 2010/2012/2014 Panel Study . . . . . . . . . . . . . . . . 83

A.6 Discussion of Health Care Policy Topics: Evidence for Google Trends Data 84

A.7 Balance Test: IV Estimates 2010 . . . . . . . . . . . . . . . . . . 85

A.8 Balance Test: IV Estimates $2012 \ldots \ldots \ldots \ldots$

A.9 Balance Test: IV Estimates $2014 \ldots \ldots \ldots$. . . . . . . . . . 87

A.10 Balance Test: IV Estimates 2016 . . . . . . . . . . . . . . . . 88

A.11 Balance Test: Panel RDD IV Estimates . . . . . . . . . . . . . . . . . . 89

A.12 Effects of Acquiring Medicare on Placebo Outcomes: Evidence from the 2010, 2012, 2014, and 2016 Cross-Sectional CCES Surveys . . . . . . . . . . . . 91

A.13 Effects of Acquiring Medicare on Placebo Outcomes: Evidence from the 2010/2012/2014 CCES Panel Study . . . . . . . . . . . . . . . . . . 92

A.14 OLS Estimates: 2010-2012 Cross-sectional CCES Surveys . . . . . . . . . . 93

A.15 OLS Estimates: 2014-2016 Cross-sectional CCES Surveys . . . . . . . . . . 94

A.16 OLS Estimates: Panel Study . . . . . . . . . . . . . . . . . . 95

A.17 IV Estimates 2012: Those Who Did Not Have a Job in the Past Five Years 96

A.18 IV Estimates 2014: Those Who Did Not Have a Job in the Past Five Years 97

A.19 IV Estimates Using Age 64 as the Cutpoint (2010, 2012, 2014, and 2016 Cross-sectional CCES Surveys) $\ldots \ldots \ldots$

A.20 IV Estimates Using Age 66 as the Cutpoint (2010, 2012, 2014, and 2016 Cross-sectional CCES Surveys

A.21 IV Estimates Using Age 64 as the Cutpoint (2010/2012/2014 CCES Panel Study $\ldots \ldots \ldots \ldots$. . . . . . . . . . . . . . . . . . . . . . . . .

A.22 IV Estimates Using Age 66 as the Cutpoint (2010/2012/2014 CCES Panel

Study $\ldots \ldots \ldots \ldots \ldots$. . . . . . . . . . . . . . . . . . . . . . . . . 
B.1 Robustness Check: Effect of Being Awarded the NSF Graduate Research Fellowship on Political Donations $(N=2,119)$ by Setting Top Donations to $\$ 0108$

B.2 Experiment 2 Results: Comfort with Political Advocacy as a Function of Advocates' Message and Discipline . . . . . . . . . . . . . . . . . . . . . . . 112

C.1 Study 1: Correlation between respondents' perceived likelihoods of their jobs becoming automated and experts' forecasts is low. . . . . . . . . . . . . . . 140

C.2 Study 1: Distribution of predicted likelihood that respondents' jobs will be automated by forecast dataset . . . . . . . . . . . . . . . . . . . 141

C.3 Respondents' trust of the expert forecasts by treatment group; the error bars are the $95 \%$ confidence intervals $\ldots \ldots \ldots$. . . . . . . . . . . 151

C.4 Respondents' self-reported feelings of anxiety by treatment group; the error bars are the $95 \%$ confidence intervals $\ldots \ldots \ldots$. . . . . . . . . 152

C.5 Respondents' self-reported feelings of negative emotions by treatment group; the error bars are the $95 \%$ confidence intervals $\ldots \ldots \ldots$. . . . . . . . . 152 


\section{List of Tables}

$1.1 \quad$ Literature Review of Policy Feedback Studies Related to the Affordable Care

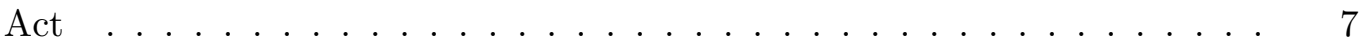

1.2 Literature Review of Policy Feedback Studies Related to the Affordable Care Act (Continued) $\ldots \ldots \ldots \ldots \ldots \ldots$

B.1 Effect of Being Awarded the NSF Graduate Research Fellowship on Political Attitudes and Behavior $(N=408)$; Including Background Covariates . . . . 103

B.2 Effect of Being Awarded the NSF Graduate Research Fellowship on Political Attitudes and Behavior $(N=408)$; Not Including Background Covariates . 104

B.3 Effect of Being Awarded the NSF Graduate Research Fellowship on Political Donations $(N=2,119)$; Including Background Covariates . . . . . . . . . . 104

B.4 Effect of Being Awarded the NSF Graduate Research Fellowship on Political Donations $(N=2,119)$; Not Including Background Covariates . . . . . . . 105

B.5 Summary Statistics of Respondents and Non-respondents . . . . . . . . . . 105

B.6 Predicting Survey Response Using Applicants' Characteristics . . . . . . . . 106

B.7 Summary Statistics of the Survey Sample . . . . . . . . . . . . . . . . . 106

B.8 Predicting Award Using Survey Sample's Respondent Characteristics . . . . 107

B.9 Naive Balance Test: Simple Difference-in-Means Between Winners and Nonwinners (All Subjects; $N=2,119)] \ldots \ldots \ldots \ldots$. . . . . . . . 107

B.10 Effect of Being Awarded the NSF Graduate Research Fellowship on Political Donation Amounts: Randomization Inference Results (Based on 1,000 Simulations $) \ldots \ldots \ldots \ldots \ldots \ldots$. . . . . . . . . . . . . . . . . . . . . 
B.11 Effect of Being Awarded the NSF Graduate Research Fellowship on Political Donations $(N=2,119)$; Including Only Predicted Gender as A Background Covariate . . . . . . . . . . . . . . . . . . 109

B.12 Interaction Effects of Award and Year of Application on Political Donations $(N=2,119) \ldots \ldots \ldots \ldots \ldots \ldots \ldots \ldots \ldots$

B.13 Interaction Effects of Award and Year of Application on Political Attitudes and Behavior $(N=408) \ldots \ldots \ldots \ldots \ldots \ldots$

B.14 Experiment 1 Results: March for Science Support as a Function of Exposure to Partisan Cue Conditions . . . . . . . . . . . . . . . . . . . . . 111

C.1 Likelihood categories linked to predicted percent chance of jobs becoming automated . . . . . . . . . . . . . . . 126

C.2 Study 1: Standardized treatment effect estimates - General Forecast . . . . 142

C.3 Study 1: Standardized treatment effect estimates - Individual Forecast . . . 143

C.4 Study 1: Non-standardized treatment effect estimates - General Forecast . 144

C.5 Study 1: Non-standardized treatment effect estimates - Individual Forecast 145

C.6 Study 1: Testing the difference in estimated effects between forecast sources (Frey and Osborne vs. OECD) - General Forecast . . . . . . . . . . . . . 146

C.7 Study 1: Testing the difference in estimated effects between forecast sources (Frey and Osborne vs. OECD) - Individual Forecast . . . . . . . . . . . . . 147

C.8 Study 1: Testing the difference in estimated effects between the General Forecast Treatment and Individual Forecast Treatment using responses from subjects in Group B . . . . . . . . . . . . . . . . . . . . . . 148

C.9 Study 1: Interaction effects - Individual Forecasts (Frey and Osborne) . . . 149 C.10 Study 1: Interaction effects - Individual Forecasts (OECD) . . . . . . . . . 150

C.11 Manipulation check: responses by experimental group . . . . . . . . . . . . 151

C.12 Study 2: Standardized treatment effect estimates . . . . . . . . . . . . . . 153

C.13 Study 2: Non-standardized treatment effect estimates . . . . . . . . . . . . 154

C.14 Study 3: Standardized treatment effect estimates . . . . . . . . . . . . . . 155

C.15 Study 3: Non-standardized treatment effect estimates . . . . . . . . . . . . 155 
C.16 Study 3: Non-standardized treatment effect estimates by demographic subgroups - gender . . . . . . . . . . . . . . . . . . . . . 156

C.17 Study 3: Non-standardized treatment effect estimates by demographic subgroups - race $\ldots \ldots \ldots \ldots \ldots \ldots \ldots$

C.18 Study 3: Non-standardized treatment effect estimates by demographic subgroups - age group . . . . . . . . . . . . . . . . . . . . 158

C.19 Study 3: Non-standardized treatment effect estimates by demographic subgroups - political party $\ldots \ldots \ldots$. . . . . . . . . . . . . . 159

C.20 Study 3: Non-standardized treatment effect estimates by demographic subgroups - level of education . . . . . . . . . . . . . . . . . . . . . 160

C.21 Study 3: Non-standardized treatment effect estimates by demographic subgroups - employment status . . . . . . . . . . . . . . . . . . . . 161 
To all the health care professionals, essential workers, and research scientists on the front lines of the COVID-19 Pandemic 


\section{Acknowledgements}

I am very grateful to all the people who made this dissertation possible, in particular, my dissertation committee, Jacob Hacker (chair), Devin Caughey, and Allan Dafoe. You provided me with helpful feedback on my research projects and moral support through my $\mathrm{PhD}$ program. Thank you for committing to my success even as my dissertation and research interests radically changed over the years. Jacob, you have inspired me to become a politically engaged scholar and prepared me for my new career teaching at a public policy school. Devin, you pushed me to excel with your constructive criticism and offered useful life advice with a dose of humor. Allan, thank you for all the research and professional opportunities you have provided me over our eight years (and counting!) of collaboration.

Although he is not officially a part of my dissertation committee, Matto Mildenberger has been an integral part of my graduate school experience; he is a co-author on Chapter 3 of this dissertation. Matto introduced me to the Yale Program on Climate Change Communication, where I worked part-time as a data scientist for two years. He has also advised me on research and professional development. Thank you for being such a patient collaborator and mentor.

Another collaborator I would like to acknowledge is David Knight, my co-author on the "Moving to Opportunity" Youth Civic Participation Study that, unfortunately, did not make it into this dissertation. David is a very caring researcher and educator committed to racial and economic justice. His hard work in grant writing and communicating with governmental agencies has moved this Sisyphean project from an idea to almost reality.

Many other colleagues and friends in Yale's academic communities have helped me throughout the years. I'm grateful for further advising by Anthony Leiserowitz, John Bul- 
lock, Maggie Peters, Alan Gerber, Greg Huber, John Henderson, Jay Emerson, Sander van der Linden, and others. Although my PhD cohort has spread their wings across the world, I am grateful for their friendship. In particular, I am thankful for Ben Miller's patience and support: you have been and continue to be my moral compass.

MIT's Political Science Department has been a second home to me. Devin Caughey, Adam Berinsky, David Singer, Fotini Christia, and many faculty and staff members who made me feel welcomed. Furthermore, I'm grateful for the friends that I have made in the Department, including Tesalia Rizzo, Dan Sands De Kadt, Parrish Bergquist, Nina McMurry, John Curiel, Alexander Agadjanian, Anna Weissman, Tom O'Grady, and members of Sandwich Club, especially Rémi Cura.

I am also grateful for the time that I spent at the University of Oxford and my continuing collaboration with the Centre for the Governance of AI (GovAI). Thank you to the Future of Humanity Institute and Nuffield College for hosting me. Markus Anderljung, Ben Ansell, Raymond Duch, and many others have been great colleagues. There is a special place in my heart for the residents and friends of 50 Walton Street, particularly Toby Nowacki, Laurin Weissinger, and Anna Mikkelborg. The Berkman Klein Center for Internet \& Society at Harvard University has become yet another academic home for me. I am so happy to have met many researchers passionate about ensuring that technology empowers the many, not the elite few.

I would also like to thank those outside the discipline who offered their moral support, including my parents, Xixi Yu, Paul Keene, Barbara Bai, Marta S. Rivera Monclova, Jane Heyes, Betsy Noecker, Lindy Noecker, Ben Perry, Angharad Davis, Briallen Hopper, Annie Wang, the Saint Peter's Episcopal Church Choir (Cambridge, Mass.), and the St Edmund Hall Chapel Choir (Oxford, U.K.). I'm also grateful to Ian Oliver (Yale) and Thea KeithLucas (MIT), two chaplains who offered me spiritual direction both in times of mirth and in times of distress.

Finally, I am grateful to the new friends and colleagues who have helped me on the academic job market over the past few months. Sarah Kreps, Karen Levy, and Peter Enns supported my successful application to the Cornell Society of Fellows. Jamie Winders and Brian Taylor have been very encouraging of my new career as an assistant professor at the 
Maxwell School, Syracuse University. Nathan Matias, Hakeem Jefferson, and Moira Weigel offered excellent career advice. I look forward to working with my new colleagues at Cornell and Syracuse.

My educational and professional is made possible through the generous financial support of many institutions. The Ethics and Governance of AI Fund has allowed me to conduct research as a postdoctoral fellow at the MIT Department of Political Science and continue my collaboration with GovAI. The Kerry Fellowship through the Yale Jackson Institute for Global Affairs and Yale Institution for Social and Policy Studies Policy (ISPS) Fellowship helped prepare me for policy research and public engagement. ISPS financially supported the research that made this dissertation possible. The National Science Foundation Graduate Research Fellowship and Allan Shelden, III Memorial Fellowship helped fund my graduate education. 


\section{Chapter 1}

\section{Introduction: When Policy}

\section{Struggles to Remake Mass Politics}

A perennial question in the study of American politics asks what factors affect political attitudes and behavior. My dissertation investigates this question using experimental and quasi-experimental methods. The well-estimated null findings in each of the chapters suggest that some of the factors theorized to affect political attitudes and behavior, such as social programs and economic conditions, are much smaller than expected. In this introduction, I consider how policy feedback, the process by which social programs impacts politics, might have a limited impact on individuals' policy preferences and political engagement. In Chapter 2, I find that seniors who acquired Medicare did not become more supportive of the Affordable Care Act (ACA) nor Medicare itself. In Chapter 3, Matto Mildenberger and I find that scientists' political activism was not motivated by individual-level benefits. By reflecting on these two studies, along with recent research on the political impacts of the ACA (summarized in Tables 1.1 and 1.2), I conclude that stability in Americans' political attitudes and behavior circumscribes policy feedback effects at the individual level. Although Chapter 4 of my dissertation does not focus on policy feedback, some of the theoretical principles in this essay could explain why expert forecasts of automation failed to change workers' preferences toward social protection. 


\subsection{Building Nuance into Policy Feedback}

The naïve account of policy feedback, a strawman that most researchers would disavow today, states that beneficiaries of social programs become politically activated to defend the policies that favor them. (See Galvin and Thurston (2017) for a spirited critique of this strawman account of policy feedback.) Recent studies have compelled researchers to develop more nuanced theories of policy feedback by recognizing the limitations of social policies to change mass politics. A meta-analysis of 65 publications on the impact of social policies on policy attitude, political attitude, and civic engagement finds that a majority of these studies failed to detect "effects" at the $\alpha=0.1$ level (Larsen, 2019). These null effects could be attributed to the fact that many Americans fail to recognize the benefits that they receive are the results of governmental policies (Mettler, 2011). Although more Americans than ever receive government benefits, their preferences toward social policies are driven more by their partisanship, race, or class identities than by their experience with social programs (Mettler, 2018).

In particular, strong partisan attachments in our current era of mass polarization hinder voters' ability to attribute policy benefits to the party that have implemented the policy and continued to defend it (Alexander Branham, 2018; Hacker and Pierson, 2019). This phenomenon is clearly visible in the partisan response to the ACA at not only at the institutional level (e.g., Republican-controlled states refusing to expand Medicaid and Congressional Republicans trying to repeal the ACA) but also the individual level (Patashnik and Zelizer, 2013). Republican voters' distrust of the ACA goes beyond mere political behavior. Republicans enrolled in Marketplace insurance plans at a lower rate than their Democratic counterparts and were less likely to enroll when presented with messaging that emphasized the role of the government in running these exchanges (Lerman, Sadin and Trachtman, 2017).

In the next two sections, I present two arguments based on political behavior methods and research findings on why the policy feedback effects in this dissertation and the studies I reviewed are limited. While these arguments are not wholly novel, they make lucid that connection between two disparate research topics. 


\subsection{Limitations of the Quantitative Causal Inference Ap- proach}

Researchers have called for more studies to identify the causal effect of a policy on political attitudes or behavior (Campbell, 2012). Nevertheless, applying the quantitative causal inference framework to the study of policy feedback also has shortcomings. First, by focusing on how a policy impacts individuals' attitudes and behavior, the research designs cannot account for how policy adoption affects politics at an institutional level. Second, the research designs limit researchers to studying individuals who are identical or nearly identical in their background characteristics.

My studies and similar ones attempt to estimate the average treatment effect of a policy on some political outcome: $\mathbb{E}\left[Y_{i}\left(B_{i}=1, P_{i}=1\right)\right]-\mathbb{E}\left[Y_{i}\left(B_{i}=0, P_{i}=1\right)\right]$, where $Y_{i}$ is the political outcome, $B_{i}$ is an indicator variable for benefiting from the program, and $P_{i}$ is an indicator variable for whether the program exists. Note that the program is presumed to exist when one makes these counterfactual comparisons; this quantity reflects a narrow conception of policy feedback. In contrast, the broader conception of policy feedback as "policy makes new politics" asks researchers to identify a different quantity: $\mathbb{E}\left[Y_{i}\left(P_{i}=\right.\right.$ $1)]-\mathbb{E}\left[Y_{i}\left(P_{i}=0\right)\right]$. In plain terms, it represents how political attitudes and behavior would differ between a counterfactual world in which the policy exists and one in which the policy does not exist. Given the high stakes with creating new programs or eliminating them, social policies are rarely adopted at random.

Clever identification strategies are much harder to come by when researchers seek to estimate the impact of a policy coming into existence. Yet, this quantity of interest may be the most policy-relevant one: new programs reshape the political landscape because they "strengthen already supportive [interest] groups or induce previously neutral or skeptical groups to reassess their interests" (Hacker and Pierson, 2019, 21). For example, wellfunded conservative interest groups have helped Republicans to win state-level elections and draft policies to reduce funding on unemployment insurance, food stamps, and Medicaid (Hertel-Fernandez, 2019). Studying the role of institutions (e.g., interest groups and state legislators) play in policy feedback likely requires researchers to take up qualitative methods, 
including process tracing, archival research, and elite interviews.

The causal inference approach also requires researchers to find random or as-if random processes by which benefits are distributed. Typically, those who are impacted by a policy are unlike those who are not (e.g., older vs. younger in Medicare eligibility, poorer vs. wealthier in Medicaid eligibility, etc.). As a result, differences in the observed outcomes between those impacted and those not impacted could be attributed not only to the policy but also the background differences of the individuals. But in field experiments or natural experiments, beneficiaries and non-beneficiaries are identical or almost identical in terms of their background characteristics, allowing one to isolate the average causal effect of the policy on subjects' political attitudes and behavior.

The similarity between beneficiaries and non-beneficiaries could limit detectable effects. In the most rigorous study I reviewed (the impact of the Oregon Health Insurance Experiment on electoral participation), receiving Medicaid by lottery increased turnout in the 2008 Presidential Election by a small amount, but the effect did not persist (Baicker, Finkelstein et al., 2019). I note two potential reasons for the lack of long-term change. First, nonbeneficiaries in these cases anticipate becoming beneficiaries in the near future. In the case of the Oregon Health Insurance Experiment, the state eventually expanded Medicaid under the ACA, so even in those in the control group would qualify. Interest groups seeking to build a broad base of supporters would often recruit "near-beneficiaries." In the case of Medicare, the American Association of Retired Persons (AARP) recruits those who are 50 and above. The March for Science recruited wide swaths of scientists to participate, not only those who received government funding. Furthermore, as I will discuss in the next section, policy preferences and political engagement can be very reasonably stable; factors that induce a change in preferences or behavior needs to be strong to overcome this inertia.

\subsection{Policy Feedback Competes with Politics}

Drawing upon political behavior research, I argue that policy feedback effects could often be limited by the stability in individuals' policy preferences and political engagement. I begin this section by acknowledging that there is not complete agreement in the discipline on 
whether individuals' preferences or behavior are stable over time. For instance, from Converse (1964) to Freeder, Lenz and Turney (2019), survey data have shown that large swaths of Americans do not have stable policy preferences over time. However, those with stronger partisan ties do have more stable policy attitudes. Likewise, political engagement need not be static: field experiments have demonstrated that get-out-the-vote (GOTV) messaging, particularly those that involve personal contact and social pressure, can be effective in increasing turnout (De Rooij, Green and Gerber, 2009; Gerber, Green and Larimer, 2008, Green and Gerber, 2015). Nevertheless, successful GOTV campaigns only increase participation by the low single digits, and persuasion campaigns in elections tend to produce little to no effect (Kalla and Broockman, 2018). While acknowledging disagreements in the literature, I argue that stability in policy preferences could be attributed to rising mass polarization and stability in political engagement could be attributed to individuals' preexisting political socialization. Together, these two factors dull the impact of public policy on voters' attitudes and behavior.

Mass polarization makes voters more likely to be swayed by what elites of their own party say about a policy than by an objective evaluation of that policy. Despite their finding that less than a majority of Americans in the 1990s hold stable policy preferences, Freeder, Lenz and Turney (2019) acknowledge that "[w]ith growing polarization, the US public's knowledge of party and candidate positions appears to be rising, so we would expect levels of attitude stability to rise as well" (289). Survey research finds that American voters rarely change their votes to the politicians whose positions best agrees with their own; instead, they tend to change their attitudes to align with the politicians of their own party (Broockman and Butler, 2017; Lenz, 2013). Researchers studying motivated reasoning have feared the existence of the "backfire effect" that makes individuals hold more firmly onto their (false) preexisting beliefs when corrected (Berinsky, 2017; Nyhan and Reifler, 2010). While recent findings suggest that the "backfire effect" is rare (Guess and Coppock, 2019, Nyhan and Reifler, 2015; Wood and Porter, 2019), persuading individuals to update their policy preferences in much harder than convincing them to change their factual beliefs (see Chapter 4 for a more extended discussion). Understanding how partisanship in our current era of mass polarization is important because partisan animosity is driven by disagreements 
over policy, not merely social identity-based hostility (Orr and Huber, 2020).

Larsen's (2019) meta-analysis of the policy feedback literature finds that effects on political participation and engagement tend to be bigger than those on policy attitudes. Recent studies using more rigorous quantitative methods, including studies in this dissertation and those reviewed in this chapter, find null effects or small, non-persistent effects on political engagement are common. Research suggests that political socialization in early adulthood shapes both political interest and participation, which remain relatively stable through one's lifetime (Aldrich, Montgomery and Wood, 2011; Prior, 2010). Note that partisanship, even policy preferences, are also shaped by early political socialization and remains stable (Green, Palmquist and Schickler, 2004, O'Grady, 2019).

Electoral participation, a standard outcome measure in policy feedback research, has been the subject of many experimental and quasi-experimental studies. These studies conclude that voting is a habit: voting in the previous election increases the likelihood that one will vote in subsequent elections (Coppock and Green, 2016; Dinas, 2012; Fujiwara, Meng and Vogl, 2016; Gerber, Green and Shachar, 2003). Based on my research and review of the literature, the impact of policy on electoral participation may be minimal for individuals who are highly engaged in politics or not engaged at all. The scientists that Matto Mildenberger and I studied in Chapter 3 are so politically engaged that they have little room to improve. In contrast, the low-income individuals in Alabama's Medicaid Coverage Gap failed to be mobilized because they were habitually demobilized: most were not registered voters because they lacked political efficacy (Carpenter and Foos, 2016). Conversely, negative experience with the state by going to prison or jail did not decrease electoral participation among those with previously low levels of participation (Gerber et al., 2017, White, 2019).

While the previous section recommends further qualitative research that examines the role of institutions in policy feedback, this section points to the need for policy researchers to engage with behavioral scientists. Political scientists (and hopefully most policymakers) have rejected the strawman account of policy feedback by now. But there is still much research to be done on how the design, implementation, and marketing of social policies can impact electoral politics despite the inertia in citizens' policy preferences and civic 
engagement.

Table 1.1: Literature Review of Policy Feedback Studies Related to the Affordable Care Act

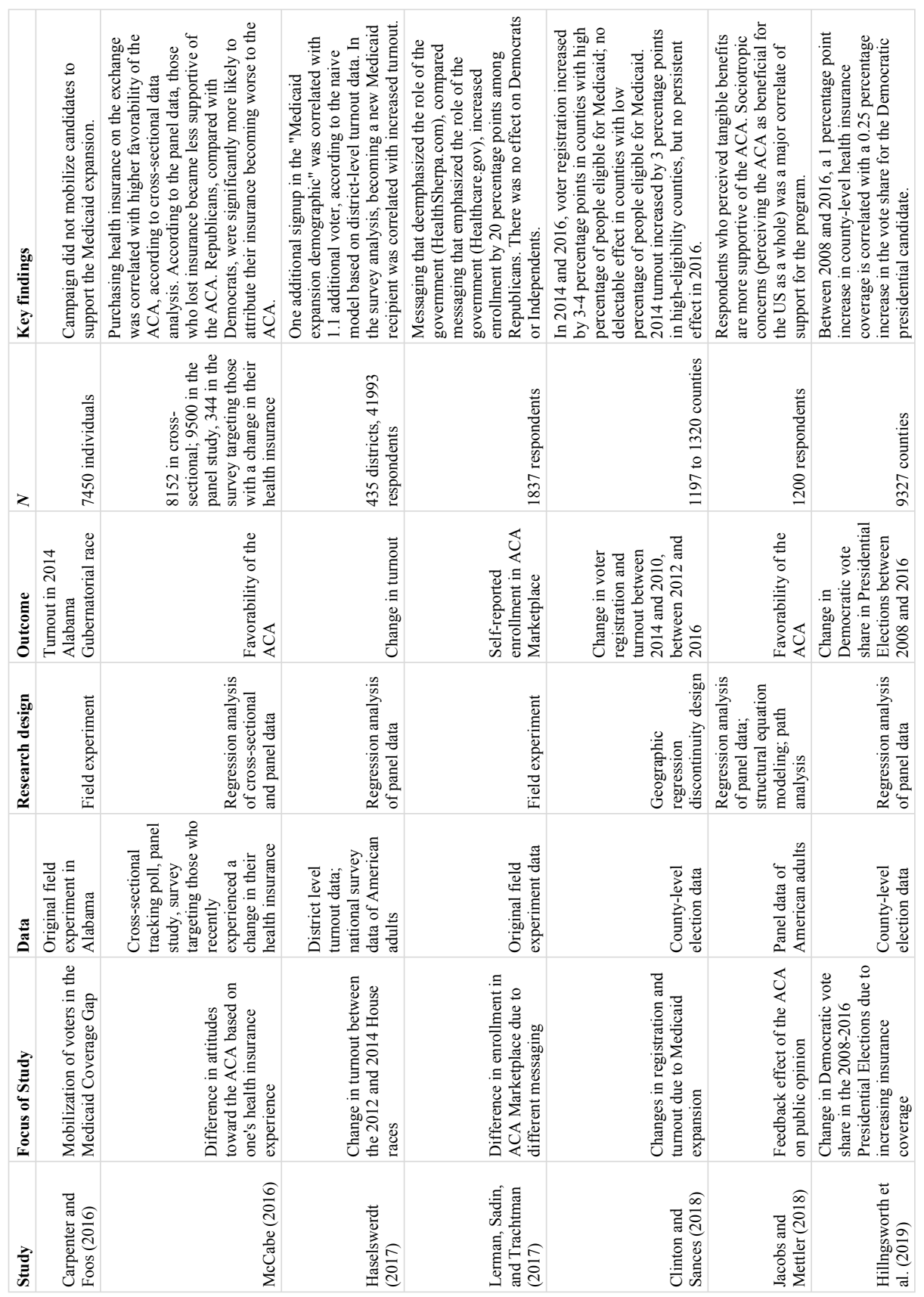


Table 1.2: Literature Review of Policy Feedback Studies Related to the Affordable Care Act (Continued)

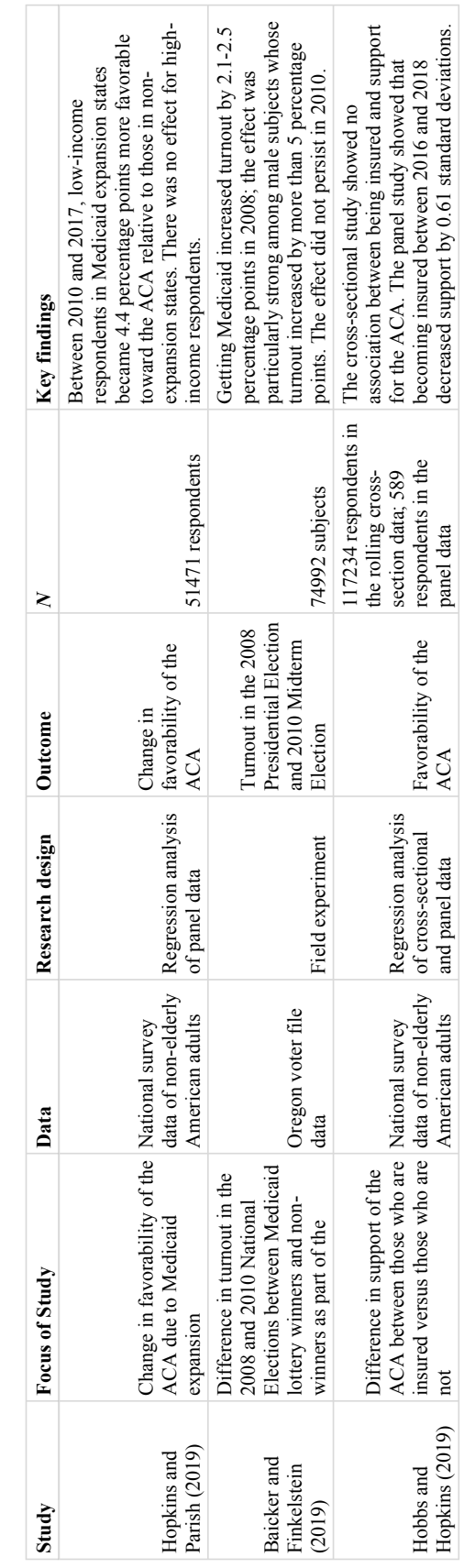




\section{Chapter 2}

\section{Hands Off My Medicare? How}

\section{Government Benefits Fail to}

\section{Change Political Attitudes}

\subsection{Introduction and Background}

Senior citizens, compared with other age groups, express the lowest level of support for the Affordable Care Act (ACA) ${ }^{1}$ One hypothesized reason that some seniors oppose the ACA is that they perceive the policy to be a threat to Medicare (Williamson, Skocpol and Coggin. 2011). Although the ACA benefits seniors by closing the Medicare drug coverage gap, Republicans claimed that the program would threaten seniors' medical benefits. In reality, does receiving Medicare reduce support for the ACA? Researchers have long studied policy feedback, or how personal experience with public policy influences one's political attitudes and behavior (Campbell, 2003a; Lerman and Weaver, 2014; Mettler, 2005, Mettler and Milstein, 2007; Pierson, 1995; Soss, 2002). Nevertheless, valid causal inference in the study of policy feedback is difficult because most social programs are not randomly assigned. Typically, those who benefit from a particular policy are unlike those who do not.

1. The percentage of respondents in the Cooperative Congressional Election Study (CCES) who support the ACA decreases with age, as Figure A.1 shows. Kaiser Family Foundation's Health Tracking Poll shows that respondents aged 65 and above - compared with other age groups - consistently express the lowest level of support for the ACA (Figure A.2. 
Lerman and McCabe's 2017 innovative study, unlike previous observational studies, uses a natural experiment - a "fuzzy" regression discontinuity design (RDD) - to study the impact of receiving Medicare on seniors' policy preferences. The authors compare respondents who are barely above and below age 65, the age at which most Americans are eligible to receive Medicare. Their study produces a surprising finding: Medicare recipients exhibit more support for the ACA than non-Medicare recipients. Also, the researchers found that Medicare recipients are more opposed to domestic spending cuts that target Medicare.

My RDD study tackles methodological problems in Lerman and McCabe (2017); furthermore, I incorporate data from three additional cross-sectional surveys and a panel study. The results of my research suggest that Medicare recipients did not exhibit greater support for the ACA or other health policies. Furthermore, receiving Medicare did not always make respondents more defensive of the program. As hard test of attitude change, I use a panel study to examine respondents' policy preference change over time. Again, the results demonstrate that attitudes towards the ACA and Medicare did not change when respondents became Medicare recipients. Overall, my study suggests that benefiting from Medicare failed to move one's attitudes towards other government health care programs and only sometimes made one more defensive of Medicare. Evidence for policy feedback through changes in public opinion is limited, and where it exists, respondents' change in attitudes reflects their self-interest.

\subsection{Research Design and Hypotheses}

My identification strategy uses a "fuzzy" RDD that exploits the Medicare age eligibility, which is 65 for most American citizens. I compare the political attitudes of Americans who are near the age cutpoint for Medicare. Those to the left of the cutpoint are very similar to those right of the outpoint except for one key difference: access to Medicare. Therefore, I use the age cutpoint as an instrumental variable for Medicare. The empirical strategy I adopt has been used by Lerman and McCabe (2017), as well as public health and economics researchers who study how Medicare affects medical service use and health outcomes (Card, Dobkin and Maestas, 2009; Lichtenberg, 2002; Polsky et al., 2009). 
Four assumptions must be met for the age 65 cutoff to function as a valid instrument in this "fuzzy" RD design. First, whether one is to the left or right of the age cutoff is as good as randomly assigned. This assumption is likely to be met since one cannot manipulate one's age. Second, for each subject, turning 65 must have at least a zero effect, if not a positive effect, on receiving Medicare. This assumption is also likely to be met since the U.S. government encourages those about to turn 65 to enroll in Medicare and penalize those who join at a later age. Third, the average treatment effect of turning 65 on receiving Medicare must be nonzero; logic and empirical estimates suggest this assumption is met. Fourth, whether one satisfies the age outpoint should only affect one's outcome variables (i.e., political attitudes) through receiving Medicare. This last assumption, commonly called the exclusion restriction assumption, might be violated because those 65 and above receive greater Social Security benefits compared with those who are younger if they choose to retire. As a result, those above the cutoff have greater incentive to retire compared with those below the cutoff; unfortunately, retirement could also induce changes in one's political attitudes and thereby violate the exclusion restriction.

My research design improves upon that of Lerman and McCabe (2017); see A.1 for my critique of the research design in Lerman and McCabe (2017). First, I define the treatment as having public insurance $\left(D_{i}=1\right.$, treated) versus not having public insurance $\left(D_{i}=0\right.$, control), in contrast to Lerman and McCabe who compared those with public insurance versus those with only private insurance. 2 My definition of the treatment does not systemically eliminated respondents from my analysis. Second, unlike in the original study, I do not condition on any potential pre-treatment covariates in my regressions, such as employment status. See Appendix A.4 for the pre-treatment covariates I use and results of balance tests to check they are not affected by the treatment. Third, to address the potential exclusion restriction violation problem, I perform the following robustness checks. I reanalyze the survey data using a "sharp" RD design by looking at the effect of Medicare eligibility (turning 65) on preferences towards health policies. Also, when data is available,

2. As a robustness check, Lerman and McCabe also define their treatment variable this way in Appendix C of their paper. This alternative model specification produce similar results to their main model specification results. 
I subset my analysis on subjects who had already stopped working several years before they were surveyed. Since these respondents have already retired, turning 65 would not affect their choice to retire.

In addition, I improve my research design by using more and higher-quality data. Instead of using only the 2012 cross-sectional CCES, I also use data from the 2010, 2014, and 2016 cross-sectional CCES 3

A greater methodological innovation is my analysis of the 2010/2012/2014 CCES Panel Study. A small but growing number of papers in the policy feedback literature have used panel studies to track changes within respondents' political attitudes and behavior as they become social program beneficiaries (Bruch, Ferree and Soss, 2010; Jacobs and Mettler, 2018; Morgan and Campbell, 2011). Going beyond typical panel data analysis, my method combines the strength of a RDD with that of a difference-in-difference design. Doing so increases the precision of my treatment effect estimates Broockman, Kalla and Sekhon, 2017; Wing and fCook, 2013).

For my analysis, I use the following 2SLS regression:

$$
\begin{gathered}
\text { First Stage: } E\left(D_{i}\right)=\alpha+\beta Z_{i}+\sum_{j=1}^{J} \gamma_{j} \bar{X}_{i, j}+\sum_{j=1}^{J} \delta_{j} Z_{i} \bar{X}_{i, j} \\
\text { Second Stage: } E\left(Y_{i}\right)=\zeta+\eta \widehat{D}_{i}+\sum_{j=1}^{J} \kappa_{j} \bar{X}_{i, j}+\sum_{j=1}^{J} \tau_{j} \widehat{D}_{i} \bar{X}_{i, j}
\end{gathered}
$$

I standardize the covariates $X_{i, j}$ to have mean 0 and unit variance and interact the treatment variable with the covariates so that $\widehat{\zeta}$ would be an estimate of the control group's outcome. When analyzing cross-sectional surveys, $Y_{i}$ is defined as the respondent $i$ 's attitude at the time of the survey; when analyzing the panel study, $Y_{i}$ is defined as the change in respondent $i$ 's attitude between the current wave and the previous wave. As in the original study, I focus my analysis on respondents within the two-year window above and below the cutoff and do not use survey weights. I mean impute missing data or "don't know'

3. I analyze the survey data from each cross-sectional survey separately because not all the questions appear in each survey and question wording sometimes change between years. See Appendix A.2 for the exact wording of the survey text. 
responses, irrespective of where respondents fall along the age cutoff. I also report the LATE estimated without using any pre-treatment covariates in the Appendix.

The main hypothesis I test is the same as Hypothesis 1 in Lerman and McCabe 2017. "Personal experience significantly increases support among beneficiaries of a given policy." I also test a secondary hypothesis that addresses the self-interest question: Personal experience with a policy does not change support for similar policies that benefit mostly others. Specifically, I hypothesize that receiving Medicare does not increase support for other health policies that benefit mainly non-seniors, such as the ACA, Medicaid, and the Children's Health Insurance Program (CHIP).

\subsection{Results}

The results of my improved and expanded analysis demonstrate that receiving Medicare has almost no effect on changing respondents' opinion about non-Medicare related health policies and limited effect in causing them to become more defensive about Medicare. Personal experience with Medicare may not significantly increase support for Medicare, let alone the ACA.

Before diving into the results, note that I replicate the main findings in Lerman and McCabe's study. The LATE of receiving Medicare on support for the ACA and opposition to domestic spending cuts (which includes cuts to Medicare) ${ }^{5}$ estimated using the 2012 cross-sectional CCES, are significant and similar in magnitude to estimates in the original study (see Figure 2.1). Nevertheless, this significant result is an outlier when considering the entirety of my findings: most of the LATEs estimated are statistical zeros. Indeed, within the 2012 cross-sectional sample, the LATE of receiving Medicare on opposition to the ACA ("Repeal ACA") is substantively small (a decrease of 3 percentage points) and not statistically significant.

4. While the authors also hypothesize that the treatment effect will be greater for low-information voters, Republicans, and those in ill-health, my paper mainly seeks to test Hypothesis 1 - their primary hypothesis.

5. The outcome "Least Favored: Cut Domestic Spending" in my study is called "Do Not Cut Medicare" in Lerman and McCabe's study. I change the variable name to more accurately reflect the actual survey text. The survey text asks about whether one favors cutting domestic spending, citing Medicare and Social Security as two domestic spending programs. 
Figure 2.1 reports the 2SLS regression results using the cross-sectional CCES surveys. Apart from the "Support ACA" result in 2012 noted above, acquiring Medicare did not change respondents' opinion about the ACA, CHIP, or Medicaid. For some years and some outcome measures, acquiring Medicare induced respondents to become more defensive about protecting Medicare funding. In some sample-years, recipients were less willing to cut domestic spending and more reluctant to support the Ryan Budget or the SimpsonBowles Budget, two budget proposals that would substantially reduce Medicare funding. However, these results do not hold up in all the sample-years. While the previous outcome measures indirectly measure respondents' preference for Medicare policy, the 2016 CCES asked directly about the Medicare Accountability and Cost Reform Act 6 The LATE of receiving Medicare on support for Medicare reform varies by the model specification; the 2SLS estimates including covariates suggest a null effect. In sum, the results suggest that acquiring Medicare is unlikely to affect beneficiaries' preferences about health policies that benefit mostly other people and somewhat increases their support for defending Medicare.

While the cross-sectional surveys provide me with a decent estimate of the LATE of acquiring Medicare on respondents' attitudes towards health policies, the panel study offers even more credible evidence. The panel study allows me to compare the within-subject change in attitudes for those who acquired Medicare between survey waves versus the change in attitudes for those who did not. As Figure A.3 shows the percent of respondents who gained government health insurance since the previous wave jumps dramatically at age 65 in the current wave.

Results from the panel study (Figure 2.2) confirms the evidence from the cross-sectional surveys: acquiring Medicare has little effect on changing respondents' attitudes towards the ACA and CHIP. The estimated LATEs on support for the ACA and CHIP are small and not statistically significant. The estimated LATEs on changing attitudes about domestic spending cuts are somewhat mixed. Acquiring Medicare have induced little change in opinions between the 2010 and 2012 wave with one exception: between the 2012 and 2014

6. Respondents are told the reform would do the following: "Shifts Medicare from fee-for-service to payfor-performance. Ties Medicare payments to doctors to quality of care measures. Requires higher premiums for seniors who make more than $\$ 134,000$. Renews the Children Health Insurance Program (CHIP)." 
Figure 2.1: Effects of Acquiring Medicare on Respondents' Attitudes: Evidence from 2010, 2012, 2014, and 2016 Cross-Sectional CCES Surveys

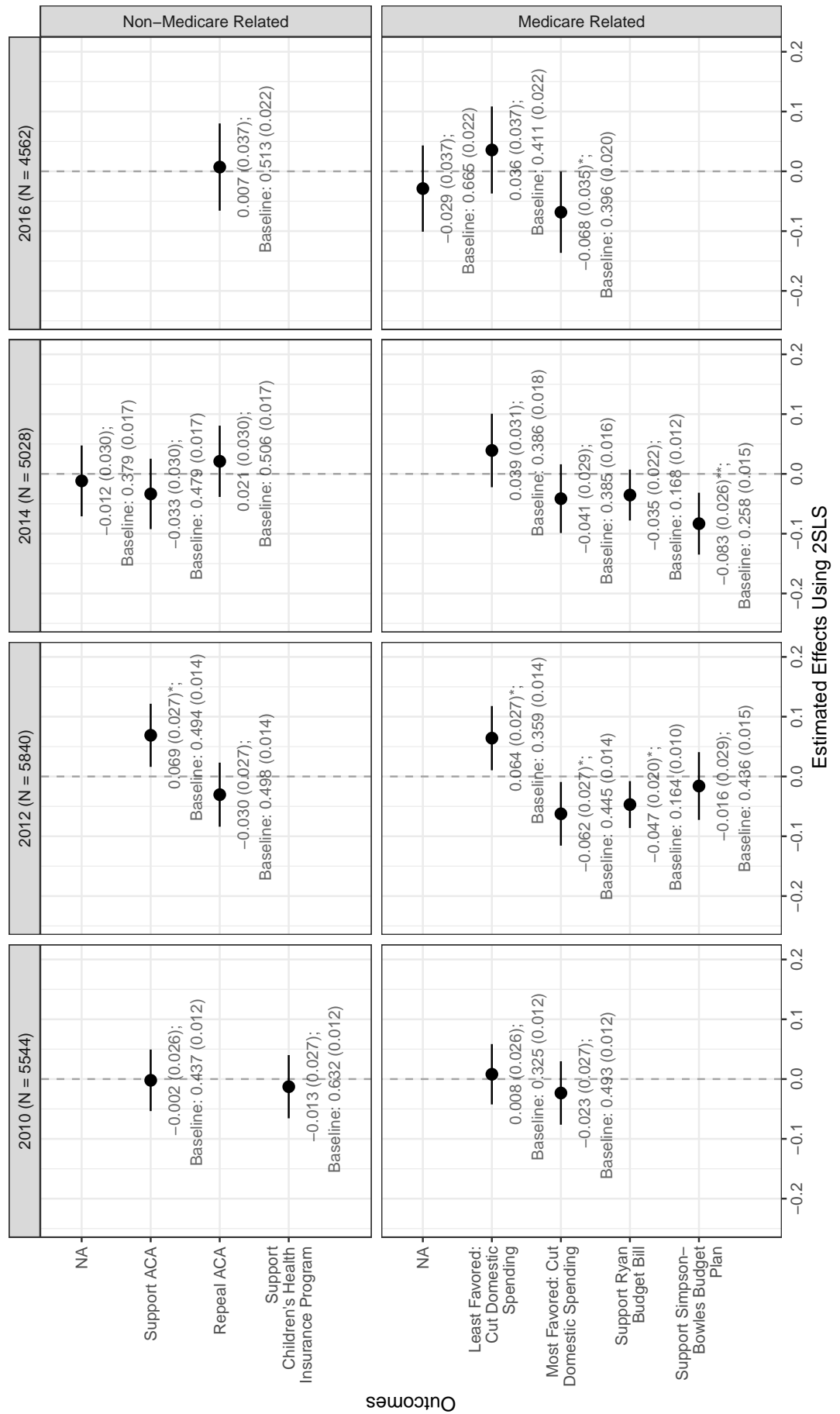

The results are from 2SLS regressions that include pre-treatment covariates. In this figure and Figure 2.2, the heteroscedasticity-consistent standard errors are reported between the parentheses next to the effect estimates. The error bars represent $95 \%$ confidence intervals calculated from the robust standard errors. $p$-value stars on the effect estimates follow the convention of $*<0.05, * *<0.01, * * *<0.001$. 
Figure 2.2: Effects of Acquiring Medicare on Respondents' Attitudes: Evidence from the 2010/2012/2014 CCES Panel Study

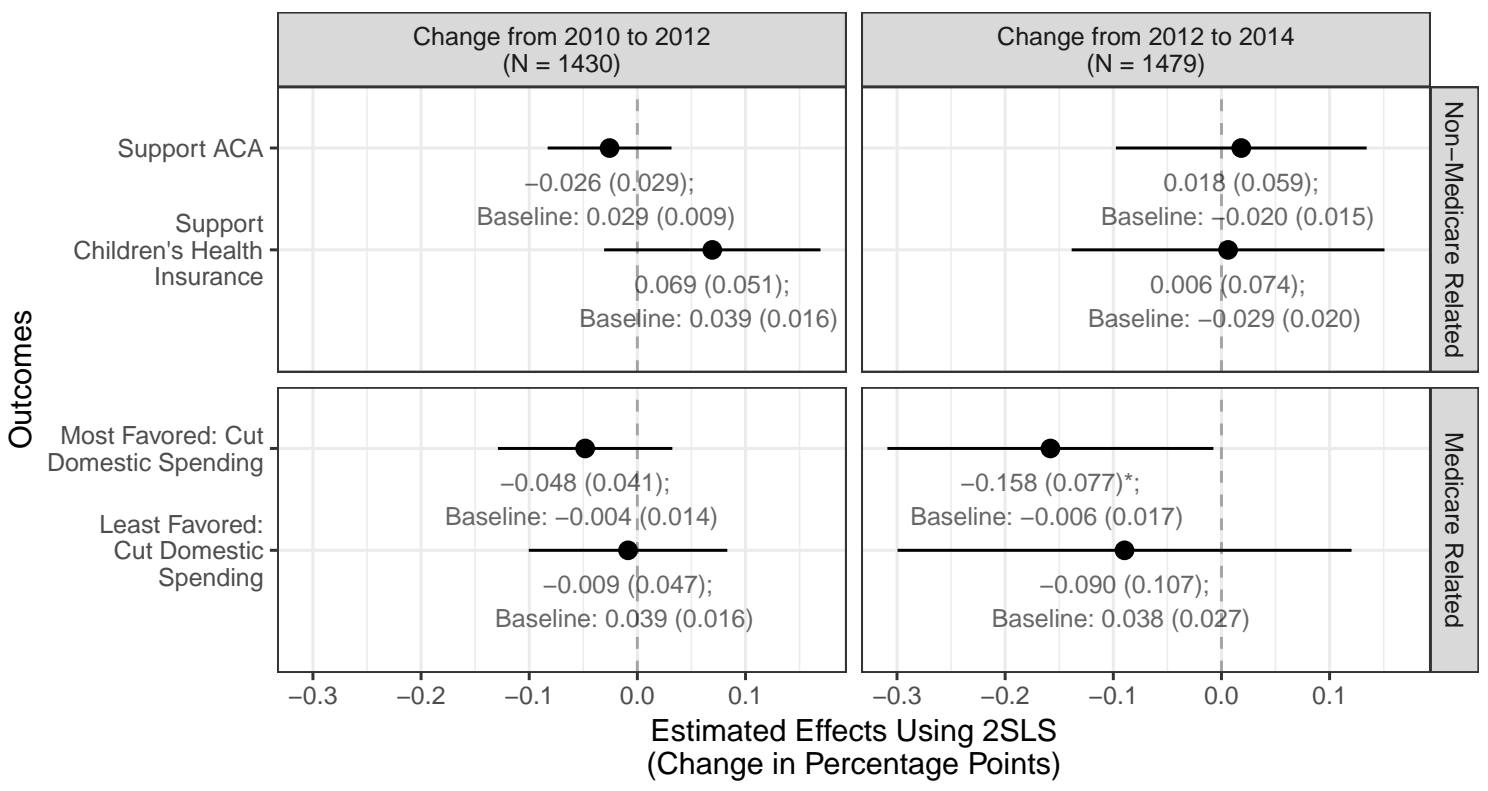

The results are from 2SLS regressions that include pre-treatment covariates.

wave, receiving Medicare caused a 15.8 point decrease in the percentage of those who prefer cutting domestic spending the most. Nevertheless, these estimates are somewhat noisy due to the smaller sample size of the panel study.

The robustness checks, reported in Appendix A.5, also suggest the LATE of acquiring Medicare had no impact on respondents' preferences towards the ACA and Medicaid and limited impact on their preference towards Medicare. The OLS models produce results in a similar direction to those in the 2SLS models, albeit with smaller estimated effects. Using the 2012 and 2014 CCES cross-sectional surveys, I perform the "fuzzy" RDD analysis on a subset of respondents who have not worked at all in the past five years to untangle the effect of acquiring Medicare from the effect of retirement.7 Figures A.17 and A.18 show that acquiring Medicare had no effect on almost all of the outcome measures. In the 2014 sub-sample, receiving Medicare decreased the percentage of respondents who support expanding Medicaid by 23 points and increased the proportion to least favored cutting domestic spending by 24 points; unfortunately, these effects are noisily estimated since the

7. Only the 2012 and 2014 CCES cross-sectional surveys asked respondents whether they have worked at all in the past five years. 
sizes of these subsamples are not as large as the sample sizes in the main analysis 8

\subsection{Discussion and Conclusion}

My study paints a nuanced picture of Medicare's effects on seniors' political attitudes. Did acquiring Medicare induce seniors to become more supportive of the ACA, as Lerman and McCabe (2017) suggest? Again, I emphasize my analysis replicates the two positive and statistically significant effects they estimate. Nevertheless, this result is an outlier among all the null findings that suggest Medicare has little impact on seniors' preference towards the ACA, Medicaid, and CHIP.

What accounts for the significant treatment effect estimates in the 2012 cross-sectional survey but not in the other datasets? Lerman and McCabe (2017) note Medicare recipients are more supportive of the ACA and aware of its benefits to seniors in 2011 and 2012 than in 2013 and 2014, according to the Kaiser Family Foundation health Tracking Polls. One could argue that the politics of the 2012 General Elections campaign might have produced this puzzling effect. According to the Google Trends data in Figure A.6, internet searches related to the ACA increased somewhat ahead of the 2012 General Elections. Nevertheless, health care policy was less salient of an issue in 2012 than in 2010: 74 percent of American voters indicated that health care is a "very important" issue in 2012, down from 78 percent in 2010, according to Pew Research Center surveys 99 The significant findings regarding support for the ACA in the original study might have arisen due to random chance. Using the same cross-sectional dataset and analysis method, I find that acquiring Medicare produced a bigger effect on support for gun control (a placebo outcome) than on support for the ACA (see Figure A.12.

While seniors in the Tea Party viewed health care policy as a zero-sum game, most seniors, when they become Medicare beneficiaries, did oppose other health care programs. Policy feedback, where it existed, consisted of seniors growing more defensive about cuts to

8. Nevertheless, thanks to the large sample size of the CCES, even the sizes of these subsamples are large by absolute standards - 1,780 respondents in the 2012 CCES and 1,639 in the 2014 CCES.

9. Pew Research Center, "With Voters Focused on Economy, Obama Lead Narrows", April 17, 2012. http://www.people-press.org/2012/04/17/with-voters-focused-on-economy-obama-lead-narrows/ 
Medicare. Senior citizens are known to be fierce defenders of social programs that benefit them (Campbell, 2003b). Nevertheless, my analysis shows that acquiring Medicare does not induce consistent changes in political attitudes. Policy feedback may be offset by political factors such as one's partisan identity Jacobs and Mettler (2018). Voters typically begin to identify with a political party early in life, and their partisan identity remains stable over time (Campbell and Converse, 1960; Green, Palmquist and Schickler, 2004). Furthermore, voters often evaluate policy and politics through a partisan lens (Achen and Bartels, 2016). As a result, even policies with massive material consequences may not shift one's political attitudes and behavior. Sometimes seniors are satisfied with a particular policy change and do not mobilize to overturn it, as in the case of Medicare Part D Morgan and Campbell, 2011). Furthermore, analysis of Medicare's effect on seniors' political participation using a similar RD design suggests that enrolling in Medicare did not make seniors more likely to participate in politics (Mazumder, 2017).

Another reason for the lack of change in political attitudes is that people in their early 60 s are not entirely different from those 65 and above. Those entering into their retirement years anticipate becoming Medicare beneficiaries and join the pro-Medicare constituency before they are eligible to enroll in the program 10 Therefore, the interpretive effect of Medicare could begin long before the resource effects kick in. Indeed, Lerman and McCabe anticipate this criticism of their RDD identification strategy and argue that any sizable effect they find only speak to the strength of Medicare's impact through personal experience with the program. My analysis suggests the impact of this personal experience are not as powerful as the original authors claim.

10. Those who are 50 or older are eligible to join the American Association of Retired Persons (AARP), the most prominent interest group for seniors in the U.S. 


\section{Chapter 3}

\section{Scientists' Political Behaviors Are}

\section{Not Driven By Individual-level}

\section{Government Benefits}

(Joint with Matto Mildenberger, Department of Political Science, University of California Santa Barbara)

\subsection{Overview}

On Earth Day 2017, thousands of scientists and their supporters protested the Trump administration in Washington, DC as part of the March for Science; marches in other American cities drew tens of thousands (Fleur, 2017). Yet, other scientists express profound misgivings about such efforts to engage in partisan politics. They criticize their colleagues for having "crossed the imaginary line" from researcher to activist, worried that political advocacy might break the social contract underlying public science and research funding (Sedlak, 2016). From this perspective, scientists' credibility as impartial actors requires withdrawing from political life (Ruggiero, 2010).

Other scientists defend colleagues' political engagement (Schneider, 2009). These scientists believe passive information provision is insufficient in a world where objective facts are

the subject of political debate (Young, 2017; ?). If political actors reject or discount severe 
risks to the public, it might be unethical for scientists to stay silent for fear that future research funding could be compromised (?).

These debates have spilled out into the public sphere. Many American political actors sharply question scientists' motives. Some have asserted that scientists' political activity reflects partisan preferences or self-interest in receiving government funding. For example, in recent decades, the Republican Party has criticized scientists, threatening to cut science funding and ignore evidence-based policies (Mooney, 2006). Similarly, American conservatives report over-time decline in trust in scientists (Gauchat, 2012). After the March for Science, the percentage of conservatives who agreed that "scientists care less about solving important problems than their own personal gain" increased (Motta, 2018).

These critiques of scientists echo arguments about policy feedback effects. Researchers who study policy feedback argue that that government programs, such as subsidies for higher education, can affect their beneficiaries' political attitudes and behaviors (Campbell, 2012; Pierson, 1993). For instance, the GI Bill increased the civic participation of the veterans who fought in WWII, particularly those who came from disadvantaged backgrounds (Mettler, 2005). Likewise, the National Defense Education Act of 1958, the Higher Education Act of 1965, and Title IX of the 1972 Education Amendments expanded higher education opportunities to women and thus increased their political participation (Rose, 2018). Researchers suggest that government programs that support higher education created engaged citizens through both resource effects (i.e., increasing the recipients' economic opportunities) and interpretative effects (i.e., making the recipients feel valued by the government) (Rose, 2017). Could these theories extend to scientists, and thus validate claims that scientists' political advocacy reflects vested interests in government resource provision?

Yet, despite contentious debates about the role of scientists in politics and policymaking, arguments about scientists' political motives have rarely been examined empirically. In this paper, we use a natural experiment to test whether a major government subsidy for science education, the National Science Foundation Graduate Research Fellowship (NSFGRF) Program, increased civic engagement by scientists. Contrary to partisan critiques of scientists' political behavior, our study finds no robust evidence that scientists' motivations to engage in science-related and non-science-related political advocacy are a function of 
individual-level government benefits provision. Scientists who did not benefit from the NSFGRF, compared with scientists who benefited but are otherwise similar, were no less likely to vote, donate to political candidates, or participate in the March for Science. Consequently, our research provides credible empirical evidence against rhetorical arguments that link scientists' political behavior with self-interested financial agendas. It also highlights the limited capacity of even generous government support to trigger positive policy feedbacks.

\subsection{Materials and Methods}

\subsubsection{Empirical Research Strategy}

Our empirical strategy leverages a natural experiment that uses the NSF-GRF to examine whether receiving government benefits shapes scientists' willingness to engage in political advocacy. This U.S. government award provides a three-year tuition scholarship for graduate studies in the nature and social sciences as well as a living stipend for three years. NSF-GRF applications are highly competitive; in recent years, only about one-third of all applicants receive any recognition from the NSF. Fellowship awardees are given tuition scholarships and stipends; honorable mentions are recognized for their achievement but receive no financial benefits.

Our research subjects are a special group of fellowship applicants who received either the award (treated group) or honorable mention (control group) in any given year after receiving honorable mention in the previous year. For instance, our research subjects for the year 1998 are fellowship awardees and honorable mention recipients who received honorable mentions in 1997. Conditional on performance in the previous year and other pre-treatment covariates (e.g., application year, field of study, undergraduate university, graduate university at time of application, gender, ethnicity, and immigration status), we argue that whether an applicant receives a fellowship or honorable mention in this subsequent year is conditionally as-if random. Social psychologists have used a similar research design to determine that winning an NSF-GRF increased an individual's likelihood of completing graduate school but did not improve the individual's labor market outcome (Chapman and McCauley, 1993).

A total of 6,428 applicants between 1995 and 2016 were eligible for inclusion in our 
sample; the applicants and their basic biographical information are publicly available online. Given budget constraints, we randomly sampled 2,210 applicants using stratified sampling; respondents within each year/field-of-study stratum had a $1 / 3$ probability of being sampled. Some strata did not have at least one subject in each condition; we eliminated those strata and were left with 2,119 subjects. For each subject, we collected the following information: full name at the time of the NSF application, undergraduate institution, and graduate institution. Using only this information, we were able to locate current contact information (e.g., email addresses, mailing address, web contact form URLs) using public online searches. We could not find any contact information for 27 subjects ( $1.2 \%$ of the sample), and so they were dropped from the study.

Critically, our study focuses on causal inferences regarding the drivers of scientists' mobilization, not descriptive inferences about scientists' political advocacy. Correspondingly, we choose a sampling strategy tailored to causal inference-making over a design that optimizes a descriptively representative sample of all American scientists. While our subjects are not a random sample of American scientists, they represent a wide range of disciplines (e.g., computer scientists, engineers, biologists) and research institutions (e.g., universities, private companies, the government).

\subsubsection{Data}

We conducted an original survey of individuals who applied for the NSF-GRF during graduate school between 1995 and 2016 in late April 2017, in the immediate aftermath of the March for Science. To recruit individuals, we emailed a link to the Qualtrics-hosted survey to scientists in our sample who have an email address we can locate $(N=2,090)$. We contacted a subset of individuals without email addresses through web contact forms $(N=4)$ or via postal mail invitations $(N=25)$. We recontacted respondents who did not take the survey a week later reminding them to take the survey. We received complete responses from 499 individuals or $23 \%$ of our sample; our analysis used responses from 408 subjects because we selected year/field-of-study blocks with at least one winner and one non-winner. We report summary statistics associated with our sample in Tables B.5, B.6. B.7, and B.8. In particular, we find no significant differences between survey respondents 
and non-respondents' background characteristics besides that respondents are more likely to be male and have applied for the fellowship in later years.

Our survey measured a series of political attitudes and behaviors, including 1) their support for the March for Science, 2) applicants' attitudes towards government funding for science, 3) their public communication of research findings, 4) their political identity, and 5) their willingness to donate to non-profit organizations (including ones with political agenda) through a donation experiment $\left.\right|^{1}$ We provide a full copy of our survey instrument in B.7.

For all individuals in our sample (irrespective of whether an individual responded to our survey), we also compiled applicants' political donation records using the OpenSecrets.org's Donor Lookup tool. We manually matched applicants to the political donation records via name, city, and employer (if available). Out of 2,119 subjects, we were able to match 114 subjects $(5.4 \%)$ to political donations; we coded unmatched subjects as not having made any political donations. We detail the procedure used to match subjects with donation records in B.2.

\subsubsection{Balance Tests}

Our research design depends on the presence of balance in subjects' background characteristics between our treated and control groups. To evaluate this feature of our design, we analyzed the natural experiment as a block-randomized experiment (assuming complete randomization within block), where each block is a year/field-of-study. There are a total of 56 year/field-of-study blocks. For each background characteristic, we used the following inverse propensity-weighted (IPW) linear regression to estimate the differences in applicant characteristics between the award winners and non-winners:

$$
W S S(\beta, \mathbf{p})=\sum_{i=1}^{N} \frac{1}{p_{i}}\left[X_{i}-\left(\alpha+\beta A_{i}\right)\right]^{2}
$$

1. For the donation experiment, respondents were told at the end of the survey that three survey-takers would be randomly chosen to win $\$ 100$. They were asked how much of this potential prize they might be willing to donate and to indicate which of the following organizations they might like to donate part of their prize to the American Association for the Advancement of Science, the American Cancer Society, the Union of Concerned Scientists, the Red Cross, or the March for Science. 
where $p_{i}$ is the probability that subject $i$ is in the condition that they are in given their year/field-of-study, $X_{i}$ is the background characteristic of subject $i$, and $A_{i}$ is an indicator variable for subject $i$ 's award status. $\widehat{\beta}$ is the estimate of the difference in the background characteristic between the winners and non-winners. We used IPW linear regression because subjects have different probability of getting an award depending on their year/field-ofstudy. These probabilities range from 0.17 to 0.83 , with a mean of 0.45 and a median of 0.50 .

We performed balance tests to assess whether the award winners are different from the honorable mentions along five metrics: 1) undergraduate university is an Ivy League, 2) undergraduate university is an Ivy League Plus (the Ivy League plus MIT, Caltech, Stanford, University of Chicago, Duke, and UC Berkeley), 3) graduate university (at the time of application) is an Ivy League, 4) graduate university (at the time of application) is an Ivy League Plus, 5) predicted gender of the applicant. The gender of the applicant was predicted using first name data from the U.S. Social Security Administration (SSA). We performed web searches for those applicants with gender-neutral names or names not within the SSA database to determine their gender.

In Figure 3.1, we find that award winners and non-winners are not statistically different when it comes to the quality of their undergraduate or graduate institutions, though winners are 5.7 percentage points $(\mathrm{SE}=2.3)$ less likely to be predicted male compared with non-winners. This difference is perhaps not surprising because the NSF seeks to increase diversity in science education; as a result, application reviewers might favor women and ethnic minorities. To address this imbalance in background covariates, we conditioned on predicted gender (along with self-reported racial identity and place of birth in the survey analysis), along with the quality of education background covariates, in subsequent analyses.

Aside from gender, we find no statistical or substantive differences between in survey sample winners and sample non-winners in background covariates (e.g., quality of education, ethnicity, or U.S.-born). Furthermore, these background characteristics do not individually or jointly predict who won a fellowship (see Tables B.7 and B.8). These results increase our confidence that treatment assignment (whether an individual received an NSF or honorable mention) is conditionally as-if random in our survey sample. 


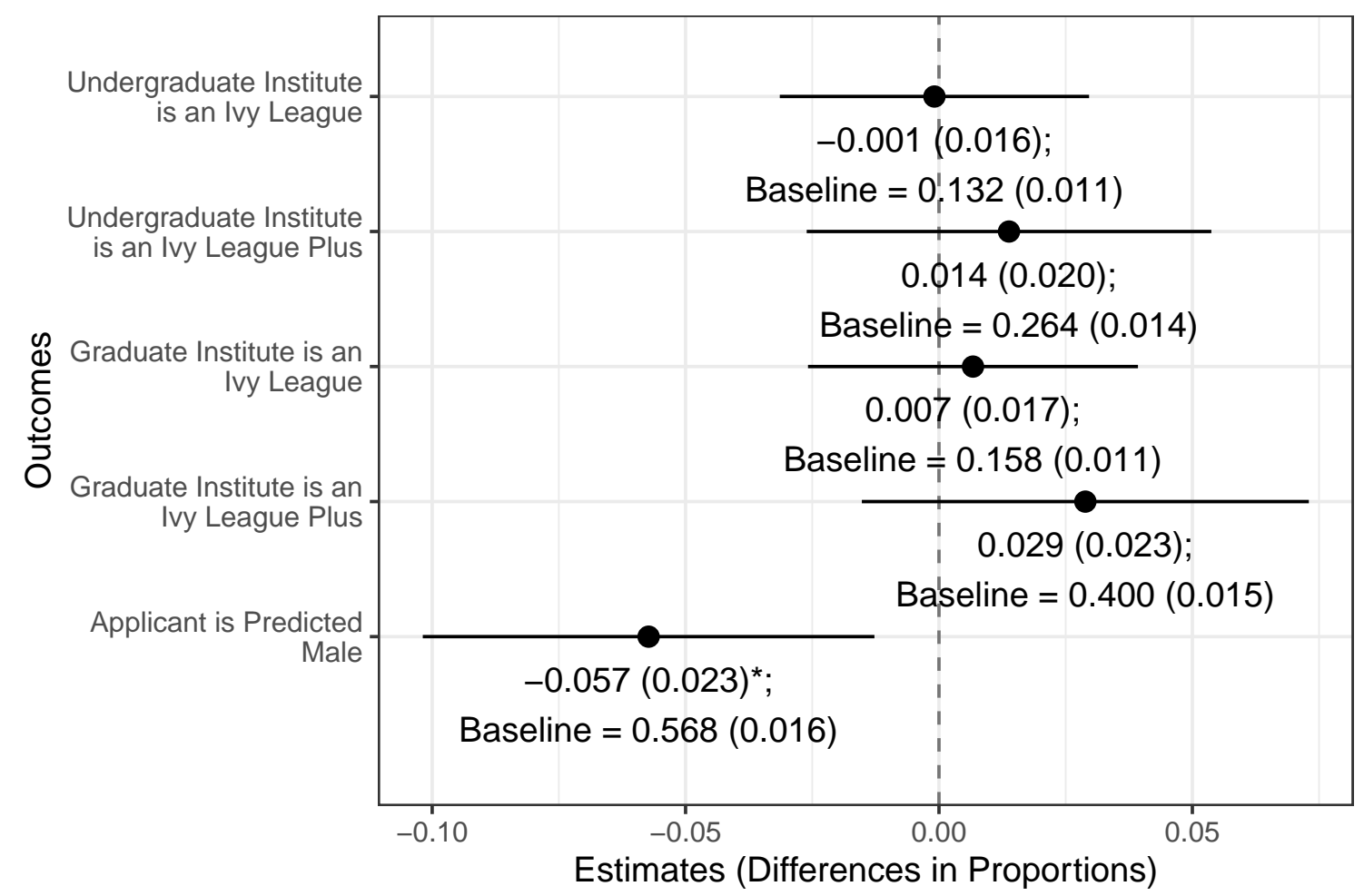

Figure 3.1: Comparing Differences in Background Characteristics Between Winners and Non-winners

$N=2,119$. We find only a slight imbalance between treated and control groups in predicted gender; however, the groups are balanced on the quality of undergraduate university and quality of graduate university.

Finally, as shown in Figure 3.2, there are no statistical or substantive differences between award winners and non-winners regarding missing email addresses or all other contact information. Those who were given an award were more slightly likely to have a ".edu" email address, suggesting that winners are more likely to work in academia.

\subsubsection{Analysis of Main Outcomes}

We use the following IPW linear regression to estimate the effect of winning a fellowship on the outcome of interest:

$$
W S S(\beta, \boldsymbol{\theta}, \boldsymbol{\tau}, \mathbf{p})=\sum_{i=1}^{N} \frac{1}{p_{i}}\left[Y_{i}-\left(\alpha+\beta A_{i}+\sum_{k=1}^{K} \theta_{k} \bar{X}_{i, k}+\sum_{k=1}^{K} \tau_{k} A_{i} \bar{X}_{i, k}\right)\right]^{2}
$$




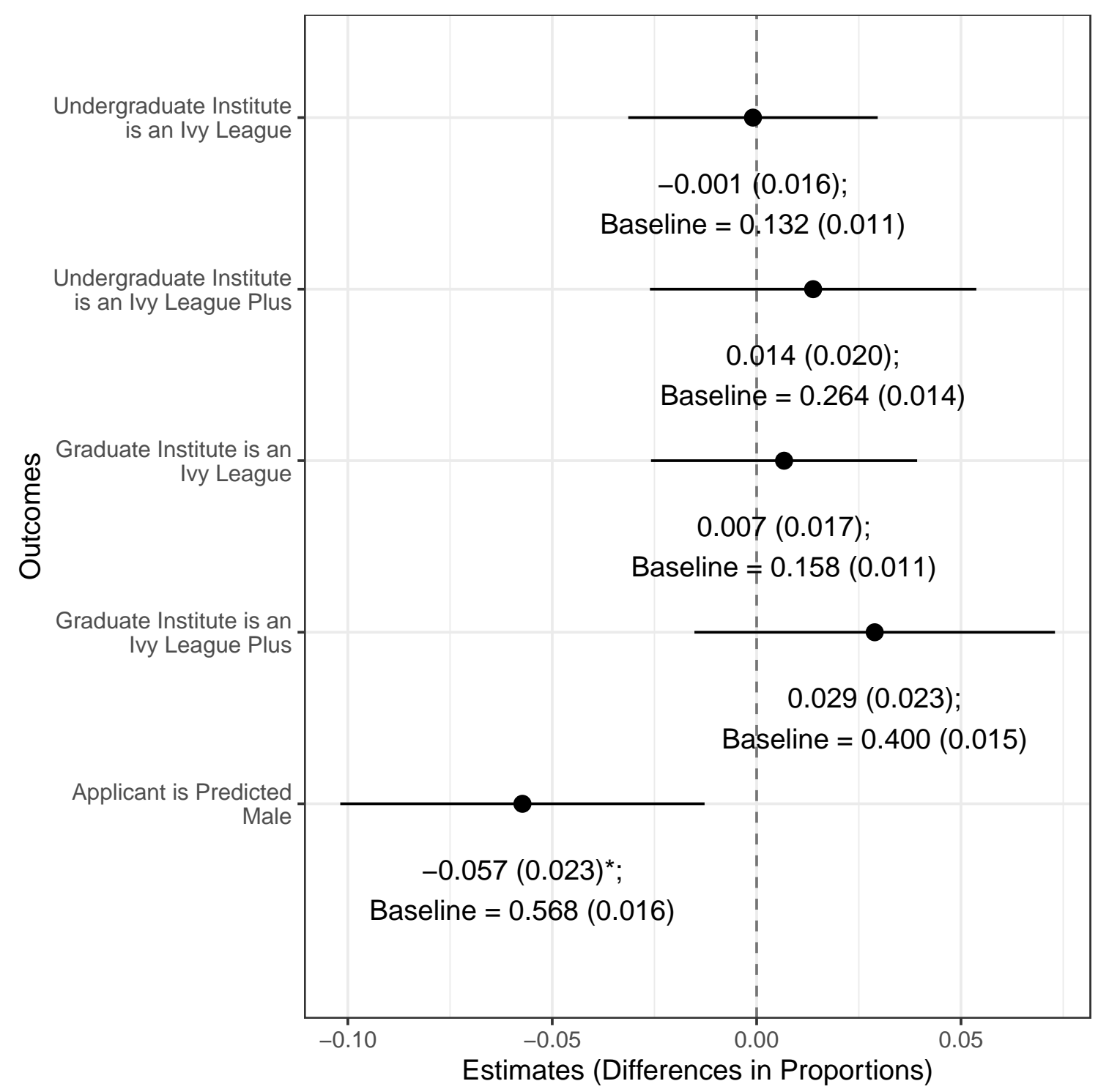

Figure 3.2: Comparing Differences in Contact Information Between Winners and Nonwinners

where $Y_{i}$ is the outcome measure for applicant $i$ and all other variables are the same ones described previously. $\widehat{\beta}$ is the estimate of the individual-level average treatment effect of receiving a fellowship on the outcome. We mean-centered the background covariates, $X_{k}$, so that $\widehat{\alpha}$ represents the estimate of the mean outcome for the non-winner group (i.e., the baseline). For the donation outcomes, the background covariates include quality of the subjects' undergraduate and graduate institutions and their predicted gender. For the survey outcomes, the background covariates include those in addition to the subjects' self- 
reported racial identity (i.e., as Black/Hispanic/Native American; as Asian) and whether they self-reported as being born in the U.S. We adjusted for the background covariates, even when there is balance in background covariates between winners and non-winners, to increase the precision of our estimates (Lin et al., 2013).

\subsection{Results}

Receiving a fellowship did little to change scientists' political attitudes or self-reported behavior (see Figure 3.3). Interestingly, winners' support for the March for Science is 3.5\% lower than non-winners' support; however, this difference is not statistically significant at

the $5 \%$ level. Award winners do not indicate greater support for federal funding for the sciences, for the NSF, or for the NSF-GRF Program. Neither does winning the fellowship induce respondents to communicate their research findings with policymakers and journalists more frequently. Winning the fellowship do little to alter the respondents' political party affiliation. Winners are somewhat more conservative in terms of political ideology, but this effect is not robust to an alternative model specification where we do not include background covariates (see Table B.2). Finally, in the donation experiment, respondents' willingness to donate, whether in general or to organizations with a political agenda, is unaffected by their award status.

We then directly evaluated individuals' political participation using campaign donation data. This analysis was conducted across all individuals in our sampling frame $(N=2,119)$, rather than simply across individuals who responded to the survey $(N=499)$. We do not find that applicants who were awarded the fellowship gave larger political donations to Democratic candidates or causes, as seen in Figure 3.4 .

For a further robustness check on the impact of the fellowship on political donation amounts, for each outcome, we conducted a randomization inference test to test the sharp null hypothesis of no individual treatment effect. For our test statistic, we used the Wilcoxon rank statistic because it is robust to outliers (Lehmann and D'Abrera, 1975). For each outcome, we performed 1,000 simulations assuming the sharp null and the block randomization in our existing data to get the randomization distribution of the test statistic. Each one- 

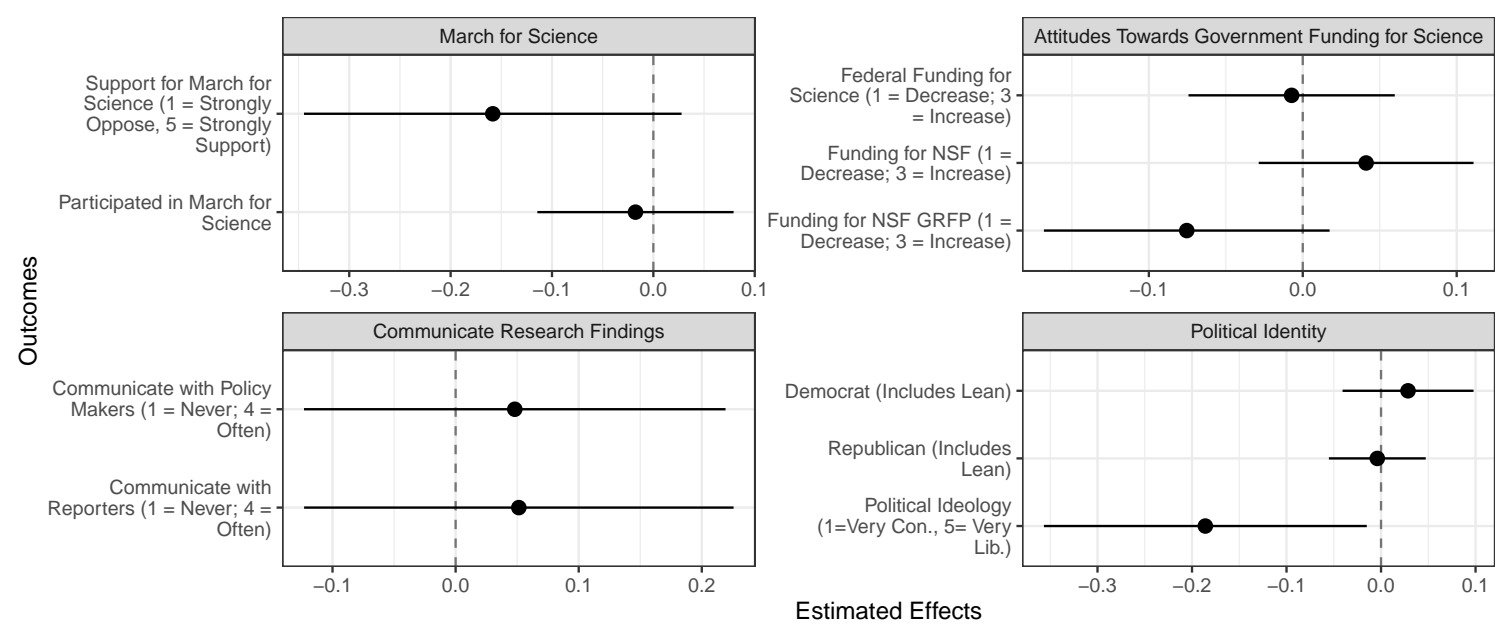

Figure 3.3: Effect of Being Awarded the NSF Graduate Research Fellowship on Political Attitudes and Behavior

$N=408$. The error bars represent $95 \%$ confidence intervals calculated from the robust standard errors. Table B.1 contains the effect estimates, standard errors, two-sided $p$-values, and baseline estimates.

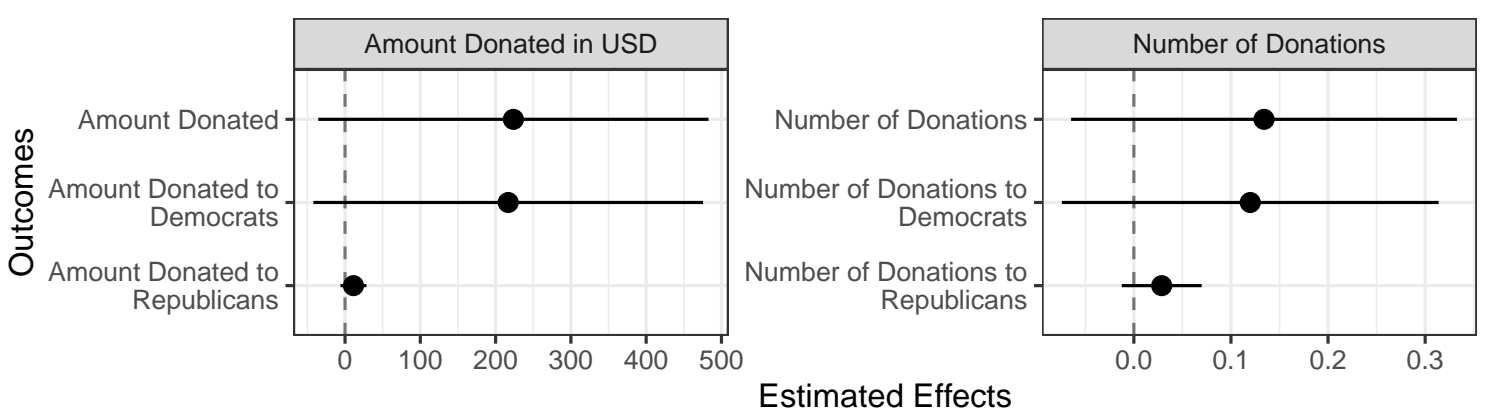

Figure 3.4: Effect of Being Awarded the NSF Graduate Research Fellowship on Political Donations

$N=2,119$. The error bars represent $95 \%$ confidence intervals calculated from the robust standard errors. Table B.3 contains the effect estimates, standard errors, two-sided $p$-values, and baseline estimates.

sided $p$-value is the proportion of the randomization distribution that is more extreme than our observed test statistic. We find that the two-sided $p$-values (twice the one-sided $p$ values) are all above 0.90 ; therefore, we cannot reject the null hypothesis of no individual treatment effect for each outcome. 


\subsection{Discussion}

In sum, the null results of award receipt on campaign donations and survey responses suggest that receiving the award did little to change respondents' political attitudes or behavior. More broadly, we conclude that individual government benefits do not appear to shape scientists' willingness to engage in either science-related or non-science-related political advocacy. NSF fellowship winners are no more likely than non-winners to support and participate in the March for Science or make political donations.

In B.6, we also report the results of two experiments embedded in our survey. In Experiment 1, we randomly divided the survey sample into three groups. The first group received a politically neutral statement about the 2017 March for Science. The second group received the same message with explicit noting that "many March participants wanted to resist Republican party attacks on science and protest federal science policy's general direction." A third group received a message that framed the perceived attacks as coming from the Trump administration rather than the Republican Party. Results are reported in Table B.14. Support for the March for Science is equivalent across all conditions. This suggests our sample's support for political advocacy is relatively non-responsive to partisan cues.

In Experiment 2, we presented respondents with a simple vignette describing the climate advocacy behavior of a hypothetical scholar. We varied both the scholar's discipline (atmospheric chemistry vs. economics) as well as the nature of the scholar's advocacy (communication about atmospheric climate science, public endorsement of a carbon tax, public endorsement of a carbon tax plus endorsement of political candidates who support carbon taxes). Results are reported in B.2. We find that scientists' comfort with political advocacy does not shift as a function of advocacy content. Scientists are as comfortable with a peer advocating for a carbon tax and endorsing candidates who support climate policies, as they are with a peer who limits their advocacy to climate science narrowly.

These results, taken together with our core political advocacy and donation findings, offer an empirical basis to doubt criticism of scientists as being motivated by self-interested political or financial agendas. Other potential mechanisms might contribute to this null 
finding. While the size of the benefit is significant (amounting to over $\$ 200,000$ in recent years) and the program is highly visible (recipients receive regular communication from the NSF), its duration is only three years. Furthermore, the program's beneficiaries might not view the fellowship as a government social program but rather as just reward for their hard work - much like the many Americans who failed to recognize that Social Security is a government social program (Mettler, 2011). As a result, the recipients might not have acknowledged the need to engage in politics to defend the program or the NSF. Alternatively, scientists may fear the loss of future government funding. The March for Science instructed protesters not to wear attire that would identify their universities, use government-funded websites for advertising the protest, or communicate about the March using their institutional email accounts (Climate Science Legal Defense Fund, 2017). Because participating in partisan politics could jeopardize their careers, scientists may be reluctant to speak out.

One likely explanation for these findings is the high baseline levels of political engagement in our sample. Evidence from our survey and other surveys of scientists suggest that scientists, as a whole, are politically engaged; interventions to increase their political engagement is likely to hit a ceiling. As the baseline (non-winner) estimates in Tables B.1 and B.3 show, non-winners in ours survey sample support increasing government funding for science, endorse the March for Science, and overwhelmingly identify as Democrats. More than one-third of the survey sample participated in the March for Science, a costly form of political participation. Regarding a less costly but common form of civic participation, over $98 \%$ of both sample winners and non-winners reported they have registered to vote. We also note that government benefits received at an early stage in an individual's career may have different long-term effects than benefits received at later stages. Follow-up work could investigate the causal effects of other government grant-making programs.

However, none of these potential explanations provide evidence in support of critics' key claim: that scientists' political behavior reflects individual financial self-interest. Even at a moment of heightened science politicization, we cannot find empirical evidence in support of the proposition scientists' political behavior is shaped by having received individual-level government benefits provision. Scientists and their critics should look elsewhere to make sense of scientists' political interventions. 


\section{Chapter 4}

\section{No Rage Against the Machines: Threat of Automation Does Not Change Policy Preferences}

\subsection{Introduction}

Information and communications technology, as well as industrial robots, have contributed to employment and wage polarization by displacing middle-skill workers (Autor, 2015). Experts predict that advances in artificial intelligence (AI) and robotics will enable machines to perform even more tasks currently done by human workers than they are able to today (Ford, 2015; Frey, 2019; West, 2018). According to one forecast, one in ten American jobs is at high risk of being automated in the coming decades (Nedelkoska and Quintini, 2018). A more pessimistic forecast puts the number at $47 \%$ (Frey and Osborne, 2017). Some experts even believe that highly intelligent machines could one day outperform human workers in nearly all tasks (Grace et al., 2018). Even those who do not subscribe to this alarmist view acknowledge the disruptions caused by the current wave of advanced automation will be painful for many workers (Brynjolfsson and McAfee, 2014).

The threat of automation to American workers became more politically salient when Andrew Yang, entrepreneur and 2020 Democratic presidential candidate, made the issue 
a centerpiece of his campaign. However, recent political science research suggests that workplace automation may already be impacting mass politics. Several observational studies find that workers who have been exposed to automation shocks or are expected to experience them express greater support for not only redistribution but also right-wing populist policies and candidates (Anelli, Colantone and Stanig, 2019; Frey, Berger and Chen, 2018; Gingrich, 2019; Im et al., 2019; Thewissen and Rueda, 2019). While these correlational studies add a new perspective to the study of right-wing populism in the U.S. and Europe, they also raise many questions. Chief among them is this: Why do workers oppose free trade and immigration more than automation, when it is automation that poses a more significant threat to their job security and livelihood? Observational research, including my own, finds that workers underestimate the risk posed by automation to their jobs. Workers harmed by automation may have misplaced the blame for their economic distress on outgroups, such as immigrants and workers in foreign countries ( $\mathrm{Wu}, 2019)$.

This paper presents the results of the first experimental studies to examine the impact of workplace automation on mass politics. In three survey experiments, I informed Americans about the current and future effects of labor-saving technology. In two of the three experiments, I found the informational treatments convinced workers that automation threatens American jobs. In all three survey experiments, the information failed to change respondents' preferences on welfare, immigration, and trade policies. Appeals to sociotropic concerns (i.e., the threat to all American workers) were not more effective than appeals to egotropic concerns (i.e., the threat to the respondent's own job). Personalized treatments that emphasized automation's threat to the respondent's own job were not more effective for those whose occupations face a higher risk of automation. Raising awareness about the impact of automation is not enough to decrease Americans' opposition to globalization or to increase their support for policies that will prepare workers for the AI Revolution.

\subsection{Literature Review}

In this section, I introduce some background literature that informed the three empirical studies I have conducted. First, I review research on the existent and future impact of 
automation on the labor market. Next, I summarize then critique recent studies that find exposure to workplace automation risks is correlated with trends in mass politics. Finally, I discuss how public opinion research on trade and immigration policies has influenced my survey experiments.

\subsubsection{Impact of Automation on the Labor Market}

Recent scholarship suggests that automation has negatively impacted workers in developed economies. Experts anticipate these impacts will intensify as labor-saving technology becomes more capable and intelligent, but predictions of these impacts vary significantly between studies.

Economists observe that workers in the U.S. and other developed economies have experienced employment and wage polarization in the past three decades due to technological advances Acemoglu and Autor, 2011; Goos and Manning, 2007; Michaels, Natraj and Van Reenen, 2014). Industries have used computer software and robots to automate routine tasks, thereby reducing the demand for middle-skill workers, who make up a large bulk of the American middle class (Autor, Levy and Murnane, 2003). As a result, the displaced middle-skill workers are forced to work in low-wage service jobs that are difficult to automate (Autor and Salomons, 2018; David and Dorn, 2013). It's important to note that at the same time, demand and wages rose for highly-skilled workers who can perform nonroutine tasks involving problem-solving and complex communication (Autor, 2015).

Newer research has attempted to more precisely estimate the impact of industrial robots on employment and wages. According to one estimate, in the U.S., one more robot per 1000 workers decreased the employment to population ratio by about 0.2 percentage points and wage by $0.42 \%$ between 1990 and 2007 (Acemoglu and Restrepo, 2017). By another estimate, in Germany, each additional robot destroyed two manufacturing jobs and led to a 23\% decline in manufacturing employment between 1994 and 2014 (Dauth et al., 2017). Analysis of data across 17 countries finds that the introduction of industrial robots did not significantly decrease total employment but reduced the share of hours worked by low-skilled workers (Graetz and Michaels, 2018).

Anticipating advances in $\mathrm{AI}$ and robotics, companies, think tanks, and research institu- 
tions have published forecasts regarding the impact of automation on individual occupations as well as total employment. Many of these forecasts use 1) data on tasks performed by various occupations and 2) expert evaluation by computer scientists and engineers regarding the difficulty of automating these tasks to build predictive models. A review of these forecasts reveals the considerable uncertainty in experts' predictions: the number of American jobs at risk of automation ranges between 3.4 million and 80 million over the next two decades (Winick, 2018). The informational treatments in my survey experiments use two sets of these forecasts, (Frey and Osborne, 2017) and (Nedelkoska and Quintini, 2018), to inform American workers about how automation could affect their and others' jobs. The former study predicts that $47 \%$ of jobs in the U.S. are at high risk of automation in the next 10 to 20 years, while the latter study predicts a less drastic but still disruptive $10 \%$.

\subsubsection{Impact of Automation on Mass Politics}

\section{Summaries of Existing Research}

Automation's impact on the labor market may already be affecting mass politics. One common finding among recent observational studies is that actual or anticipated exposure to automation is positively correlated with support for right-wing populist parties, candidates, or policies. Comparative analysis using regional-level and individual-level data from several European countries find that those more exposed to automation shocks indicated greater support for nationalist and radical-right parties Anelli, Colantone and Stanig, 2019; Im et al., 2019), even after accounting for social welfare programs that potentially helped workers harmed by automation (Gingrich, 2019). In the U.S., exposure to industrial robots is positively correlated with support for Donald Trump in the 2016 Presidential Election at the electoral district level (Frey, Berger and Chen, 2018). Individual-level survey data suggests that Americans who are more exposed to automation express greater opposition to free trade and immigration $(\mathrm{Wu}, 2019)$.

Note that other studies find that workers exposed to automation risks are more in favor of left-wing policies or parties. An analysis of survey data from 17 European countries between 2002 and 2012 finds that respondents whose jobs were more automatable expressed 
greater support for redistribution (Thewissen and Rueda, 2019). Exposure to automation is positively correlated with support for not only radical right-wing parties but also mainstream left-wing parties (Gingrich, 2019). Notably, in a survey experiment, an informational treatment that made American respondents more aware of automation's threat increased support of universal basic income among low-skilled workers (Lekalake et al., 2019).

\section{Critiques of Existing Research}

The findings from these studies are compelling because they offer a new explanation for the rise of right-wing populism in the U.S. and Europe. Nevertheless, I offer three methodological critiques. First, most of these studies lack empirical evidence regarding the mechanism through which the threat from automation changes political attitudes and behavior. Second, although many of these studies make causal claims, they do not employ effective causal identification strategies. Third, these studies tend to focus on workers' egotropic concerns without speaking to their sociotropic concerns. I conclude by explaining how my three survey experiments attempt to overcome the limitations of these existing studies.

My first critique of the existing literature is that they do not provide much empirical evidence explaining why exposure to automation changes workers' political attitudes and behavior. Answering this mechanism question is difficult since most of the studies rely on omnibus surveys that ask general political questions, not questions regarding workers' concerns about workplace automation. Instead, these researchers theorize that economic distress felt by workers motivated them to support the right-wing populist agenda. "Populism and identity politics have been fueled by diminishing economic opportunity for the unskilled and the lack of a political response to their concerns," (Frey, 2019) argues, pointing to the white working-class voters who helped elect Donald Trump in 2016. Nevertheless, economic anxiety fails to entirely explain the rise of right-wing populism in the U.S. A robust body of research argues that racial resentment played a more prominent role in the election of Donald Trump than economic anxiety Abramowitz and McCoy, 2019; Mutz, 2018: Schaffner, Macwilllams and Nteta, 2018).

One thing is clear: workers who have been harmed by labor-saving technology do not necessarily become neo-Luddites. Many are unaware that technology is affecting them at 
work. American workers exhibit an optimism bias regarding automation: they believe that while many jobs are likely to be automated, their own will be safe from automation (Smith and Anderson, 2017). Respondents whose occupations are more likely to be automated do not perceive that their jobs are at higher risk of automation. In my study, I found the correlation between workers' forecasts and experts' forecast to be as low as 0.11 (see Figure C.1). Furthermore, workers express greater concern about losing their jobs to cheaper labor than being replaced by computers and machines (Smith, 2016). Fear of outgroups, such as immigrants and workers in foreign countries, appears to drive the policy preferences of those at high risk of automation. While these workers support restricting immigration and free trade, they do not oppose greater government investment in science and technology (Wu, 2019).

Apart from my second critique, causally identifying the impact of workplace automation on mass politics is difficult because workers' exposure to automation is not as-if random. The correlational studies I summarized used pre-exposure covariates to control for the differences between those who are affected by automation and those who are not affected. Nevertheless, researchers cannot control for unobserved differences between those who are affected and those who are not affected; these differences could very well impact workers' political attitudes and behavior. Firms make strategic decisions when deciding to invest in labor-saving technologies, and how they make these decisions is not apparent to outside observers (Raj and Seamans, 2018). Likewise, one's selection into occupations is influenced not only by demographic characteristics commonly found in public opinion surveys, such as age or level of education but also difficult-to-measure characteristics, such as personality traits and intelligence (Holland, 1959).

My final critique is that much of the existing studies focus on voters' egotropic concerns without addressing their sociotropic concerns. Egotropic versus sociotropic voting has been a long-standing debate in political economy (Markus, 1988; Nannestad and Paldam, 1994). Research in support of egotropic voting suggests one's concerns about personal finances, income, and employment predominantly drives one's political preferences (Fiorina, 1978, Grafstein, 2005, Hacker, Rehm and Schlesinger, 2013, Margalit, 2013). Research in support of sociotropic voting argues that policy preferences are mostly shaped instead by one's 
concerns about the state of the national economy (Evans and Andersen, 2006; Kinder and Kiewiet, 1979; Nadeau and Lewis-Beck, 2001). Given that AI and robotics are generalpurpose tools, those who are not at risk of being impacted by automation might also worry about these technologies' impact on the economy as a whole. Interestingly, some of the most vocal alarmists about technological unemployment are current or former tech company CEOs, including Elon Musk and Bill Gates, who have been made wealthier — not poorer - by labor-saving technology. Furthermore, analysis of recent survey data reveals that sociotropic employment concerns regarding automation are more widespread than egotropic ones in Europe (Heinrich and Witko, 2019).

My empirical studies sought to overcome these three limitations of the existing literature. I used survey experiments to causally identify the effect of learning about automation's threat to workers on policy preferences. While it is impossible to expose randomly-selected groups of workers to competition from machines and computers, I presented a randomlyselected group of workers information about this type of competition. In some ways, the informational treatments I designed may be more direct and powerful than the actual threat of automation, which many Americans are unaware of. My empirical studies also probed at the mechanism by which the threat of automation affects Americans' policy preferences. Misunderstanding among the working-class white population about the cause of American workers' economic distress may have contributed to the group's support for right-wing populism. I examined whether educating workers about the impact of automation while shifting the blame away from immigrants and workers in foreign countries would decrease hostility toward these outgroups and increase support programs that directly help those displaced by automation. Finally, I tested whether information that appeals to workers' sociotropic concerns is more effective at changing policy preferences than appeals to their egotropic concerns.

\subsubsection{Lessons From Public Opinion Research on Trade and Immigration}

Public opinion research on voters' preferences toward trade and immigration policies can inform empirical studies of how automation impacts mass politics. A key takeaway is that economic self-interest does not necessarily drive policy preferences. Another lesson is that 
survey experiments can be a useful tool to study public opinion toward economic policy.

A central finding in political science is that non-materialist factors, such as ethnocentrism or nationalism, influence voters' preferences on trade and immigration as much as, if not more, than economic self-interest. Regarding trade policy, out-group anxiety and sociotropic concerns about workers in one's own country drives support for protectionism (Lü, Scheve and Slaughter, 2012, Mansfield and Mutz, 2009, 2013, Rho and Tomz, 2017). Furthermore, many do not understand how trade policy impacts their own financial well-being. In survey experiments, researchers find that educating respondents about the impact of free trade can induce preferences that reflect economic self-interest (Hiscox, 2006; Rho and Tomz, 2017). Similarly, there is robust evidence that cultural anxiety and racial resentment decrease voters' support for immigration, particularly immigration from countries whose cultures are perceived to be threatening (Brader, Valentino and Suhay, 2008; Hainmueller and Hangartner, 2013; Kinder and Kam, 2010; Valentino, Brader and Jardina, 2013). Labor market competition does not appear to be a compelling driver of voters' opposition to immigration: both highly-skilled and low-skilled native workers favor highly-skilled immigrants over low-skilled immigrants (Hainmueller and Hopkins, 2015, Hainmueller and Hiscox, 2010).

Applying these findings to my research, it becomes apparent that workers' response to the threat of automation may not necessarily reflect their economic self-interest. Many workers do not understand how automation has and will continue to impact them, making it difficult for them to support policies that benefit their financial well-being. Furthermore, workers who misdirected their blame onto immigrants and foreign workers, instead of automation, could be driven by their resentment of outgroups.

A review of the literature reveals that survey experiments have been enormously useful for researchers studying public opinion regarding trade and immigration. Survey experiments allow researchers to test causal hypotheses that would have been otherwise impossible in observational studies (Hyde, 2015). In addition, researchers have used this method to study how increasing voters' economic or political knowledge shapes their policy preferences (Hiscox, 2006; Rho and Tomz, 2017). Many voters are not informed about complex policy issues; as a result, their attitudes and behavior may seem puzzling to experts. Survey ex- 
periments shed light on how educating voters can help them make more informed decisions. Finally, survey experiments also allow researchers to probe at the mechanisms that connect a cause and an effect. The researcher could design several treatment arms that experimentally manipulate the said mechanisms (Gerber and Green, 2012). For these reasons, I used survey experiments in my empirical studies to understand how the threat of automation affects policy preferences.

\subsection{Hypotheses and Outcome Measures}

This section details the hypotheses that my survey experiments tested and the outcome variables the survey questions measured.

\subsubsection{Hypotheses}

Across my three survey experiments, I tested the following primary hypotheses:

- H1: Learning about automation's threat to jobs currently performed by humans will cause respondents to believe that automation is more likely to impact workers.

- H2: Learning about automation's threat to jobs currently performed by humans will change respondents' policy preferences.

In Study 1, the most extensive of the three studies, I tested these secondary hypotheses:

- H3: Treatments that highlight sociotropic concerns (i.e., automation's threat to American jobs in general) will produce effects that are unequal to the effects produced by treatments that express egotropic concerns (i.e., automation's threat to an individual's job).

- H4: Among those informed of automation's threat to their own jobs, those whose jobs are more likely to be automated will be more responsive to the informational treatment.

Note that Hypotheses 2 and 3 are two-sided because I do not have strong priors regarding the direction of the effects. In terms of Hypothesis 2, the existing literature described 
in the previous section suggests that learning about automation's threat would increase respondents' support for redistribution and decrease their support for immigration and free trade. Nevertheless, results from pilot studies produced inconclusive evidence about the direction of the effects in Hypotheses 2 and 3.

\subsubsection{Outcome Measures}

The outcomes I measure were roughly divided into two categories. The first category of outcomes measured respondents' beliefs about the future of work. I eschewed a simple manipulation check in which respondents asked to recall the information presented in treatment. Instead, I asked a series of questions that provided me with a nuanced understanding of respondents' beliefs about how automation will impact their work and others' work. These questions include respondents' own forecasts about workplace automation, concerns about job loss, and predicted results of advanced automation. The outcome measure questions were derived from (Smith, 2016) and (Smith and Anderson, 2017).

The second category of questions measures respondents' policy preferences. These include respondents' attitudes towards welfare, immigration, and trade policies. I plan to study these policy areas because related observational studies have examined the impact of automation on support for 1) redistribution policies and 2) right-wing parties or candidates who oppose immigration and free trade. These outcome measure questions were not only standard ones from the American National Election Studies or Pew Research Center surveys but also questions with more extreme policy positions in their answer choices taken from (Broockman, 2016). Beyond measuring preferences toward bread-and-butter economic policies, I also asked respondents about policies that specifically address technological unemployment, such as creating a guaranteed basic income, limiting workplace automation, and expanding job retraining programs. 


\subsection{Three Empirical Studies}

\subsubsection{Study 1: The Impact of Expert Forecasts on Factual Beliefs and Policy Preferences}

Study 1 is the most comprehensive of the three empirical studies: it tested all four of the hypotheses stated in the previous section. I used a novel survey experiment to evaluate the effectiveness of four informational treatments on influencing American workers' beliefs about the future of work and policy preferences. Results from the survey experiment suggest that presenting the public with expert forecasts about workplace automation changed their beliefs about the future of work but did not affect their policy preferences. Furthermore, the General Forecast and the Individual Forecast treatments produced similar null effects. Finally, for respondents assigned to the Individual Forecasts, the informational treatment was not stronger for those whose jobs were more automatable according to expert forecasts.

\section{Survey Experiment Design}

To test the four hypotheses, I designed a survey experiment with four treatment arms. The designed allowed me to test more than just the primary hypotheses (Hypotheses 1 and 2). To test Hypothesis 3, I created two types of treatments that highlighted either sociotropic or egotropic concerns about workplace automation. To test Hypothesis 4, I designed Individual Forecast treatments that mimicked popular interactive websites in which users can input their occupations to view the predicted probabilities that their jobs will be automated 1

To increase the external validity of my survey experiment, I used general and individual forecasts from two different data sources: (Frey and Osborne, 2017) and (Nedelkoska and Quintini, 2018) 2 ${ }^{2}$ Note that I will refer to the (Nedelkoska and Quintini, 2018) forecasts as

1. The website "Will Robots Take My Job" (https://willrobotstakemyjob.com/) is one such example.

2. Figure C.2 illustrates how the differences in the two forecast datasets produced differences in the distribution of individual forecasts presented to my survey respondents. The Frey and Osborne forecasts have a bimodal distribution where most of the jobs are either at low or high risk of automation; in contrast, the OECD forecasts follow a normal distribution. Differences in modeling assumptions cause the differences between the two forecast datasets. While Frey and Osborne's model assumed that everyone in the same occupation performs the same tasks, the OECD model did not. Instead, Nedelkoska and Quiniti used individual-level survey data on what tasks workers within each occupation performed to create the OECD model. 
the OECD forecasts throughout this paper.

There were five experimental groups in my study:

- Control: No informational treatment was given.

- Treatment 1 (General Forecast - Frey and Osborne): A short news article explained that Oxford researchers predict that $47 \%$ of American jobs are at risk of being automated in the upcoming decades, based on forecasts by (Frey and Osborne, 2017).

- Treatment 2 (General Forecast - OECD): A short news article explained that OECD researchers predict that $10 \%$ of American jobs are at risk of being automated in the upcoming decades, based on forecasts by (Nedelkoska and Quintini, 2018).

- Treatment 3 (Individual Forecast - Frey and Osborne): A short passage presented the likelihood that the respondent's job will be automated according to (Frey and Osborne, 2017).

- Treatment 4 (Individual Forecast - OECD): A short passage presented the likelihood that the respondent's job will be automated according to (Nedelkoska and Quintini, 2018).

The complete text of the experimental treatments and survey questions is found in Appendix C.1

My survey experiment followed the procedure described in Figure 4.1. At the beginning of the survey, respondents used a dropdown menu to select their industry, followed by their occupation. The dropdown menu included 214 common occupations in the U.S $\mathrm{I}^{3}$ If the respondent's occupation was not found in the dropdown menu, she could enter it in a textbox. Respondents were sorted into two groups depending on their occupation.

Subjects in Group A reported occupations not included in the dropdown menu. Those in Group A had 1/3 equal probability of being assigned to Treatment 1, Treatment 2, or

3. These jobs are the 150 most common jobs in the U.S. according to the Bureau of Labor Statistics as well as the ten most common jobs within each industry category. 


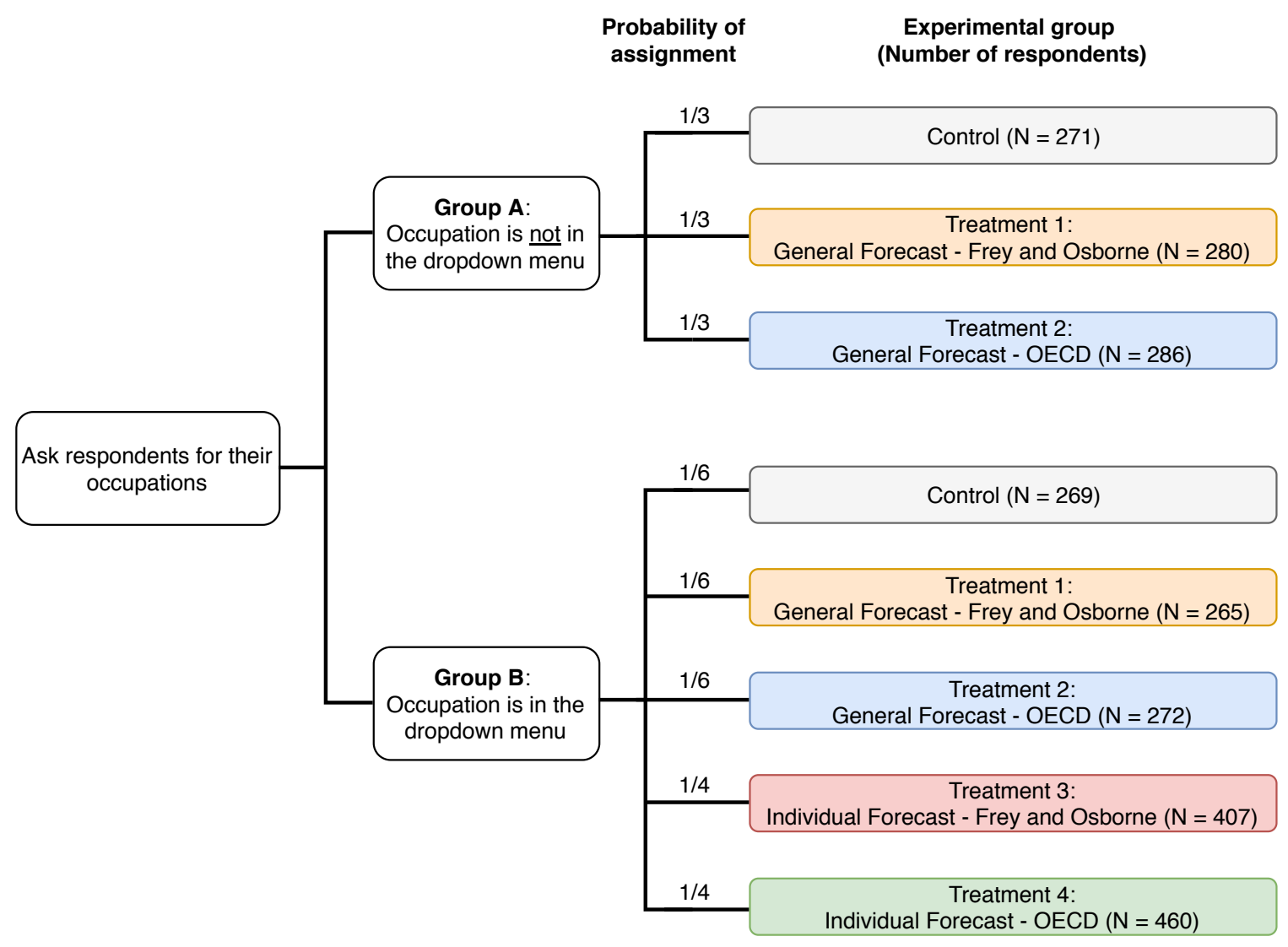

Figure 4.1: Study 1 Survey Experiment Flowchart

The number of respondents assigned to each experiment group is also included. 
the Control group. Group B consisted of those whose occupations were in the dropdown menu. Those in Group B were randomly assigned to one of the five experimental groups, although with unequal probability. To ensure that I have enough respondents who viewed the individual forecasts so that I could test Hypothesis 4, I randomly assigned respondents to Treatment 3 or Treatment 4 with $1 / 4$ probability each. Group B respondents were randomly assigned with $1 / 6$ probability to Treatment 1 , Treatment 2 , or Control.

Each respondent read the manipulation assigned to her. Afterward, the respondent answered a series of outcome questions.

\section{Outcomes Measures}

First, the respondents answered a series of questions regarding their beliefs about the future of work. These questions asked respondents to forecast the likelihood that their own jobs, all American jobs, and three randomly-selected occupations $4^{4}$ will be automated in 20 years. Furthermore, the survey also measured respondents' concern about losing their jobs to computers or machines. Finally, respondents were asked to predict whether income inequality would worsen and whether new, better-paying jobs would be created if machines were able to do most tasks currently performed by humans.

Next, respondents were asked about their attitudes towards a range of economic policies. The welfare policy questions asked about whether the government should guarantee jobs and a good standard of living, work to reduce income equality, provide health insurance, and fund job retraining. The two immigration policy questions measured support for restricting immigration. The two trade policy questions measured support for limiting imports and government discouraging outsourcing. Finally, respondents were asked whether they support the government creating a guaranteed basic income program or limiting workplace automation as potential policies to mitigate the harms of technological unemployment.

A random sample of respondents in the treatment groups $(N=1293)$ was also presented with questions that 1) asked them whether they perceive the information they read to be

4. Respondents were asked to make predictions about three occupations randomly selected from a list of seven. The list included software engineers, legal clerks, nurses, construction workers, fast food workers, teachers, and insurance claims processors. 
credible and 2) measured their emotional response to the informational treatments.

\section{Survey Data}

The survey experiment respondents were recruited using Lucid, an online survey sample platform, in August 2018. While Lucid does not provide probability samples of the U.S. adult population, its quota samples approximate the marginal distribution of key demographic characteristics (e.g., gender, age, race, etc.). Recent validation exercises found that Lucid samples approximate nationally representative samples in terms of demographic characteristics and survey experiment effects (Coppock and McClellan, 2019). For this study, I asked Lucid to sample only those who are in the labor market 52510 American respondents completed the survey. The size of each experimental group is reported in Figure 4.1.

\section{Data Analysis}

For Hypotheses 1 and 2, I tested whether the estimated effect of each treatment is distinguishable from zero. To estimate the treatment effects for each outcome, I use separate weighted least-squares regressions for the General Forecast treatments and the Individual Forecast treatments ${ }^{6}$ The analysis of the General Forecast treatments included respondents from Groups A and B; analysis of the Individual Forecast treatments included respondents from Group B only.

Recall from Figure 4.1 that individuals had different probabilities of being assigned to each experimental group. Therefore, in my regressions, each respondent was weighted by the inverse of the probability that she was assigned to her group $\sqrt[7]{7}$

Equation 4.1 shows the weighted sum of squares that my regression minimized: $w_{i}$ is the

5. Of the 2510 respondents in the sample, 2396 reported that they were working, 33 reported that they were temporarily laid off, and 81 reported that they were unemployed and looking for work.

6. I pooled Treatments 1 and 2 in my analysis of the General Forecast treatments; likewise, I pooled Treatments 3 and 4 in my analysis of the Individual Forecast treatments. The chief reason for pooling the treatments is that I wanted to increase the power of the experiment. Furthermore, as Tables C.6 and C.7 show, which expert forecast dataset the informational treatment was derived from (Frey and Osborne vs. OECD) did not impact the treatment effects.

7. For example, suppose that a subject was in Group B and she was randomly assigned to the Control group. Because she had a $1 / 6$ probability of being assigned to the Control group, her weight is 6 . 
inverse probability weight for Subject $i, Y_{i}$ is the outcome, $T_{i}$ is the indicator variable for assignment to the informational treatment. I tested whether $\hat{\beta}_{1}$, the estimated treatment effect, is non-zero.

$$
W S S(\beta, \mathbf{w})=\sum_{i=1}^{N} w_{i}\left[Y_{i}-\left(\beta_{0}+\beta_{1} T_{i}\right)\right]^{2}
$$

To test Hypothesis 3 for each outcome, I used $F$-tests to test whether the effect differed between the General Forecast treatment and the Individual Forecast treatment. For this regression analysis, I focused on the 1673 respondents in Group B. To increase power, I performed the analysis by pooling Treatments 1 and 2 into a General Forecast treatment group; likewise, I pooled Treatment 3 and 4 into an Individual Forecast treatment group. Because respondents in the latter group were assigned individual - and therefore heterogeneous treatments, the regression controlled for the predicted likelihoods that each respondent's job will become automated according to the two forecast datasets. Finally, given the different probabilities of assignment to each group, each respondent was weighted by the inverse of the probability that she was assigned to her experimental group.

Equation 4.2 shows the weighted sum of squares that my regression minimized: $w_{i}$ is the inverse probability weight, $Y_{i}$ is the outcome, $T_{\text {General }, i}$ is the indicator variable for assignment to the General Forecast treatment, $T_{O E C D, i}$ is the indicator variable for assignment to the Individual Forecast treatment, $A_{F O, i}$ is the predicted likelihood of Subject $i$ 's job becoming automated according to Frey and Osborne, and $A_{O E C D, i}$ is the predicted likelihood of Subject $i$ 's job becoming automated according to the OECD. I used $F$-tests to test the equivalence of the estimated coefficients $\hat{\beta}_{1}$ and $\hat{\beta}_{2}$.

$$
W S S(\beta, \mathbf{w})=\sum_{i=1}^{N} w_{i}\left[Y_{i}-\left(\beta_{0}+\beta_{1} T_{\text {General }, i}+\beta_{2} T_{\text {Individual }, i}+\beta_{3} A_{F O, i}+\beta_{4} A_{O E C D, i}\right)\right]^{2}
$$

Finally, regarding Hypothesis 4, I tested whether the estimated interaction effect between the individual treatment and the predicted probability of the respondent's job becoming automated is non-zero. Note that for this analysis. I focused exclusively on respondents 
in Group B who were assigned to Control, Treatment 3, and Treatment 4. Because Treatments 3 and 4 presented respondents with different predicted probabilities, I use separate weighted regressions to perform the analysis for each treatment group. Again, each respondent was weighted by the inverse of the probability that she was assigned to her group. Equation 4.3 shows the weighted sum of squares that my regression minimized: $w_{i}$ is the inverse probability weight, $Y_{i}$ is the outcome, $T_{i}$ is the indicator variable of assignment to the individual treatment, and $A_{i}$ is the predicted likelihood that Subject $i$ 's job will be automated according to the expert forecast. I tested whether $\hat{\beta}_{3}$, the estimated interaction effect, is non-zero.

$$
W S S(\beta, \mathbf{w})=\sum_{i=1}^{N} w_{i}\left[Y_{i}-\left(\beta_{0}+\beta_{1} T_{i}+\beta_{2} A_{i}+\beta_{3} T_{i} A_{i}\right)\right]^{2}
$$

The pre-analysis plan for this study and the other two are registered using the Open Science Framework 8

\section{Study Results: Beliefs About the Future of Work}

The General Forecast treatments produced small but statistically significant changes in respondents' beliefs about the future of work, as seen in Figure 4.2 . The treatments increased the perceived likelihood of one's job becoming automated by $17 \%$ (standardized effect of $0.15 ; \mathrm{SE}=0.06$ ) and increased the perceived likelihood of three randomly-selected jobs becoming automated by $10 \%$ (standardized effect of $0.14 ; \mathrm{SE}=0.05$ ). Furthermore, the treatments increased respondents' concern about losing their jobs due to automation by $21 \%$ (standardized effect of 0.20; $\mathrm{SE}=0.06) .{ }^{10}$ While the General Forecast treatments induced respondents to become more concerned about machines replacing human workers, they did not cause respondents to predict that income inequality would worsen as automation gets more advanced. Instead, it increased respondents' perceived likelihood that the economy

8. The pre-analysis plans for all three studies are available at https://osf.io/8tjvq/.

9. Appendix C.4.1 contains the comprehensive data analysis results, including robustness checks, in the table format.

10. As a robustness check shows, the treatment did not affect respondents' concern about losing their jobs to cheaper labor, as seen in Table C.2. 


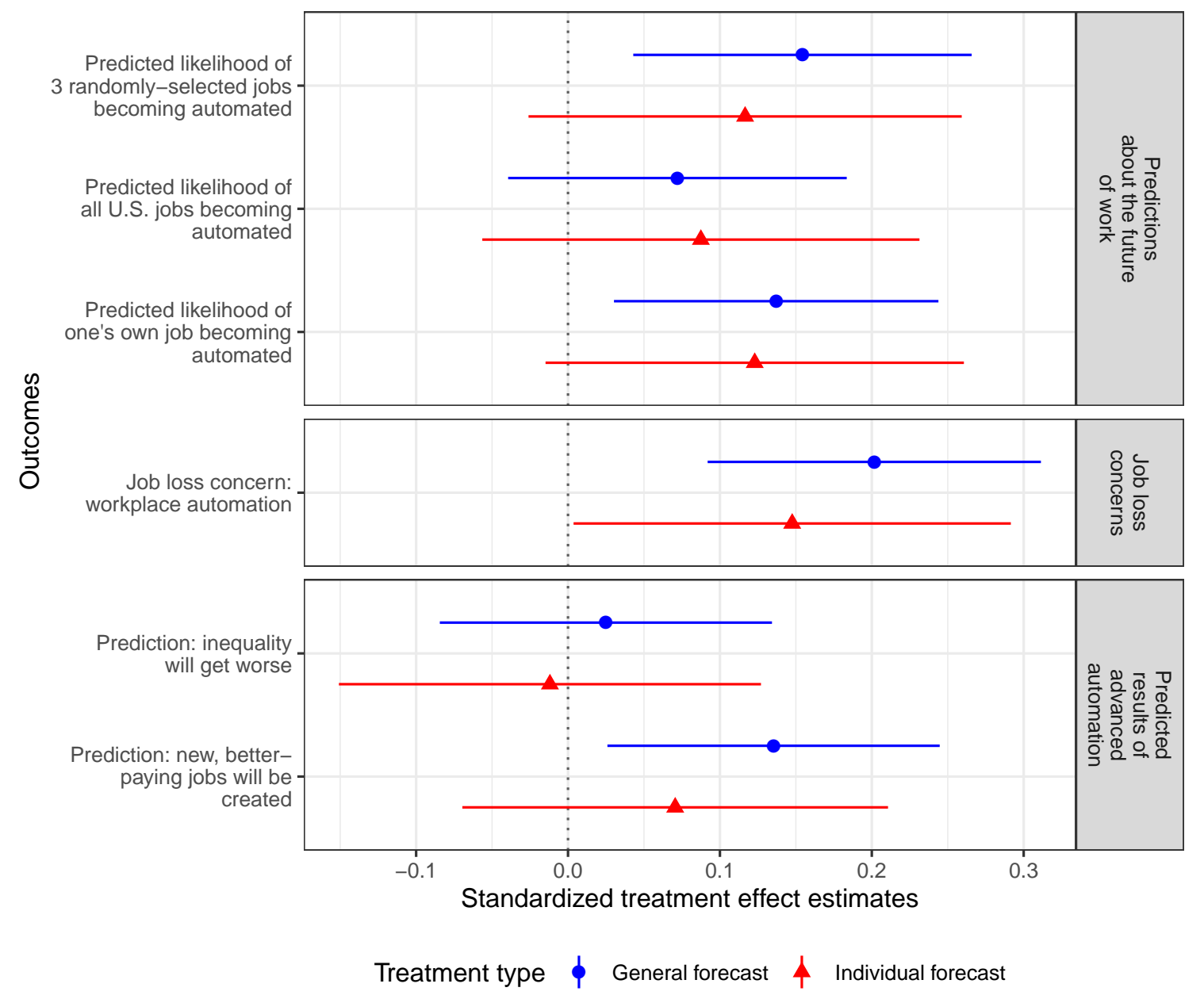

Figure 4.2: Study 1 Results: Beliefs About the Future of Work

A more positive treatment effect estimate means a greater predicted likelihood or a great level of concern. The estimated effects and the 95\% confidence intervals are shown. 540 respondents were in the Control group, 1103 respondents viewed the General Forecast treatments, and 867 respondents viewed the Individual Forecast treatments. 
would create many more new, better-paying jobs for humans by $10 \%$ (standardized effect of $0.14 ; \mathrm{SE}=0.06)$.

To test Hypothesis 3, I compared the effects of the General Forecast treatments with those of the Individual Forecast treatments. As Table C.8 shows, the differences in effects for all but one outcome variables are statistically indistinguishable. Overall, the study finds that treatments that highlight sociotropic concerns worked no better than treatments that highlight egotropic ones 11

I hypothesized that the Individual Forecast treatment effects are likely heterogeneous across the sample. To test Hypothesis 4, I estimated the interaction effect between the predicted probability of the respondents' jobs becoming automated and the individual treatment effect. According to Table C.9, the effect of Treatment 3 on respondents' perceived likelihood of their own jobs becoming automated is much stronger for respondents whose jobs are more automatable according to the expert forecast $(p$-value $<0.001)$. Each ten percentage point increase in the likelihood of one's job becoming automated is correlated with a 0.06 standard deviation increase in the treatment effect. Regarding the other outcomes, the Individual Forecast treatments do not appear to be stronger for respondents whose jobs are more automatable according to the expert forecasts.

Overall, the treatment effects were weak. Changing respondents' beliefs about the future of work proved difficult for a few potential reasons. For one, respondents' baseline beliefs suggest that they thought workplace automation is an unlikely threat in the next two decades ${ }^{12}$ Therefore, persuading them that automation will impact their and others' jobs proved more difficult than I anticipated. Next, respondents did not place great trust in the forecast information presented to them. Among those who were asked how confident they place in the expert forecasts, the average responses across the four treatments were all below "fairly confident," as shown in Figure C.3 ${ }^{13}$ Finally, the informational treatments

11. One critique of the survey experiment design is that the General Forecast treatments highlighted not only sociotropic concerns but also egotropic ones. After all, the treatments increased respondents' predicted likelihood of their own jobs becoming automated and fear about losing their jobs to machines.

12. For the Control group, the mean responses to the manipulation questions are in the "very unlikely" to "unlikely" range, as reported in Table C.11. The responses are all between 0.86 and 1.31 on a scale from 0 to 4 , with 0 meaning "very unlikely" and 4 meaning "very likely."

13. "Fairly confident" is a 2 on the scale from 0 to 3 . 
did not induce great anxiety or negative emotions in the respondents, as Figures C.4 and C.5 show.

\section{Study Results: Policy Preferences}

The informational treatments, across the board, did not change policy preferences, as seen in Figure 4.3. The treatments did not increase support for adopting redistributive policies, restricting immigration into the U.S., or limiting free trade. Moreover, the treatments did not impact respondents' support for potential policies that address the impact of workplace automation, such as government-funded job retraining programs, guaranteed basic income, or limiting automation to jobs that are unsafe for humans.

Regarding Hypothesis 3, there exists no difference between the General Forecast treatments and the Individual Forecast treatments, as seen in Table C.8. The one exception is that the effect of the General Forecast treatments on support for the government reducing income inequality is greater the effect produced by the Individual Forecast treatments $(p$ value $=0.005)$; this result is likely a statistical fluke. Regarding Hypothesis 4, respondents whose jobs are more likely to be automated were no more responsive to the Individual Forecast treatment, according to Tables C.9 and C.10.

Several factors could explain why the informational treatments had no impact on policy preferences. First, the treatments produced relatively weak effects in changing respondents beliefs about the future of work. Second, although the General Forecast treatments caused respondents to be more concerned about losing their jobs to machines, it did not cause them to imagine society would be worse off in other ways. In fact, respondents given the treatments did not think that inequality would worsen but rather that many new, betterpaying jobs would be created. Therefore, respondents may have thought that policy changes in response to increasing workplace automation may not be warranted. Third, respondents could have difficulty connecting the information presented in the treatments with the policies they were asked to consider. The informational treatments did not explicitly discuss how workplace automation relates to the policies the survey asked about, nor did the treatments make policy recommendations. Study 2's informational treatment addressed this flaw by explicitly discussing policy challenges and making policy recommendations. 


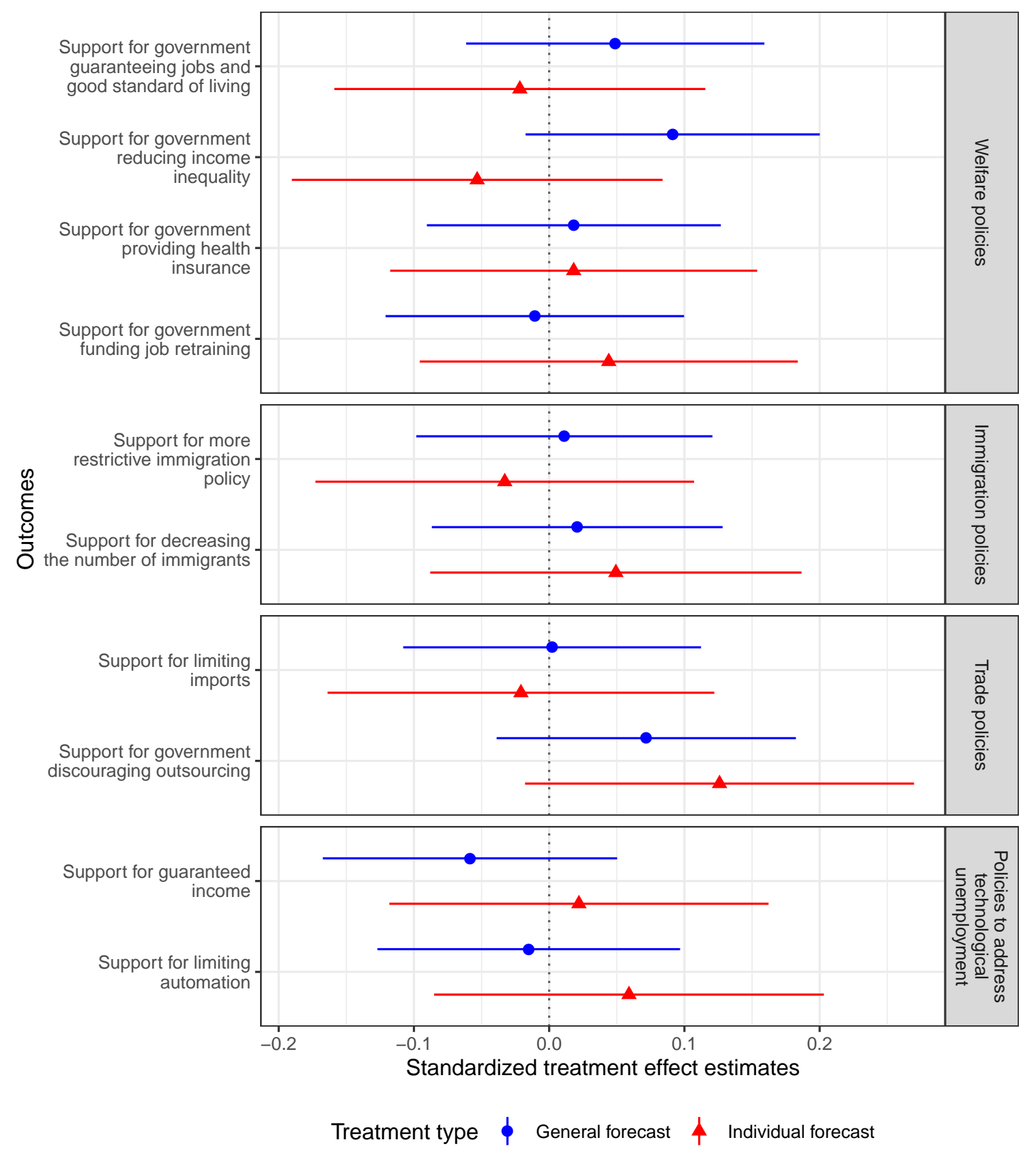

Figure 4.3: Study 1 Results: Policy Preferences

A more positive treatment effect estimate means a greater level of support. The estimated effects and the 95\% confidence intervals are shown. 540 respondents were in the Control group, 1103 respondents viewed the General Forecast treatments, and 867 respondents viewed the Individual Forecast treatments. 


\subsubsection{Study 2: Survey Experiment Studies Workers Highly Affected Au- tomation}

Study 2 sought to both replicate parts of Study 1 and expand upon the original study. More interestingly, the subjects in Study 2 are a sub-population profoundly affected by automation: Americans performing "gig work" on Amazon Mechanical Turk (MTurk), a crowdsourcing platform. The findings of Study 2 are mostly consistent with those of Study 1. In this new study, I designed a news article that explained the existent and future impact of workplace automation. This informational treatment increased workers' perceived likelihood that their jobs and others' jobs will be automated and made workers more concerned about job loss. Nevertheless, the treatment did not affect workers' policy preferences.

\section{Study Design}

The goal of Study 2 was to replicate Study 1 and fix its flaws. I honed in on MTurk workers because I suspected they are more receptive to the informational treatment. Gig workers on crowdsourcing platforms, such as MTurk, are paving "automation's last mile" by performing tasks that algorithms cannot yet do. At the same time, they are creating training data to improve algorithms that could one day put humans out of work (Gray and Suri, 2019). Typical tasks that MTurk workers perform include image and video classification, sentiment analysis, and audio transcription, areas where machine learning has made substantial gains in recent years (Eckersley and Nasser, 2019). Therefore, it is unsurprising that the Control group in Study 2 (i.e., American MTurk workers), compared with the Control group in Study 1 (i.e., a quasi-representative sample of all American workers), reported a $51 \%$ greater concern about losing their job to machines and computers ${ }^{14}$

The experimental design in Study 2 is straight-forward: respondents were randomly assigned either to the Treatment group or the Control group with equal probability. Those assigned to the Treatment group read a news article explaining the existent and future impact of workplace automation, as shown in Figure 4.4. This news article is based on

14. Note that the MTurk workers in my sample reported working an average of 28 hours per week outside of MTurk; therefore, some of them may not think of their work on MTurk as their primary job. 


\section{Nearly Half of American Jobs Are at Risk of Automation}

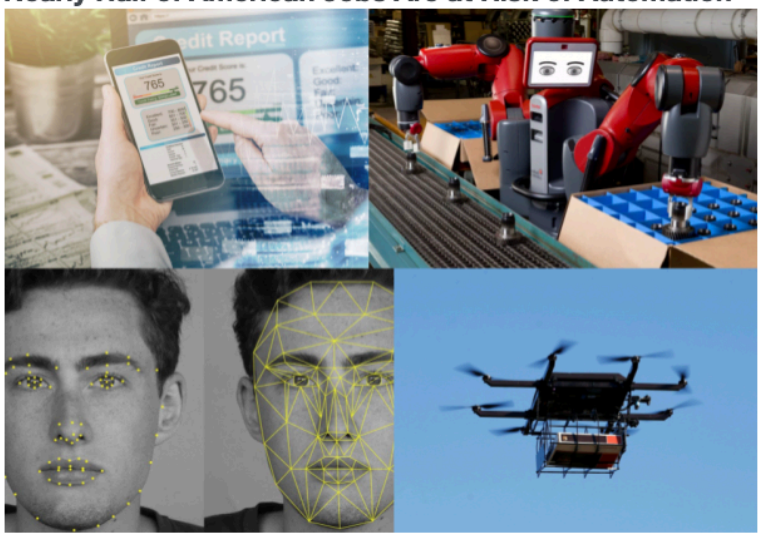

Machine learning is used to perform many tasks that previously required human workers, such as generating credit reports, operating machinery, recognizing faces, and delivering packages.

A new study predicts that $47 \%$ of jobs in the U.S. are at risk of becoming automated in the next 10 to 20 years.

The study by researchers at the University of Oxford examined hundreds of occupations to predict how likely computers and machines are to automate these occupations. To make their forecasts, the researchers considered the tasks workers performed, the skills required for each occupation, and engineering challenges.

Automation has already impacted American workers in the past few decades. Technological advances have reduced the demand for middle-skilled jobs that require more education and training than a high school diploma but less than a four-year college degree. For example, computers have reduced the demand for secretaries, and industrial robots have reduced the need for factory workers. This wave of workplace automation has led to the decline of the middle class in the U.S., some economists argue.

Today, advances in machine learning, artificial intelligence, and robotics have increased the pace of automation. Computers and robots are now trained to perform tasks that typically require human intelligence. The resulting automation is threatening not only routine jobs, but also jobs that require expertise: computer programmers, judges, and radiologists.

The public, not just experts, is concerned about the disruptive impact of workplace automation. Three out of every four Americans are worried about a future where robots and computers can do many jobs currently done by humans, according to a study by Pew Research Center. A higher percentage of Americans think that in such a future, inequality between the rich and poor will be much worse than it is today.

The impact of advanced automation will be felt not only in the U.S. but also around the world. For instance, China has invested heavily in artificial intelligence research to boost its economic productivity. Limiting international trade or immigration into the U.S. is unlikely to stop the disruptive effects of technology on American jobs.

Figure 4.4: The Informational Treatment News Article Displayed in Study 2 A condensed version of this news article displayed in Study 3. Appendix C.2 contains the text of the article in Study 2; Appendix C.3 contains the text of the article in Study 3. 
Treatment 1 (General Forecast - Frey and Osborne) from Study 1 but extended to include a photo collage and a more extended text passage 15 The photo collage displayed examples of computers and machines performing tasks that typically require human intelligence. The extended text fixes potential flaws in Study 1's informational treatments by highlighting how workplace automation could worsen income inequality and explaining that limiting trade or immigration is unlikely to stop the disruptive effects of workplace automation. Respondents in the Control group received no informational treatment. The survey experiment was conducted in July and August of 2019; 345 respondents were assigned to the Control group, and 291 were assigned to the Treatment group 16 For the data analysis, I estimated the average treatment effect for each outcome using ordinary least squares regression.

\section{Results}

The results of Study 2 largely mirror the results from Study 1: the informational treatment changed respondents' beliefs about the future of work but not their policy preferences, as seen in Figures 4.5 and $4.6{ }^{17}$ The news article treatment increased respondents' predicted percentage of American jobs that will be automated from $36.8 \%$ to $41.4 \%$ ( $\mathrm{SE}=1.78$ ). The treatments increased the perceived likelihood of one's job becoming automated by $16 \%$ (standardized effect of $0.18 ; \mathrm{SE}=0.09$ ) and increased the perceived likelihood of three randomly-selected jobs becoming automated by $15 \%$ (standardized effect of $0.24 ; \mathrm{SE}$ $=0.08)$. Furthermore, it increased respondents' concern about losing their jobs by $20 \%$ (standardized effect of $0.19 ; \mathrm{SE}=0.10) 18$

The news article explained that automation has contributed to the decline of the Amer-

15. In the online survey, respondents in the Treatment group were required to spend at least 30 seconds on the page containing the treatment information before they could advance to the next page.

16. Study 2 included not only the outcome measures found in Study 1 but also some new ones. I added a direct manipulation check that asked respondents to predict the percentage of American jobs that will be automated in 20 years and a question that asked respondents how concerned they are about losing their jobs in general.

17. Appendix C.4.2 contains the comprehensive data analysis results, including robustness checks, in the table format.

18. The treatment somewhat increased respondents' concern about losing their job due to automation, but the effect size is not statistically significant at the $5 \%$ level. As a robust check (see Table C.12), I found that the treatment did not impact respondents' concern about losing their jobs to immigrants or workers in foreign countries. 


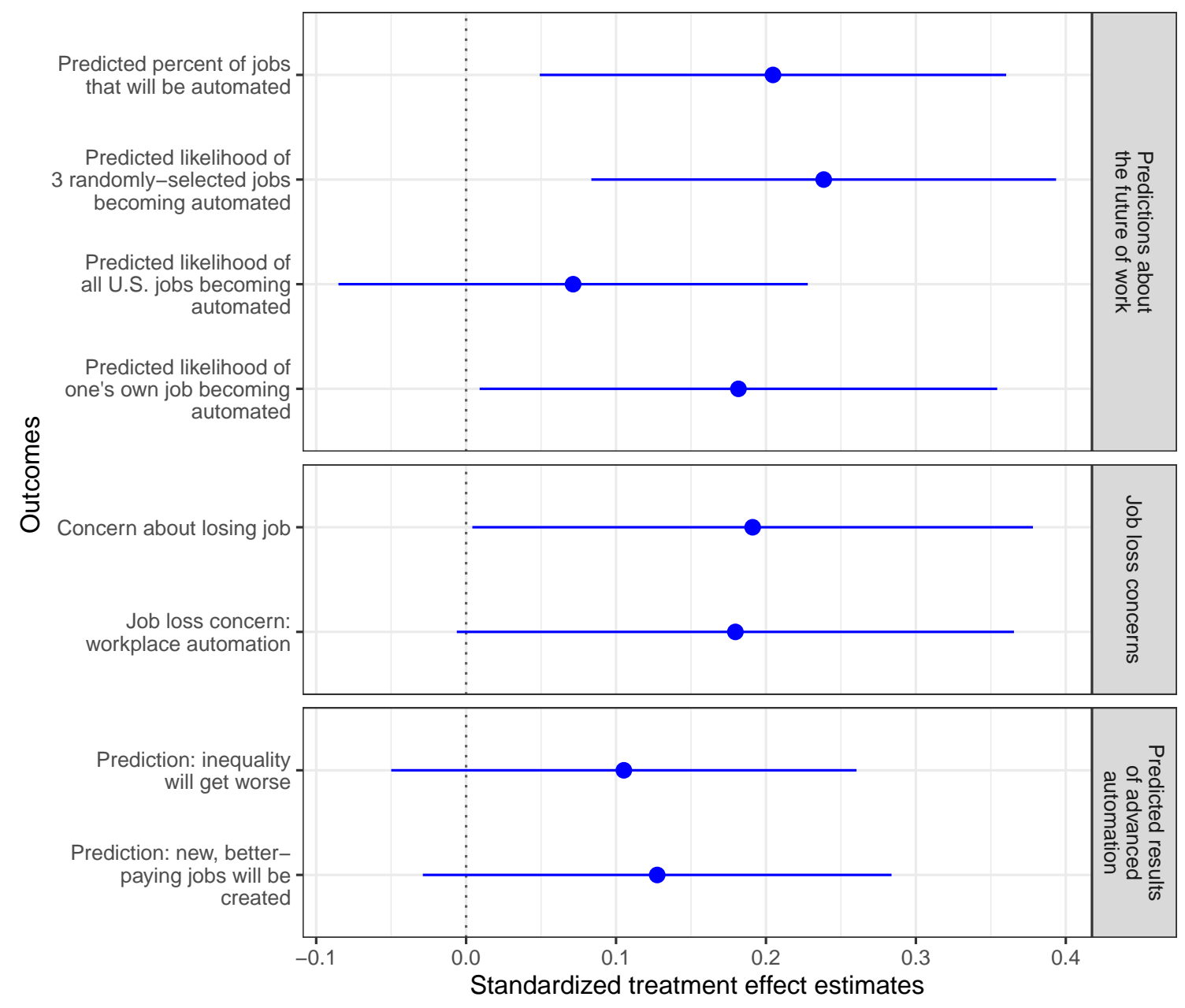

Figure 4.5: Study 2 Results: Beliefs About the Future of Work A more positive treatment effect estimate means a greater predicted likelihood or a greater level of concern. The estimated effects and the $95 \%$ confidence intervals are shown. 345 respondents were in the Control group and 291 were in the Treatment group. 


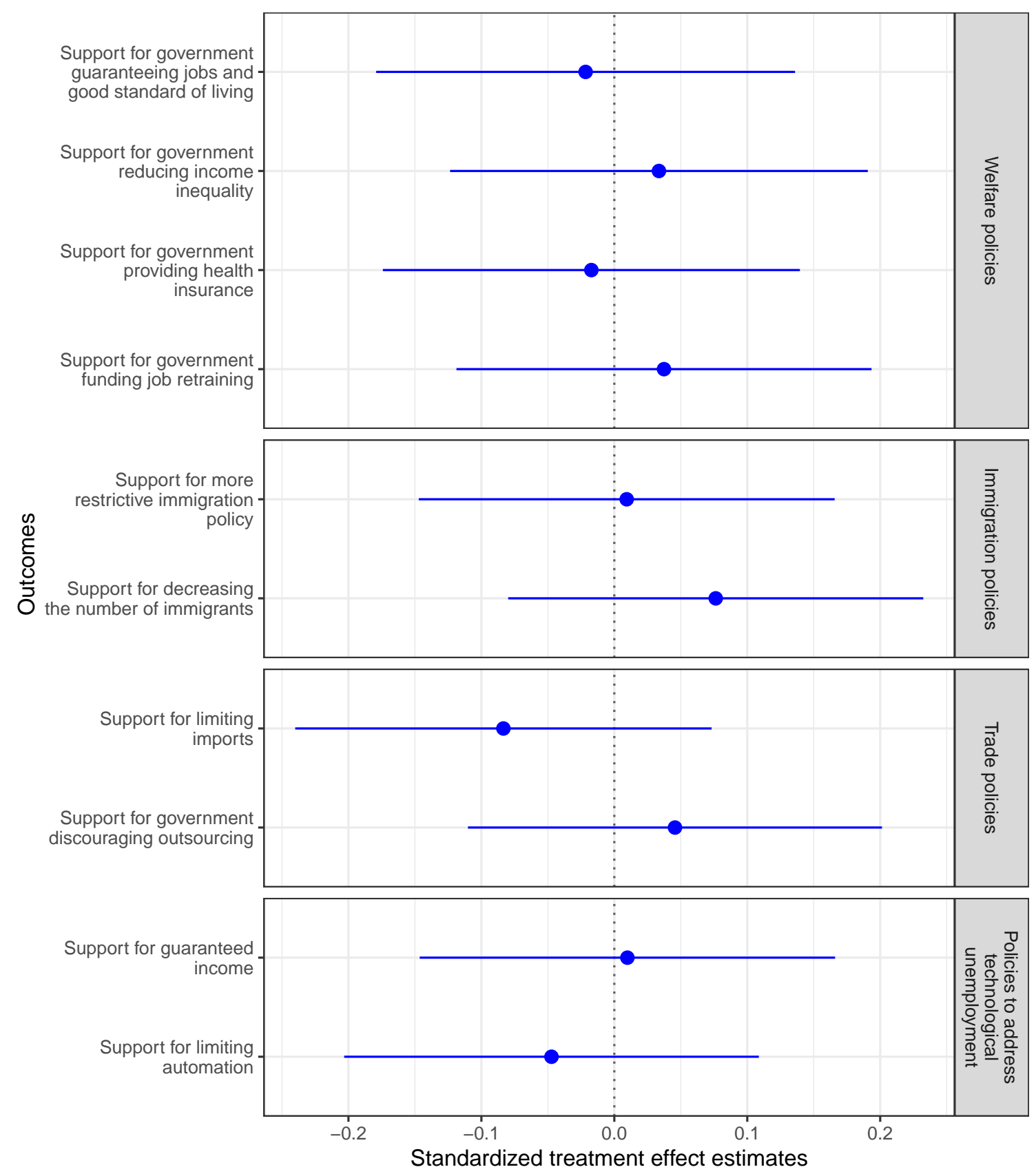

Figure 4.6: Study 2 Results: Policy Preferences

A more positive treatment effect estimate means a greater level of support for the policy. The estimated effects and the $95 \%$ confidence intervals are shown. 345 respondents were in the Control group and 291 were in the treatment group. 
ican middle class. Furthermore, it mentioned that an overwhelming majority of Americans are worried that advanced workplace automation will exacerbate income inequality. Still, the treatment did not cause respondents to predict that income inequality would get worse. One possible explanation for this null result is that the baseline belief that workplace automation will worsen income inequality is already high (2.33 on a 0 to 3 point scale); therefore, any treatment to increase this belief will hit a ceiling. Furthermore, the article did not change respondents' beliefs that the economy will create many new better-paying jobs even though it discussed machines becoming capable of performing tasks that require currently high-level human intelligence.

The news article failed to change respondents' policy preferences across the board despite its explicit discussion of policy challenges. Respondents in the treatment group did not become more supportive of redistributive policies. This null effect is perhaps not surprising, given that the treatment also failed to change respondents' beliefs about workplace automation worsening income inequality. Likewise, my attempt to correct misdirected blame against immigrants and foreign workers in the informational treatment was unable to change respondents' preferences on immigration and trade policies 19 Lastly, the treatments did not alter respondents' support for policies that address problems related to technological unemployment, such as funding government job retraining programs, creating a guaranteed basic income, or limiting automation to jobs that are unsafe for humans.

\subsubsection{Study 3: Survey Experiment Investigates Policy Responses to Workplace Automation}

Study 3 is a small-scale replication of Study 2, but it focuses on policy responses to workplace automation. The effects of the news article informational treatment in this study failed the manipulation check and did not induce changes in policy preferences. The results of this study suggest that the treatment barely registered with an inattentive audience.

19. The treatment also had no effect on respondents' approval of Donald Trump, as seen in Table C.12 


\section{Study Design}

Study 3 tested the effectiveness of a news article on shaping respondents' preferences toward policies that directly address the potential disruptions caused by workplace automation. As in Study 2, respondents were randomly assigned to the Treatment group or the Control group with equal probability. The informational treatment in this study is a condensed version of the one in Study 2; the full text of the news article is in Appendix C.3 ${ }^{20}$ Respondents in the Control group did not receive an informational treatment. The study was conducted in August 2019 using a quasi-nationally representative sample of respondents from Lucid ${ }^{21}$ Study 3 is high-powered: 773 respondents were assigned to the Treatment group, and 992 were assigned to the Control group. For the data analysis, I estimated the average treatment effect for each outcome using ordinary least squares regression.

\section{Results}

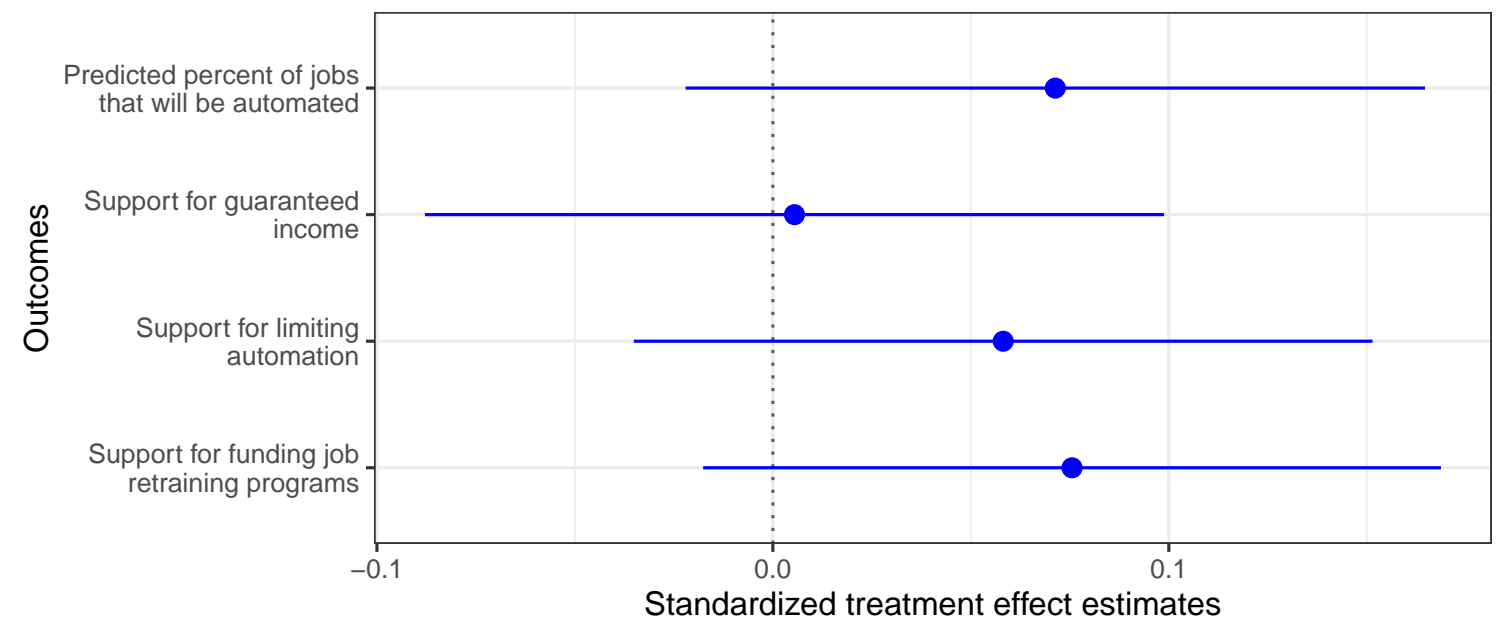

Figure 4.7: Study 3 Results: Manipulation Check and Policy Preferences

A more positive treatment effect estimate means a greater predicted likelihood or a great level of support for the policy. The estimated effects and the $95 \%$ confidence intervals are shown. 992 respondents were assigned to the Control group and 773 were assigned to the Treatment group.

20. As in Study 2, respondents in the Treatment group were required to spend at least 30 seconds on the page with the news article before they could advance to the next page of the survey.

21. The study is one component of an omnibus survey conducted by the MIT Political Experiments Research Lab. 
The treatment in Study 3 failed to change any of the outcomes, as seen in Figure 4.7. First, the treatment failed the manipulation check: those in the Treatment group did not predict that a higher percentage of jobs will become automated. This null result could be explained by inattentive respondents speeding through the survey ${ }^{22}$ A large number of respondents in the Control group moved the answer input slider to $50 \%$, which was conveniently located in the middle of the scale. Unfortunately, the news article treatment stated that nearly half of American jobs are at high risk of automation; therefore, respondents in the Treatment group were expected to move the slider close to $50 \% \cdot 23$

In terms of the substantive outcomes, the treatment also failed to change respondents' support for policies that seek to mitigate disruptions caused by workplace automation. The null results could be attributed to the inattentive respondents who did not fully pay attention to the informational treatment. Still, these null effects, viewed in light of other null results from Studies 1 and 2, suggest that informing Americans about automation's threat to jobs is not enough to change their policy preferences.

\subsection{Discussion}

Findings from my three empirical studies suggest that Americans' political attitudes regarding the future of work are complex. In this section, I discuss the results of my survey experiments in the context of existing research.

22. Inattentive survey respondents tend to produce noisy responses by selecting answer choices at random, repeatedly answering "don't know," or speeding through the survey. Researchers can use attention check questions to identify inattentive respondents (Berinsky, Margolis and Sances, 2014). The omnibus survey, which Study 3 is a part of, asked four attention check questions. The survey respondents performed very poorly: not a single one answered all four attention check questions correctly, and only one respondent correctly answered three out of the four questions.

23. Appendix C.4.3 contains the comprehensive data analysis results, including robustness checks, in the table format. Subgroup analysis finds that the treatment is persuasive for white Americans, those who are older than 54, Republicans, and those who are not in the labor force. 


\subsubsection{Changing Political Preferences Is Harder than Changing Factual Beliefs}

Studies 1 and 2 show that changing the public's policy preferences is much harder than changing their beliefs about the state of the world. My informational treatments caused respondents to believe that workplace automation is a more significant threat to their jobs and American jobs than they had previously anticipated. Nevertheless, the shift in their beliefs failed to change their support for policies to help American workers adapt to the work of the future.

My findings are in line with social scientific research that shows that correcting false beliefs does not necessarily lead to changes in political attitudes. For years, researchers worried that presenting the public with uncongenial factual information would produce a "backfire effect" such that the public hold even more firmly onto their misperceptions (Nyhan and Reifler, 2010). However, more recent studies suggest that this "backfire effect" is rare and that fact-checking can correct misconceptions (Guess and Coppock, 2019; Nyhan and Reifler, 2015; Wood and Porter, 2019). Nevertheless, correcting one's factual beliefs may not alter one's interpretation of the facts or how one uses these facts when forming political opinions (Gaines et al., 2007; Khanna and Sood, 2018). For example, Democrats and Republicans held similar factual beliefs about the Iraq War but interpreted these facts differently in line with their party's position (Gaines et al., 2007). Likewise, fact-checking Donald Trump's false statements improved the accuracy of his supporters' factual beliefs but did not lessen their support for him (Nyhan et al. 2019).

Still, changing the public's beliefs about the future of work could be the first step in shifting the political conversation around this topic. To this point, we can look to climate change mitigation, another policy area where collective action is needed to solve future challenges. Research suggests that accepting the scientific consensus on human-caused climate change is a "gateway belief" that leads one to update one's own beliefs about

climate change and, eventually, one's willingness to support public action van der Linden et al. 2015). In future research, I will investigate strategies to help the public connect their factual beliefs about the future of work with support for political action. An early work in 
this vein, (Lekalake et al., 2019), finds that political messages that promote universal basic income as a solution to technological unemployment increased support for the policy among low-skilled American workers.

\subsubsection{Uncertain Future, Uncertain Workers}

Another key theme to emerge from my research findings is that American workers are uncertain about the impact of advanced workplace automation. The informational treatments increased the respondents' 1) perceived likelihood that their and others' jobs would be automated and 2) concerns about losing their jobs to computers and machines. Nevertheless, the treatments did not change respondents' other beliefs (i.e., beliefs about income inequality or job creation) about a future world in which machines can perform tasks that require high-level human intelligence. Curiously, in Study 1, workers responded to the Frey and Osborne and the OECD expert forecasts similarly. A future in which $47 \%$ of American jobs are highly automatable is far more disruptive than a future in which $10 \%$ of American jobs are highly automatable. Yet, the subjects in Study 1 did not react to these radically different futures in different ways.

Rather than castigating the respondents in my studies, I argue that forecasting what the labor market would look like in the AI Revolution is difficult for many people. Survey research shows that the public has difficulty thinking concretely about the future beyond 15 to 20 years (Tonn, Hemrick and Conrad, 2006). The public's confusion about the impact of workplace automation could also be attributed to the lack of consensus among economic forecasts and media narratives. As the difference between the two forecast sources in Study 1 shows, economists are highly uncertain about what the impact of automation will be. As discussed in Section 2, a review of expert forecasts reveals that projections for the number of American jobs at risk of automation range between 3.4 million and 80 million over the next two decades (Winick, 2018). Furthermore, most of these forecasts do not include predictions regarding the numbers of new jobs that will be created. Content analysis of U.S. news articles about the future of work finds that the media also gives conflicting forecasts about the impact and immediacy of workplace automation, which may confuse the public (Ndulue, 2019). 
Expert consensus plays a crucial role in building political will to solve policy challenges (Lewandowsky, Gignac and Vaughan, 2013). Conversely, bad actors have cast doubt on the scientific consensus on climate change to hamper environmental protection policies (Oreskes and Conway, 2011). Even without these bad actors pushing misinformation, those advocating for policies to alleviate labor market disruptions caused by new technology will likely fight an uphill battle. I anticipate that the lack of expert consensus on the effects of advanced workplace automation will divide voters and thereby hinder policymakers' ability to act.

\subsubsection{Politics of Workplace Automation in the Era of Right-wing Pop- ulism}

A growing number of researchers worry that workplace automation has contributed to the rise of right-wing populism in the U.S. and Western Europe, as discussed in Section 2. My studies find that workers' concern about technological unemployment did not directly cause them to endorse right-wing populist policies, such as restricting immigration or free-trade. My findings lend support for the argument that workers negatively impacted by automation adopt right-wing populist positions because they misdirect their woes to immigrants and outsourcing.

However, my attempt to correct this misdirected blame using economic arguments in Study 2 failed to change respondents' attitudes on immigration and trade. This null effect is not entirely surprising because racial resentment, perhaps more so than economic anxiety, played a significant role in voters' support for Donald Trump and his brand of right-wing populism (Abramowitz and McCoy, 2019; Mutz, 2018; Schaffner, Macwilllams and Nteta, 2018). Apart from the Trump phenomenon, Americans' attitudes toward immigration and trade are driven by not only economic self-interest but also nationalism and ethnocentrism Abrajano and Hajnal, 2017; Jardina, 2019, Mansfield and Mutz, 2009, 2013; Newman and Malhotra, 2019). Overcoming these non-materialist motivations could be particularly challenging.

As more industries deploy labor-saving technology, would right-wing populists in the U.S. oppose automation as they have opposed globalization? No, I predict for three rea- 
sons. First, nationalist policymakers, including the Trump administration, view AI as a general-purpose technology that will help the U.S. maintain its supremacy in both the economic and security realm (Executive office of the President, 2019). Before the Industrial Revolution, governments frequently suppressed the use of labor-saving technology, fearing that technological unemployment would cause social unrest. However, since the Industrial Revolution, governments have promoted the mechanization of labor because they recognized its importance for both economic growth and military security (Frey, 2019). Today,

the U.S. government views advancing AI development as a way to stay ahead of China both economically and militarily.

Second, automation is not an easy target of political attacks. When attacking globalization, one can use many scapegoats: politicians can point out identifiable targets like immigrants or workers in a foreign country (Rodrik, 2018). In contrast, many applications of automation are not visible objects like industrial robots but disembodied computer programs. One cannot smash an algorithm like one can break a power loom. Third, the American brand of right-wing populism is funded by and therefore constrained by plutocratic business interests (Pierson, 2017). In its opposition to the Affordable Care Act and its support of corporate tax cuts - among other policies — the Trump administration has sided with business interests against the welfare of ordinary workers. As more and more industries deploy automated systems to increase productivity at the expense of their employees, business interests can successfully lobby the government to side with firm owners rather than workers.

\subsection{Conclusion}

Policy responses to advanced automation will likely become an increasingly salient topic. Although labor-saving technology has eroded the American middle class by eliminating many middle-skill jobs, workers in the U.S. underestimate the existent and future impact of automation. My three empirical studies find that it is possible to persuade Americans that workplace automation is a serious threat to their jobs. Nevertheless, changing their beliefs about the future of work failed to affect their attitudes on welfare, immigration, and 
trade policies. One particularly troubling finding is that the treatments did not increase respondents' support for expanding existing social programs aimed at helping displaced workers (e.g., job retraining) let alone experimental ones (e.g., guaranteed basic income). At the same time, informing workers that restricting immigration and trade will not address the impact of automation did not reduce opposition to globalization.

This set of experimental studies is my first attempt to investigate the impact of workplace automation on mass politics. I discuss two directions for my future research. First, I plan to conduct qualitative research to understand how workers impacted by automation perceive the future of their work and the role the government should play to prepare them for that future. Sociologists have used ethnographic research to explain the impact of technology on workers vulnerable to automation, such as truckers (Levy, 2015, 2016) and those who perform "gig work" on crowdsourcing platforms (Gray and Suri, 2019). In-depth interviews will allow me to construct a more nuanced understanding of how these types of workers perceive themselves as voters and citizens.

Second, I plan to use computational content analysis to study the media narrative around the future of work. Although stories about workplace automation represent a relatively small percentage of all news articles, I anticipate this topic will become prominent in the upcoming decade. I hope to analyze the corpus of news articles in (Ndulue, 2019) to dive deeper into the conflicting viewpoints in discussions of workplace automation. In particular, I want to explore whether partisan media have begun to polarize on this issue. A politically polarized media narrative around the future of work could cause voters to form divergent opinions based on their partisan affiliation.

The deployment of increasingly intelligent machines could impact large numbers of American workers in the near future. Mitigating the potential disruptions requires not only technical solutions but also the political will to enact them. Therefore, research on how the threat of automation shapes the public's political attitudes and behavior is critical for preparing policy responses. 


\section{Appendix A}

\section{Appendix for "Hands Off My}

\section{Medicare? How Government}

\section{Benefits Fail to Change Political}

\section{Attitudes"}

Unless otherwise noted, heteroscedasticity-consistent standard errors are reported between the parentheses next to the effect estimates. The error bars represent $95 \%$ confidence intervals calculated from the robust standard errors. $p$-value stars on the effect estimates follow the convention of $*<0.05, * *<0.01, * * *<0.001$.

\section{A.1 Critique of Previous Research}

Lerman and McCabe (2017) employ a "fuzzy" RDD that uses the Medicare age cutoff as an instrumental variable for receiving Medicare. Drawing on survey data from the 2012 CCES, the authors focus their analysis on those just above the 65-year-old age cutoff in 2012 (those born in 1946 or 1947) and those just below the cutoff (those born in 1948 or 1949). Lerman and McCabe use the following two-stage least squares (2SLS) regression to analyze their data: 


$$
\begin{gathered}
\text { First Stage: } E\left(D_{i}\right)=\alpha+\beta Z_{i}+\sum_{j=1}^{J} \rho_{j} X_{i, j} \\
\text { Second Stage: } E\left(Y_{i}\right)=\gamma+\tau \widehat{D}_{i}+\sum_{j=1}^{J} \eta_{j} X_{i, j}
\end{gathered}
$$

where $Z_{i}$ is an indicator variable for where subject $i$ is 65 or above, $D_{i}$ is whether she has public health insurance $\left(D_{i}=1\right.$, treated) versus only private insurance $\left(D_{i}=0\right.$, control), $X_{i, j}$ is her value for covariate $j$ in $J$ covariates, and $Y_{i}$ is her public opinion outcome. The authors interpret their estimate of $\tau$ as the late average treatment effect (LATE) of receiving Medicare on respondents' attitudes towards the ACA and Medicare.

My new research design addresses three potential problems in Lerman and McCabe's analysis: 1) incorrectly defining the treatment variable, 2) conditioning on possible pretreatment covariates, and 3) incorrectly addressing the exclusion restriction violation mentioned previously. In their primary analysis, the authors define the treatment as having public health insurance (treated) versus having private health insurance only (control); those who do not have health insurance are excluded from the analysis. As Lerman and McCabe's Appendix B1 shows, the percentage of those without health insurance is 10 points higher among the 1948/1949 group compared with the 1946/1947 group. By eliminating those without health insurance from their primary analysis, the authors drop subjects in a systematic way correlated with the instrumental variable.

Another problem is that the authors condition on possible pre-treatment covariates in their primary analysis. Medicare could affect one's employment status (and therefore income), as well as one's political ideology if the policy feedback theory holds 11 Finally, Lerman and McCabe address the exclusion restriction violation problem in two inappropriate ways: by conditioning on retirement and by using birth year as an instrument for retirement in a separate "fuzzy" RDD analysis. Since receiving Medicare increases the likelihood that one would retire, conditioning on retirement would introduce reverse causality

1. Existing literature suggests that Medicare eligibility increases the probability of retirement (Madrian and Beaulieu, 1998). 
bias. By using birth year as an instrument for retirement, the authors implicitly admit that age could affect the outcome through both Medicare and retirement.

\section{A.2 Survey Text}

The coding for each survey response appears after the response in parentheses. For each variable, I mean-impute the missing and "don't know" responses.

\section{A.2.1 2010 CCES}

Support ACA Congress considered many important bills over the past two years. For each of the following tell us whether you support or oppose the legislation in principle.

Requires all Americans to obtain health insurance. Allows people to keep current provider. Sets up health insurance option for those without coverage. Increase taxes on those making more than $\$ 280,000$ a year.

- Support (1)

- Oppose (0)

Support Children's Health Insurance Program Congress considered many important bills over the past two years. For each of the following tell us whether you support or oppose the legislation in principle.

Program insures children in low income households. Act would renew the program through 2014 and include 4 million additional children.

- Support (1)

- Oppose (0) 
Least Favored: Cut Domestic Spending The federal budget is approximately $\$ 600$ billion this year. If the Congress were to balance the budget it would have to consider cutting defense spending, cutting domestic spending (such as Medicare or Social Security), or raising taxes to cover the deficit. What would you least prefer that Congress do - cut domestic spending, cut defense spending, or raise taxes?

- Cut defense spending (0)

- Cut domestic spending (1)

- Raise Taxes (0)

Most Favored: Cut Domestic Spending The federal budget is approximately $\$ 600$ billion this year. If the Congress were to balance the budget it would have to consider cutting defense spending, cutting domestic spending (such as Medicare or Social Security), or raising taxes to cover the deficit. What would you most prefer that Congress do - cut domestic spending, cut defense spending, or raise taxes?

- Cut defense spending (0)

- Cut domestic spending (1)

- Raise Taxes (0)

\section{A.2.2 2012 CCES}

Support ACA Congress Considered many important bills over the past two years. For each of the following tell us whether you support or oppose the legislation in principle.

Requires all Americans to obtain health insurance. Allows people to keep current provider. Sets up health insurance option for those without coverage. Increase taxes on those making more than $\$ 280,000$ a year.

- Support (1) 
- Oppose $(0)$

Repeal ACA Congress Considered many important bills over the past two years. For each of the following tell us whether you support or oppose the legislation in principle.

Would repeal the Affordable Care Act.

- Support (1)

- Oppose (0)

Least Favored: Cut Domestic Spending The federal budget deficit is approximate $\$ 1$ trillion this year. If the Congress were to balance the budget it would have to consider cutting defense spending, cutting domestic spending (such as Medicare and Social Security), or raising taxes to cover the deficit. What you LEAST prefer that Congress do?

- Cut defense spending (0)

- Cut domestic spending (1)

- Raise taxes (0)

Most Favored: Cut Domestic Spending The federal budget deficit is approximate $\$ 1$ trillion this year. If the Congress were to balance the budget it would have to consider cutting defense spending, cutting domestic spending (such as Medicare and Social Security), or raising taxes to cover the deficit. What you MOST prefer that Congress do?

- Cut defense spending (0)

- Cut domestic spending (1)

- Raise taxes (0) 
Support Ryan Budget Bill Congress considered many important bills over the past two years. For each of the following tell us whether you support or oppose the legislation in principle.

2011 House Budget Plan. The Budget plan would cut Medicare and Medicaid by $42 \%$. Would reduce debt by $16 \%$ by 2020 .

- Support (1)

- Oppose (0)

Support Simpson-Bowles Budget Plan Congress Considered many important bills over the past two years. For each of the following tell us whether you support or oppose the legislation in principle.

Simpson-Bowles Budget Plan. Plan would make 15\% cuts across the board in Social Security, Medicare, Medicaid, and Defense, as well as other programs. Eliminate many tax breaks for corporations. Would reduce debt by $21 \%$ by 2020 .

- Support (1)

- Oppose (0)

\section{A.2.3 2014 CCES}

Support ACA The Affordable Health Care Act was passed into law in 2010. It does the following: Requires Americans to obtain health insurance. Prevents insurance companies from denying coverage for pre-existing conditions. Allows people to keep current health insurance and care provider. Sets up national health insurance option for those without coverage, but allows states the option to implement their own insurance system.

Would you have voted for the Affordable Care Act if you were in Congress in 2010?

- Yes (1)

- No (0) 
Repeal ACA Would you vote to repeal the Affordable Care Act if you were in Congress in today?

- Yes (1)

- No (0)

Support Expanding Medicaid Should your state refuse to implement the expansion of health care for poor people, even if it costs the state federal Medicaid funds?

- Yes (1)

- No $(0)$

Least Favored: Cut Domestic Spending The federal budget deficit is approximately $\$ 500$ billion this year. If the Congress were to balance the budget it would have to consider cutting defense spending, cutting domestic spending (such as Medicare and Social Security), or raising taxes to cover the deficit. What would you least prefer that Congress do?

- Cut defense spending (0)

- Cut domestic spending (1)

- Raise taxes (0)

Most Favored: Cut Domestic Spending The federal budget deficit is approximately $\$ 500$ billion this year. If the Congress were to balance the budget it would have to consider cutting defense spending, cutting domestic spending (such as Medicare and Social Security), or raising taxes to cover the deficit. What would you most prefer that Congress do?

- Cut defense spending (0) 
- Cut domestic spending (1)

- Raise taxes (0)

Support Ryan Budget Bill For each proposal indicate whether you would support it or oppose it. Ryan Budget. Budget would Medicare and Medicaid by $42 \%$. Would reduce debt by $16 \%$ by 2020 .

- Support (1)

- Oppose (0)

Support Simpson-Bowles Budget Plan Simpson-Bowles Budget Plan. Plan would make $15 \%$ cuts across the board in Social Security, Medicare, Medicaid, and Defense, as well as other programs. Eliminate many tax breaks for individuals and corporations. Would reduce debt by $21 \%$ by 2020 .

- Support (1)

- Oppose (0)

\section{CCES}

Repeal ACA Congress considers many issues. If you were in Congress would you vote FOR or AGAINST each of the following?

Repeal Affordable Care Act. Would repeal the Affordable Care Act of 2009 (also known as Obamacare).

- For (1)

- Against (0) 
Support Medicare Reform Accountability and Cost Reform Act. Shifts Medicare from fee- for-service to pay-for-performance. Ties Medicare payments to doctors to quality of care measures. Requires higher premiums for seniors who make more than $\$ 134,000$. Renews the Children Health Insurance Program (CHIP).

Least Favored: Cut Domestic Spending The federal budget deficit is approximately 1 trillion this year. If the Congress were to balance the budget it would have to consider cutting defense spending, cutting domestic spending (such as Medicare and Social Security), or raising taxes to cover the deficit. Please rank the options below from would least prefer they do.

- Cut defense spending

- Cut domestic spending

- Raise taxes

Variable is coded 1 if the respondent ranks "Cut domestic spending" as the least preferred and 0 otherwise.

Most Favored: Cut Domestic Spending Question format is same as above. Variable is coded 1 if the respondent ranks "Cut domestic spending" as the most preferred and 0 otherwise.

\section{A.2.4 Questions from the 2010/2012/2014 CCES Panel Study}

Support ACA For each of the following bills please tell us whether you would vote for (yes) or against (no): Affordable Care Act requires that all Americans have health insurance. Allows people to keep current provider. Sets up health insurance exchange for those without coverage. Increases taxes on investment income for families making more than $\$ 250,000$.

- Yes (1) 
- No $(0)$

Support Children's Health Insurance For each of the following bills please tell us whether you would vote for (yes) or against (no): State Children's Health Insurance Program insures children in low income households. Act would renew the program through 2014 and include an additional 4 million children.

- Yes $(1)$

- No $(0)$

Least Favored: Cut Domestic Spending The federal budget is approximately 600 billion this year. If the Congress were to balance the budget it would have to consider cutting defense spending, cutting domestic spending (such as Medicare or Social Security), or raising taxes to cover the deficit. What would you most prefer that Congress do - cut domestic spending, cut defense spending, or raise taxes?

- Cut defense spending (0)

- Cut domestic spending (1)

- Raise Taxes (0)

Most Favored: Cut Domestic Spending The federal budget is approximately 600 billion this year. If the Congress were to balance the budget it would have to consider cutting defense spending, cutting domestic spending (such as Medicare or Social Security), or raising taxes to cover the deficit. What would you least want Congress to do?

- Cut defense spending (0) 
- Cut domestic spending (1)

- Raise Taxes (0)

\section{A.2.5 Placebo Outcome Questions}

Unless overwise noted, the same placebo outcome questions appear in all surveys.

\section{Support Birth Control Exemption}

2012 and 2014 cross-sectional CCES surveys: A Bill to let employers and insurers refuse to cover birth control and other health services that violate their religious beliefs ${ }^{2}$

- Support (1)

- Oppose (0)

2012 and 2014 waves of the CCES Panel Study: For each of the following bills please tell us whether you would vote for (yes) or against (no): Birth Control Exemption a bill to let employers and insurers refuse to cover birth control and other health services that violate their religious beliefs $3^{3}$

- Yes (1)

- No $(0)$

Support Building Keystone Pipeline 2012 cross-sectional CCES survey: A bill to approve the Keystone XL pipeline from Montana to Texas and provide for environmental protection and government oversight 4

- Support (1)

2. Appears only in the 2012 and 2014 cross-sectional CCES surveys.

3. Appears only in the 2012 and 2014 waves of the CCES Panel Study.

4. Appears only in the 2012 cross-sectional CCES survey. 
- Oppose (0)

\section{Support Banning Same-Sex Marriage}

2010 cross-sectional CCES survey; 2010, 2012, and 2014 waves of the CCES Panel Study: Do you support a Constitutional Amendment banning Gay Marriage?

- Yes (1)

- No $(0)$

2012, 2014, and 2016 cross-sectional CCES surveys: Do you favor or oppose allowing gays and lesbians to marry legally?

- Favor (0)

- Oppose (1)

Support Stricter Gun Control 2010 and 2012 cross-sectional CCES surveys; 2010, 2012, and 2014 waves of the CCES Panel Study: In general, do you feel that the laws covering the sale of firearms should be made more strict, less strict, or kept as they are?

- More strict (1)

- Less strict $(-1)$

- Keep as they are (0)

2014 and 2016 cross-sectional CCES surveys: On the issue of gun regulation, are you for or against each of the following...

To code the "Support Stricter Gun Control" variable, I sum up the following variables: 
- Background checks $(1=$ For, $0=$ Against $)$

- Prohibit state and local governments from publishing the names and addresses of all gun owners $(0=$ For, $1=$ Against $)$

- Ban high-capacity magazines for guns (more than 20 bullets) $(1=$ For, 0 = Against)

- Ban assault rifles $(1=$ For, $0=$ Against $)$

- Make it easier for people to obtain concealed weapons permits $(0=$ For, $1=$ Against $)$

Support Increasing Border Patrols What do you think the U.S. government should do about immigration? Select all that apply.

If "Increase the number of border patrols on the US-Mexican border" is selected, then the variable is coded 1 and 0 otherwise.

Support Affirmative Action Affirmative action programs give preference to racial minorities in employment and college admissions in order to correct the past discrimination. Do you support or oppose affirmative action?5

- Strongly support (2)

- Somewhat support (1)

- Somewhat oppose $(-1)$

- Strongly oppose $(-2)$

5. This question does not appear in the 2016 cross-section CCES survey. 
Support Abortion Rights 2010 and 2012 cross-sectional CCES surveys; 2010, 2012, and 2014 waves of the CCES Panel Study: Which one of the opinions on this page best agrees with your view on abortion?

- By law, abortion should never be permitted (0)

- The law should permit abortion only in case of rape, incest, or when the woman's life is in danger (1)

- The law should permit abortion for reasons other than rape, incest, or danger to the woman's life, but only after the need for the abortion has been clearly established (2)

- By law, a woman should always be able to obtain an abortion as a matter of personal choice (3)

2014 and 2016 cross-sectional CCES surveys: Do you support or oppose each of the following proposals?

- Always allow a woman to obtain an abortion as a matter of choice (2 if "For" is selected)

- Permit abortion only in cases of rape, incest, or when the woman's life is in danger (0 if "For" is selected)

- Prohibit abortions after the 20th week of pregnancy (1 if "For" is selected) 


\section{A.3 Additional Figures}

Figure A.1: Support of the Affordable Care Act (ACA) by Age
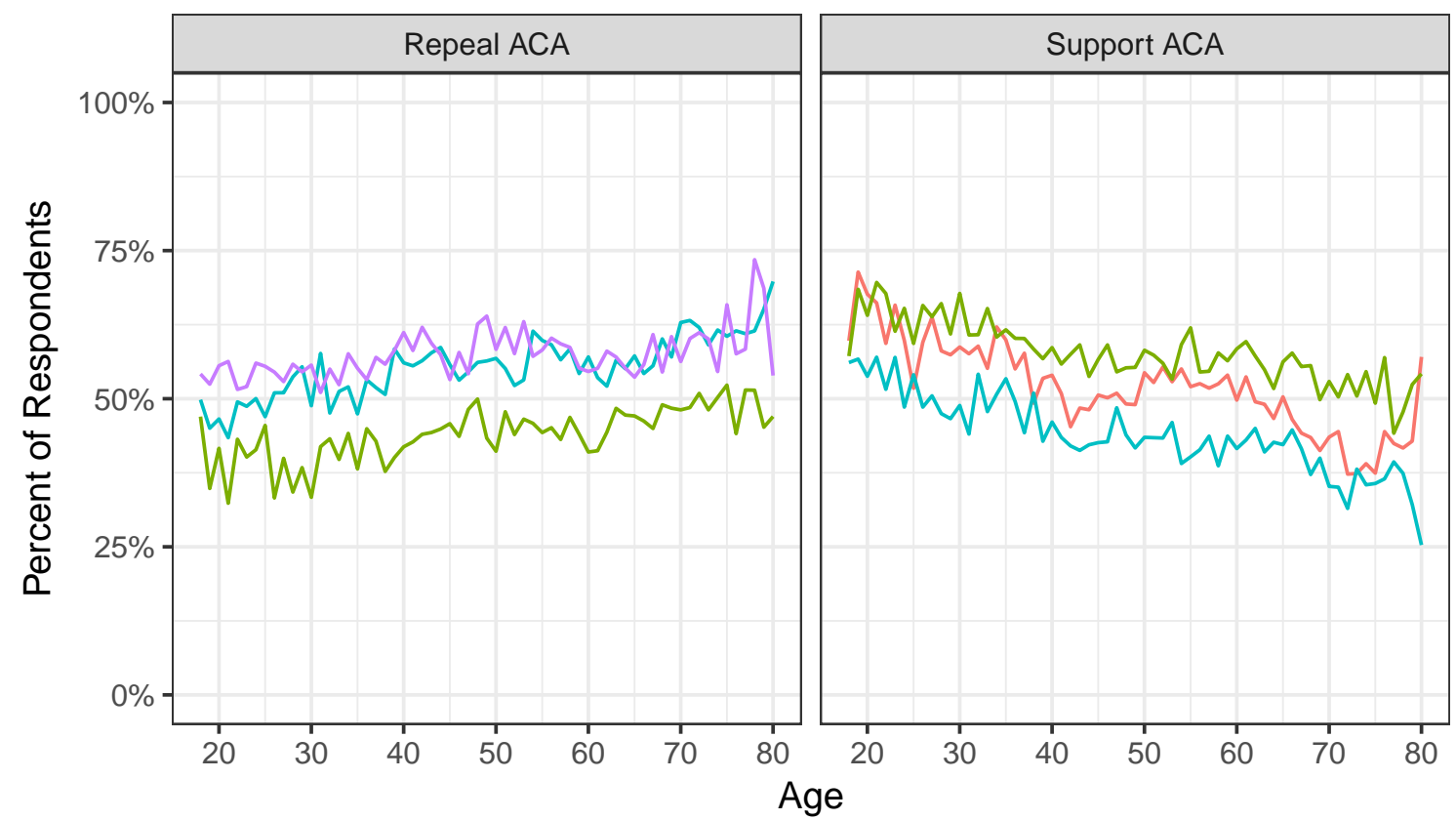

Survey Wave — CCES 2010 - CCES 2012 - CCES 2014 - CCES 2016

The percentages are calculated using the survey weights provided by the CCES. 
Figure A.2: Support of the Affordable Care Act (ACA) by Age Group Across Time

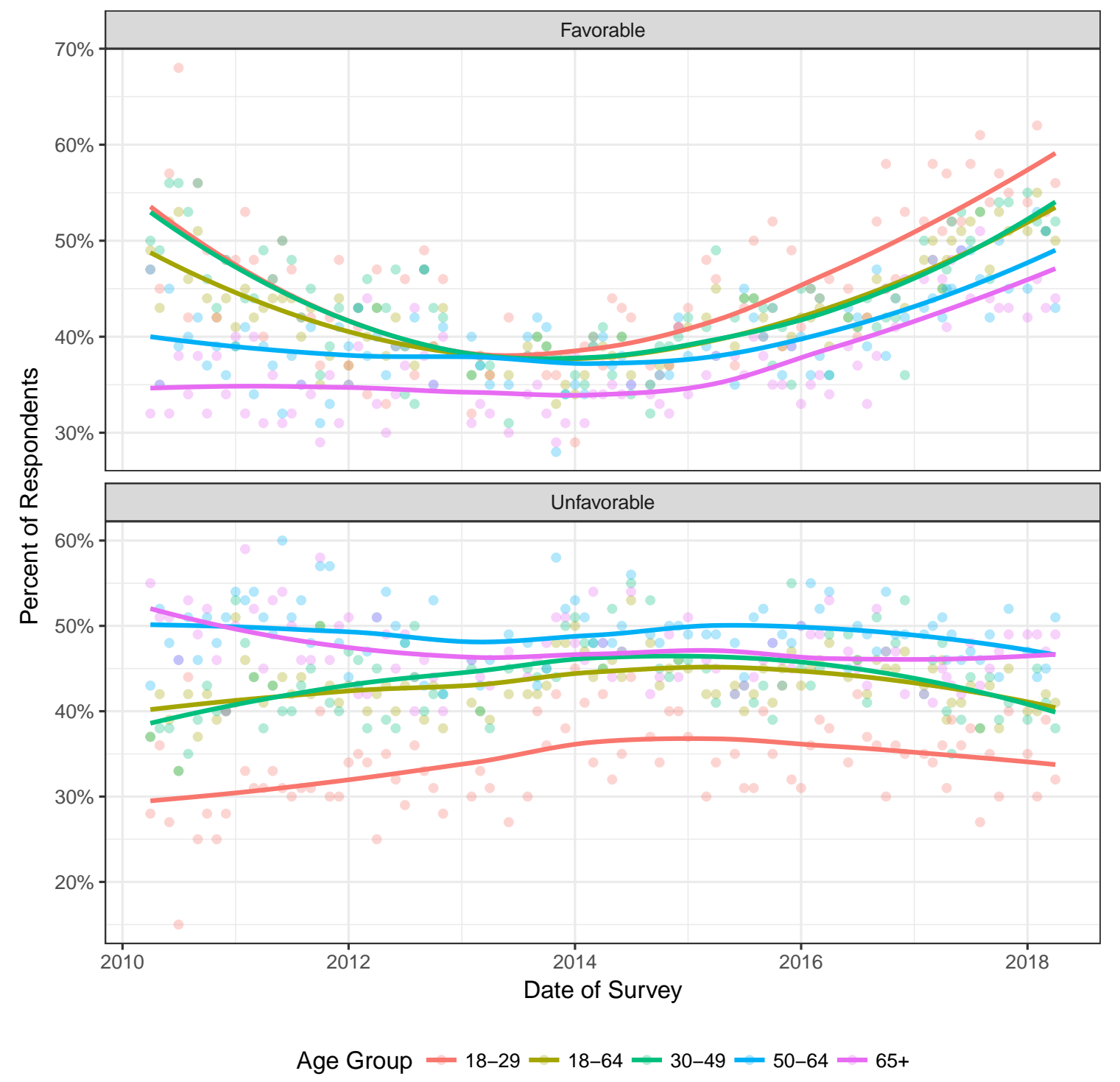

The data for this figure come from the Kasier Family Foundation's Health Tracking Poll. Respondents were asked: "As you may know, a health reform bill was signed into law in 2010. Given what you know about the health reform law, do you have a generally favorable or generally unfavorable opinion of it?" To provide a clearer visualization, the data for each age group have been smoothed using locally weighted smoothing. The data points are also displayed as transparent dots in the background. 
Figure A.3: Percent of Respondents Who Gained Government Health Insurance Between Waves of the 2010-2014 CCES Panel Study

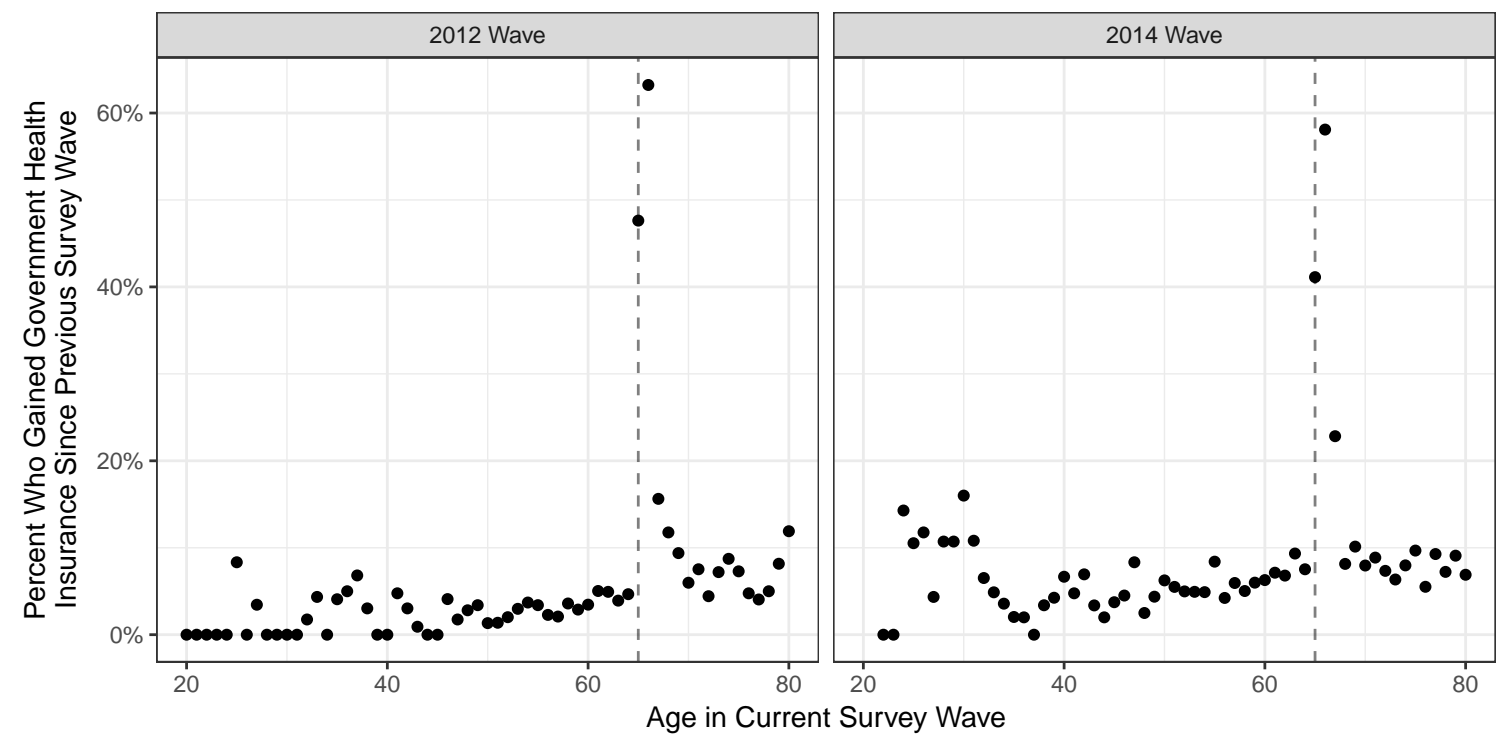

The percentages are calculated using the survey weights provided by the CCES. 
Figure A.4: Effects of Acquiring Medicare on Respondents' Attitudes: Evidence from 2010, 2012, 2014, and 2016 Cross-Sectional CCES Surveys

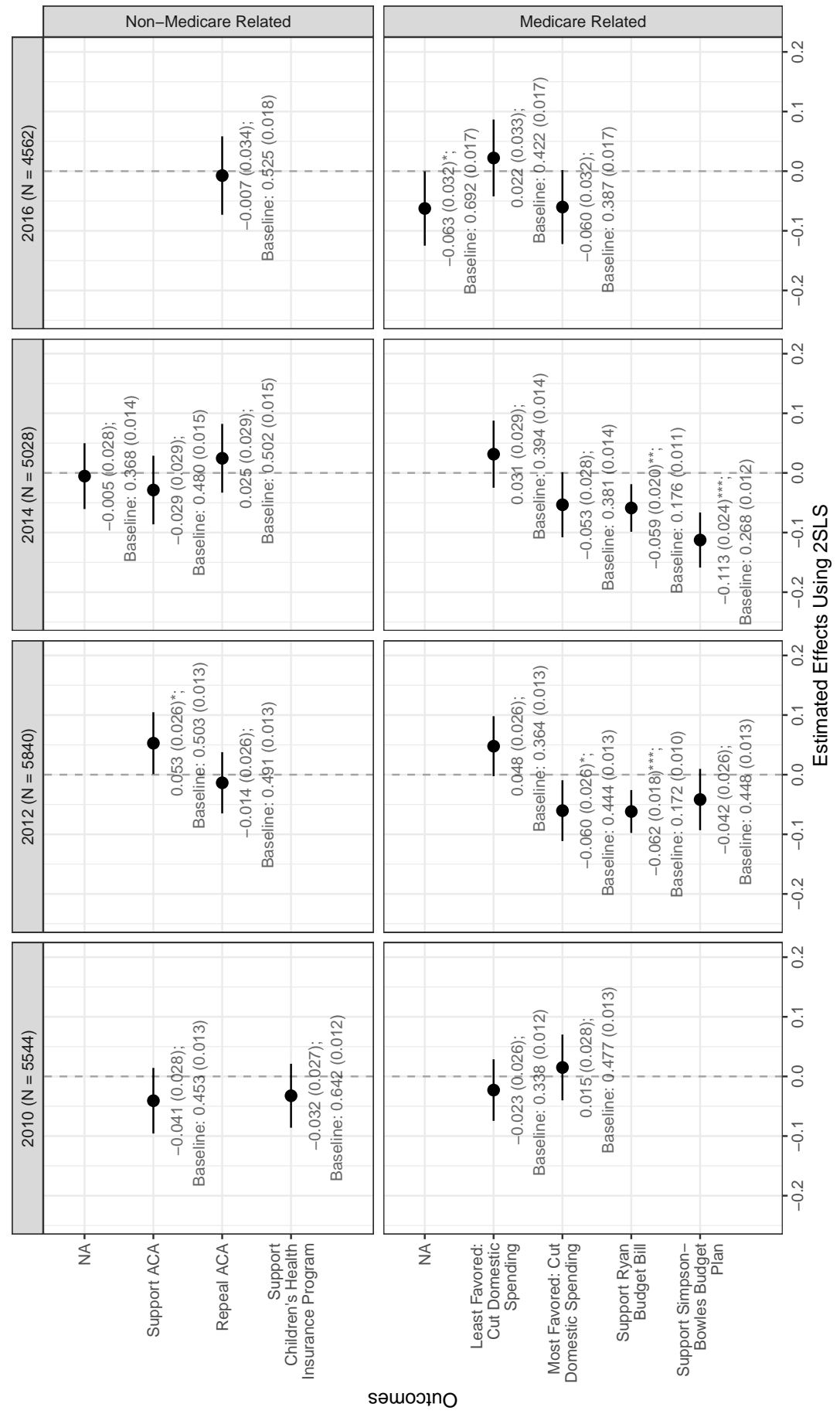

The results are from 2SLS regressions that do not include pre-treatment covariates. 
Figure A.5: Effects of Acquiring Medicare on Respondents' Attitudes: Evidence from the CCES 2010/2012/2014 Panel Study

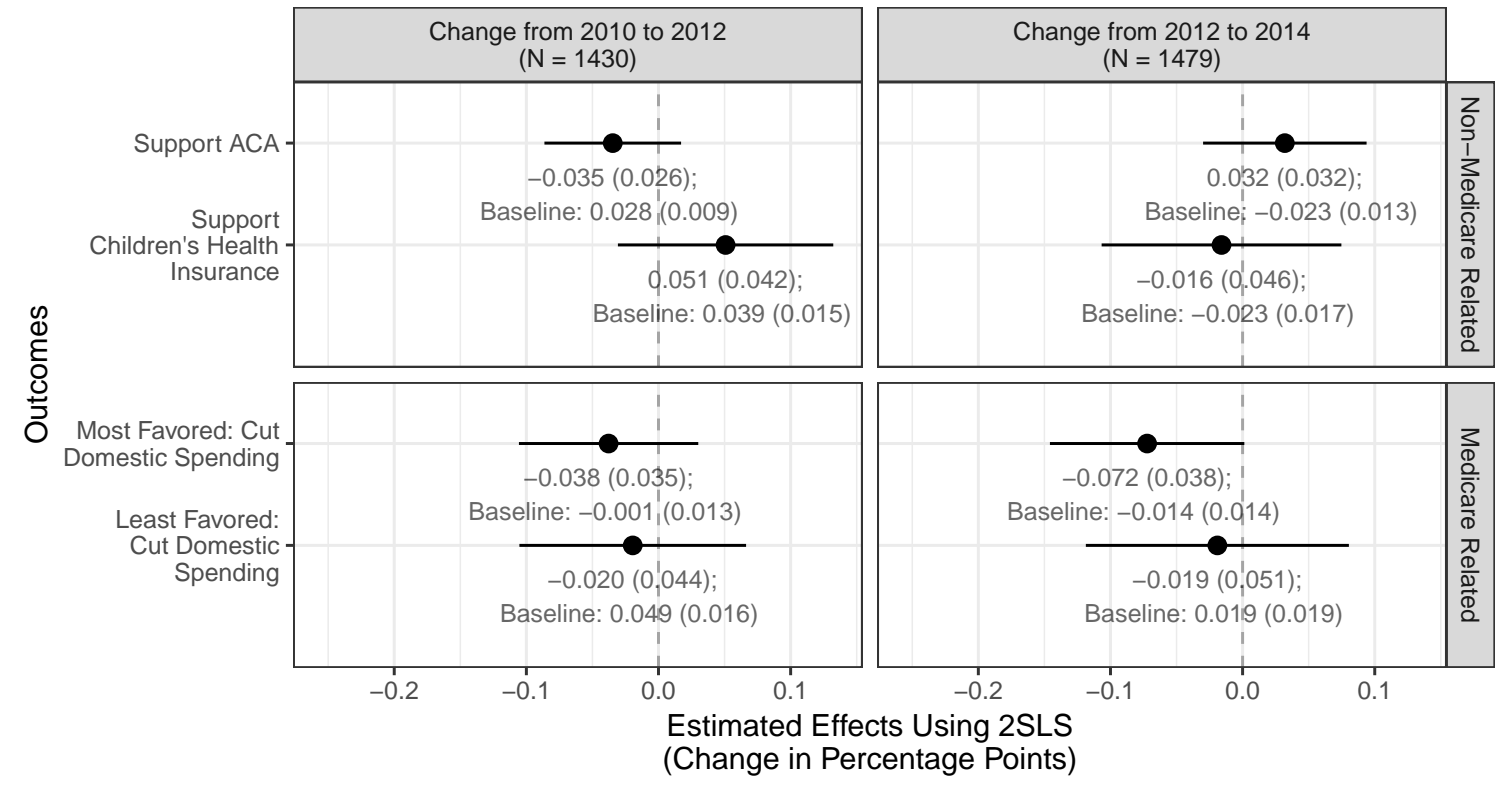

The results are from 2SLS regressions that do not include pre-treatment covariates. 
Figure A.6: Discussion of Health Care Policy Topics: Evidence for Google Trends Data

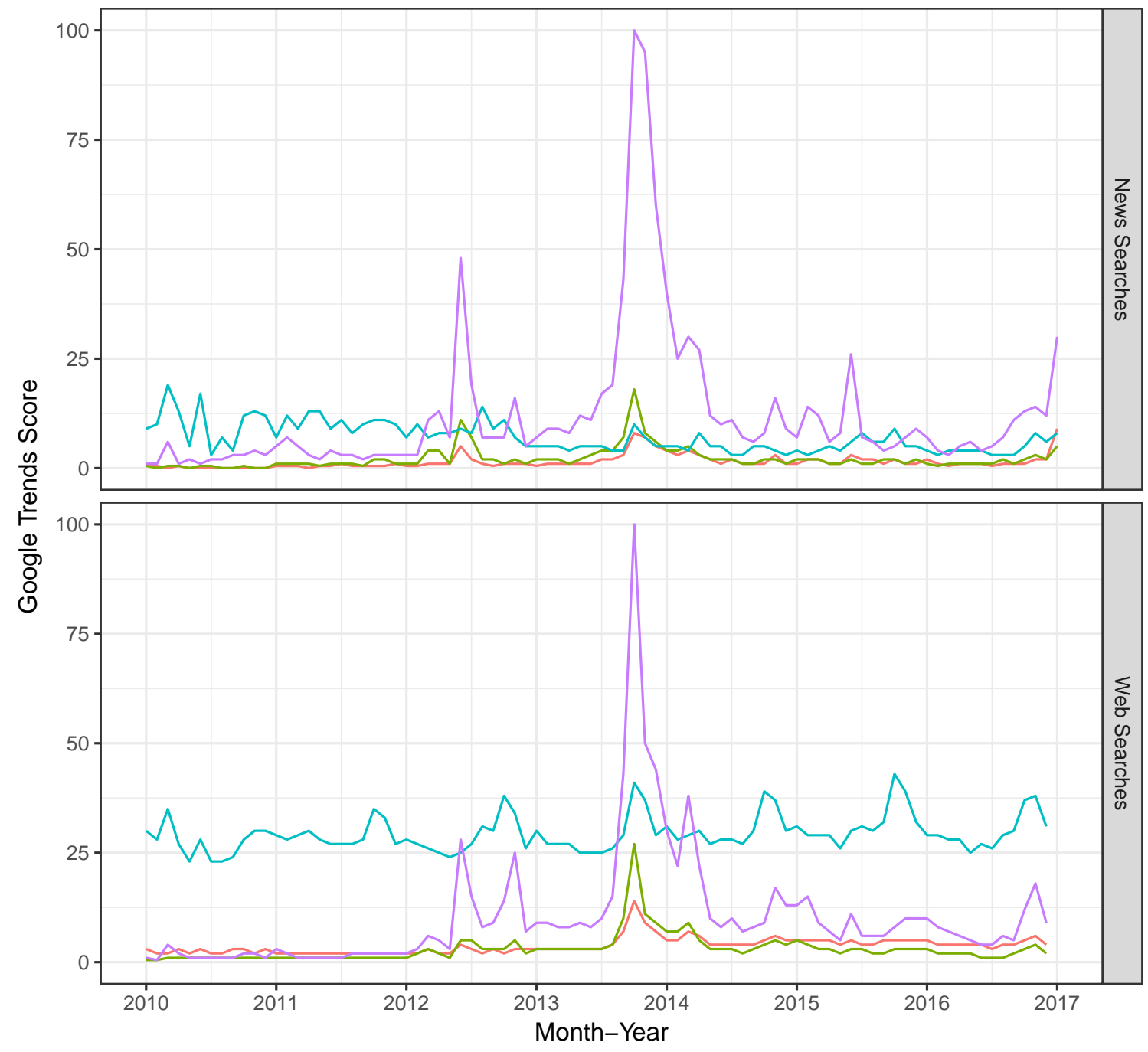

Search Terms - ACA — Affordable Care Act - Medicare — Obamacare

News searches are searches through Google News; web searches are general searches through the Google search engine. The Google Trends scores represent search interest relative to the highest point on the chart for the given region and time. A value of 100 is the peak popularity for the term. A value of 50 means that the term is half as popular. A score of less than 0 is coded as 0.5 . 


\section{A.4 Balance Tests}

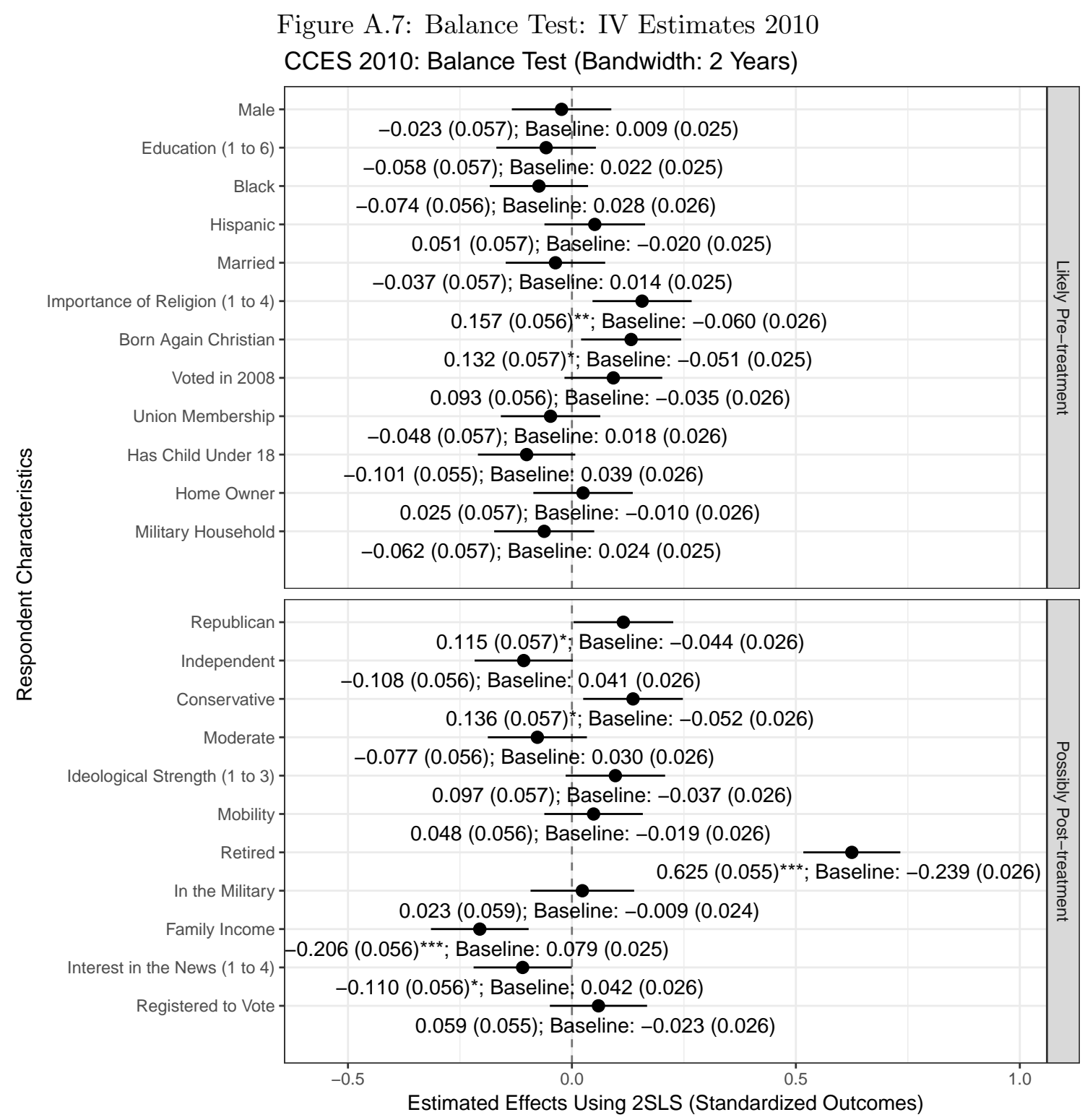


Figure A.8: Balance Test: IV Estimates 2012 CCES 2012: Balance Test (Bandwidth: 2 Years)

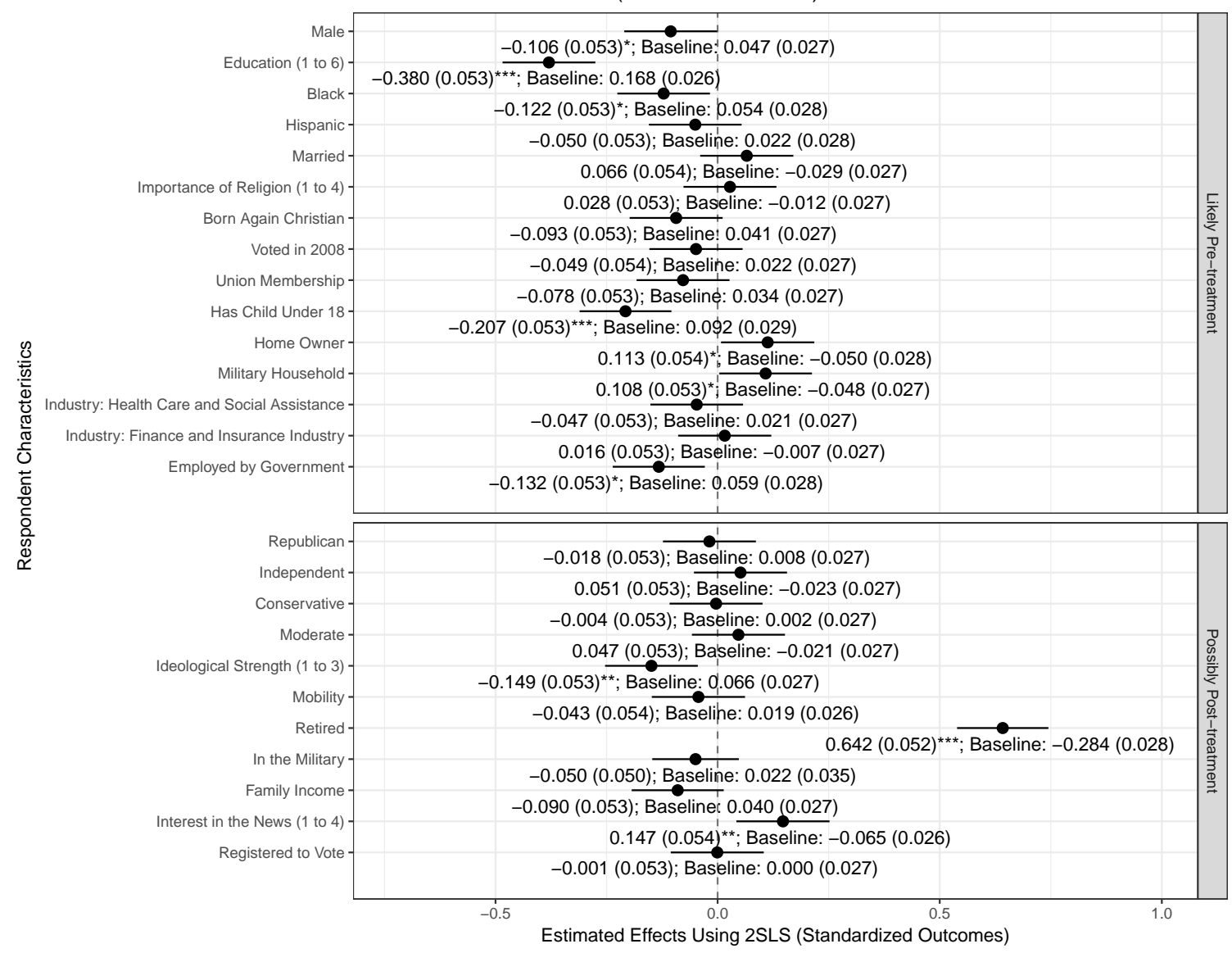


Figure A.9: Balance Test: IV Estimates 2014 CCES 2014: Balance Test (Bandwidth: 2 Years)

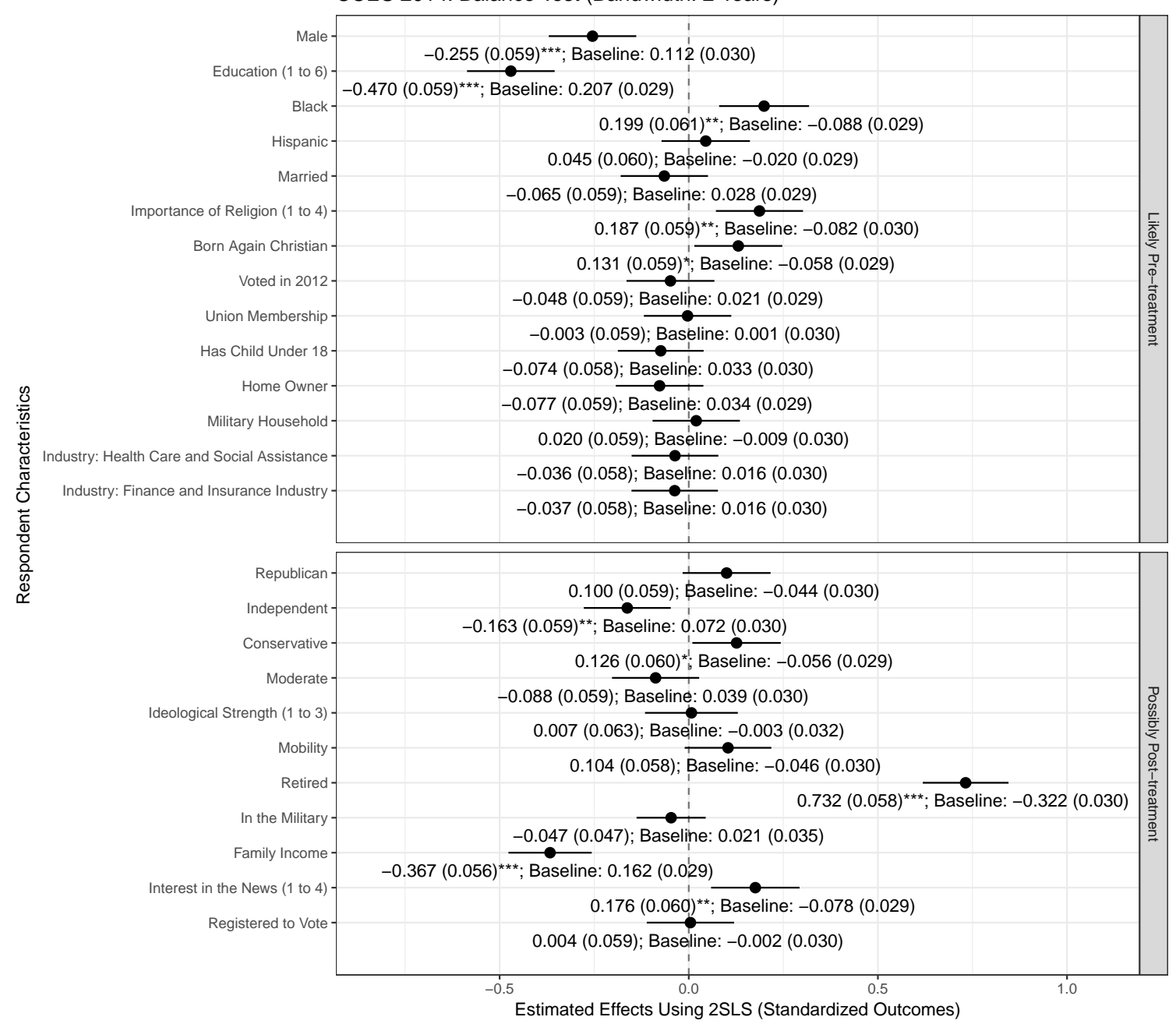


Figure A.10: Balance Test: IV Estimates 2016

CCES 2016: Balance Test (Bandwidth: 2 Years)

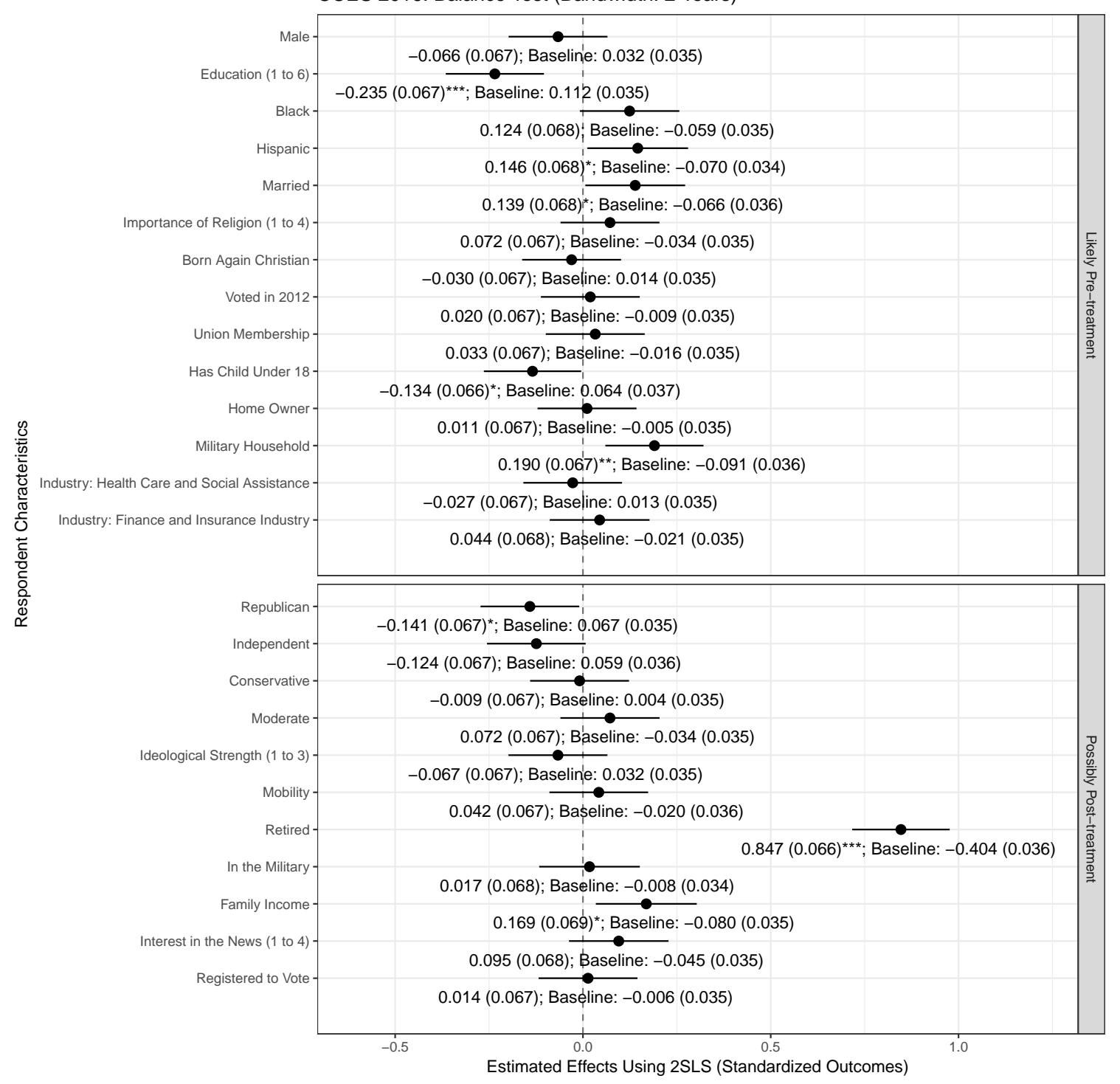


Figure A.11: Balance Test: Panel RDD IV Estimates

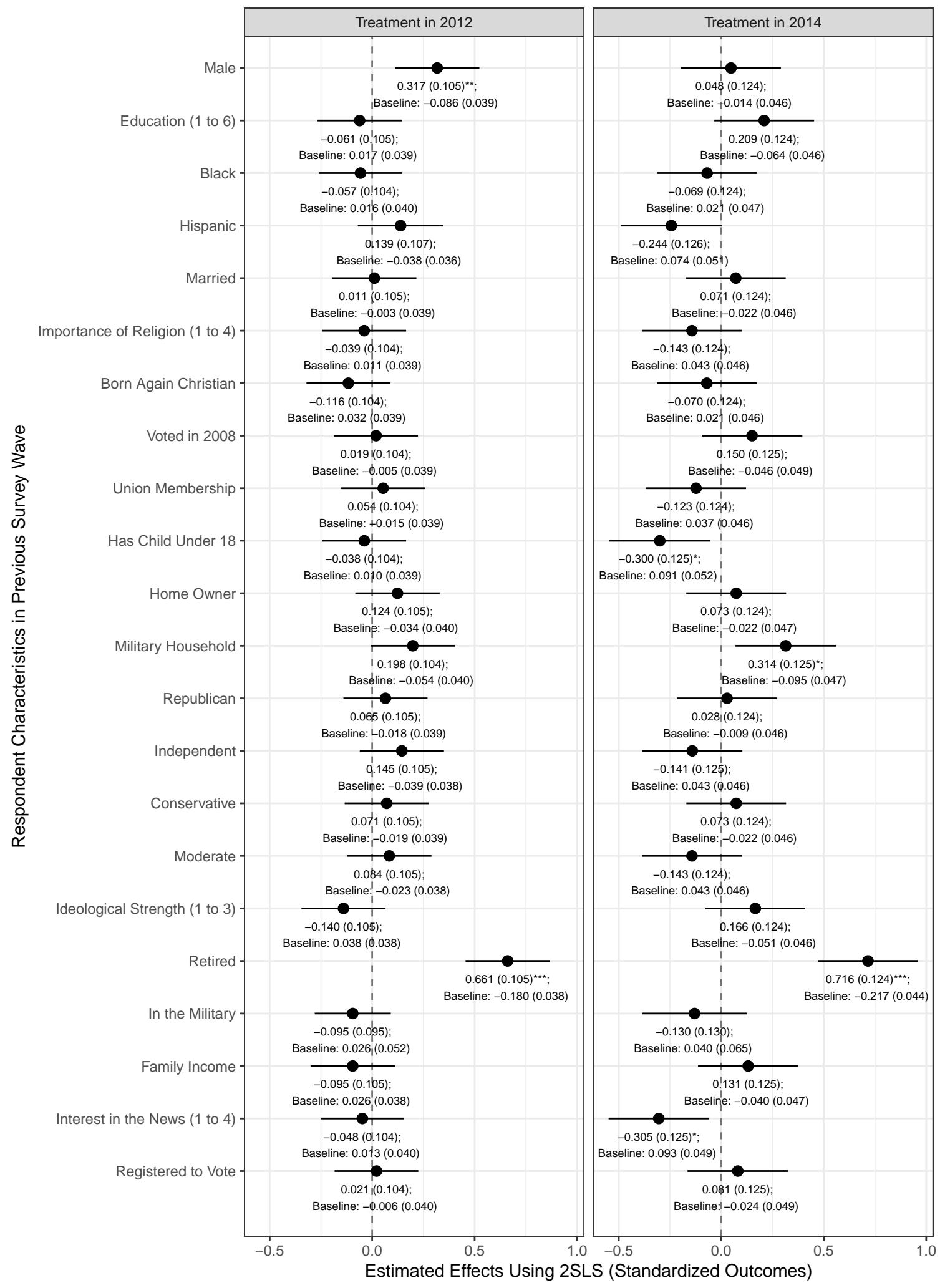




\section{A.5 Robustness Checks}

\section{A.5.1 Placebo Outcomes}

I use the 2SLS regression in Equation 2 to estimate the effect of acquiring Medicare on a variety of placebo outcomes. The placebo outcomes are respondents' preferences on policies that should not be affected by acquiring Medicare. I include the placebo outcomes used in Lerman and McCabe's 2017 paper:

- Support birth control exemption

- Support building the Keystone Pipeline

- Support banning same-sex marriage

- Support increasing border patrols

Because these placebo outcome variables are not available in all surveys, I include these additional placebo outcomes:

- Support stricter gun control

- Support affirmative action

- Support abortion rights 
Figure A.12: Effects of Acquiring Medicare on Placebo Outcomes: Evidence from the 2010, 2012, 2014, and 2016 Cross-Sectional CCES Surveys
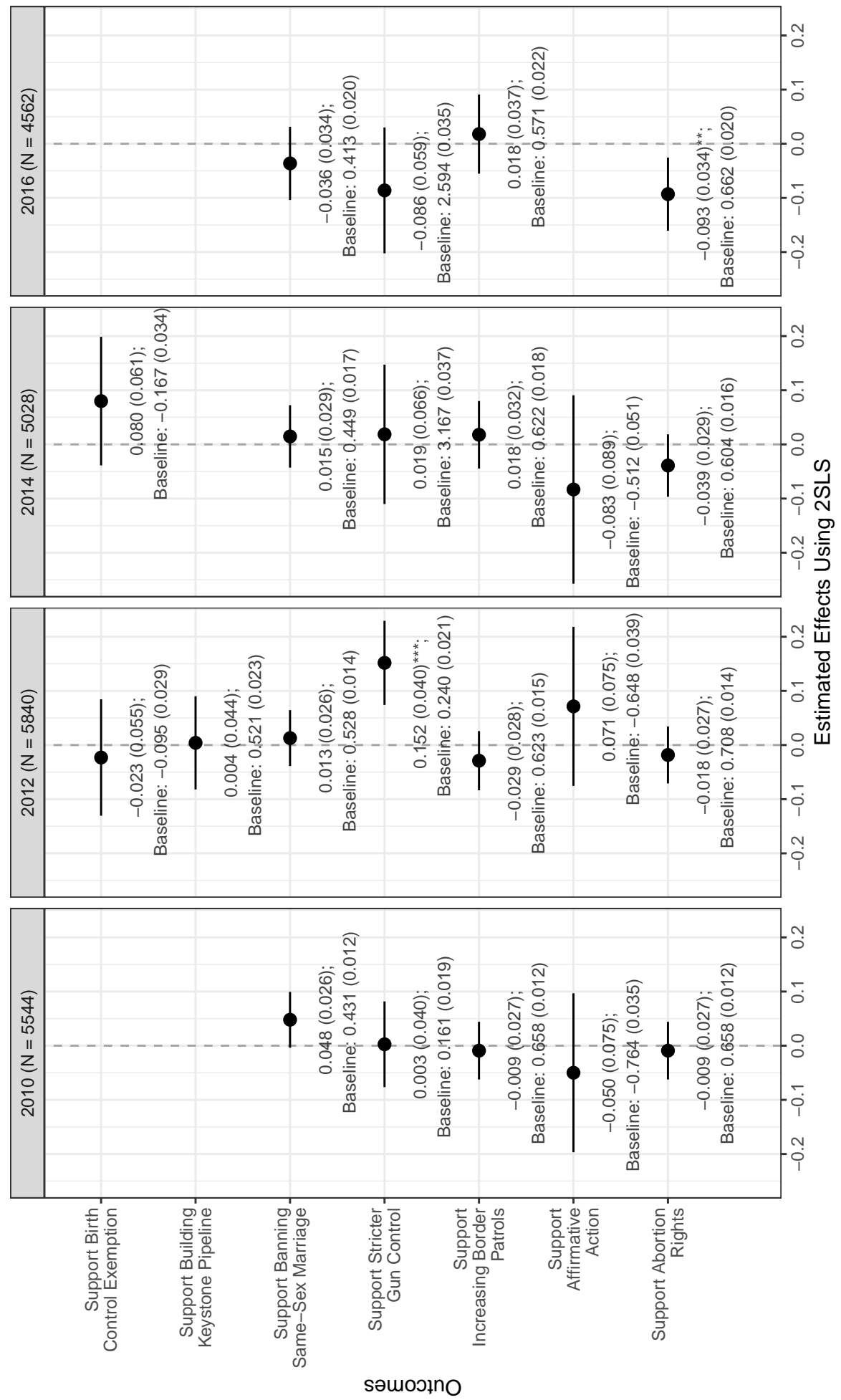

The results are from 2SLS regressions that include pre-treatment covariates. 
Figure A.13: Effects of Acquiring Medicare on Placebo Outcomes: Evidence from the 2010/2012/2014 CCES Panel Study

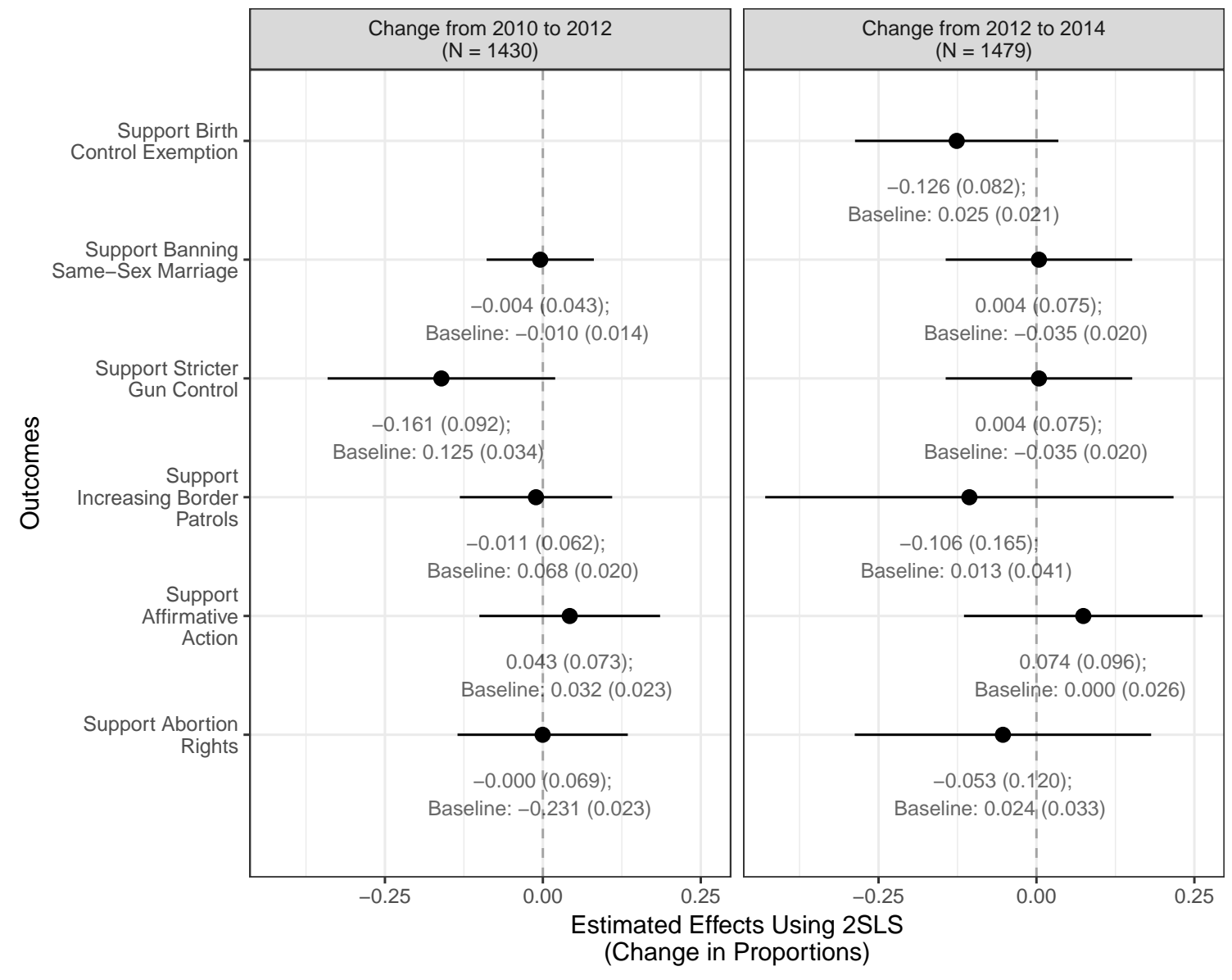

The results are from 2SLS regressions that include pre-treatment covariates.

\section{A.5.2 OLS Estimates}

I estimate the effect of being 65 or above on the main outcome measures using OLS regression, including and excluding pre-treatment covariates. The results are reported in the following figures. 
Figure A.14: OLS Estimates: 2010-2012 Cross-sectional CCES Surveys

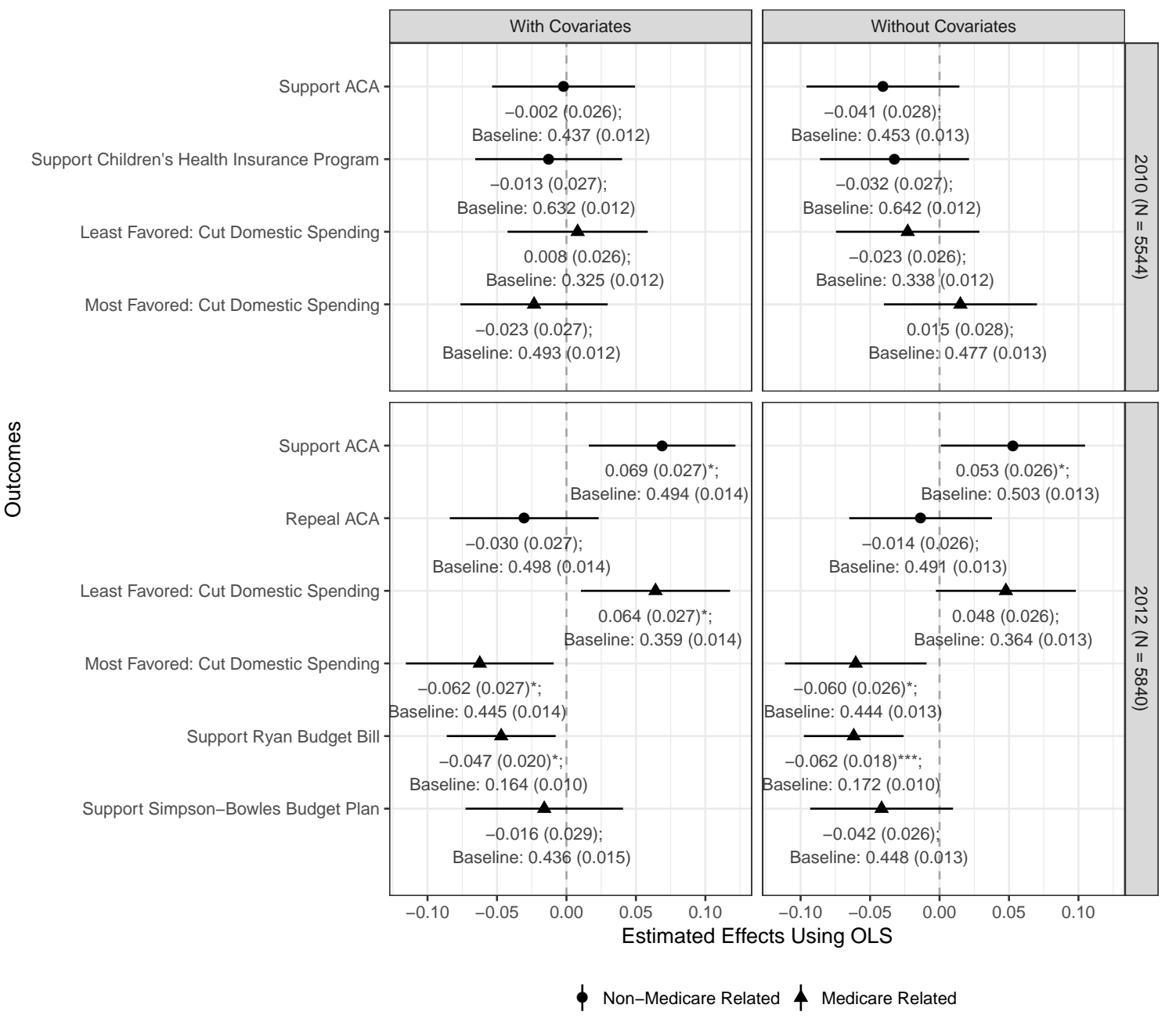


Figure A.15: OLS Estimates: 2014-2016 Cross-sectional CCES Surveys

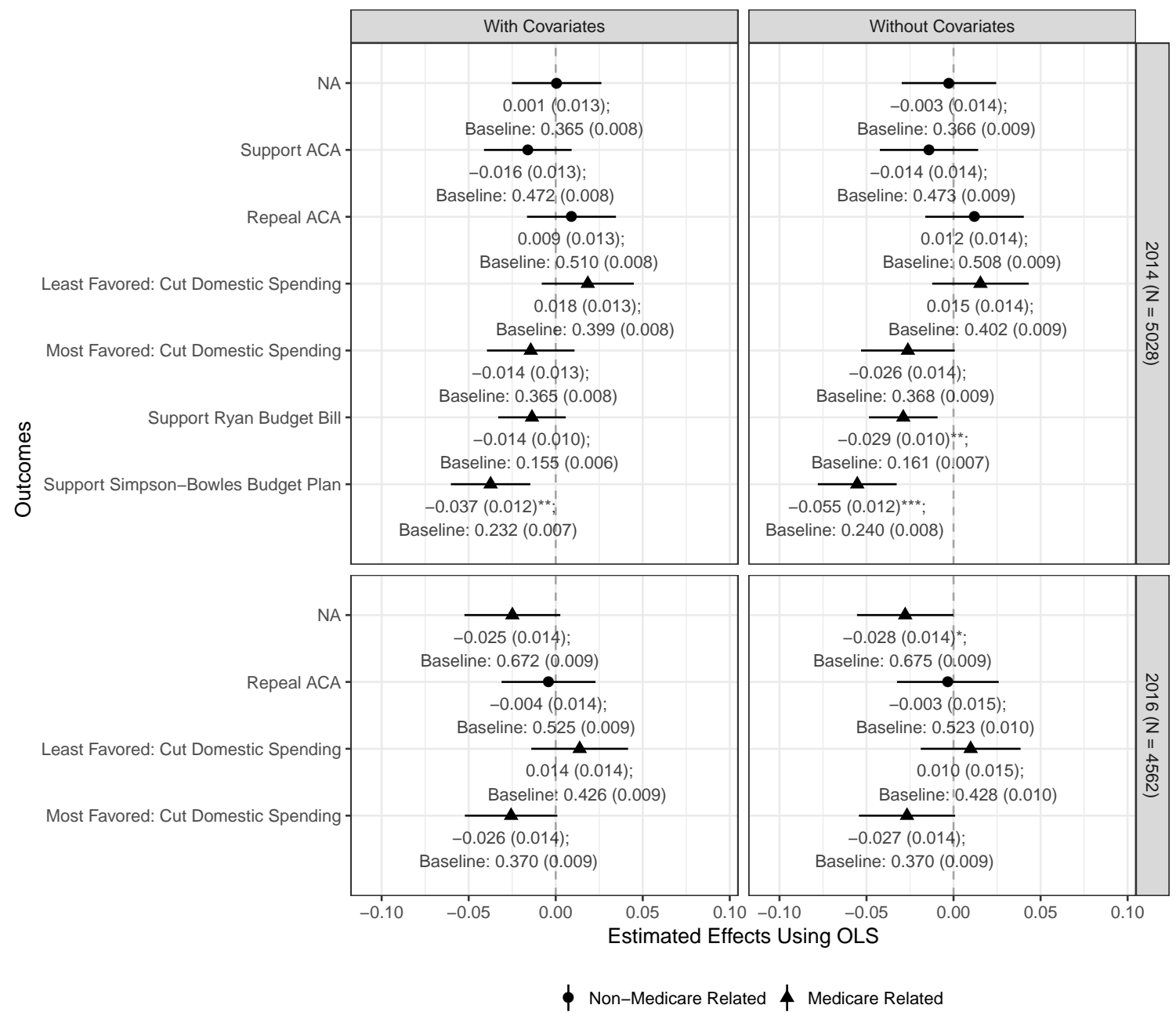


Figure A.16: OLS Estimates: Panel Study

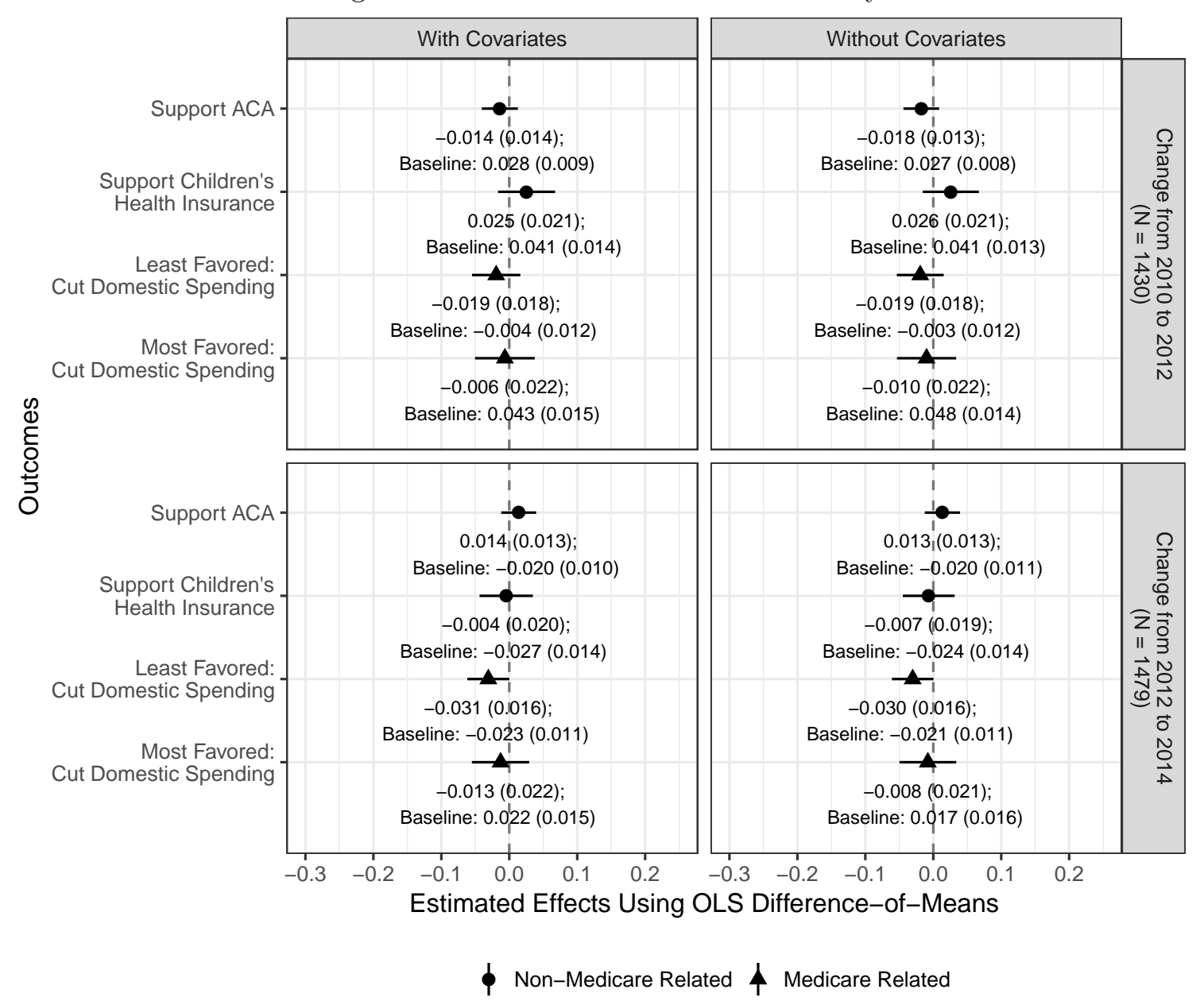

\section{A.5.3 Those Who Did Not Have a Job in the Past Five Years}

To disentangle the effect of Medicare from that of retirement, I conduct the main analysis using data from respondents who had not had a job in the past five years. Only the 2012 and 2014 cross-sectional CCES surveys contain this demographic variable. 
Figure A.17: IV Estimates 2012: Those Who Did Not Have a Job in the Past Five Years CCES 2012: Results for No Job for Past 5 Years

(Bandwidth: 2 Years, With Covariates)

$\mathrm{N}=1780$

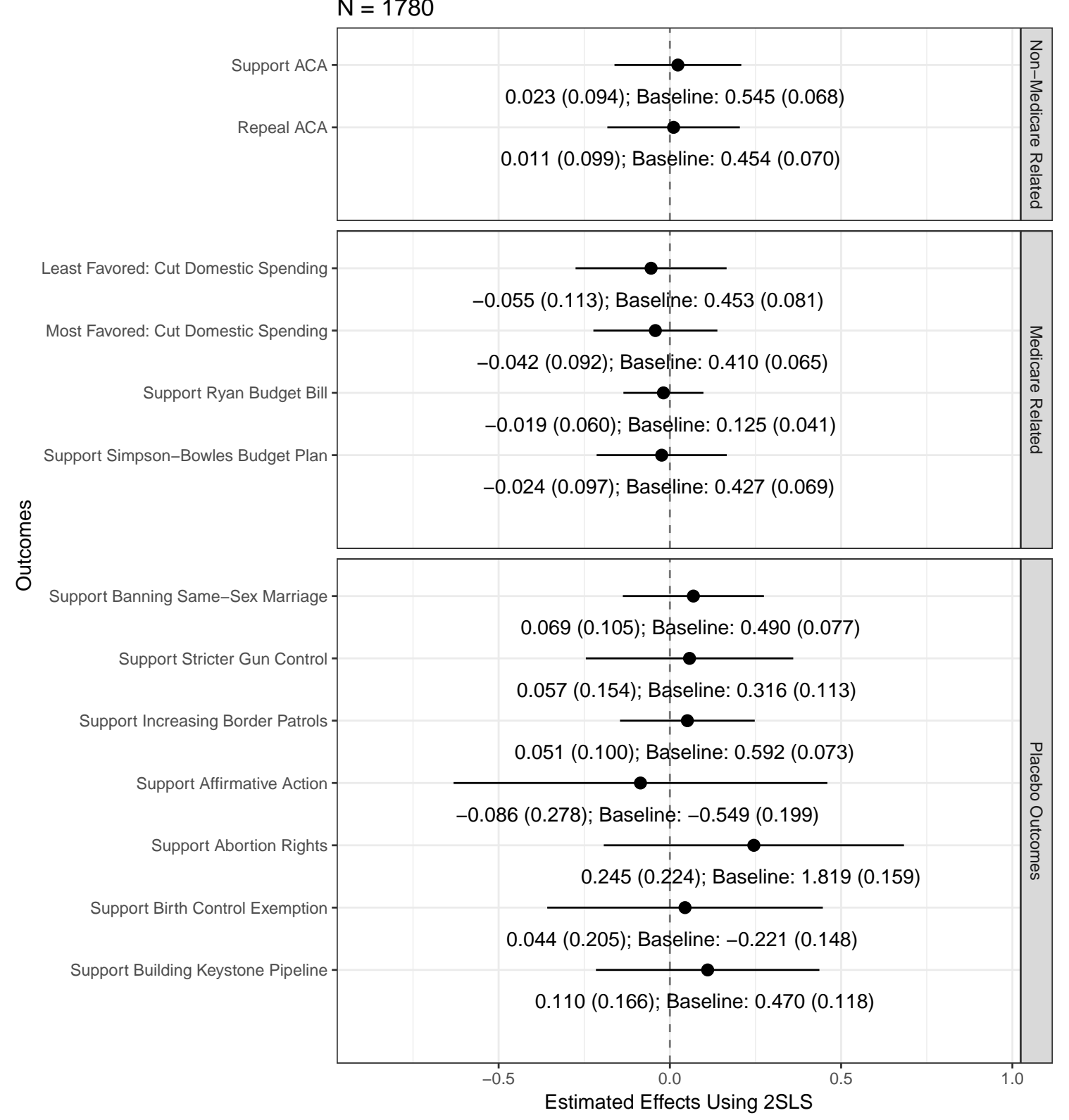


Figure A.18: IV Estimates 2014: Those Who Did Not Have a Job in the Past Five Years CCES 2014: Results for No Job for Past 5 Years

(Bandwidth: 2 Years, With Covariates)

$\mathrm{N}=1639$

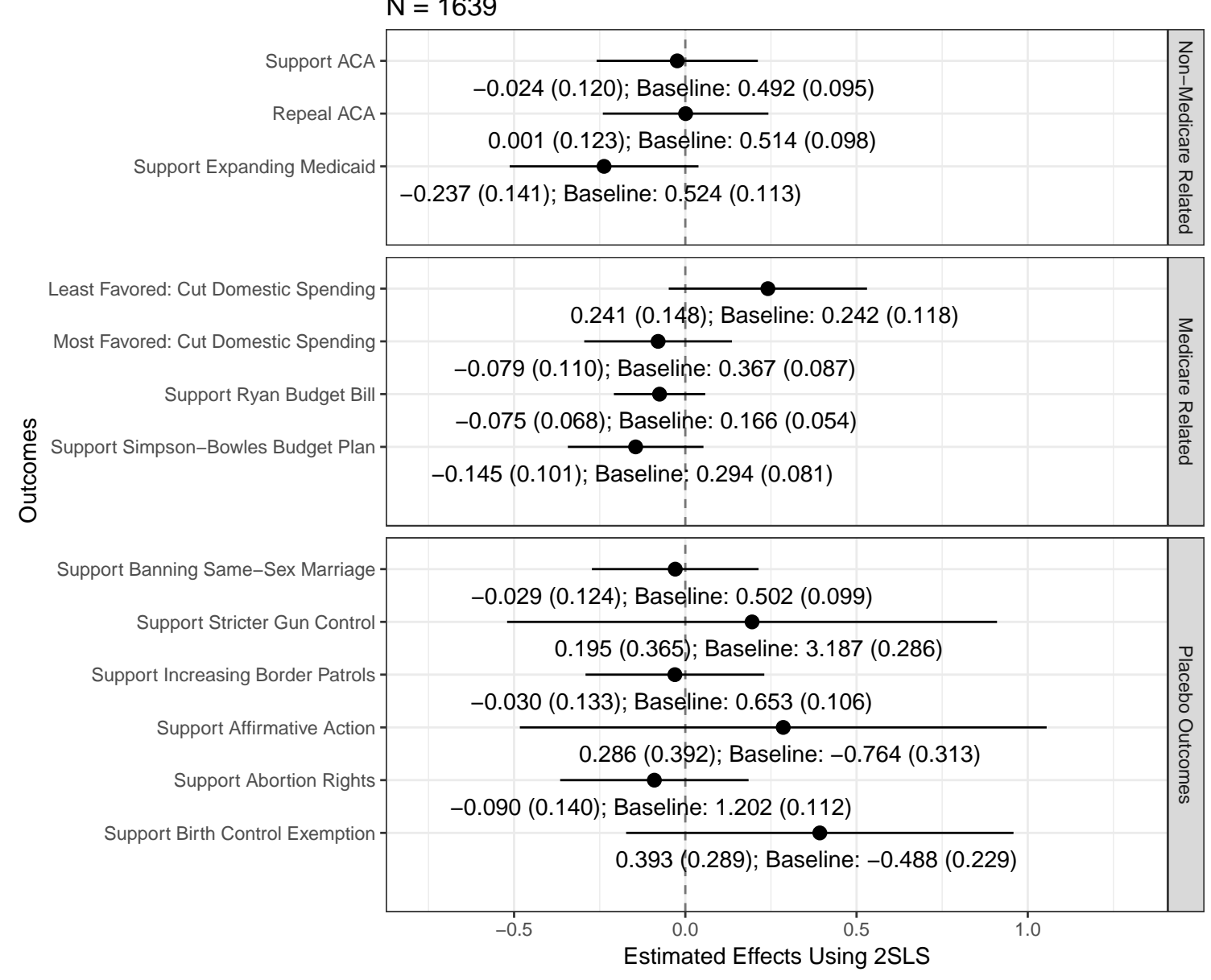

\section{A.5.4 Placebo Treatment Using Placebo Age Cutpoints}

I perform the main analysis using the 2SLS regression in Equation 2 but with placebo cutpoints (age 64 and age 66). The results are reported in the following graphs. 
Figure A.19: IV Estimates Using Age 64 as the Cutpoint (2010, 2012, 2014, and 2016 Cross-sectional CCES Surveys)
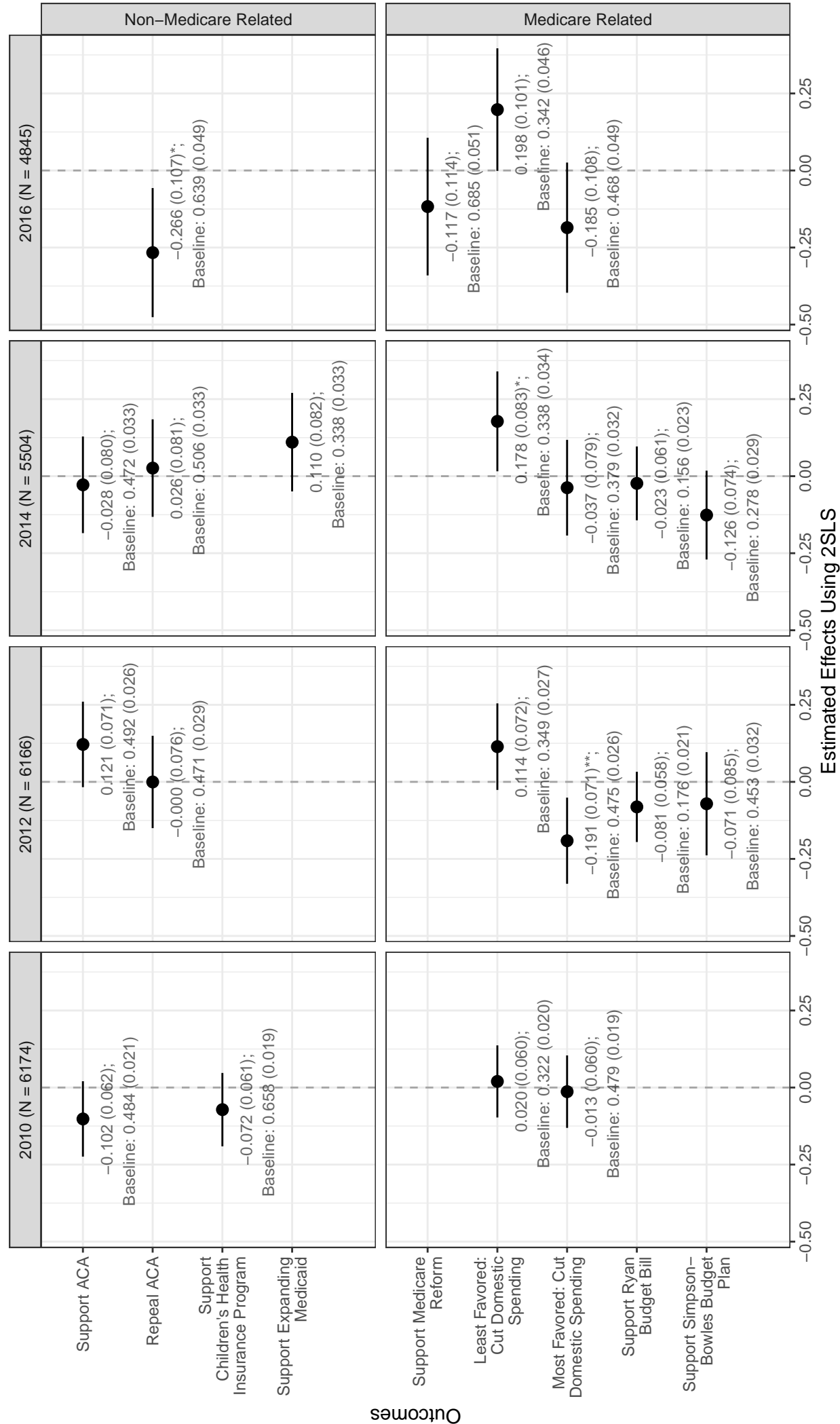

The results are from 2SLS regressions that include pre-treatment covariates. 
Figure A.20: IV Estimates Using Age 66 as the Cutpoint (2010, 2012, 2014, and 2016 Cross-sectional CCES Surveys)
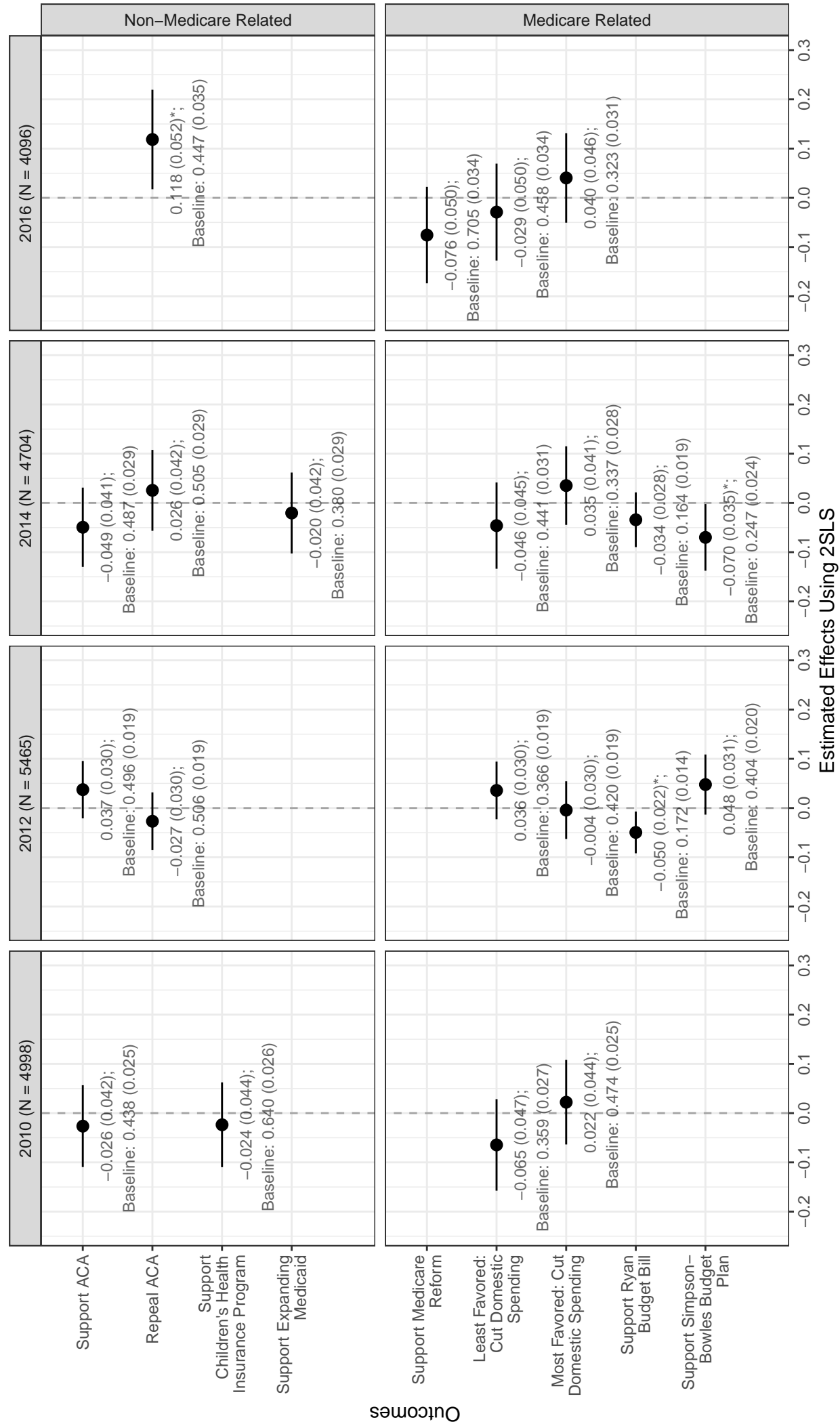

The results are from 2SLS regressions that include pre-treatment covariates. 
Figure A.21: IV Estimates Using Age 64 as the Cutpoint (2010/2012/2014 CCES Panel Study)

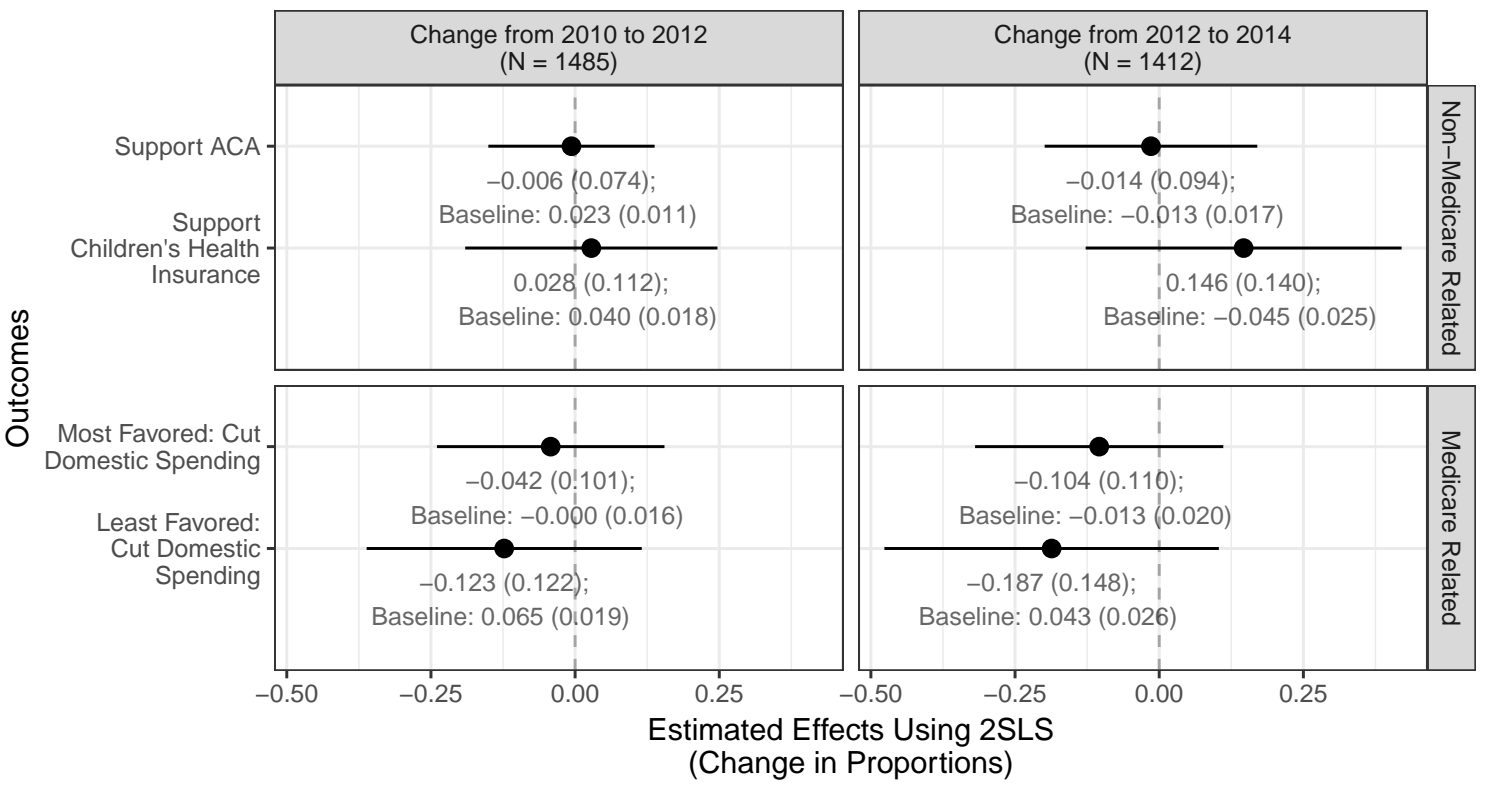

The results are from 2SLS regressions that include pre-treatment covariates.

Figure A.22: IV Estimates Using Age 66 as the Cutpoint (2010/2012/2014 CCES Panel Study)

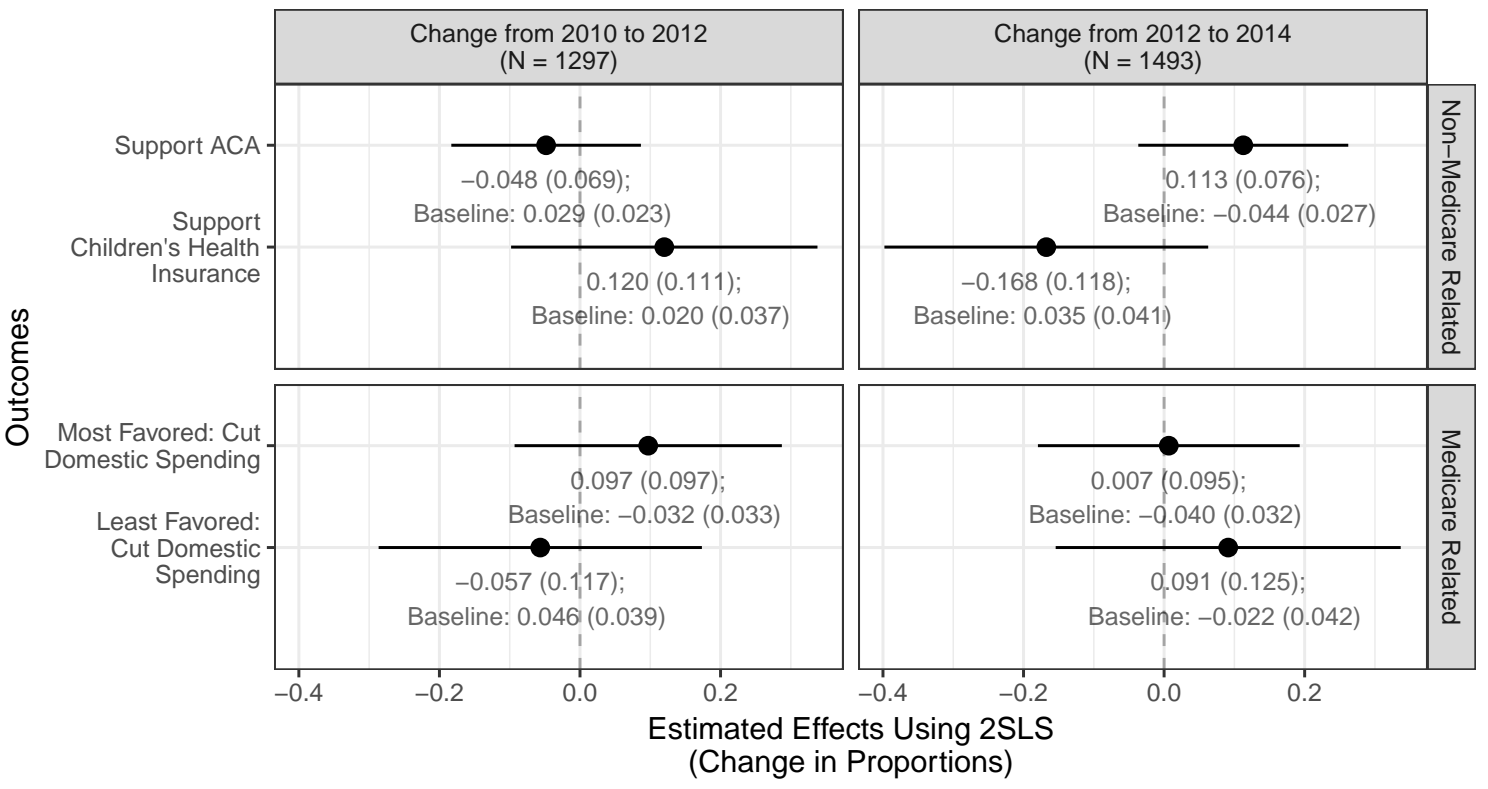

The results are from 2SLS regressions that include pre-treatment covariates. 


\section{Appendix B}

\section{Appendix for "Scientists' Political \\ Behaviors Are Not Driven By \\ Individual-level Government \\ Benefits"}

\section{B.1 Replication Materials}

Replication materials have been deposited to the Harvard Dataverse, and can be accessed here: https://dataverse.harvard.edu/dataset.xhtml?persistentId=doi:10. 7910/DVN/HVKKHL

\section{B.2 Procedure to Match Subjects with Political Donation Records}

For all individuals in our sample (irrespective of whether an individual responded to our survey), we also compiled applicants' political donation records using the OpenSecrets.org's Donor Lookup tool. We manually matched applicants to the political donation records via name, city, and employer (if available). We use the following procedure: 
1. Search if any donor matches the subject's first and last name.

2. For female subjects who changed their last name, search using both their maiden names and married names.

3. For subjects with nicknames or more commonly use their middle names, also search using their nicknames or middle names.

4. If there are no name matches, record the subject's donation as $\$ 0$.

5. If there is a name match, check if the donor's middle name matches the subject's middle name. In addition, check if the donor's employers and locations (i.e., city and state) match the subject's current or past employers or locations. If all three matches, record the matched donor's donation record. If the donor's middle name is not available, download if her employers and location match those of the subject. Out of 2,119 subjects, we were able to match 114 subjects $(5.4 \%)$ to political donations.

Political donation records were compiled into six outcome variables: 1) amount donated (in USD), 2) amount donated to Democrats or Democratic causes, 3) amount donated

to Republicans or Republican causes, 4) number of donations, 5) number of donations to Democrats or Democratic causes, and 6) number of donations to Republicans or Republican causes.

\section{B.3 Main Results Tables}

The following tables present the numerical results that are used to generate the two figures in the main text. 
Table B.1: Effect of Being Awarded the NSF Graduate Research Fellowship on Political Attitudes and Behavior $(N=408)$; Including Background Covariates

\begin{tabular}{|c|c|c|c|}
\hline Outcome & Estimate (SE) & Baseline & $p$-value \\
\hline $\begin{array}{l}\text { Support for March for Science }(1=\text { Strongly Op- } \\
\text { pose, } 5=\text { Strongly Support })\end{array}$ & $-0.158(0.095)$ & 4.460 & 0.096 \\
\hline Participated in March for Science & $-0.018(0.049)$ & 0.358 & 0.721 \\
\hline $\begin{array}{l}\text { Federal Funding for Science }(1=\text { Decrease; } 3= \\
\text { Increase })\end{array}$ & $-0.007(0.034)$ & 2.921 & 0.832 \\
\hline Funding for NSF ( $1=$ Decrease; $3=$ Increase $)$ & $0.041(0.036)$ & 2.878 & 0.248 \\
\hline $\begin{array}{l}\text { Funding for NSF GRFP }(1=\text { Decrease; } 3=\text { In- } \\
\text { crease) }\end{array}$ & $-0.075(0.047)$ & 2.758 & 0.112 \\
\hline $\begin{array}{l}\text { Communicate with Policy Makers }(1=\text { Never; } 4 \\
=\text { Often })\end{array}$ & $0.048(0.087)$ & 1.617 & 0.583 \\
\hline $\begin{array}{l}\text { Communicate with Reporters }(1=\text { Never; } 4= \\
\text { Often) }\end{array}$ & $0.051(0.089)$ & 1.689 & 0.564 \\
\hline Donation Dollar Amount & $-0.017(4.469)$ & 38.852 & 0.997 \\
\hline $\begin{array}{l}\text { Amount Donated to Organizations with Politi- } \\
\text { cal Agenda (in USD) }\end{array}$ & $1.654(3.377)$ & 13.180 & 0.625 \\
\hline Democrat (Includes Lean) & $0.029(0.035)$ & 0.857 & 0.420 \\
\hline Republican (Includes Lean) & $-0.004(0.026)$ & 0.064 & 0.880 \\
\hline Political Ideology ( $1=$ Very Con., $5=$ Very Lib.) & $-0.186(0.087)$ & 4.104 & 0.033 \\
\hline
\end{tabular}


Table B.2: Effect of Being Awarded the NSF Graduate Research Fellowship on Political Attitudes and Behavior $(N=408)$; Not Including Background Covariates

\begin{tabular}{|c|c|c|c|}
\hline Outcome & Estimate (SE) & Baseline & $p$-value \\
\hline $\begin{array}{l}\text { Support for March for Science }(1=\text { Strongly Op- } \\
\text { pose, } 5=\text { Strongly Support) }\end{array}$ & $-0.125(0.100)$ & 4.440 & 0.212 \\
\hline Participated in March for Science & $-0.002(0.049)$ & 0.351 & 0.963 \\
\hline $\begin{array}{l}\text { Federal Funding for Science }(1=\text { Decrease; } 3= \\
\text { Increase) }\end{array}$ & $0.004(0.035)$ & 2.916 & 0.912 \\
\hline Funding for NSF ( $1=$ Decrease; $3=$ Increase) & $0.044(0.035)$ & 2.877 & 0.212 \\
\hline $\begin{array}{l}\text { Funding for NSF GRFP ( } 1=\text { Decrease; } 3=\text { In- } \\
\text { crease) }\end{array}$ & $-0.071(0.046)$ & 2.758 & 0.127 \\
\hline $\begin{array}{l}\text { Communicate with Policy Makers }(1=\text { Never; } 4 \\
=\text { Often })\end{array}$ & $0.056(0.088)$ & 1.612 & 0.523 \\
\hline $\begin{array}{l}\text { Communicate with Reporters }(1=\text { Never; } 4= \\
\text { Often) }\end{array}$ & $0.047(0.090)$ & 1.690 & 0.603 \\
\hline Donation Dollar Amount & $0.043(4.458)$ & 38.714 & 0.992 \\
\hline $\begin{array}{l}\text { Amount Donated to Organizations with Politi- } \\
\text { cal Agenda (in USD) }\end{array}$ & $1.661(3.340)$ & 13.058 & 0.619 \\
\hline Democrat (Includes Lean) & $0.04(0.036)$ & 0.851 & 0.272 \\
\hline Republican (Includes Lean) & $-0.013(0.027)$ & 0.070 & 0.632 \\
\hline Political Ideology ( $1=$ Very Con., $5=$ Very Lib.) & $-0.144(0.092)$ & 4.077 & 0.118 \\
\hline
\end{tabular}

Table B.3: Effect of Being Awarded the NSF Graduate Research Fellowship on Political Donations $(N=2,119)$; Including Background Covariates

\begin{tabular}{llll}
\hline \hline Outcome & Estimate (SE) & Baseline & $p$-value \\
\hline Amount Donated & $223.63(132.22)$ & 29.31 & 0.091 \\
Amount Donated to Democrats & $216.76(132.03)$ & 24.56 & 0.101 \\
Amount Donated to Republicans & $11.22(8.8)$ & 4.53 & 0.202 \\
Number of Donations & $0.13(0.1)$ & 0.22 & 0.186 \\
Number of Donations to Democrats & $0.12(0.1)$ & 0.21 & 0.226 \\
Number of Donations to Republicans & $0.03(0.02)$ & 0.01 & 0.172 \\
\hline
\end{tabular}


Table B.4: Effect of Being Awarded the NSF Graduate Research Fellowship on Political Donations $(N=2,119)$; Not Including Background Covariates

\begin{tabular}{llll}
\hline \hline Outcome & Estimate (SE) & Baseline & $p$-value \\
\hline Amount Donated & $215.64(129.85)$ & 29.45 & 0.097 \\
Amount Donated to Democrats & $209.81(129.68)$ & 24.46 & 0.106 \\
Amount Donated to Republicans & $9.93(8.35)$ & 4.91 & 0.235 \\
Number of Donations & $0.13(0.1)$ & 0.22 & 0.199 \\
Number of Donations to Democrats & $0.11(0.1)$ & 0.2 & 0.235 \\
Number of Donations to Republicans & $0.03(0.02)$ & 0.01 & 0.193 \\
\hline
\end{tabular}

\section{B.4 Further Details About the Subjects}

In this subsection, we present further information about the study subjects.

Table B.5: Summary Statistics of Respondents and Non-respondents

\begin{tabular}{llll}
\hline \hline & Did Not Take Surve & Took Survey & Difference \\
\hline Award Winner & 0.480 & 0.511 & $-0.031(0.026)$ \\
Undergraduate Institute Is an & 0.134 & 0.122 & $0.012(0.017)$ \\
$\begin{array}{l}\text { Ivy League } \\
\text { Undergraduate Institute Is an }\end{array}$ & 0.271 & & \\
Ivy League Plus & & 0.269 & $0.002(0.023)$ \\
Graduate Institute Is an Ivy & 0.161 & & \\
League & & 0.180 & $-0.019(0.019)$ \\
Graduate Institute Is an Ivy & 0.419 & & \\
League Plus & & 0.421 & $-0.002(0.025)$ \\
Applicant is Predicted Male & 0.560 & & \\
Year Applied & 2007.309 & 0.481 & $0.080(0.026) * *$ \\
Field: Chemistry & 0.066 & 2008.731 & $-1.422(0.306) * * *$ \\
Field: Computer Science & 0.042 & 0.058 & $0.008(0.012)$ \\
Field: Engineering & 0.183 & 0.034 & $0.008(0.010)$ \\
Field: Geosciences & 0.023 & 0.156 & $0.026(0.019)$ \\
Field: Life Sciences & 0.378 & 0.016 & $0.007(0.007)$ \\
Field: Material Sciences & 0.001 & 0.387 & $-0.008(0.025)$ \\
Field: Math & 0.026 & 0.002 & $-0.001(0.002)$ \\
Field: Physics and Astronomy & 0.064 & 0.042 & $-0.016(0.010)$ \\
Field: Psychology & 0.122 & 0.056 & $0.008(0.012)$ \\
Field: Social Sciences & 0.094 & 0.132 & $-0.010(0.017)$ \\
\hline
\end{tabular}


Table B.6: Predicting Survey Response Using Applicants' Characteristics

\begin{tabular}{lll}
\hline \hline Characteristic & Estimate (SE) & $p$-value \\
\hline Award Winner & $0.016(0.018)$ & 0.393 \\
Undergraduate Institute Is an Ivy League & $-0.025(0.036)$ & 0.482 \\
Undergraduate Institute Is an Ivy League Plus & $0.013(0.028)$ & 0.641 \\
Graduate Institute Is an Ivy League & $0.027(0.029)$ & 0.361 \\
Graduate Institute Is an Ivy League Plus & $-0.006(0.022)$ & 0.779 \\
Applicant is Male & $-0.045(0.020)$ & 0.021 \\
Year Applied & $0.006(0.001)$ & $<0.001$ \\
Field: Computer Science & $0.003(0.057)$ & 0.953 \\
Field: Engineering & $0.011(0.041)$ & 0.781 \\
Field: Geosciences & $-0.051(0.065)$ & 0.436 \\
Field: Life Sciences & $0.023(0.039)$ & 0.545 \\
Field: Material Sciences & $0.260(0.520)$ & 0.618 \\
Field: Math & $0.136(0.068)$ & 0.048 \\
Field: Physics and Astronomy & $0.016(0.051)$ & 0.756 \\
Field: Psychology & $0.030(0.045)$ & 0.497 \\
Field: Social Sciences & $0.070(0.047)$ & 0.137 \\
Intercept & $-12.496(3.009)$ & $<0.001$ \\
$N$ & 2119 & \\
$F$-statistic & $F(16,2102)=2.453$ & $p$-value $=0.001$ \\
\hline
\end{tabular}

Table B.7: Summary Statistics of the Survey Sample

\begin{tabular}{lccc}
\hline \hline Characteristic & No Award & Award & Difference \\
\hline Undergraduate Institute Is an Ivy League & 0.123 & 0.135 & $0.013(0.036)$ \\
Undergraduate Institute Is an Ivy League Plus & 0.245 & 0.244 & $<-0.001(0.045)$ \\
Graduate Institute Is an Ivy League & 0.172 & 0.187 & $0.015(0.040)$ \\
Graduate Institute Is an Ivy League Plus & 0.387 & 0.415 & $0.028(0.051)$ \\
Applicant is Predicted Male & 0.509 & 0.418 & $-0.092(0.052)$ \\
Self-reported Under-represented Minority & 0.063 & 0.074 & $0.011(0.026)$ \\
(Black, Hispanic, and/or Native American) & & & \\
Self-reported Asian & 0.098 & 0.095 & $-0.003(0.029)$ \\
Self-reported Born in the US & 0.891 & 0.888 & $-0.003(0.034)$ \\
\hline$N=408$ & & & \\
\hline
\end{tabular}


Table B.8: Predicting Award Using Survey Sample's Respondent Characteristics

\begin{tabular}{lcc}
\hline \hline Characteristic & Estimate (SE) & $p$-value \\
\hline Undergraduate Institute Is an Ivy League & $0.072(0.111)$ & 0.520 \\
Undergraduate Institute Is an Ivy League Plus & $-0.037(0.086)$ & 0.668 \\
Graduate Institute Is an Ivy League & $0.015(0.084)$ & 0.858 \\
Graduate Institute Is an Ivy League Plus & $0.032(0.068)$ & 0.633 \\
Applicant is Predicted Male & $-0.101(0.053)$ & 0.058 \\
Self-reported Under-represented Minority & $0.023(0.106)$ & 0.826 \\
(Black, Hispanic, and/or Native American) & $-0.025(0.089)$ & 0.776 \\
Self-reported Asian & $0.002(0.099)$ & 0.984 \\
Self-reported Born in the US & $0.532(0.103)$ & $<0.001$ \\
Intercept & 408 & \\
$N$ & $F(8,399)=0.539$ & $p$-value $=0.827$ \\
$F$-statistic &
\end{tabular}

\section{B.5 Additional Results}

This section includes the results of secondary analyses.

Table B.9: Naive Balance Test: Simple Difference-in-Means Between Winners and Nonwinners (All Subjects; $N=2,119$ )

\begin{tabular}{llll}
\hline \hline Outcome & Estimate (SE) & Baseline & $p$-value \\
\hline Undergraduate Institute is an Ivy League & $-0.009(0.015)$ & 0.135 & 0.560 \\
Undergraduate Institute is an Ivy League Plus & $0.001(0.019)$ & 0.270 & 0.948 \\
Graduate Institute is an Ivy League & $-0.002(0.016)$ & 0.167 & 0.897 \\
Graduate Institute is an Ivy League Plus & $0.015(0.021)$ & 0.412 & 0.476 \\
Applicant is Predicted Male & $-0.071(0.022)$ & 0.576 & 0.001 \\
\hline
\end{tabular}

Table B.10: Effect of Being Awarded the NSF Graduate Research Fellowship on Political Donation Amounts: Randomization Inference Results (Based on 1,000 Simulations)

\begin{tabular}{lll}
\hline \hline Outcome & Wilcoxon rank statistic & Two-sided $p$-value \\
\hline Amount Donated & $526,881.500$ & 0.989 \\
Amount Donated to Democrats & 534,369 & 0.957 \\
Amount Donated to Republicans & $512,128.500$ & 0.998 \\
\hline
\end{tabular}




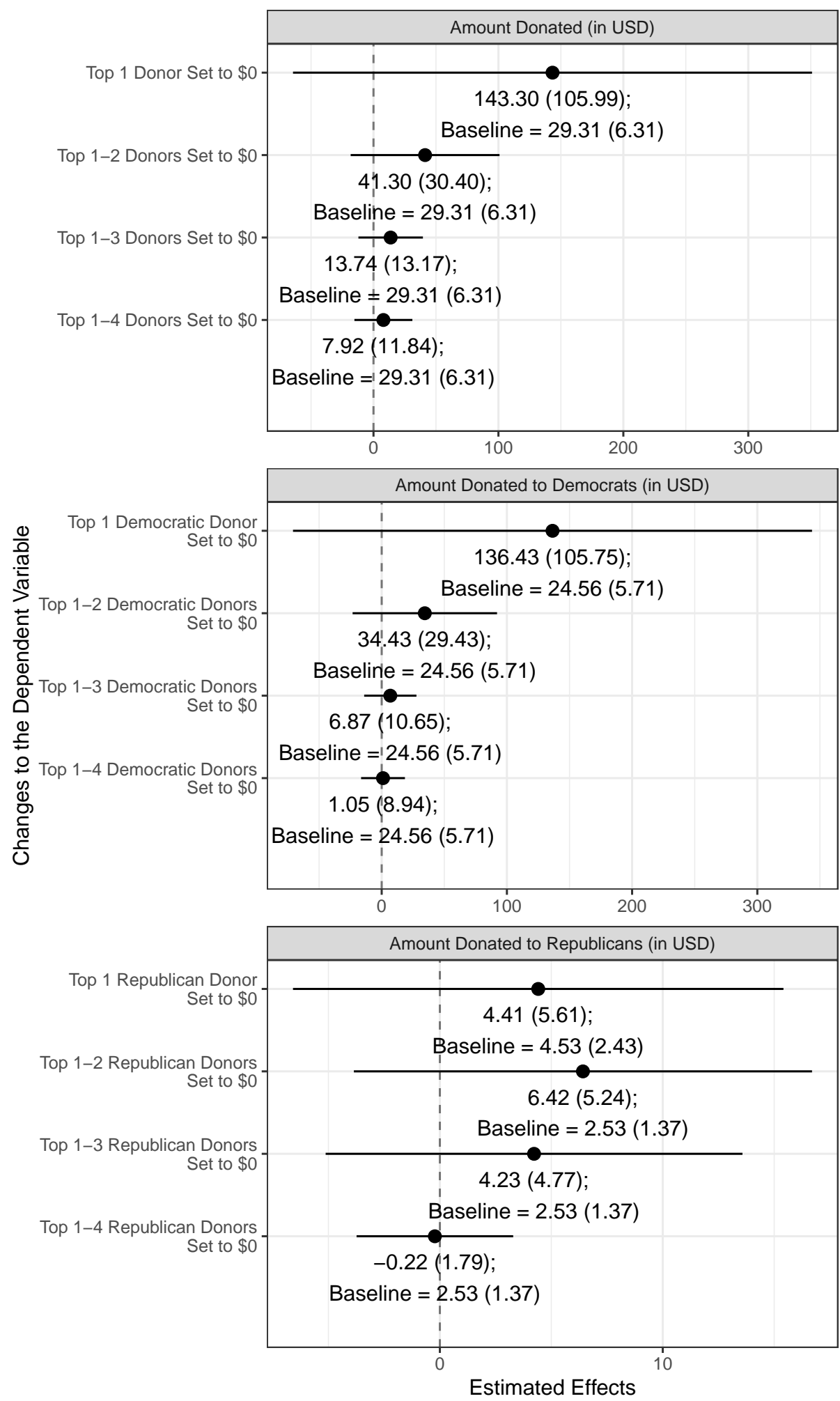

Figure B.1: Robustness Check: Effect of Being Awarded the NSF Graduate Research Fellowship on Political Donations $(N=2,119)$ by Setting Top Donations to $\$ 0$ 
Table B.11: Effect of Being Awarded the NSF Graduate Research Fellowship on Political Donations $(N=2,119)$; Including Only Predicted Gender as A Background Covariate

\begin{tabular}{llll}
\hline \hline Outcome & Estimate (SE) & Baseline & $p$-value \\
\hline Amount Donated & $229.59(137.23)$ & 29.15 & 0.094 \\
Amount Donated to Democrats & $223.04(137.1)$ & 24.24 & 0.104 \\
Amount Donated to Republicans & $11.04(8.75)$ & 4.69 & 0.207 \\
Number of Donations & $0.14(0.1)$ & 0.22 & 0.181 \\
Number of Donations to Democrats & $0.12(0.1)$ & 0.2 & 0.218 \\
Number of Donations to Republicans & $0.03(0.02)$ & 0.01 & 0.173 \\
\hline
\end{tabular}

Table B.12: Interaction Effects of Award and Year of Application on Political Donations $(N=2,119)$

\begin{tabular}{lll}
\hline \hline Outcome & Interaction Effect Estimate (SE) & $p$-value \\
\hline Amount Donated & $-61.952(37.572)$ & 0.099 \\
Amount Donated to Democrats & $-60.106(37.564)$ & 0.110 \\
Amount Donated to Republicans & $-3.196(2.492)$ & 0.200 \\
Number of Donations & $-0.047(0.025)$ & 0.064 \\
Number of Donations to Democrats & $-0.045(0.025)$ & 0.071 \\
Number of Donations to Republicans & $-0.006(0.006)$ & 0.346 \\
\hline
\end{tabular}


Table B.13: Interaction Effects of Award and Year of Application on Political Attitudes and Behavior $(N=408)$

\begin{tabular}{|c|c|c|}
\hline Outcome & Interaction Effect Estimate (SE) & $p$-value \\
\hline $\begin{array}{l}\text { Support for March for Science }(1=\text { Strongly Op- } \\
\text { pose, } 5=\text { Strongly Support })\end{array}$ & $-0.013(0.019)$ & 0.476 \\
\hline Participated in March for Science & $-0.005(0.009)$ & 0.629 \\
\hline $\begin{array}{l}\text { Federal Funding for Science }(1=\text { Decrease } ; 3= \\
\text { Increase) }\end{array}$ & $0.005(0.008)$ & 0.557 \\
\hline Funding for NSF ( $1=$ Decrease; $3=$ Increase) & $0.003(0.009)$ & 0.725 \\
\hline $\begin{array}{l}\text { Funding for NSF GRFP ( } 1=\text { Decrease; } 3=\text { In- } \\
\text { crease) }\end{array}$ & $-0.007(0.01)$ & 0.471 \\
\hline $\begin{array}{l}\text { Communicate with Policy Makers }(1=\text { Never; } 4 \\
=\text { Often })\end{array}$ & $0.008(0.015)$ & 0.582 \\
\hline $\begin{array}{l}\text { Communicate with Reporters }(1=\text { Never; } 4= \\
\text { Often) }\end{array}$ & $-0.001(0.015)$ & 0.967 \\
\hline Donation Dollar Amount & $-0.263(0.833)$ & 0.752 \\
\hline $\begin{array}{l}\text { Amount Donated to Organizations with Politi- } \\
\text { cal Agenda (in USD) }\end{array}$ & $-0.501(0.735)$ & 0.496 \\
\hline Democrat (Includes Lean) & $<0.001(0.006)$ & 0.943 \\
\hline Republican (Includes Lean) & $0.006(0.005)$ & 0.275 \\
\hline Political Ideology ( $1=$ Very Con., $5=$ Very Lib.) & $<0.001(0.016)$ & 0.994 \\
\hline
\end{tabular}

\section{B.6 Additional Survey Experimental Results}

This section describes the two experiments embedded in our survey.

\section{B.6.1 Partisan Cues Survey Experiment}

In Experiment 1, we randomly divided the survey sample into three groups. The first group received a politically neutral statement about the 2017 March for Science. The second group received the same message with additional content noting that "many March participants wanted to resist Republican party attacks on science and protest federal science policy's general direction." A third group received a message that framed the perceived attacks as coming from the Trump administration rather than the Republican party. All respondents were then asked to indicate their support or opposition to the March for Science on a 5-point scale from "strongly support" to "strongly oppose." 
Support for the March for Science was statistically identical across all three experimental groups, as shown in Table B.14. We do not find greater support for the March for Science for respondents given the Trump cue or Republican cue, relative to the neutral message. These null results could plausibly be a function of ceiling effects in political support for the Science March.

Table B.14: Experiment 1 Results: March for Science Support as a Function of Exposure to Partisan Cue Conditions

\begin{tabular}{lll}
\hline \hline Variable & Estimate & $p$-value \\
\hline Trump Cue Treatment & $0.120(0.108)$ & 0.268 \\
Republican Cue Treatment & $0.113(0.108)$ & 0.293 \\
(Intercept: Mean Outcome for Neutral Condition) & $4.327(0.086)$ & $<0.001$ \\
\hline$N$ & 408 & \\
$F$-statistic & $F(2,405)=0.717$ & $p$-value $=0.489$ \\
\hline
\end{tabular}

The outcome is the support for the March for Science, in which 1 means "strongly oppose" and 5 means "strongly support." The heteroskedasticity-robust standard errors are reported in the parentheses after the point estimates.

\section{B.6.2 Domain Expertise Survey Experiment}

In a separate survey experiment, we presented respondents with a simple vignette describing the climate advocacy behavior of a hypothetical scholar. We varied both the scholar's discipline (atmospheric chemistry, economics) as well as the nature of the scholar's advocacy (communication about atmospheric climate science, public endorsement of a carbon tax, public endorsement of a carbon tax plus endorsement of political candidates who support carbon taxes). 
Figure B.2: Experiment 2 Results: Comfort with Political Advocacy as a Function of Advocates' Message and Discipline

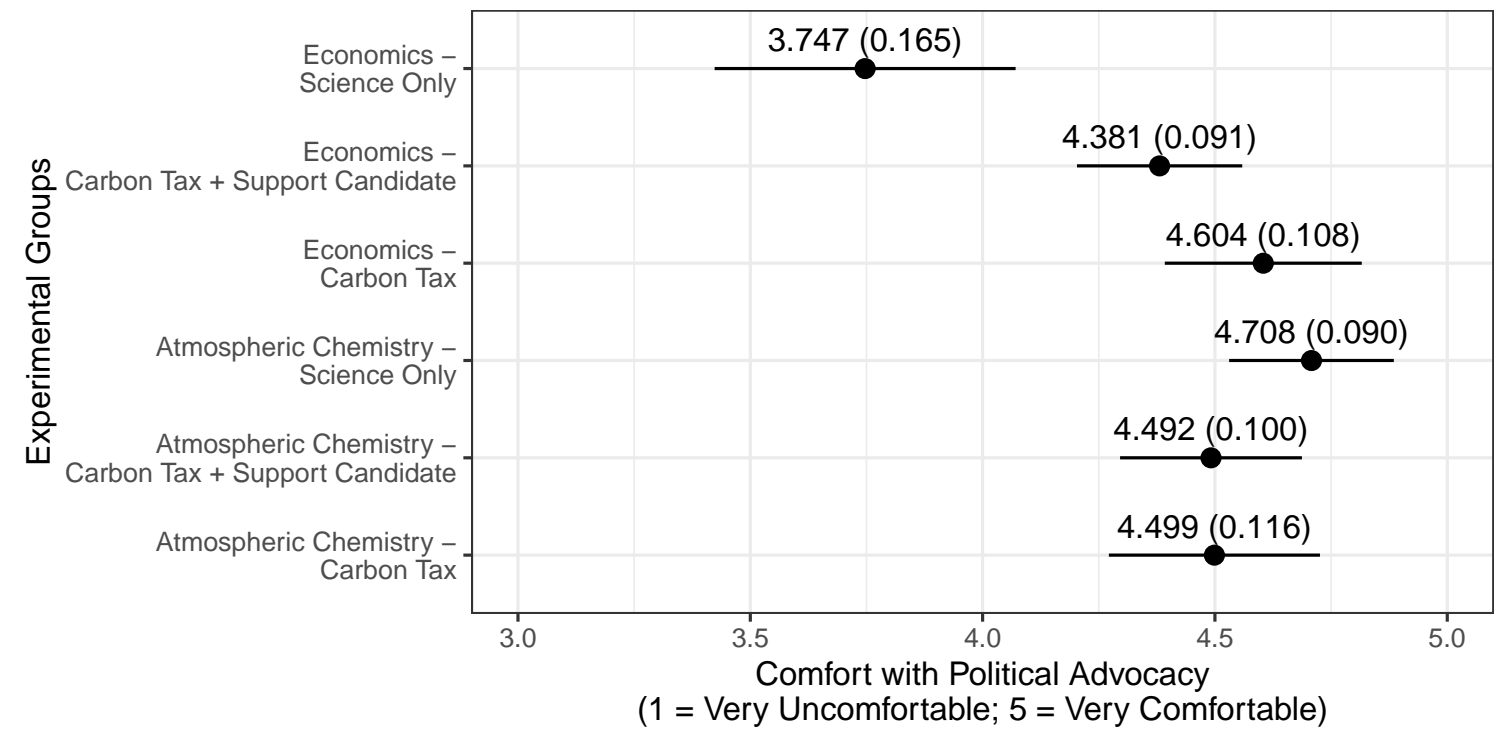

The figure above shows the group mean, standard error, and $95 \%$ confidence interval for each experimental group; $N=408$.

Scientists' comfort with political advocacy does not shift as a function of advocacy content. Scientists are as comfortable with a peer advocating for a carbon tax and endorsing candidates who advocate for climate policies, as they are with a peer who limits their advocacy to climate science communication. Further, scientists are equally comfortable with scientists and economists making these types of political interventions. The only exception is that scientists are less comfortable with economists intervening in political debates to speak on behalf of climate science.

\section{B.7 Text of the survey}

The text of the survey appears below.

NSF apply: Have you ever applied to the National Science Foundation Graduate Fellowship Program?

- Yes 
- No

- I don't remember

Those who replied "No" are taken to a page that states they are not eligible to take the survey.

edu: What degrees do you have? Please check all that apply.

- Bachelor's Degree

- Master's Degree

- $\mathrm{PhD}$

- MD

- Law Degree

- Other advanced degree(s)

identity: Would you describe yourself as a scientist or social scientist?

- Yes, always

- Yes, sometimes

- No, never

If the subject answered "No, never" to the previous question, they are shown this message:

That's OK! In fact, we want to hear your opinions even more. We hope you'll continue taking our survey. Your opinion is particularly important to us. 
fund: Within the last five years, have you received any funding for a research project?

- Yes

- No

Those who answered "Yes" to the previous question are shown this following question:

funder: Over the past five years, which sources did you receive research funding from? Select as many as apply.

- US federal government

- State government

- Foreign government

- Private foundations or non-profit organizations

- Industry

- Direct support from a university or college

- Scientific professional associations

group: Are you a member of the following scientific organizations? Select as many as apply.

- American Association for the Advancement of Science

- National Academy of Sciences

- National Academy of Engineering

- National Academy of Medicine

- Union of Concerned Scientists 
- A scientific organization within my discipline

- Other [text box]

policy1 Which of these statements comes closer to your own view, even if neither is exactly right?

- Scientists should take an active role in public policy debates about issues related to science and technology.

- Scientists should focus on establishing sound scientific facts and stay out of public policy debates.

- I don’t know

policy2: Which of these statements comes closer to your own view, even if neither is exactly right?

- Scientists should take an active role in public policy debates when they are topic experts on an issue.

- Scientists should focus on establishing sound scientific facts and stay out of public policy debates, even when they are topic experts on an issue.

- I don’t know

fedfund: Do you think that government funding for scientific research should be increased, kept the same, or decreased?

- Increased

- Kept the same

- Decreased 
- I don't know

nsf1: Do you think that government funding for the National Science Foundation should be increased, kept the same, or decreased?

- Increased

- Kept the same

- Decreased

- I don’t know

nsf2: Do you think that government funding for the National Science Foundation Graduate Research Fellowship Program should be increased, kept the same, or decreased?

- Increased

- Kept the same

- Decreased

- I don't know

comm1: How often, if ever, do you talk with policymakers about research findings?

- Often

- Occasionally

- Rarely

- Never

comm2: How often, if ever, do you talk with reporters about new research findings? 
- Often

- Occasionally

- Rarely

- Never

social1: How often, if ever, do you post about science on social media?

- Often

- Occasionally

- Rarely

- Never

social2: How often, if ever, do you post about political issues on social media?

- Often

- Occasionally

- Rarely

- Never

This is the first of two experiments embedded within the survey. Respondents are randomly assigned to read one of three paragraphs before answering the questions march1 and march2.

Condition 1: The March for Science was a series of rallies and marches held in Washington, DC and over 300 cities across the world on April 22, 2017. The goal of the March was to promote science and to call on politicians and policymakers to enact policies based on scientific evidence. 
Condition 2: The March for Science was a series of rallies and marches held in Washington, DC and over 300 cities across the world on April 22, 2017. The goal of the March was to promote science and to call on politicians and policymakers to enact policies based on scientific evidence. Many March participants wanted to resist the Trump Administration's attacks on science and protest federal science policy's general direction.

Condition 3: The March for Science was a series of rallies and marches held in Washington, DC and over 300 cities across the world on April 22, 2017. The goal of the March was to promote science and to call on politicians and policymakers to enact policies based on scientific evidence. Many March participants wanted to resist Republican party attacks on science and protest federal science policy's general direction.

march1: Did you support or oppose the March for Science?

- Strongly support

- Somewhat support

- Neither support nor oppose

- Somewhat oppose

- Strongly oppose

- I don't know

march2: Did you participate in the March for Science? Select as many as apply.

- I participated in the march in Washington, DC

- I participated in the march in another city

- I donated to the March for Science

- I did not participate in the March for Science 
This is the second of two experiments embedded within the survey. Respondents are randomly assigned to read the following before answering the question comfort.

comfort experiment: Imagine you have a colleague who studies climate change. Their specific expertise is on [economics/climate science]. In recent years, your colleague has become frustrated with the slow pace of climate change policy action in the United States. This colleague has begun to make public statements, speeches, and testimony in support of the US taking more aggressive climate [economics/climate science].

comfort: How comfortable are you with the behavior of your colleague?

- Very comfortable

- Somewhat comfortable

- Neither comfortable or uncomfortable

- Somewhat uncomfortable

- Very uncomfortable

age: In what year were you born? [Drop-down menu]

race: What is your race or origin? Select as many as apply.

- White

- Hispanic, Latino or Spanish origin

- Black or African American

- Asian

- Native American 
- Native Hawaiian or Other Pacific Islander

- Other

employ: What is your current employment status?

- Working full time now

- Working part time now

- Temporarily laid off

- Unemployed

- Student

- Homemaker

- Retired

- Permanently disabled

- Other

Those who selected "working full time now" or "working part time now" are asked the following question:

employer: Which of these best describes your current employer?

- University or college

- Business or industry

- Government

- Non-profit organization

- Other 
field: What is your primary field or scientific discipline?

- Chemistry

- Computer and Information Sciences \& Engineering

- Engineering

- Geoscience

- Life Science

- Materials Research

- Mathematical Science

- Physics \& Astronomy

- Psychology

- Social Science

- STEM Education \& Learning Research

- I no longer work in any scientific discipline

citizen: Which of these statements best describes you?

- I was born in the USA.

- I am an immigrant to the USA and a naturalized citizen.

- I am an immigrant to the USA but not a citizen.

Those who indicated that they are US citizens are asked the following question:

register Which of these statements best describes you? 
- I am absolutely certain that I am registered to vote in my precinct, election district, or by mail.

- I'm not sure if I am registered to vote.

- I am not registered to vote.

party: In politics today, do you consider yourself a Republican, Democrat, Independent, or something else?

- Republican

- Democrat

- Independent

- Something else

Those who answered "Independent" or "Something else" in the previous question is asked the following question:

party: As of today, do you lean more to the Republican Party or more to the Democratic Party?

- Republican Party

- Democratic Party

- I do not lean to either party

ideo: In general, would you describe your political views as...

- Very conservative

- Conservative 
- Moderate

- Liberal

- Very Liberal

amount: Thank you for completing this survey! You have been entered into a lottery to win one of three $\$ 100$ cash prizes. If you want, we can donate a portion of your prize to one of the following organizations should you win the prize. Please let us know below how much you would like to donate and which organization you would like to donate.

Optional Donation Amount:

org: Preferred Donation Organization:

- American Association for the Advancement of Science

- American Cancer Society

- Union of Concerned Scientists

- The Red Cross

- March for Science

- None

End of the Survey Text:

Thanks for your participation in this survey! Your responses will help us better understand the role of science in American society today. We will be in touch by email if you are selected to win one of the three $\$ 100$ cash prizes.

We welcome feedback from you. If you have suggestions or comments for us, please write in the textbox below. 


\section{Appendix $\mathrm{C}$}

\section{Appendix for "No Rage Against}

the Machines: Threat of

\section{Automation Does Not Change \\ Policy Preferences"}

\section{C.1 Text of Study 1 \\ C.1.1 Instructions}

You will read a short passage about interesting research that has been in the news lately.

\section{C.1.2 Control}

[The control group does not receive any informational treatment.]

\section{C.1.3 Treatment 1: General Forecast - Frey and Osborne}

Nearly Half of American Jobs Are at Risk of Automation

A new study predicts that $47 \%$ of jobs in the U.S. are at risk of becoming automated in the coming decades. 
The study by researchers at the University of Oxford examined hundreds of occupations. For each occupation, the researchers noted the types of tasks workers perform and the skills required. By weighing these factors, as well as engineering challenges, the researchers assessed the degree to which computers and machines could do these jobs.

Automation may sound futuristic, but machines have replaced human workers in the past. For example, computers, ATMs, and self-serve pumps have largely replaced secretaries, bank tellers, and gas station attendants, respectively.

Today, advances in artificial intelligence and robotics have increased the pace of automation. Automation is threatening not only routine jobs (e.g., cashiers, truck drivers, and factory workers) but also jobs that require highly skilled expertise (e.g., computer programmers, judges, and radiologists).

\section{C.1.4 Treatment 2: General Forecast - OECD}

\section{1 in 10 American Jobs Are at Risk of Automation}

A new study predicts that $10 \%$ of jobs in the U.S. are at risk of becoming automated in the coming decades.

The study by researchers at the Organisation for Economic Co-operation and Development, an intergovernmental organization, examined hundreds of occupations. For each occupation, the researchers noted the types of tasks workers perform and the skills required. By weighing these factors, as well as engineering challenges, the researchers assessed the degree to which computers and machines could do these jobs.

Automation may sound futuristic, but machines have replaced human workers in the past. For example, computers, ATMs, and self-serve pumps have largely replaced secretaries, bank tellers, and gas station attendants, respectively.

Today, advances in artificial intelligence and robotics have increased the pace of automation. Automation is threatening not only routine jobs (e.g., cashiers, truck drivers, and factory workers) but also jobs that require highly skilled expertise (e.g., computer programmers, judges, and radiologists). 


\section{C.1.5 Treatment 3: Individual Forecast - Frey and Osborne}

\section{Will Your Job Be Done By A Machine?}

Will your job be around in the future? A new study predicts the likelihood of different jobs becoming automated in the upcoming decades.

According to their research, here is the prediction for your job:

[Respondent's occupation] have a [very low/somewhat low/moderate/somewhat high/very high] likelihood ([Predicted likelihood for respondent's occupation]\% chance) of becoming automated.

The study by researchers at the University of Oxford examined hundreds of occupations. For each occupation, the researchers noted the types of tasks workers perform and the skills required. By weighing these factors, as well as engineering challenges, the researchers assessed the degree to which computers and machines could do these jobs.

Note: Table C.1 shows the correspondence between the likelihood categories and the predicted probabilities.

Table C.1: Likelihood categories linked to predicted percent chance of jobs becoming automated

\begin{tabular}{|l|l|}
\hline Likelihood categories & Predicted percentage chance \\
\hline very low & {$[0,20) \%$} \\
\hline somewhat low & {$[20,40) \%$} \\
\hline moderate & {$[40,60) \%$} \\
\hline somewhat high & {$[60,80) \%$} \\
\hline very high & {$[80,100] \%$} \\
\hline
\end{tabular}

\section{C.1.6 Treatment 4: Individual Forecast - OECD}

\section{Will Your Job Be Done By A Machine?}

Will your job be around in the future? A new study predicts the likelihood of different jobs becoming automated in the upcoming decades.

According to their research, here is the prediction for your job:

[Respondent's occupation] have a [very low/somewhat low/moderate/somewhat high/very high] likelihood ([Predicted likelihood for respondent's occupation]\% chance) of becoming automated. 
The study by researchers at the Organisation for Economic Co-operation and Development, an intergovernmental organization, examined hundreds of occupations. For each occupation, the researchers noted the types of tasks workers perform and the skills required. By weighing these factors, as well as engineering challenges, the researchers assessed the degree to which computers and machines could do these jobs. Control

\section{C.1.7 Outcome Measures}

This subsection contains the survey questions, answer choices, and the coding for the answer choices.

How likely, if at all, do you think it is that your own job or profession will be mostly done by robots or computers within the next two decades?

- Very low likelihood (0-20\% chance) (0)

- Somewhat low likelihood (20-40\% chance) (1)

- Moderate likelihood (40-60\% chance) (2)

- Somewhat high likelihood (60-80\% chance) (3)

- Very high likelihood (80-100\% chance) (4)

- I don't know

How likely, if at all, do you think it is that all jobs in the U.S. will be mostly done by robots or computers within the next two decades?

- Very low likelihood (0-20\% chance) (0)

- Somewhat low likelihood (20-40\% chance) (1)

- Moderate likelihood (40-60\% chance) (2) 
- Somewhat high likelihood (60-80\% chance) (3)

- Very high likelihood (80-100\% chance) (4)

- I don't know

How likely, if at all, do you think that the following jobs will be mostly replaced by robots or computers within the next two decades?

[Display three randomly selected jobs from the list below.]

- Software engineers

- Legal clerks

- Nurses

- Construction workers

- Fast food workers

- Teachers

- Insurance claims processors

Answer choices for each:

- Very low likelihood (0-20\% chance) (0)

- Somewhat low likelihood (20-40\% chance) (1)

- Moderate likelihood (40-60\% chance) (2)

- Somewhat high likelihood (60-80\% chance) (3)

- Very high likelihood (80-100\% chance) (4)

- I don't know 
Please rate how realistic you find the following statement about the future of automation.

New developments in robotics and computing are changing the nature of many jobs. Today, these technologies are mostly being used in certain settings to perform routine tasks that are repeated throughout the day. But in the future, robots and computers with advanced capabilities may be able to do most of the jobs that are currently done by humans today.

- Not at all realistic (0)

- Not very realistic (1)

- Somewhat realistic (2)

- Extremely realistic (3)

- I don't know

If robots and computers were able to perform most of the jobs currently being done by humans, do you think the following would be likely or not likely to happen as a result?

Items:

- Inequality between the rich and poor would be much worse than it is today.

- The economy would create many new, better-paying jobs for humans.

Answer choices for each item:

- Not at all likely (0)

- Not very likely (1)

- Somewhat likely (2) 
- Very likely (3)

- I don't know

Some people feel that the government in Washington should see to it that every person has a job and a good standard of living. Others think the government should just let each person get ahead on his own. Where would you place yourself on this scale, or haven't you thought much about this?

[1 to 7 scale; with the option to select "I haven't thought much about this"]

There is much concern about the rapid rise in medical and hospital costs. Some people feel there should be a government insurance plan which would cover all medical and hospital expenses for everyone. Suppose these people are at one end of a scale, at point 1. Others feel that all medical expenses should be paid by individuals through private insurance plans like Blue Cross or other company paid plans. Suppose these people are at the other end, at point 7 . Where would you place yourself on this scale, or haven't you thought much about this?

[1 to 7 scale; with the option to select "I haven't thought much about this"]

Some people think that the government in Washington ought to reduce the income differences between the rich and the poor, perhaps by raising the taxes of wealthy families or by giving income assistance to the poor. Suppose these people are at one end of a scale, at point 1 . Others think that the government should not concern itself with reducing this income difference between the rich and the poor. Suppose these people are at the other end, at point 7 . Where would you place yourself on this scale, or haven't you thought much about this? 
[1 to 7 scale; with the option to select "I haven't thought much about this"]

Which of the following should fund retraining programs for those who lose their jobs because of new technology? Select all that apply.

- Employers

- Unions, industry, or trade associates

- Federal government

- State government

- Local government

- Workers themselves

- Colleges and universities

Which comes closest to your view about what government policy should be towards immigrants?

- The United States should have open borders and allow further immigration on an unlimited basis. (1)

- Legal immigration to the United States should greatly increase among all immigrant groups, regardless of their skills. Immigrants already in the United States should be put on the path to citizenship. (2)

- Immigration of highly skilled individuals should greatly increase. Immigration by those without such skills should continue at its current pace, although this immigration should be legalized. (3)

- Immigration of highly skilled individuals should greatly increase, and immigration among those without such skills should be limited in time and/or magnitude, e.g., through a guest worker program. (4) 
- The United States should admit more highly skilled immigrants and secure the border with increased physical barriers to stem the flow of other immigrants. (5)

- Only a small number of highly skilled immigrants should be allowed into the United States until the border is fully secured, and all illegal immigrants currently in the US should be deported. (6)

- Further immigration to the United States should be banned until the border is fully secured, and all illegal immigrants currently in the US should be deported immediately.

- I don't know

Do you think the number of immigrants from foreign countries who are permitted to come to the United States to live should be ...?

- Decreased a lot $(-2)$

- Decreased a little (-1)

- Left the same as it is now (0)

- Increased a little (1)

- Increased a lot (2)

- I don’t know

Some people have suggested placing new limits on foreign imports in order to protect American jobs. Others say that such limits would raise consumer prices and hurt American exports. Do you favor or oppose placing new limits on imports, or haven't you thought much about this?

- Strongly oppose $(-2)$ 
- Somewhat oppose $(-1)$

- Neither favor nor oppose (0)

- Somewhat favor (1)

- Strongly favor (2)

- I haven't thought much about this

Recently, some big American companies have been hiring workers in foreign countries to replace workers in the U.S. Do you think the federal government should discourage companies from doing this, encourage companies to do this, or stay out of this matter?

- Discourage $(-1)$

- Encourage (1)

- Should stay out of this matter (0)

- I don’t know

In the event that robots and computers are able to do most of the jobs that are done by humans today, would you favor or oppose the following? Items:

- The federal government providing all Americans with a guaranteed income that would allow them to meet their basic needs

- Robots and computers mostly limited to doing jobs that are dangerous or unhealthy for humans to do

Answer choices for each item: 
- Strongly oppose $(-2)$

- Oppose $(-1)$

- Favor (1)

- Strongly favor $(2)$

- I don't know

\section{C.2 Text of Study 2}

\section{C.2.1 News Article Informational Treatment}

\section{Nearly Half of American Jobs Are at Risk of Automation}

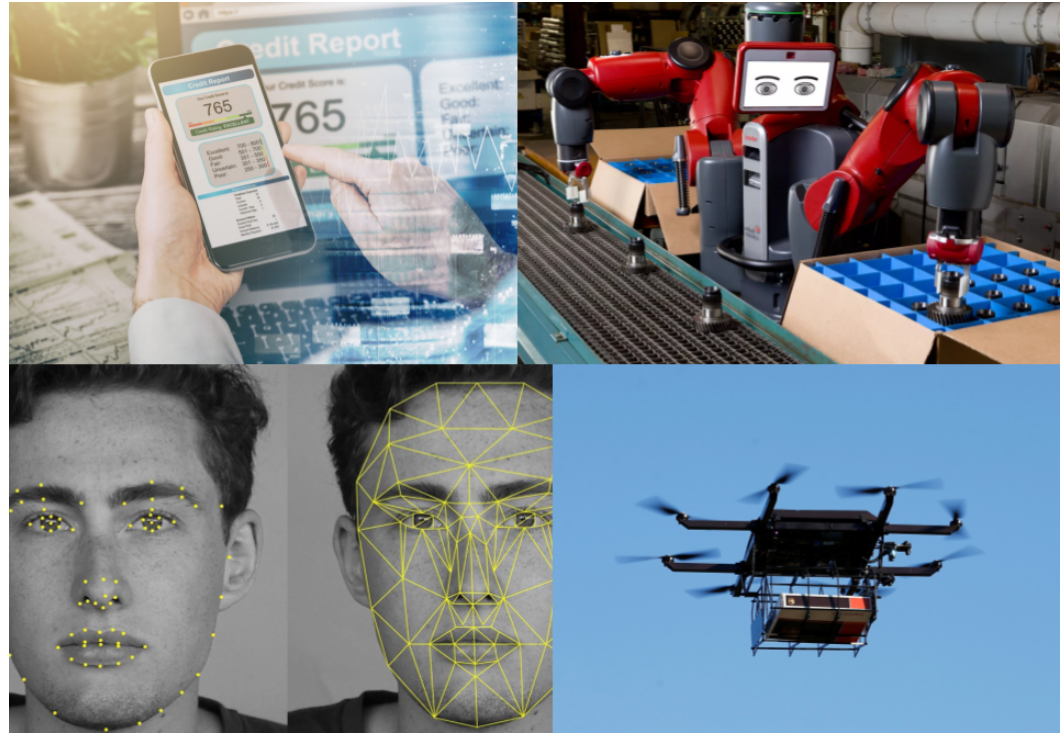

Machine learning is used to perform many tasks that previously required human workers, such as generating credit reports, operating machinery, recognizing faces, and delivering packages.

A new study predicts that $47 \%$ of jobs in the U.S. are at risk of becoming automated in the next 10 to 20 years.

The study by researchers at the University of Oxford examined hundreds of occupations to predict how likely computers and machines are to automate these occupations. To make 
their forecasts, the researchers considered the tasks workers performed, the skills required for each occupation, and engineering challenges.

Automation has already impacted American workers in the past few decades. Technological advances have reduced the demand for middle-skilled jobs that require more education and training than a high school diploma but less than a four-year college degree. For example, computers have reduced the demand for secretaries, and industrial robots have reduced the need for factory workers. This wave of workplace automation has led to the decline of the middle class in the U.S., some economists argue.

Today, advances in machine learning, artificial intelligence, and robotics have increased the pace of automation. Computers and robots are now trained to perform tasks that typically require human intelligence. The resulting automation is threatening not only routine jobs, but also jobs that require expertise: computer programmers, judges, and radiologists.

The public, not just experts, is concerned about the disruptive impact of workplace automation. Three out of every four Americans are worried about a future where robots and computers can do many jobs currently done by humans, according to a study by Pew Research Center. A higher percentage of Americans think that in such a future, inequality between the rich and poor will be much worse than it is today.

The impact of advanced automation will be felt not only in the U.S. but also around the world. For instance, China has invested heavily in artificial intelligence research to boost its economic productivity. Limiting international trade or immigration into the U.S. is unlikely to stop the disruptive effects of technology on American jobs.

\section{C.2.2 Outcome Measures}

Study 2 included the same set of questions found in Study 1 with some minor differences. Two additional questions have been added.

The minor differences between the questions in Study 1 and Study 2 are as follows:

- In Study 1, questions that ask respondents to give predictions about the likelihood of jobs becoming automated use the phrase "within the next two decades." In Study 2, 
the questions use the phrase "in 10 to 20 years" instead.

- In Study 1, in the job loss concern question, one of the item states, "Your employer finds someone who is willing to do your job for less money." In Study 2, I divided this item into following two items:

- Your employer finds someone outside the U.S. who is willing to do your job for less money.

- Your employer finds an immigrant to the U.S. who is willing to do your job for less money.

Study 2 included these additional questions:

What percent of jobs currently done by human workers in the U.S. do you think will be done by robots or computers in the next 10 to 20 years? [Slider from 0 to 100; there is also an option to select "I don't know"]

How worried are you about losing your job in the near future?

- Not at all worried (0)

- A little worried (1)

- Moderately worried (2)

- Very worried (3)

- Extremely worried (4)

- I don't know 
Do you approve or disapprove of the way Donald Trump is handling his job as president?

- Strongly disapprove $(-2)$

- Somewhat disapprove $(-1)$

- Neither approve nor disapprove (0)

- Somewhat approve (1)

- Strongly approve (2)

- I don't know

\section{C.3 Text of Study 3}

\section{C.3.1 News Article Informational Treatment}

Nearly Half of American Jobs Are at Risk of Automation

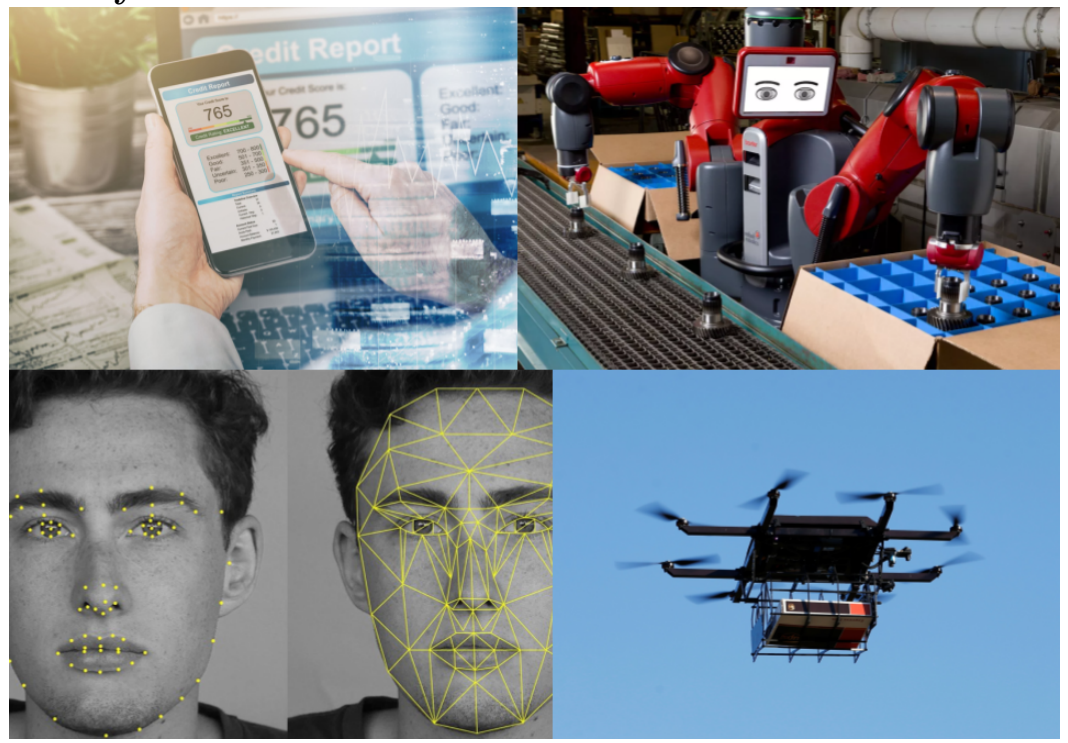

Machine learning is used to perform many tasks that previously required human workers, such as generating credit reports, operating machinery, recognizing faces, and delivering packages. 
A new study predicts that $47 \%$ of jobs in the U.S. are at risk of becoming automated in the next 10 to 20 years.

The study by researchers at the University of Oxford examined hundreds of occupations to predict how likely computers and machines are to automate these occupations. To make their forecasts, the researchers considered the tasks workers performed, the skills required for each occupation, and engineering challenges.

Automation has already impacted American workers in the past few decades. Technological advances have reduced the demand for middle-skilled jobs that require more education and training than a high school diploma but less than a four-year college degree. For example, computers have reduced the demand for secretaries, and industrial robots have reduced the need for factory workers. This wave of workplace automation has led to the decline of the middle class in the U.S., some economists argue.

Today, advances in machine learning, artificial intelligence, and robotics have increased the pace of automation. Computers and robots are now trained to perform tasks that typically require human intelligence. The resulting automation is threatening not only routine jobs, but also jobs that require expertise: computer programmers, judges, and radiologists.

The public, not just experts, is concerned about the disruptive impact of workplace automation. Three out of every four Americans are worried about a future where robots and computers can do many jobs currently done by humans, according to a study by Pew Research Center. A higher percentage of Americans think that in such a future, inequality between the rich and poor will be much worse than it is today.

\section{C.3.2 Outcome Measures}

What percent of jobs currently done by human workers in the U.S. do you think will be done by robots or computers in the next 10 to 20 years? [Slider from 0 to 100 ; there is also an option to select "I don't know"] 
As robots and computers are able to do more and more tasks currently done by humans, would you favor or oppose the federal government doing the following? The policies:

- Providing all Americans with a guaranteed income that would allow them to meet their basic needs

- Limiting robots and computers to doing mostly jobs that are dangerous or unhealthy for humans to do

- Funding retraining programs for those who lose their jobs because of new technology

Answer choices for each:

- Strongly favor (2)

- Somewhat favor (1)

- Somewhat oppose $(-1)$

- Strongly oppose $(-2)$

- I don’t know 


\section{C.4 Additional Figures and Tables}

\section{C.4.1 Study 1}
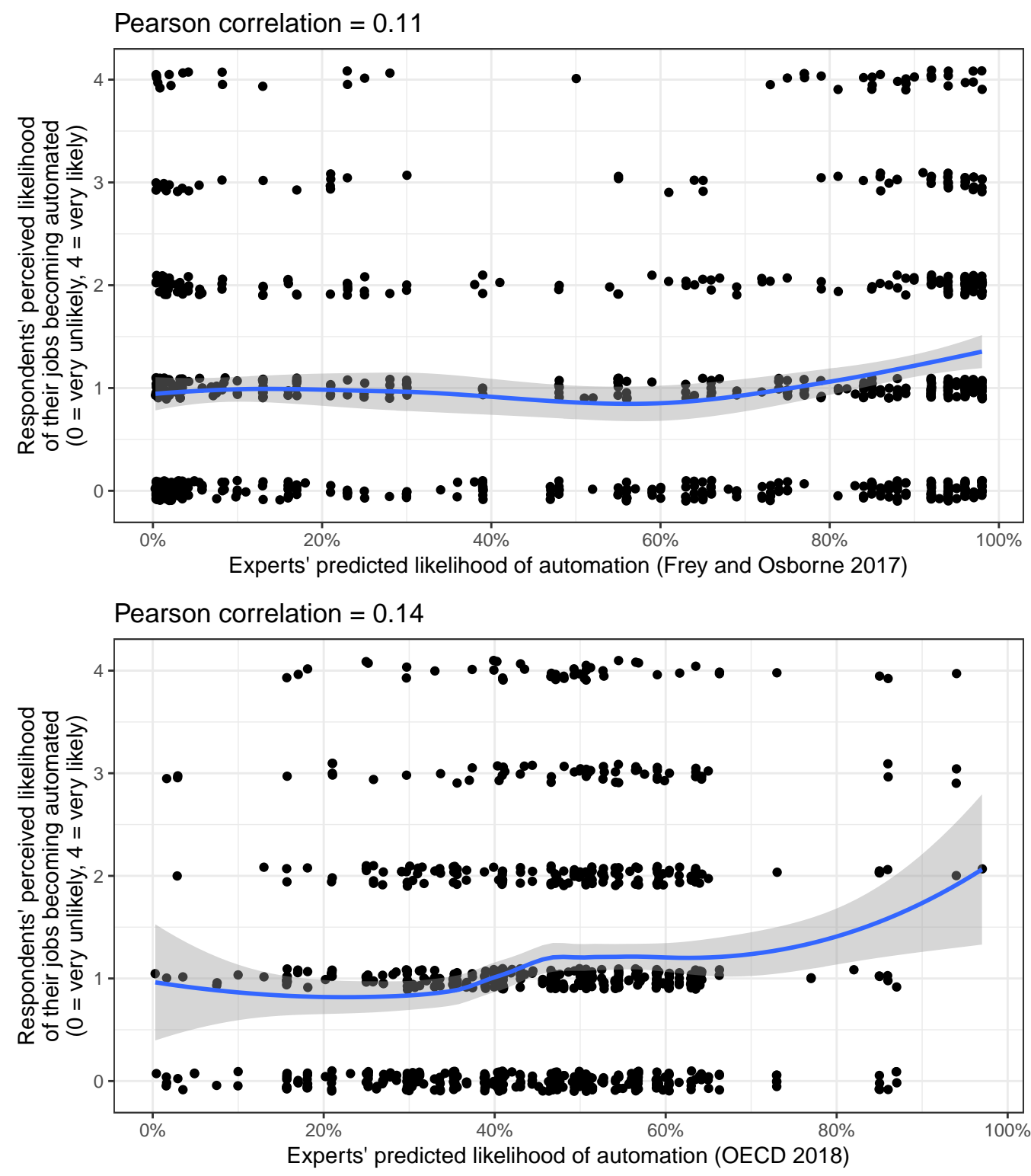

Figure C.1: Study 1: Correlation between respondents' perceived likelihoods of their jobs becoming automated and experts' forecasts is low.

The data displayed come from the Control group in Study 1. 


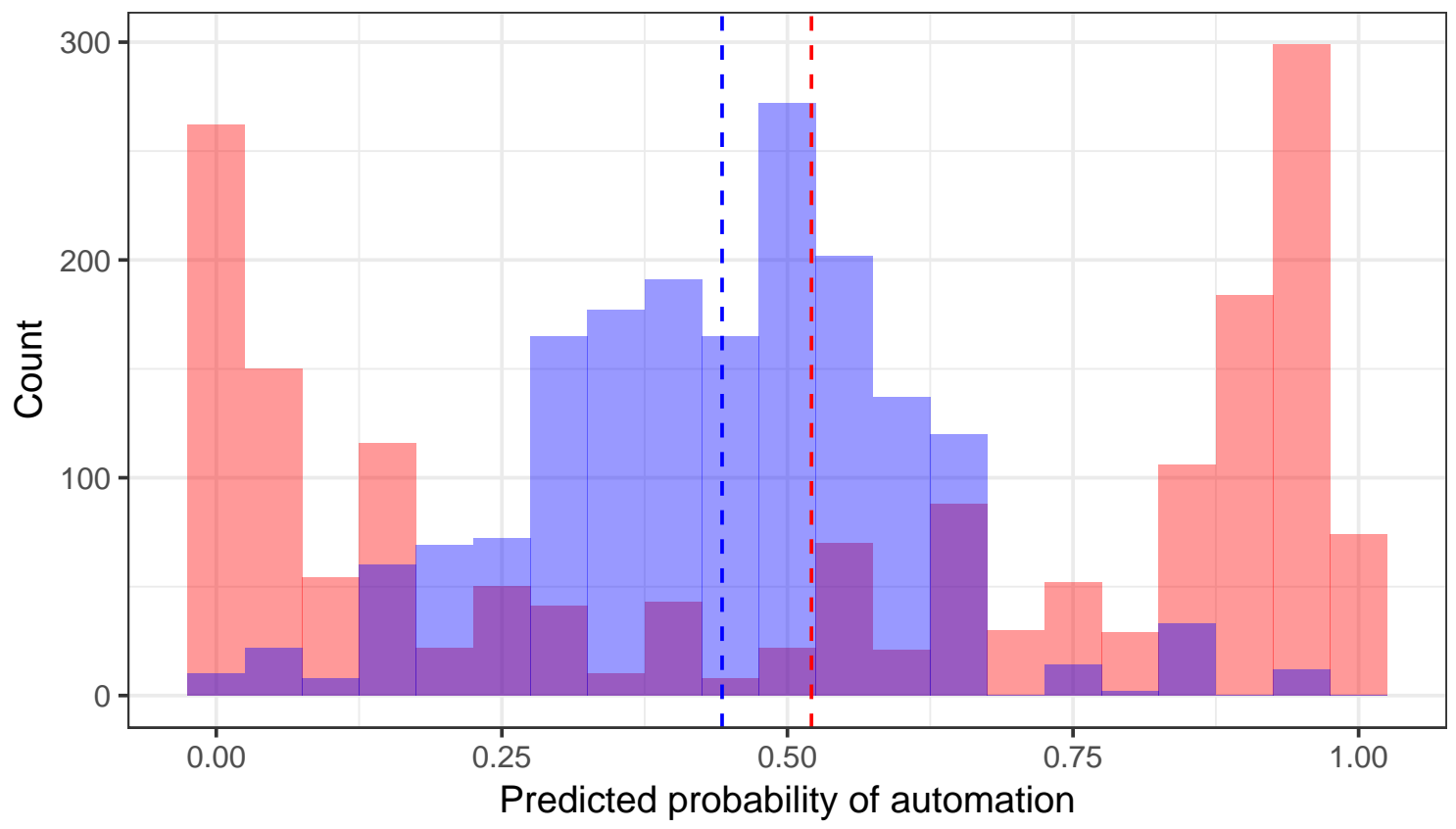

Forecast data source $\quad$ Frey and Osborne

Figure C.2: Study 1: Distribution of predicted likelihood that respondents' jobs will be automated by forecast dataset 
Table C.2: Study 1: Standardized treatment effect estimates - General Forecast

\begin{tabular}{|c|c|c|c|c|}
\hline Outcome & $\begin{array}{l}\text { Estimated } \\
\text { effect (SE) }\end{array}$ & $p$-value & $\begin{array}{l}\text { Control } \\
\text { mean }\end{array}$ & $N$ \\
\hline $\begin{array}{l}\text { Predicted likelihood of } 3 \text { randomly- } \\
\text { selected jobs becoming automated }\end{array}$ & $0.15(0.06)$ & 0.007 & -0.10 & 1,643 \\
\hline $\begin{array}{l}\text { Predicted likelihood of all U.S. jobs } \\
\text { becoming automated }\end{array}$ & $0.07(0.06)$ & 0.205 & -0.04 & 1,643 \\
\hline $\begin{array}{l}\text { Predicted likelihood of one's own } \\
\text { job becoming automated }\end{array}$ & $0.14(0.05)$ & 0.012 & -0.09 & 1,643 \\
\hline Job loss concern: cheaper labor & $0.10(0.06)$ & 0.069 & -0.09 & 1,643 \\
\hline $\begin{array}{l}\text { Job loss concern: workplace au- } \\
\text { tomation }\end{array}$ & $0.20(0.06)$ & $<0.001$ & -0.13 & 1,643 \\
\hline $\begin{array}{l}\text { Perceived realism of mostly auto- } \\
\text { mated future }\end{array}$ & $0.04(0.06)$ & 0.497 & -0.03 & 1,643 \\
\hline Prediction: inequality will get worse & $0.02(0.06)$ & 0.655 & -0.01 & 1,643 \\
\hline $\begin{array}{l}\text { Prediction: new, better-paying jobs } \\
\text { will be created }\end{array}$ & $0.14(0.06)$ & 0.015 & -0.08 & 1,643 \\
\hline $\begin{array}{l}\text { Support for government guarantee- } \\
\text { ing jobs and good standard of living }\end{array}$ & $0.05(0.06)$ & 0.386 & -0.01 & 1,643 \\
\hline $\begin{array}{l}\text { Support for government reducing in- } \\
\text { come inequality }\end{array}$ & $0.09(0.06)$ & 0.100 & -0.01 & 1,643 \\
\hline $\begin{array}{l}\text { Support for government providing } \\
\text { health insurance }\end{array}$ & $0.02(0.06)$ & 0.742 & -0.01 & 1,643 \\
\hline $\begin{array}{l}\text { Support for government funding job } \\
\text { retraining }\end{array}$ & $-0.01(0.06)$ & 0.850 & $>-0.01$ & 1,643 \\
\hline $\begin{array}{l}\text { Support for more restrictive immi- } \\
\text { gration policy }\end{array}$ & $0.01(0.06)$ & 0.841 & 0.01 & 1,643 \\
\hline $\begin{array}{l}\text { Support for decreasing the number } \\
\text { of immigrants }\end{array}$ & $0.02(0.05)$ & 0.706 & -0.03 & 1,643 \\
\hline Support for limiting imports & $\begin{array}{l}<0.01 \\
(0.06)\end{array}$ & 0.969 & 0.02 & 1,643 \\
\hline $\begin{array}{l}\text { Support for government discourag- } \\
\text { ing outsourcing }\end{array}$ & $0.07(0.06)$ & 0.204 & -0.07 & 1,643 \\
\hline Support for guaranteed income & $-0.06(0.06)$ & 0.292 & 0.02 & 1,643 \\
\hline Support for limiting automation & $-0.02(0.06)$ & 0.791 & -0.01 & 1,643 \\
\hline
\end{tabular}


Table C.3: Study 1: Standardized treatment effect estimates - Individual Forecast

\begin{tabular}{|c|c|c|c|c|}
\hline Outcome & $\begin{array}{l}\text { Estimated } \\
\text { effect (SE) }\end{array}$ & $p$-value & $\begin{array}{l}\text { Control } \\
\text { mean }\end{array}$ & $N$ \\
\hline $\begin{array}{l}\text { Predicted likelihood of } 3 \text { randomly- } \\
\text { selected jobs becoming automated }\end{array}$ & $0.12(0.07)$ & 0.109 & -0.05 & 1,136 \\
\hline $\begin{array}{l}\text { Predicted likelihood of all U.S. jobs } \\
\text { becoming automated }\end{array}$ & $0.09(0.07)$ & 0.234 & -0.03 & 1,136 \\
\hline $\begin{array}{l}\text { Predicted likelihood of one's own } \\
\text { job becoming automated }\end{array}$ & $0.12(0.07)$ & 0.080 & -0.04 & 1,136 \\
\hline Job loss concern: cheaper labor & $0.14(0.07)$ & 0.059 & -0.07 & 1,136 \\
\hline $\begin{array}{l}\text { Job loss concern: workplace au- } \\
\text { tomation }\end{array}$ & $0.15(0.07)$ & 0.045 & -0.08 & 1,136 \\
\hline $\begin{array}{l}\text { Perceived realism of mostly auto- } \\
\text { mated future }\end{array}$ & $0.01(0.08)$ & 0.936 & 0.01 & 1,136 \\
\hline Prediction: inequality will get worse & $-0.01(0.07)$ & 0.867 & -0.01 & 1,136 \\
\hline $\begin{array}{l}\text { Prediction: new, better-paying jobs } \\
\text { will be created }\end{array}$ & $0.07(0.07)$ & 0.324 & -0.04 & 1,136 \\
\hline $\begin{array}{l}\text { Support for government guarantee- } \\
\text { ing jobs and good standard of living }\end{array}$ & $-0.02(0.07)$ & 0.757 & 0.02 & 1,136 \\
\hline $\begin{array}{l}\text { Support for government reducing in- } \\
\text { come inequality }\end{array}$ & $-0.05(0.07)$ & 0.447 & 0.01 & 1,136 \\
\hline $\begin{array}{l}\text { Support for government providing } \\
\text { health insurance }\end{array}$ & $0.02(0.07)$ & 0.794 & 0.01 & 1,136 \\
\hline $\begin{array}{l}\text { Support for government funding job } \\
\text { retraining }\end{array}$ & $0.04(0.07)$ & 0.537 & -0.05 & 1,136 \\
\hline $\begin{array}{l}\text { Support for more restrictive immi- } \\
\text { gration policy }\end{array}$ & $-0.03(0.07)$ & 0.646 & -0.01 & 1,136 \\
\hline $\begin{array}{l}\text { Support for decreasing the number } \\
\text { of immigrants }\end{array}$ & $0.05(0.07)$ & 0.482 & -0.01 & 1,136 \\
\hline Support for limiting imports & $-0.02(0.07)$ & 0.775 & $>-0.01$ & 1,136 \\
\hline $\begin{array}{l}\text { Support for government discourag- } \\
\text { ing outsourcing }\end{array}$ & $0.13(0.07)$ & 0.086 & -0.02 & 1,136 \\
\hline Support for guaranteed income & $0.02(0.07)$ & 0.758 & 0.01 & 1,136 \\
\hline Support for limiting automation & $0.06(0.07)$ & 0.422 & -0.06 & 1,136 \\
\hline
\end{tabular}


Table C.4: Study 1: Non-standardized treatment effect estimates - General Forecast

\begin{tabular}{|c|c|c|c|c|}
\hline Outcome & $\begin{array}{l}\text { Estimated } \\
\text { effect (SE) }\end{array}$ & $p$-value & $\begin{array}{l}\text { Control } \\
\text { mean }\end{array}$ & $N$ \\
\hline $\begin{array}{l}\text { Predicted likelihood of } 3 \text { randomly- } \\
\text { selected jobs becoming automated }\end{array}$ & $0.14(0.05)$ & 0.007 & 1.33 & 1,643 \\
\hline $\begin{array}{l}\text { Predicted likelihood of all U.S. jobs } \\
\text { becoming automated }\end{array}$ & $0.08(0.06)$ & 0.205 & 1.06 & 1,643 \\
\hline $\begin{array}{l}\text { Predicted likelihood of one's own } \\
\text { job becoming automated }\end{array}$ & $0.15(0.06)$ & 0.012 & 0.89 & 1,643 \\
\hline Job loss concern: cheaper labor & $0.11(0.06)$ & 0.069 & 1.35 & 1,643 \\
\hline $\begin{array}{l}\text { Job loss concern: workplace au- } \\
\text { tomation }\end{array}$ & $0.21(0.06)$ & $<0.001$ & 0.97 & 1,643 \\
\hline $\begin{array}{l}\text { Perceived realism of mostly auto- } \\
\text { mated future }\end{array}$ & $0.03(0.05)$ & 0.497 & 1.78 & 1,643 \\
\hline Prediction: inequality will get worse & $0.02(0.04)$ & 0.655 & 2.28 & 1,643 \\
\hline $\begin{array}{l}\text { Prediction: new, better-paying jobs } \\
\text { will be created }\end{array}$ & $0.12(0.05)$ & 0.015 & 1.26 & 1,643 \\
\hline $\begin{array}{l}\text { Support for government guarantee- } \\
\text { ing jobs and good standard of living }\end{array}$ & $0.07(0.09)$ & 0.386 & 4.16 & 1,643 \\
\hline $\begin{array}{l}\text { Support for government reducing in- } \\
\text { come inequality }\end{array}$ & $0.16(0.10)$ & 0.100 & 3.65 & 1,643 \\
\hline $\begin{array}{l}\text { Support for government providing } \\
\text { health insurance }\end{array}$ & $0.03(0.09)$ & 0.742 & 3.83 & 1,643 \\
\hline $\begin{array}{l}\text { Support for government funding job } \\
\text { retraining }\end{array}$ & $-0.01(0.06)$ & 0.850 & 1.19 & 1,643 \\
\hline $\begin{array}{l}\text { Support for more restrictive immi- } \\
\text { gration policy }\end{array}$ & $0.02(0.10)$ & 0.841 & 4.07 & 1,643 \\
\hline $\begin{array}{l}\text { Support for decreasing the number } \\
\text { of immigrants }\end{array}$ & $0.02(0.06)$ & 0.706 & -0.49 & 1,643 \\
\hline Support for limiting imports & $\begin{array}{l}<0.01 \\
(0.06)\end{array}$ & 0.969 & -0.05 & 1,643 \\
\hline $\begin{array}{l}\text { Support for government discourag- } \\
\text { ing outsourcing }\end{array}$ & $0.04(0.04)$ & 0.204 & -0.58 & 1,643 \\
\hline Support for guaranteed income & $-0.08(0.08)$ & 0.292 & 0.54 & 1,643 \\
\hline Support for limiting automation & $-0.02(0.06)$ & 0.791 & 1.19 & 1,643 \\
\hline
\end{tabular}


Table C.5: Study 1: Non-standardized treatment effect estimates - Individual Forecast

\begin{tabular}{|c|c|c|c|c|}
\hline Outcome & $\begin{array}{l}\text { Estimated } \\
\text { effect (SE) }\end{array}$ & $p$-value & $\begin{array}{l}\text { Control } \\
\text { mean }\end{array}$ & $N$ \\
\hline $\begin{array}{l}\text { Predicted likelihood of } 3 \text { randomly- } \\
\text { selected jobs becoming automated }\end{array}$ & $0.11(0.07)$ & 0.109 & 1.38 & 1,136 \\
\hline $\begin{array}{l}\text { Predicted likelihood of all U.S. jobs } \\
\text { becoming automated }\end{array}$ & $0.10(0.08)$ & 0.234 & 1.08 & 1,136 \\
\hline $\begin{array}{l}\text { Predicted likelihood of one's own } \\
\text { job becoming automated }\end{array}$ & $0.14(0.08)$ & 0.080 & 0.94 & 1,136 \\
\hline Job loss concern: cheaper labor & $0.14(0.07)$ & 0.059 & 1.37 & 1,136 \\
\hline $\begin{array}{l}\text { Job loss concern: workplace au- } \\
\text { tomation }\end{array}$ & $0.15(0.08)$ & 0.045 & 1.02 & 1,136 \\
\hline $\begin{array}{l}\text { Perceived realism of mostly auto- } \\
\text { mated future }\end{array}$ & $\begin{array}{l}<0.01 \\
(0.06)\end{array}$ & 0.936 & 1.81 & 1,136 \\
\hline Prediction: inequality will get worse & $-0.01(0.06)$ & 0.867 & 2.28 & 1,136 \\
\hline $\begin{array}{l}\text { Prediction: new, better-paying jobs } \\
\text { will be created }\end{array}$ & $0.06(0.06)$ & 0.324 & 1.29 & 1,136 \\
\hline $\begin{array}{l}\text { Support for government guarantee- } \\
\text { ing jobs and good standard of living }\end{array}$ & $-0.03(0.11)$ & 0.757 & 4.20 & 1,136 \\
\hline $\begin{array}{l}\text { Support for government reducing in- } \\
\text { come inequality }\end{array}$ & $-0.09(0.12)$ & 0.447 & 3.69 & 1,136 \\
\hline $\begin{array}{l}\text { Support for government providing } \\
\text { health insurance }\end{array}$ & $0.03(0.11)$ & 0.794 & 3.86 & 1,136 \\
\hline $\begin{array}{l}\text { Support for government funding job } \\
\text { retraining }\end{array}$ & $0.05(0.08)$ & 0.537 & 1.14 & 1,136 \\
\hline $\begin{array}{l}\text { Support for more restrictive immi- } \\
\text { gration policy }\end{array}$ & $-0.06(0.13)$ & 0.646 & 4.03 & 1,136 \\
\hline $\begin{array}{l}\text { Support for decreasing the number } \\
\text { of immigrants }\end{array}$ & $0.05(0.08)$ & 0.482 & -0.47 & 1,136 \\
\hline Support for limiting imports & $-0.02(0.07)$ & 0.775 & -0.07 & 1,136 \\
\hline $\begin{array}{l}\text { Support for government discourag- } \\
\text { ing outsourcing }\end{array}$ & $0.08(0.05)$ & 0.086 & -0.55 & 1,136 \\
\hline Support for guaranteed income & $0.03(0.10)$ & 0.758 & 0.53 & 1,136 \\
\hline Support for limiting automation & $0.06(0.08)$ & 0.422 & 1.13 & 1,136 \\
\hline
\end{tabular}


Table C.6: Study 1: Testing the difference in estimated effects between forecast sources (Frey and Osborne vs. OECD) - General Forecast

\begin{tabular}{|c|c|c|}
\hline Outcome & $F$-statistic & $p$-value \\
\hline $\begin{array}{l}\text { Predicted likelihood of } 3 \text { randomly-selected jobs be- } \\
\text { coming automated }\end{array}$ & $F(1,1637)=1.08$ & 0.300 \\
\hline $\begin{array}{l}\text { Predicted likelihood of all U.S. jobs becoming auto- } \\
\text { mated }\end{array}$ & $F(1,1637)=1.13$ & 0.288 \\
\hline $\begin{array}{l}\text { Predicted likelihood of one's own job becoming auto- } \\
\text { mated }\end{array}$ & $F(1,1637)=0.51$ & 0.476 \\
\hline Job loss concern: cheaper labor & $F(1,1637)=0.03$ & 0.871 \\
\hline Job loss concern: workplace automation & $F(1,1637)=<0.01$ & 0.949 \\
\hline Perceived realism of mostly automated future & $F(1,1637)=0.31$ & 0.580 \\
\hline Prediction: inequality will get worse & $F(1,1637)=0.12$ & 0.733 \\
\hline Prediction: new, better-paying jobs will be created & $F(1,1637)=1.79$ & 0.181 \\
\hline $\begin{array}{l}\text { Support for government guaranteeing jobs and good } \\
\text { standard of living }\end{array}$ & $F(1,1637)=6.79$ & 0.009 \\
\hline Support for government reducing income inequality & $F(1,1637)=2.69$ & 0.101 \\
\hline Support for government providing health insurance & $F(1,1637)=0.32$ & 0.574 \\
\hline Support for government funding job retraining & $F(1,1640)=0.13$ & 0.717 \\
\hline Support for more restrictive immigration policy & $F(1,1637)=0.91$ & 0.340 \\
\hline Support for decreasing the number of immigrants & $F(1,1637)=0.13$ & 0.716 \\
\hline Support for limiting imports & $F(1,1637)=0.13$ & 0.716 \\
\hline Support for government discouraging outsourcing & $F(1,1637)=1.39$ & 0.239 \\
\hline Support for guaranteed income & $F(1,1637)=0.10$ & 0.748 \\
\hline Support for limiting automation & $F(1,1637)=1.34$ & 0.247 \\
\hline
\end{tabular}


Table C.7: Study 1: Testing the difference in estimated effects between forecast sources (Frey and Osborne vs. OECD) - Individual Forecast

\begin{tabular}{|c|c|c|}
\hline Outcome & $F$-statistic & $p$-value \\
\hline $\begin{array}{l}\text { Predicted likelihood of } 3 \text { randomly-selected jobs be- } \\
\text { coming automated }\end{array}$ & $F(1,1133)=0.01$ & 0.921 \\
\hline $\begin{array}{l}\text { Predicted likelihood of all U.S. jobs becoming auto- } \\
\text { mated }\end{array}$ & $F(1,1133)=0.05$ & 0.825 \\
\hline $\begin{array}{l}\text { Predicted likelihood of one's own job becoming auto- } \\
\text { mated }\end{array}$ & $F(1,1133)=0.33$ & 0.564 \\
\hline Job loss concern: cheaper labor & $F(1,1133)=0.98$ & 0.323 \\
\hline Job loss concern: workplace automation & $F(1,1133)=3.62$ & 0.057 \\
\hline Perceived realism of mostly automated future & $F(1,1133)=0.17$ & 0.679 \\
\hline Prediction: inequality will get worse & $F(1,1130)=0.47$ & 0.495 \\
\hline Prediction: new, better-paying jobs will be created & $F(1,1130)=0.10$ & 0.757 \\
\hline $\begin{array}{l}\text { Support for government guaranteeing jobs and good } \\
\text { standard of living }\end{array}$ & $F(1,1130)=3.31$ & 0.069 \\
\hline Support for government reducing income inequality & $F(1,1130)=1.75$ & 0.186 \\
\hline Support for government providing health insurance & $F(1,1130)=0.86$ & 0.353 \\
\hline Support for government funding job retraining & $F(1,1133)=1.92$ & 0.166 \\
\hline Support for more restrictive immigration policy & $F(1,1130)=0.89$ & 0.346 \\
\hline Support for decreasing the number of immigrants & $F(1,1130)=0.43$ & 0.512 \\
\hline Support for limiting imports & $F(1,1130)=5.55$ & 0.019 \\
\hline Support for government discouraging outsourcing & $F(1,1130)=0.23$ & 0.634 \\
\hline Support for guaranteed income & $F(1,1130)=0.80$ & 0.370 \\
\hline Support for limiting automation & $F(1,1130)=0.29$ & 0.591 \\
\hline
\end{tabular}


Table C.8: Study 1: Testing the difference in estimated effects between the General Forecast Treatment and Individual Forecast Treatment using responses from subjects in Group B

\begin{tabular}{|c|c|c|}
\hline Outcome & $F$-statistic & $p$-value \\
\hline $\begin{array}{l}\text { Predicted likelihood of } 3 \text { randomly-selected jobs be- } \\
\text { coming automated }\end{array}$ & $F(1,1664)=1.48$ & 0.224 \\
\hline $\begin{array}{l}\text { Predicted likelihood of all U.S. jobs becoming auto- } \\
\text { mated }\end{array}$ & $F(1,1664)=1.16$ & 0.282 \\
\hline $\begin{array}{l}\text { Predicted likelihood of one's own job becoming auto- } \\
\text { mated }\end{array}$ & $F(1,1664)=1.03$ & 0.310 \\
\hline Job loss concern: cheaper labor & $F(1,1664)=0.23$ & 0.632 \\
\hline Job loss concern: workplace automation & $F(1,1664)=1.83$ & 0.177 \\
\hline Perceived realism of mostly automated future & $F(1,1664)=0.02$ & 0.890 \\
\hline Prediction: inequality will get worse & $F(1,1661)=0.49$ & 0.485 \\
\hline Prediction: new, better-paying jobs will be created & $F(1,1661)=1.26$ & 0.263 \\
\hline $\begin{array}{l}\text { Support for government guaranteeing jobs and good } \\
\text { standard of living }\end{array}$ & $F(1,1661)=2.51$ & 0.114 \\
\hline Support for government reducing income inequality & $F(1,1661)=7.96$ & 0.005 \\
\hline Support for government providing health insurance & $F(1,1661)=0.05$ & 0.829 \\
\hline Support for government funding job retraining & $F(1,1664)=0.13$ & 0.717 \\
\hline Support for more restrictive immigration policy & $F(1,1661)=1.30$ & 0.255 \\
\hline Support for decreasing the number of immigrants & $F(1,1661)=0.43$ & 0.514 \\
\hline Support for limiting imports & $F(1,1661)=0.86$ & 0.354 \\
\hline Support for government discouraging outsourcing & $F(1,1661)=0.17$ & 0.680 \\
\hline Support for guaranteed income & $F(1,1661)=0.66$ & 0.417 \\
\hline Support for limiting automation & $F(1,1661)=0.74$ & 0.391 \\
\hline
\end{tabular}


Table C.9: Study 1: Interaction effects - Individual Forecasts (Frey and Osborne)

\begin{tabular}{llcc}
\hline \hline Outcome & Interaction Effects (SE) & $p$-value & $\mathrm{N}$ \\
\hline $\begin{array}{l}\text { Predicted likelihood of } 3 \text { randomly- } \\
\text { selected jobs becoming automated }\end{array}$ & $-0.25(0.21)$ & 0.244 & 676 \\
$\begin{array}{l}\text { Predicted likelihood of all U.S. jobs } \\
\text { becoming automated }\end{array}$ & $-0.16(0.21)$ & 0.443 & 676 \\
$\begin{array}{l}\text { Predicted likelihood of one's own } \\
\text { job becoming automated }\end{array}$ & $0.68(0.20)$ & $<0.001$ & 676 \\
$\begin{array}{l}\text { Job loss concern: cheaper labor } \\
\text { Job loss concern: workplace au- }\end{array}$ & $-0.15(0.21)$ & 0.488 & 676 \\
$\begin{array}{l}\text { tomation } \\
\text { Perceived realism of mostly auto- }\end{array}$ & $0.09(0.22)$ & 0.485 & 676 \\
$\begin{array}{l}\text { mated future } \\
\text { Prediction: inequality will get worse }\end{array}$ & $-0.02(0.21)$ & 0.675 & 676 \\
$\begin{array}{l}\text { Prediction: new, better-paying jobs } \\
\text { will be created }\end{array}$ & $-0.02(0.21)$ & 0.941 & 676 \\
\hline $\begin{array}{l}\text { Support for government guarantee- } \\
\text { ing jobs and good standard of living }\end{array}$ & $0.20(0.21)$ & 0.906 & 676 \\
$\begin{array}{l}\text { Support for government reducing in- } \\
\text { come inequality }\end{array}$ & $0.03(0.21)$ & 0.335 & 676 \\
$\begin{array}{l}\text { Support for government providing } \\
\text { health insurance }\end{array}$ & $0.11(0.20)$ & 0.893 & 676 \\
$\begin{array}{l}\text { Support for government funding job } \\
\text { retraining }\end{array}$ & $-0.10(0.21)$ & 0.583 & 676 \\
$\begin{array}{l}\text { Support for more restrictive immi- } \\
\text { gration policy }\end{array}$ & $-0.29(0.21)$ & 0.549 & 676 \\
$\begin{array}{l}\text { Support for decreasing the number } \\
\text { of immigrants }\end{array}$ & $0.28(0.21)$ & 0.160 & 676 \\
$\begin{array}{l}\text { Support for limiting imports } \\
\begin{array}{l}\text { Support for government discourag- } \\
\text { ing outsourcing }\end{array}\end{array}$ & $-0.13(0.21)$ & 676 \\
$\begin{array}{l}\text { Support for guaranteed income } \\
\text { Support for limiting automation }\end{array}$ & $-0.17(0.20)$ & 676 \\
\hline
\end{tabular}


Table C.10: Study 1: Interaction effects - Individual Forecasts (OECD)

\begin{tabular}{|c|c|c|c|}
\hline Outcome & Interaction Effects (SE) & $p$-value & $\mathrm{N}$ \\
\hline $\begin{array}{l}\text { Predicted likelihood of } 3 \text { randomly- } \\
\text { selected jobs becoming automated }\end{array}$ & $-0.23(0.47)$ & 0.620 & 729 \\
\hline $\begin{array}{l}\text { Predicted likelihood of all U.S. jobs } \\
\text { becoming automated }\end{array}$ & $-0.21(0.51)$ & 0.686 & 729 \\
\hline $\begin{array}{l}\text { Predicted likelihood of one's own } \\
\text { job becoming automated }\end{array}$ & $0.50(0.51)$ & 0.325 & 729 \\
\hline Job loss concern: cheaper labor & $-0.82(0.45)$ & 0.070 & 729 \\
\hline $\begin{array}{l}\text { Job loss concern: workplace au- } \\
\text { tomation }\end{array}$ & $-0.37(0.48)$ & 0.440 & 729 \\
\hline $\begin{array}{l}\text { Perceived realism of mostly auto- } \\
\text { mated future }\end{array}$ & $0.29(0.52)$ & 0.581 & 729 \\
\hline Prediction: inequality will get worse & $0.25(0.49)$ & 0.608 & 729 \\
\hline $\begin{array}{l}\text { Prediction: new, better-paying jobs } \\
\text { will be created }\end{array}$ & $-0.63(0.49)$ & 0.201 & 729 \\
\hline $\begin{array}{l}\text { Support for government guarantee- } \\
\text { ing jobs and good standard of living }\end{array}$ & $1.18(0.53)$ & 0.026 & 729 \\
\hline $\begin{array}{l}\text { Support for government reducing in- } \\
\text { come inequality }\end{array}$ & $0.07(0.50)$ & 0.882 & 729 \\
\hline $\begin{array}{l}\text { Support for government providing } \\
\text { health insurance }\end{array}$ & $0.45(0.50)$ & 0.371 & 729 \\
\hline $\begin{array}{l}\text { Support for government funding job } \\
\text { retraining }\end{array}$ & $-0.05(0.47)$ & 0.908 & 729 \\
\hline $\begin{array}{l}\text { Support for more restrictive immi- } \\
\text { gration policy }\end{array}$ & $-0.76(0.48)$ & 0.112 & 729 \\
\hline $\begin{array}{l}\text { Support for decreasing the number } \\
\text { of immigrants }\end{array}$ & $0.52(0.49)$ & 0.281 & 729 \\
\hline Support for limiting imports & $-0.62(0.51)$ & 0.225 & 729 \\
\hline $\begin{array}{l}\text { Support for government discourag- } \\
\text { ing outsourcing }\end{array}$ & $-0.65(0.46)$ & 0.159 & 729 \\
\hline Support for guaranteed income & $-0.07(0.50)$ & 0.887 & 729 \\
\hline Support for limiting automation & $0.23(0.43)$ & 0.597 & 729 \\
\hline
\end{tabular}


Table C.11: Manipulation check: responses by experimental group

\begin{tabular}{|c|c|c|c|}
\hline Experimental group & $\begin{array}{l}\text { Perceived like- } \\
\text { lihood of one's } \\
\text { own job becoming } \\
\text { automated }\end{array}$ & $\begin{array}{l}\text { Perceived likeli- } \\
\text { hood of all U.S. } \\
\text { jobs becoming } \\
\text { automated }\end{array}$ & \begin{tabular}{lr} 
Perceived like- & \multicolumn{1}{r}{ lihood of } \\
lihoodomly- \\
randoled \\
selected & jobs \\
becoming & auto- \\
mated & \\
\end{tabular} \\
\hline Control & 0.86 & 1.06 & 1.31 \\
\hline $\begin{array}{l}\text { General forecast: Frey } \\
\text { and Osborne }\end{array}$ & 0.98 & 1.07 & 1.42 \\
\hline $\begin{array}{l}\text { General forecast: } \\
\text { OECD }\end{array}$ & 0.99 & 1.1 & 1.46 \\
\hline $\begin{array}{l}\text { Individual forecast: } \\
\text { Frey and Osborne }\end{array}$ & 1.11 & 1.19 & 1.5 \\
\hline $\begin{array}{l}\text { Individual forecast: } \\
\text { OECD }\end{array}$ & 1.05 & 1.16 & 1.48 \\
\hline
\end{tabular}

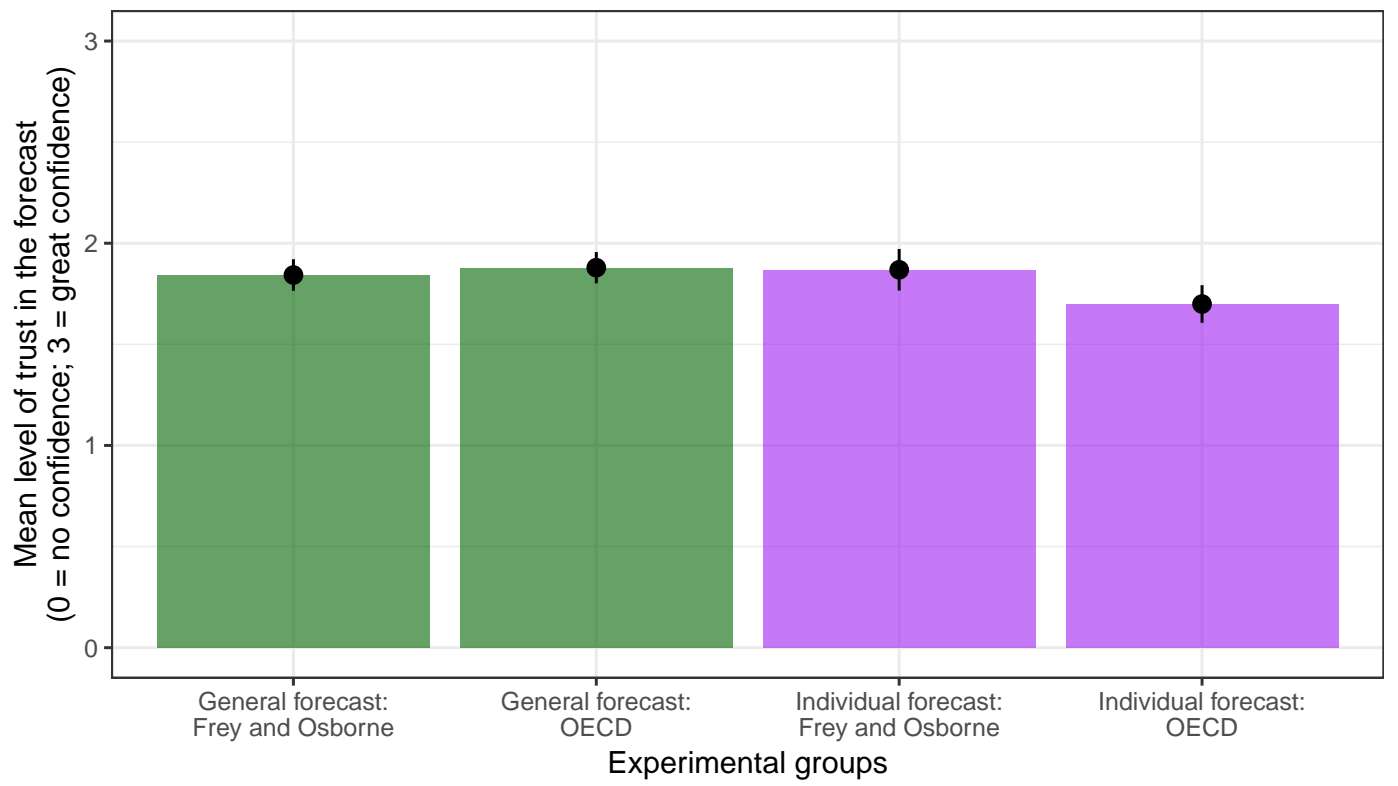

Figure C.3: Respondents' trust of the expert forecasts by treatment group; the error bars are the $95 \%$ confidence intervals 


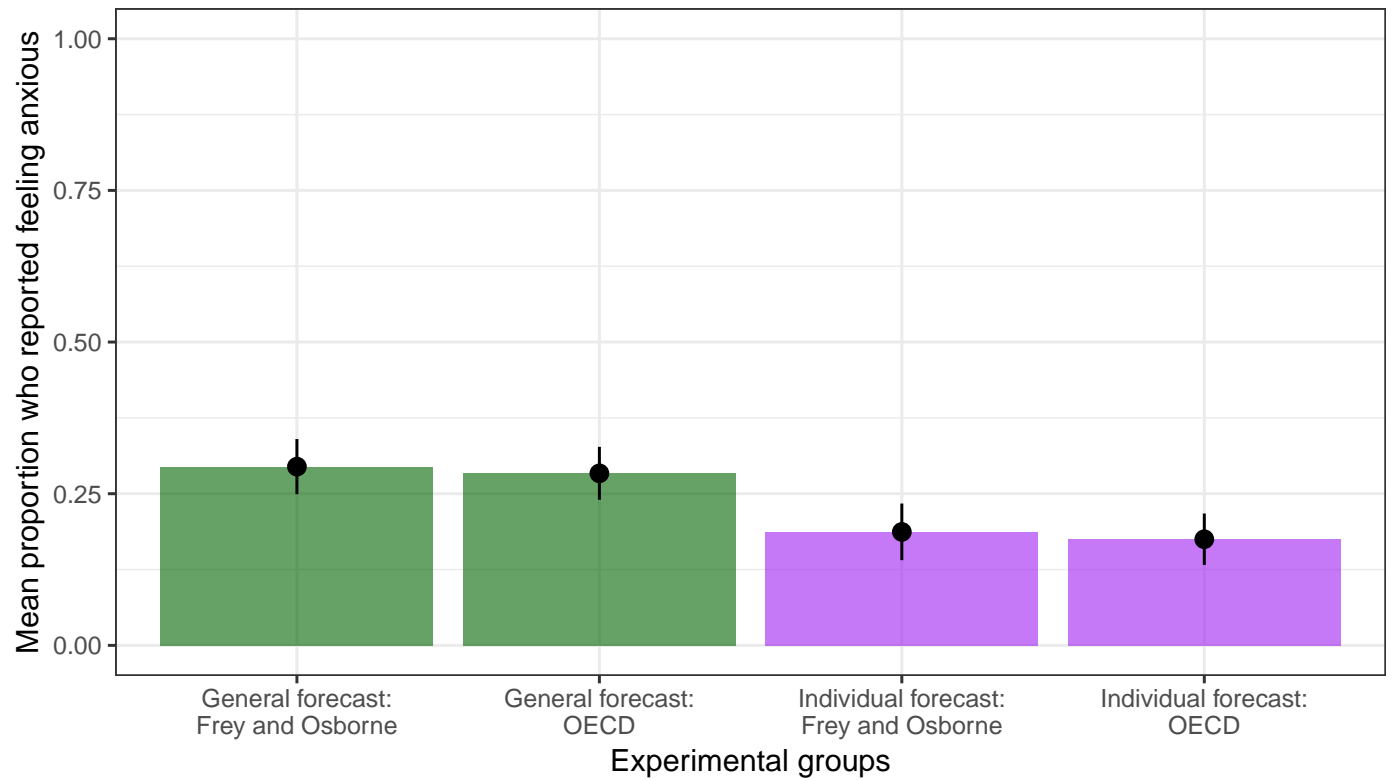

Figure C.4: Respondents' self-reported feelings of anxiety by treatment group; the error bars are the $95 \%$ confidence intervals

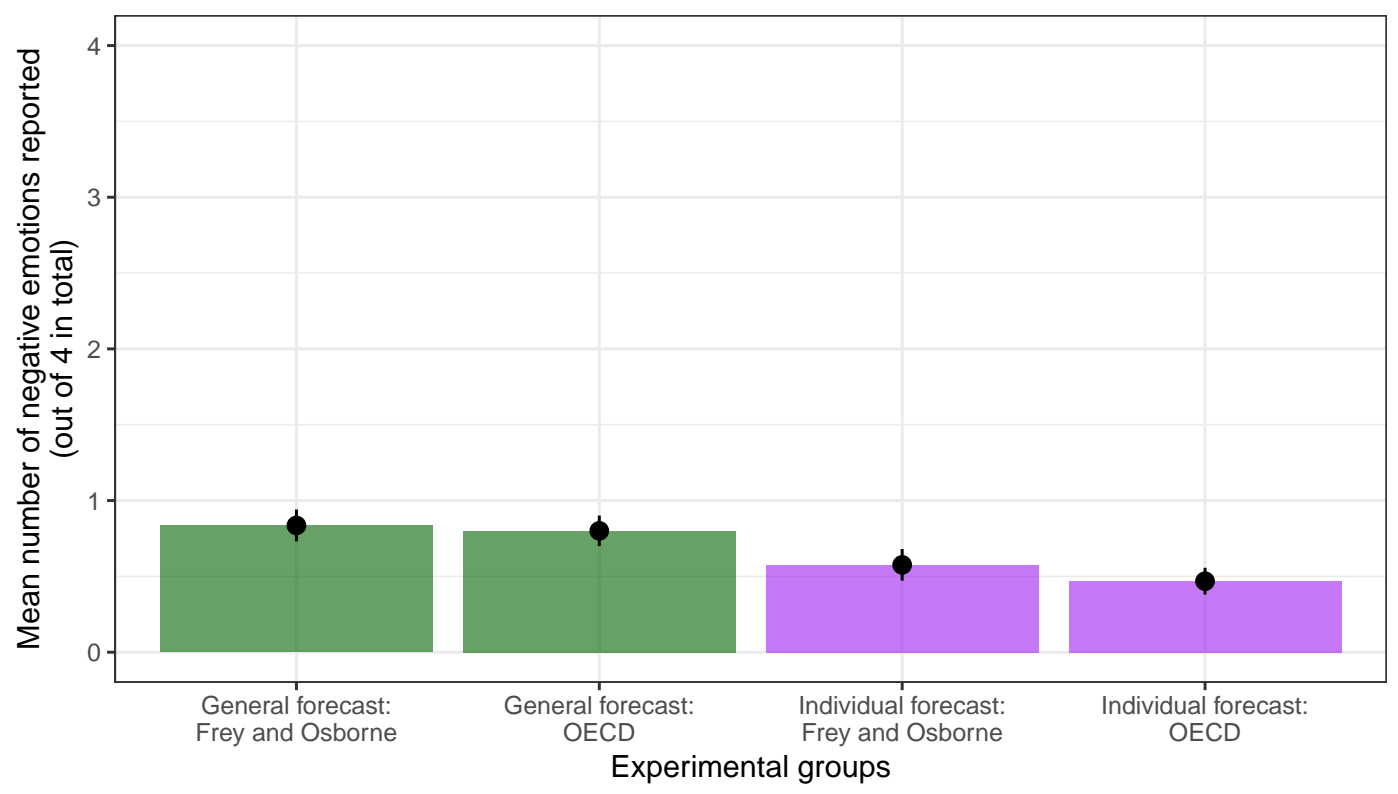

Figure C.5: Respondents' self-reported feelings of negative emotions by treatment group; the error bars are the $95 \%$ confidence intervals 


\section{C.4.2 Study 2}

Table C.12: Study 2: Standardized treatment effect estimates

\begin{tabular}{|c|c|c|c|c|}
\hline Outcome & $\begin{array}{l}\text { Estimated } \\
\text { effect (SE) }\end{array}$ & $p$-value & $\begin{array}{l}\text { Control } \\
\text { mean }\end{array}$ & $N$ \\
\hline $\begin{array}{l}\text { Predicted percent of jobs that will be au- } \\
\text { tomated }\end{array}$ & $0.20(0.08)$ & 0.010 & -0.09 & 636 \\
\hline $\begin{array}{l}\text { Predicted likelihood of } 3 \text { randomly- } \\
\text { selected jobs becoming automated }\end{array}$ & $0.24(0.08)$ & 0.003 & -0.11 & 636 \\
\hline $\begin{array}{l}\text { Predicted likelihood of all U.S. jobs be- } \\
\text { coming automated }\end{array}$ & $0.07(0.08)$ & 0.372 & -0.03 & 636 \\
\hline $\begin{array}{l}\text { Predicted likelihood of one's own job be- } \\
\text { coming automated }\end{array}$ & $0.18(0.09)$ & 0.040 & -0.08 & 576 \\
\hline Concern about losing job & $0.19(0.10)$ & 0.046 & -0.08 & 536 \\
\hline $\begin{array}{l}\text { Job loss concern: cheaper labor outside } \\
\text { U.S. }\end{array}$ & $0.06(0.10)$ & 0.546 & -0.03 & 536 \\
\hline Job loss concern: workplace automation & $0.18(0.09)$ & 0.059 & -0.08 & 536 \\
\hline $\begin{array}{l}\text { Job loss concern: cheaper labor by immi- } \\
\text { grant to the U.S. }\end{array}$ & $0.05(0.10)$ & 0.582 & -0.02 & 536 \\
\hline $\begin{array}{l}\text { Perceived realism of mostly automated fu- } \\
\text { ture }\end{array}$ & $0.06(0.08)$ & 0.452 & -0.03 & 636 \\
\hline Prediction: inequality will get worse & $0.11(0.08)$ & 0.184 & -0.05 & 636 \\
\hline $\begin{array}{l}\text { Prediction: new, better-paying jobs will } \\
\text { be created }\end{array}$ & $0.13(0.08)$ & 0.111 & -0.06 & 636 \\
\hline $\begin{array}{l}\text { Support for government guaranteeing jobs } \\
\text { and good standard of living }\end{array}$ & $-0.02(0.08)$ & 0.788 & 0.01 & 636 \\
\hline $\begin{array}{l}\text { Support for government reducing income } \\
\text { inequality }\end{array}$ & $0.03(0.08)$ & 0.676 & -0.02 & 636 \\
\hline $\begin{array}{l}\text { Support for government providing health } \\
\text { insurance }\end{array}$ & $-0.02(0.08)$ & 0.829 & 0.01 & 636 \\
\hline $\begin{array}{l}\text { Support for government funding job re- } \\
\text { training }\end{array}$ & $0.04(0.08)$ & 0.639 & -0.02 & 636 \\
\hline $\begin{array}{l}\text { Support for more restrictive immigration } \\
\text { policy }\end{array}$ & $0.01(0.08)$ & 0.907 & $>-0.01$ & 636 \\
\hline $\begin{array}{l}\text { Support for decreasing the number of im- } \\
\text { migrants }\end{array}$ & $0.08(0.08)$ & 0.339 & -0.03 & 636 \\
\hline Support for limiting imports & $-0.08(0.08)$ & 0.297 & 0.04 & 636 \\
\hline $\begin{array}{l}\text { Support for government discouraging out- } \\
\text { sourcing }\end{array}$ & $0.05(0.08)$ & 0.566 & -0.02 & 636 \\
\hline Support for guaranteed income & $0.01(0.08)$ & 0.902 & $>-0.01$ & 636 \\
\hline Support for limiting automation & $-0.05(0.08)$ & 0.553 & 0.02 & 636 \\
\hline Approval of Donald Trump & $-0.04(0.08)$ & 0.659 & 0.02 & 636 \\
\hline
\end{tabular}


Table C.13: Study 2: Non-standardized treatment effect estimates

\begin{tabular}{|c|c|c|c|c|}
\hline Outcome & $\begin{array}{l}\text { Estimated } \\
\text { effect (SE) }\end{array}$ & $p$-value & $\begin{array}{l}\text { Control } \\
\text { mean }\end{array}$ & $N$ \\
\hline $\begin{array}{l}\text { Predicted percent of jobs that will be au- } \\
\text { tomated }\end{array}$ & $4.59(1.78)$ & 0.010 & 36.81 & 636 \\
\hline $\begin{array}{l}\text { Predicted likelihood of } 3 \text { randomly- } \\
\text { selected jobs becoming automated }\end{array}$ & $0.26(0.08)$ & 0.003 & 1.68 & 636 \\
\hline $\begin{array}{l}\text { Predicted likelihood of all U.S. jobs be- } \\
\text { coming automated }\end{array}$ & $0.09(0.10)$ & 0.372 & 1.16 & 636 \\
\hline $\begin{array}{l}\text { Predicted likelihood of one's own job be- } \\
\text { coming automated }\end{array}$ & $0.21(0.10)$ & 0.040 & 1.28 & 576 \\
\hline Concern about losing job & $0.22(0.11)$ & 0.046 & 1.12 & 536 \\
\hline $\begin{array}{l}\text { Job loss concern: cheaper labor outside } \\
\text { U.S. }\end{array}$ & $0.06(0.10)$ & 0.546 & 1.39 & 536 \\
\hline Job loss concern: workplace automation & $0.19(0.10)$ & 0.059 & 1.39 & 536 \\
\hline $\begin{array}{l}\text { Job loss concern: cheaper labor by immi- } \\
\text { grant to the U.S. }\end{array}$ & $0.05(0.10)$ & 0.582 & 1.25 & 536 \\
\hline $\begin{array}{l}\text { Perceived realism of mostly automated fu- } \\
\text { ture }\end{array}$ & $0.04(0.06)$ & 0.452 & 2.11 & 636 \\
\hline Prediction: inequality will get worse & $0.08(0.06)$ & 0.184 & 2.33 & 636 \\
\hline $\begin{array}{l}\text { Prediction: new, better-paying jobs will } \\
\text { be created }\end{array}$ & $0.12(0.07)$ & 0.111 & 1.41 & 636 \\
\hline $\begin{array}{l}\text { Support for government guaranteeing jobs } \\
\text { and good standard of living }\end{array}$ & $-0.04(0.15)$ & 0.788 & 4.07 & 636 \\
\hline $\begin{array}{l}\text { Support for government reducing income } \\
\text { inequality }\end{array}$ & $0.07(0.16)$ & 0.676 & 3.47 & 636 \\
\hline $\begin{array}{l}\text { Support for government providing health } \\
\text { insurance }\end{array}$ & $-0.03(0.15)$ & 0.829 & 3.78 & 636 \\
\hline $\begin{array}{l}\text { Support for government funding job re- } \\
\text { training }\end{array}$ & $0.04(0.10)$ & 0.639 & 1.39 & 636 \\
\hline $\begin{array}{l}\text { Support for more restrictive immigration } \\
\text { policy }\end{array}$ & $0.02(0.15)$ & 0.907 & 3.62 & 636 \\
\hline $\begin{array}{l}\text { Support for decreasing the number of im- } \\
\text { migrants }\end{array}$ & $0.09(0.10)$ & 0.339 & -0.03 & 636 \\
\hline Support for limiting imports & $-0.10(0.09)$ & 0.297 & 0.01 & 636 \\
\hline $\begin{array}{l}\text { Support for government discouraging out- } \\
\text { sourcing }\end{array}$ & $0.03(0.06)$ & 0.566 & -0.39 & 636 \\
\hline Support for guaranteed income & $0.01(0.10)$ & 0.902 & 0.99 & 636 \\
\hline Support for limiting automation & $-0.06(0.10)$ & 0.553 & 0.82 & 636 \\
\hline Approval of Donald Trump & $-0.06(0.13)$ & 0.659 & -0.27 & 636 \\
\hline
\end{tabular}




\section{C.4.3 Study 3}

Table C.14: Study 3: Standardized treatment effect estimates

\begin{tabular}{|c|c|c|c|c|}
\hline Outcome & $\begin{array}{l}\text { Estimated } \\
\text { effect (SE) }\end{array}$ & $p$-value & $\begin{array}{l}\text { Control } \\
\text { mean }\end{array}$ & $N$ \\
\hline $\begin{array}{l}\text { Predicted percent of jobs that will be au- } \\
\text { tomated }\end{array}$ & $0.07(0.05)$ & 0.134 & -0.04 & 1,765 \\
\hline Support for guaranteed income & $0.01(0.05)$ & 0.909 & $>-0.01$ & 1,765 \\
\hline Support for limiting automation & $0.06(0.05)$ & 0.222 & -0.03 & 1,765 \\
\hline $\begin{array}{l}\text { Support for funding job retraining pro- } \\
\text { grams }\end{array}$ & $0.08(0.05)$ & 0.112 & -0.04 & 1,765 \\
\hline
\end{tabular}

Table C.15: Study 3: Non-standardized treatment effect estimates

\begin{tabular}{lcccc}
\hline \hline Outcome & $\begin{array}{l}\text { Estimated } \\
\text { effect (SE) }\end{array}$ & $p$-value & $\begin{array}{l}\text { Control } \\
\text { mean }\end{array}$ & $N$ \\
\hline $\begin{array}{l}\text { Predicted percent of jobs that will be au- } \\
\text { tomated }\end{array}$ & $1.28(0.86)$ & 0.134 & 48.80 & 1,765 \\
$\begin{array}{l}\text { Support for guaranteed income } \\
\text { Support for limiting automation }\end{array}$ & $0.01(0.07)$ & 0.909 & 0.54 & 1,765 \\
$\begin{array}{l}\text { Support for funding job retraining pro- } \\
\text { grams }\end{array}$ & $0.09(0.06)$ & 0.222 & 0.59 & 1,765 \\
\hline
\end{tabular}


Table C.16: Study 3: Non-standardized treatment effect estimates by demographic subgroups - gender

\begin{tabular}{llllll}
\hline \hline Outcome & Subgroup & $\begin{array}{l}\text { Estimated } \\
\text { effect (SE) }\end{array}$ & p-value & $\begin{array}{l}\text { Control } \\
\text { mean }\end{array}$ & $N$ \\
\hline $\begin{array}{l}\text { Predicted percent } \\
\text { of jobs that will be } \\
\text { automated }\end{array}$ & Females & $0.69(1.15)$ & 0.549 & 50.35 & 941 \\
$\begin{array}{l}\text { Support for guaranteed } \\
\text { income }\end{array}$ & Females & $\begin{array}{l}<0.01 \\
(0.09)\end{array}$ & 0.968 & 0.61 & 941 \\
$\begin{array}{l}\text { Support for limiting au- } \\
\text { tomation }\end{array}$ & Females & $0.09(0.08)$ & 0.275 & 0.79 & 941 \\
$\begin{array}{l}\text { Support for funding job } \\
\text { retraining programs }\end{array}$ & Females & $0.09(0.07)$ & 0.202 & 1.07 & 941 \\
$\begin{array}{l}\text { Predicted percent } \\
\text { of jobs that will be } \\
\text { automated }\end{array}$ & Males & $1.97(1.27)$ & 0.122 & 47.08 & 824 \\
$\begin{array}{l}\text { Support for guaranteed } \\
\text { income }\end{array}$ & Males & $0.01(0.10)$ & 0.900 & 0.47 & 824 \\
$\begin{array}{l}\text { Support for limiting au- } \\
\text { tomation }\end{array}$ & Males & $0.07(0.10)$ & 0.447 & 0.37 & 824 \\
$\begin{array}{l}\text { Support for funding job } \\
\text { retraining programs }\end{array}$ & Males & $0.08(0.08)$ & 0.309 & 0.90 & 824 \\
\hline
\end{tabular}


Table C.17: Study 3: Non-standardized treatment effect estimates by demographic subgroups - race

\begin{tabular}{|c|c|c|c|c|c|}
\hline Outcome & Subgroup & $\begin{array}{l}\text { Estimated } \\
\text { effect (SE) }\end{array}$ & $p$-value & $\begin{array}{l}\text { Control } \\
\text { mean }\end{array}$ & $N$ \\
\hline $\begin{array}{l}\text { Predicted percent } \\
\text { of jobs that will be } \\
\text { automated }\end{array}$ & $\begin{array}{l}\text { Race: white } \\
\text { only }\end{array}$ & $2.63(1.00)$ & 0.009 & 46.03 & 1,198 \\
\hline $\begin{array}{l}\text { Support for guaranteed } \\
\text { income }\end{array}$ & $\begin{array}{l}\text { Race: white } \\
\text { only }\end{array}$ & $-0.06(0.08)$ & 0.494 & 0.48 & 1,198 \\
\hline $\begin{array}{l}\text { Support for limiting au- } \\
\text { tomation }\end{array}$ & $\begin{array}{l}\text { Race: white } \\
\text { only }\end{array}$ & $0.02(0.07)$ & 0.785 & 0.65 & 1,198 \\
\hline $\begin{array}{l}\text { Support for funding job } \\
\text { retraining programs }\end{array}$ & $\begin{array}{l}\text { Race: white } \\
\text { only }\end{array}$ & $0.03(0.06)$ & 0.662 & 1.10 & 1,198 \\
\hline $\begin{array}{l}\text { Predicted percent } \\
\text { of jobs that will be } \\
\text { automated }\end{array}$ & $\begin{array}{l}\text { Race: not } \\
\text { white only }\end{array}$ & $-1.92(1.56)$ & 0.220 & 55.14 & 567 \\
\hline $\begin{array}{l}\text { Support for guaranteed } \\
\text { income }\end{array}$ & $\begin{array}{l}\text { Race: not } \\
\text { white only }\end{array}$ & $0.12(0.11)$ & 0.265 & 0.69 & 567 \\
\hline $\begin{array}{l}\text { Support for limiting au- } \\
\text { tomation }\end{array}$ & $\begin{array}{l}\text { Race: not } \\
\text { white only }\end{array}$ & $0.20(0.11)$ & 0.077 & 0.48 & 567 \\
\hline $\begin{array}{l}\text { Support for funding job } \\
\text { retraining programs }\end{array}$ & $\begin{array}{l}\text { Race: not } \\
\text { white only }\end{array}$ & $0.23(0.10)$ & 0.028 & 0.74 & 567 \\
\hline
\end{tabular}


Table C.18: Study 3: Non-standardized treatment effect estimates by demographic subgroups - age group

\begin{tabular}{|c|c|c|c|c|c|}
\hline Outcome & Subgroup & $\begin{array}{l}\text { Estimated } \\
\text { effect (SE) }\end{array}$ & $p$-value & $\begin{array}{l}\text { Control } \\
\text { mean }\end{array}$ & $N$ \\
\hline $\begin{array}{l}\text { Predicted } \\
\text { of jobs that will be } \\
\text { automated }\end{array}$ & Age: $18-38$ & $-0.71(1.40)$ & 0.614 & 51.67 & 714 \\
\hline $\begin{array}{l}\text { Support for guaranteed } \\
\text { income }\end{array}$ & Age: $18-38$ & $0.06(0.10)$ & 0.558 & 0.73 & 714 \\
\hline $\begin{array}{l}\text { Support for limiting au- } \\
\text { tomation }\end{array}$ & Age: $18-38$ & $0.16(0.10)$ & 0.097 & 0.50 & 714 \\
\hline $\begin{array}{l}\text { Support for funding job } \\
\text { retraining programs }\end{array}$ & Age: $18-38$ & $0.10(0.09)$ & 0.261 & 0.80 & 714 \\
\hline $\begin{array}{l}\text { Predicted percent } \\
\text { of jobs that will be } \\
\text { automated }\end{array}$ & Age: $39-54$ & $0.38(1.65)$ & 0.820 & 50.68 & 471 \\
\hline $\begin{array}{l}\text { Support for guaranteed } \\
\text { income }\end{array}$ & Age: $39-54$ & $-0.06(0.13)$ & 0.651 & 0.66 & 471 \\
\hline $\begin{array}{l}\text { Support for limiting au- } \\
\text { tomation }\end{array}$ & Age: 39-54 & $\begin{array}{l}<0.01 \\
(0.12)\end{array}$ & 0.982 & 0.70 & 471 \\
\hline $\begin{array}{l}\text { Support for funding job } \\
\text { retraining programs }\end{array}$ & Age: $39-54$ & $0.10(0.11)$ & 0.370 & 1.02 & 471 \\
\hline $\begin{array}{l}\text { Predicted percent } \\
\text { of jobs that will be } \\
\text { automated }\end{array}$ & $\begin{array}{l}\text { Age: } 55 \text { and } \\
\text { older }\end{array}$ & $4.28(1.39)$ & 0.002 & 43.94 & 580 \\
\hline $\begin{array}{l}\text { Support for guaranteed } \\
\text { income }\end{array}$ & $\begin{array}{l}\text { Age: } 55 \text { and } \\
\text { older }\end{array}$ & $-0.02(0.12)$ & 0.875 & 0.22 & 580 \\
\hline $\begin{array}{l}\text { Support for limiting au- } \\
\text { tomation }\end{array}$ & $\begin{array}{l}\text { Age: } 55 \text { and } \\
\text { older }\end{array}$ & $0.03(0.11)$ & 0.814 & 0.62 & 580 \\
\hline $\begin{array}{l}\text { Support for funding job } \\
\text { retraining programs }\end{array}$ & $\begin{array}{l}\text { Age: } 55 \text { and } \\
\text { older }\end{array}$ & $0.06(0.09)$ & 0.455 & 1.19 & 580 \\
\hline
\end{tabular}


Table C.19: Study 3: Non-standardized treatment effect estimates by demographic subgroups - political party

\begin{tabular}{|c|c|c|c|c|c|}
\hline Outcome & Subgroup & $\begin{array}{l}\text { Estimated } \\
\text { effect (SE) }\end{array}$ & $p$-value & $\begin{array}{l}\text { Control } \\
\text { mean }\end{array}$ & $N$ \\
\hline $\begin{array}{l}\text { Predicted percent } \\
\text { of jobs that will be } \\
\text { automated }\end{array}$ & Democrats & $0.07(1.24)$ & 0.956 & 51.08 & 825 \\
\hline $\begin{array}{l}\text { Support for guaranteed } \\
\text { income }\end{array}$ & Democrats & $0.03(0.09)$ & 0.732 & 0.89 & 825 \\
\hline $\begin{array}{l}\text { Support for limiting au- } \\
\text { tomation }\end{array}$ & Democrats & $0.10(0.09)$ & 0.256 & 0.55 & 825 \\
\hline $\begin{array}{l}\text { Support for funding job } \\
\text { retraining programs }\end{array}$ & Democrats & $0.03(0.08)$ & 0.741 & 1.17 & 825 \\
\hline $\begin{array}{l}\text { Predicted percent } \\
\text { of jobs that will be } \\
\text { automated }\end{array}$ & Republicans & $3.29(1.50)$ & 0.029 & 45.26 & 627 \\
\hline $\begin{array}{l}\text { Support for guaranteed } \\
\text { income }\end{array}$ & Republicans & $-0.07(0.12)$ & 0.583 & 0.04 & 627 \\
\hline $\begin{array}{l}\text { Support for limiting au- } \\
\text { tomation }\end{array}$ & Republicans & $-0.01(0.10)$ & 0.909 & 0.65 & 627 \\
\hline $\begin{array}{l}\text { Support for funding job } \\
\text { retraining programs }\end{array}$ & Republicans & $0.09(0.10)$ & 0.379 & 0.82 & 627 \\
\hline $\begin{array}{l}\text { Predicted } \\
\text { of jobs that will be } \\
\text { automated }\end{array}$ & Independents & $0.37(1.85)$ & 0.842 & 50.06 & 313 \\
\hline $\begin{array}{l}\text { Support for guaranteed } \\
\text { income }\end{array}$ & Independents & $0.09(0.14)$ & 0.554 & 0.62 & 313 \\
\hline $\begin{array}{l}\text { Support for limiting au- } \\
\text { tomation }\end{array}$ & Independents & $0.18(0.14)$ & 0.187 & 0.60 & 313 \\
\hline $\begin{array}{l}\text { Support for funding job } \\
\text { retraining programs }\end{array}$ & Independents & $0.22(0.13)$ & 0.083 & 0.84 & 313 \\
\hline
\end{tabular}


Table C.20: Study 3: Non-standardized treatment effect estimates by demographic subgroups - level of education

\begin{tabular}{|c|c|c|c|c|c|}
\hline Outcome & Subgroup & $\begin{array}{l}\text { Estimated } \\
\text { effect (SE) }\end{array}$ & $p$-value & $\begin{array}{l}\text { Control } \\
\text { mean }\end{array}$ & $N$ \\
\hline $\begin{array}{l}\text { Predicted } \\
\text { of jobs that will be } \\
\text { automated }\end{array}$ & $\begin{array}{l}\text { College- } \\
\text { educated }\end{array}$ & $1.74(1.39)$ & 0.213 & 48.96 & 648 \\
\hline $\begin{array}{l}\text { Support for guaranteed } \\
\text { income }\end{array}$ & $\begin{array}{l}\text { College- } \\
\text { educated }\end{array}$ & $0.02(0.12)$ & 0.885 & 0.44 & 648 \\
\hline $\begin{array}{l}\text { Support for limiting au- } \\
\text { tomation }\end{array}$ & $\begin{array}{l}\text { College- } \\
\text { educated }\end{array}$ & $0.05(0.11)$ & 0.638 & 0.55 & 648 \\
\hline $\begin{array}{l}\text { Support for funding job } \\
\text { retraining programs }\end{array}$ & $\begin{array}{l}\text { College- } \\
\text { educated }\end{array}$ & $0.12(0.09)$ & 0.200 & 0.91 & 648 \\
\hline $\begin{array}{l}\text { Predicted percent } \\
\text { of jobs that will be } \\
\text { automated }\end{array}$ & $\begin{array}{l}\text { Not college- } \\
\text { educated }\end{array}$ & $0.99(1.09)$ & 0.363 & 48.70 & 1,117 \\
\hline $\begin{array}{l}\text { Support for guaranteed } \\
\text { income }\end{array}$ & $\begin{array}{l}\text { Not college- } \\
\text { educated }\end{array}$ & $0.01(0.08)$ & 0.910 & 0.60 & 1,117 \\
\hline $\begin{array}{l}\text { Support for limiting au- } \\
\text { tomation }\end{array}$ & $\begin{array}{l}\text { Not college- } \\
\text { educated }\end{array}$ & $0.09(0.08)$ & 0.215 & 0.62 & 1,117 \\
\hline $\begin{array}{l}\text { Support for funding job } \\
\text { retraining programs }\end{array}$ & $\begin{array}{l}\text { Not college- } \\
\text { educated }\end{array}$ & $0.07(0.07)$ & 0.284 & 1.03 & 1,117 \\
\hline
\end{tabular}


Table C.21: Study 3: Non-standardized treatment effect estimates by demographic subgroups - employment status

\begin{tabular}{|c|c|c|c|c|c|}
\hline Outcome & Subgroup & $\begin{array}{l}\text { Estimated } \\
\text { effect (SE) }\end{array}$ & $p$-value & $\begin{array}{l}\text { Control } \\
\text { mean }\end{array}$ & $N$ \\
\hline $\begin{array}{l}\text { Predicted } \\
\text { of jobs that will be } \\
\text { automated }\end{array}$ & $\begin{array}{l}\text { In the labor } \\
\text { force }\end{array}$ & $-0.17(1.16)$ & 0.881 & 50.48 & 1,048 \\
\hline $\begin{array}{l}\text { Support for guaranteed } \\
\text { income }\end{array}$ & $\begin{array}{l}\text { In the labor } \\
\text { force }\end{array}$ & $0.08(0.09)$ & 0.365 & 0.50 & 1,048 \\
\hline $\begin{array}{l}\text { Support for limiting au- } \\
\text { tomation }\end{array}$ & $\begin{array}{l}\text { In the labor } \\
\text { force }\end{array}$ & $0.09(0.08)$ & 0.277 & 0.51 & 1,048 \\
\hline $\begin{array}{l}\text { Support for funding job } \\
\text { retraining programs }\end{array}$ & $\begin{array}{l}\text { In the labor } \\
\text { force }\end{array}$ & $0.08(0.07)$ & 0.272 & 0.85 & 1,048 \\
\hline $\begin{array}{l}\text { Predicted } \\
\text { of jobs that will be } \\
\text { automated }\end{array}$ & $\begin{array}{l}\text { Not in the } \\
\text { labor force }\end{array}$ & $3.47(1.24)$ & 0.005 & 46.22 & 717 \\
\hline $\begin{array}{l}\text { Support for guaranteed } \\
\text { income }\end{array}$ & $\begin{array}{l}\text { Not in the } \\
\text { labor force }\end{array}$ & $-0.10(0.10)$ & 0.350 & 0.60 & 717 \\
\hline $\begin{array}{l}\text { Support for limiting au- } \\
\text { tomation }\end{array}$ & $\begin{array}{l}\text { Not in the } \\
\text { labor force }\end{array}$ & $0.06(0.10)$ & 0.563 & 0.72 & 717 \\
\hline $\begin{array}{l}\text { Support for funding job } \\
\text { retraining programs }\end{array}$ & $\begin{array}{l}\text { Not in the } \\
\text { labor force }\end{array}$ & $0.09(0.08)$ & 0.247 & 1.19 & 717 \\
\hline
\end{tabular}




\section{Bibliography}

Abrajano, Marisa and Zoltan L Hajnal. 2017. White Backlash: Immigration, Race, and American Politics. Princeton, NJ: Princeton University Press.

Abramowitz, Alan and Jennifer McCoy. 2019. "United States: Racial Resentment, Negative Partisanship, and Polarization in Trump's America." The ANNALS of the American Academy of Political and Social Science 681(1):137-156.

Acemoglu, Daron and David Autor. 2011. Skills, Tasks and Technologies: Implications for Employment and Earnings. In Handbook of Labor Economics. Vol. 4 Elsevier pp. 10431171.

Acemoglu, Daron and Pascual Restrepo. 2017. Robots and Jobs: Evidence from US Labor Markets. Technical report National Bureau of Economic Research.

URL: https://www.nber.org/papers/w23285

Achen, Christopher H and Larry M Bartels. 2016. Democracy for realists: Why elections do not produce responsive government. Princeton University Press.

Aldrich, John H, Jacob M Montgomery and Wendy Wood. 2011. "Turnout as a habit." Political behavior 33(4):535-563.

Alexander Branham, J. 2018. "Partisan Feedback: Heterogeneity in Opinion Responsiveness." Public Opinion Quarterly 82(4):625-640.

Anelli, Massimo, Italo Colantone and Pietro Stanig. 2019. "We Were the Robots: Automation in Manufacturing and Voting Behavior in Western Europe." Working Paper.

URL: https://www.iza.org/publications/dp/12485/we-were-the-robots-automation-andvoting-behavior-in-western-europe

Autor, David and Anna Salomons. 2018. "Is Automation Labor Share-Displacing? Productivity Growth, Employment, and the Labor Share." Brookings Papers on Economic Activity 2018(1):1-87.

Autor, David H. 2015. "Why Are There Still So Many Jobs? The History and Future of Workplace Automation." The Journal of Economic Perspectives 29(3):3-30.

Autor, David H, Frank Levy and Richard J Murnane. 2003. "The Skill Content of Recent Technological Change: An Empirical Exploration." The Quarterly Journal of Economics 118(4):1279-1333.

Baicker, Katherine, Amy Finkelstein et al. 2019. "The Impact of Medicaid Expansion on Voter Participation: Evidence from the Oregon Health Insurance Experiment." Quarterly Journal of Political Science 14(4):383-400. 
Berinsky, Adam J. 2017. "Rumors and health care reform: Experiments in political misinformation." British journal of political science 47(2):241-262.

Berinsky, Adam J, Michele F Margolis and Michael W Sances. 2014. "Separating the Shirkers From the Workers? Making Sure Respondents Pay Attention on Self-Administered Surveys." American Journal of Political Science 58(3):739-753.

Brader, Ted, Nicholas A Valentino and Elizabeth Suhay. 2008. "What Triggers Public Opposition to Immigration? Anxiety, Group Cues, and Immigration Threat." American Journal of Political Science 52(4):959-978.

Broockman, David E. 2016. "Approaches to Studying Policy Representation." Legislative Studies Quarterly 41(1):181-215.

Broockman, David E and Daniel M Butler. 2017. "The Causal Effects of Elite PositionTaking on Voter Attitudes: Field Experiments with Elite Communication." American Journal of Political Science 61(1):208-221.

Broockman, David E, Joshua L Kalla and Jasjeet S Sekhon. 2017. "The design of field experiments with survey outcomes: A framework for selecting more efficient, robust, and ethical designs." Political Analysis 25(4):435-464.

Bruch, Sarah K, Myra Marx Ferree and Joe Soss. 2010. "From policy to polity: Democracy, paternalism, and the incorporation of disadvantaged citizens." American Sociological Review 75(2):205-226.

Brynjolfsson, Erik and Andrew McAfee. 2014. The Second Machine Age: Work, Progress, and Prosperity in a Time of Brilliant Technologies. New York: WW Norton \& Company.

Campbell, Andrea. 2012. "Policy makes mass politics." Annual Review of Political Science $15: 333-351$.

Campbell, Andrea Louise. 2003a. How policies make citizens: Senior political activism and the American welfare state. Princeton, NJ: Princeton University Press.

Campbell, Andrea Louise. 2003b. "Participatory reactions to policy threats: Senior citizens and the defense of Social Security and Medicare." Political Behavior 25(1):29-49.

Campbell, Angus and Philip E. Converse. 1960. The American Voter. New York: Wiley.

Card, David, Carlos Dobkin and Nicole Maestas. 2009. "Does Medicare Save Lives?" Quarterly Journal of Economics 124(2):597-636.

Carpenter, Josh and Florian Foos. 2016. Beyond the Submerged State: Exploring the Limits of Policy-Based Mobilization. In annual conference of the Midwest Political Science Association, Chicago, April. Vol. 7.

Chapman, Gretchen B and Clark McCauley. 1993. "Early career achievements of National Science Foundation (NSF) graduate applicants: Looking for Pygmalion and Galatea effects on NSF winners." Journal of Applied Psychology 78(5):815. 
Climate Science Legal Defense Fund. 2017. "Useful Steps for Marching (and other Active) Scientists.". Climate Science Legal Defense Fund Blog.

URL: $\quad$ https://www.csldf.org/2017/03/21/useful-steps-for-marching-and-other-activescientists/

Converse, Philip E. 1964. Ideology and Its Discontents. New York: The Free Press of Glencoe chapter The Nature of Belief Systems in Mass Publics.

Coppock, Alexander and Donald P Green. 2016. "Is voting habit forming? New evidence from experiments and regression discontinuities." American Journal of Political Science 60(4):1044-1062.

Coppock, Alexander and Oliver A McClellan. 2019. "Validating the Demographic, Political, Psychological, and Experimental Results Obtained From a New Source of Online Survey Respondents." Research \& Politics 6(1):2053168018822174.

Dauth, Wolfgang, Sebastian Findeisen, Jens Südekum and Nicole Woessner. 2017. "German Robots-the Impact of Industrial Robots on Workers." CEPR Discussion Paper No. DP12306.

URL: https://ssrn.com/abstract=3039031

David, H and David Dorn. 2013. "The Growth of Low-Skill Service Jobs and the Polarization of the US Labor Market." American Economic Review 103(5):1553-97.

De Rooij, Eline A, Donald P Green and Alan S Gerber. 2009. "Field experiments on political behavior and collective action." Annual Review of Political Science 12:389-395.

Dinas, Elias. 2012. "The formation of voting habits." Journal of Elections, Public Opinion E Parties 22(4):431-456.

Eckersley, Peter and Yomna Nasser. 2019. Measuring the Progress of AI Research. Technical report Electronic Frontier Foundation.

URL: https://www.eff.org/ai/metrics

Evans, Geoffrey and Robert Andersen. 2006. "The Political Conditioning of Economic Perceptions." The Journal of Politics 68(1):194-207.

Executive office of the President. 2019. "Executive Order 13859 of February 11, 2019: Maintaining American Leadership in Artificial Intelligence." U.S. Federal Register 84(31):39673972 .

URL: https://www.govinfo.gov/content/pkg/FR-2019-02-14/pdf/2019-02544.pdf

Fiorina, Morris P. 1978. "Economic Retrospective Voting in American National Elections: A Micro-analysis." American Journal of Political Science pp. 426-443.

Fleur, Nicholas St. 2017. "Scientists, Feeling Under Siege, March Against Trump Policies." New York Times .

URL: https://www.nytimes.com/2017/04/22/science/march-for-science.html

Ford, Martin. 2015. Rise of the Robots: Technology and the Threat of a Jobless Future. New York: Basic Books. 
Freeder, Sean, Gabriel S Lenz and Shad Turney. 2019. "The Importance of Knowing "What Goes with What": Reinterpreting the Evidence on Policy Attitude Stability." The Journal of Politics 81(1):274-290.

Frey, Carl Benedikt. 2019. The Technology Trap: Capital, Labor, and Power in the Age of Automation. Princeton, NJ: Princeton University Press.

Frey, Carl Benedikt and Michael A Osborne. 2017. "The Future of Employment: How Susceptible Are Jobs to Computerisation?" Technological Forecasting and Social Change 114:254-280.

Frey, Carl Benedikt, Thor Berger and Chinchih Chen. 2018. "Political Machinery: Did Robots Swing the 2016 US Presidential Election?" Oxford Review of Economic Policy 34:418-442.

Fujiwara, Thomas, Kyle Meng and Tom Vogl. 2016. "Habit formation in voting: Evidence from rainy elections." American Economic Journal: Applied Economics 8(4):160-88.

Gaines, Brian J, James H Kuklinski, Paul J Quirk, Buddy Peyton and Jay Verkuilen. 2007. "Same Facts, Different Interpretations: Partisan Motivation and Opinion on Iraq." Journal of Politics 69(4):957-974.

Galvin, Daniel J and Chloe N Thurston. 2017. The Democrats' Misplaced Faith in Policy Feedback. In The Forum. Vol. 15 De Gruyter pp. 333-343.

Gauchat, Gordon. 2012. "Politicization of science in the public sphere: A study of public trust in the United States, 1974 to 2010." American Sociological Review 77(2):167-187.

Gerber, Alan and Don Green. 2012. Field Experiments: Design, Analysis, and Interpretation. New York: W.W. Norton.

Gerber, Alan S, Donald P Green and Christopher W Larimer. 2008. "Social pressure and voter turnout: Evidence from a large-scale field experiment." American political Science review 102(1):33-48.

Gerber, Alan S, Donald P Green and Ron Shachar. 2003. "Voting may be habit-forming: evidence from a randomized field experiment." American Journal of Political Science 47(3):540-550.

Gerber, Alan S, Gregory A Huber, Marc Meredith, Daniel R Biggers and David J Hendry. 2017. "Does Incarceration Reduce Voting? Evidence about the Political Consequences of Spending Time in Prison." The Journal of Politics 79(4):000-000.

Gingrich, Jane. 2019. "Did State Responses to Automation Matter for Voters?" Research \& Politics 6(1):2053168019832745.

Goos, Maarten and Alan Manning. 2007. "Lousy and Lovely Jobs: The Rising Polarization of Work in Britain." The Review of Economics and Statistics 89(1):118-133.

Grace, Katja, John Salvatier, Allan Dafoe, Baobao Zhang and Owain Evans. 2018. "When Will AI Exceed Human Performance? Evidence From AI Experts." Journal of Artificial Intelligence Research 62:729-754. 
Graetz, Georg and Guy Michaels. 2018. "Robots at Work." Review of Economics and Statistics 100(5):753-768.

Grafstein, Robert. 2005. "The Impact of Employment Status on Voting Behavior." The Journal of Politics 67(3):804-824.

Gray, Mary L. and Siddharth Suri. 2019. Ghost Work: How to Stop Silicon Valley from Building a New Global Underclass. Houghton Mifflin Harcourt.

Green, Donald P and Alan S Gerber. 2015. Get Out the Vote: How to Increase Voter Turnout. Washington, DC: Brookings Institution Press.

Green, Donald P, Bradley Palmquist and Eric Schickler. 2004. Partisan hearts and minds: Political parties and the social identities of voters. Yale University Press.

Guess, Andrew and Alexander Coppock. 2019. "Does Counter-Attitudinal Information Cause Backlash? Results From Three Large Survey Experiments." British Journal of Political Science .

URL: https://doi.org/10.1017/S0007123418000327

Hacker, Jacob S. and Paul Pierson. 2019. "Policy Feedback in an Age of Polarization." The ANNALS of the American Academy of Political and Social Science 685(1):8-28.

Hacker, Jacob S, Philipp Rehm and Mark Schlesinger. 2013. "The Insecure American: Economic Experiences, Financial Worries, and Policy Attitudes." Perspectives on Politics $11(1): 23-49$

Hainmueller, Jens and Daniel J Hopkins. 2015. "The Hidden American Immigration Consensus: A Conjoint Analysis of Attitudes Toward Immigrants." American Journal of Political Science 59(3):529-548.

Hainmueller, Jens and Dominik Hangartner. 2013. "Who Gets a Swiss Passport? A Natural Experiment in Immigrant Discrimination." American Political Science Review 107(1):159-187.

Hainmueller, Jens and Michael J Hiscox. 2010. "Attitudes Toward Highly Skilled and LowSkilled Immigration: Evidence From a Survey Experiment." American Political Science Review 104(1):61-84.

Heinrich, Tobias and Christopher Witko. 2019. "Technology-induced Job Loss and Public Issues Priorities." Working Paper.

Hertel-Fernandez, Alex. 2019. State Capture: How Conservative Activists, Big Businesses, and Wealthy Donors Reshaped the American States-and the Nation. Oxford University Press.

Hiscox, Michael J. 2006. "Through a Glass and Darkly: Attitudes Toward International Trade and the Curious Effects of Issue Framing." International Organization 60(3):755780 .

Holland, John L. 1959. "A theory of Vocational Choice." Journal of Counseling Psychology $6(1): 35$. 
Hyde, Susan D. 2015. "Experiments in international relations: Lab, survey, and field." Annual Review of Political Science 18:403-424.

Im, Zhen Jie, Nonna Mayer, Bruno Palier and Jan Rovny. 2019. "The "Losers of Automation": A Reservoir of Votes for the Radical Right?" Research 8 Politics 6(1):2053168018822395.

Jacobs, Lawrence R and Suzanne Mettler. 2018. "When and How New Policy Creates New Politics: Examining the Feedback Effects of the Affordable Care Act on Public Opinion." Perspectives on Politics 16(2):345-363.

Jardina, Ashley. 2019. White Identity Politics. Cambridge, UK: Cambridge University Press.

Kalla, Joshua L and David E Broockman. 2018. "The minimal persuasive effects of campaign contact in general elections: Evidence from 49 field experiments." American Political Science Review 112(1):148-166.

Khanna, Kabir and Gaurav Sood. 2018. "Motivated Responding in Studies of Factual Learning." Political Behavior 40(1):79-101.

Kinder, Donald R and Cindy D Kam. 2010. Us Against Them: Ethnocentric Foundations of American Opinion. Chicago, IL: University of Chicago Press.

Kinder, Donald R and D Roderick Kiewiet. 1979. "Economic Discontent and Political Behavior: The Role of Personal Grievances and Collective Economic Judgments in Congressional Voting." American Journal of Political Science pp. 495-527.

Larsen, Erik Gahner. 2019. "Policy feedback effects on mass publics: a quantitative review." Policy Studies Journal 47(2):372-394.

Lehmann, Erich Leo and Howard J D'Abrera. 1975. Nonparametrics: Statistical Methods Based on Ranks. San Francisco, CA: Holden-Day.

Lekalake, Rorisang, Zachary Markovich, Gabirel Nahmias and Stuart Russell. 2019. "Automation Risk and Support for a Universal Basic Income." Working Paper.

Lenz, Gabriel S. 2013. Follow the leader?: how voters respond to politicians' policies and performance. Chicago, IL: University of Chicago Press.

Lerman, Amy E and Katherine T McCabe. 2017. "Personal Experience and Public Opinion: A Theory and Test of Conditional Policy Feedback." The Journal of Politics 79(2):624641.

Lerman, Amy E, Meredith L Sadin and Samuel Trachtman. 2017. "Policy uptake as political behavior: evidence from the Affordable Care Act." American Political Science Review 111(4):755-770.

Lerman, Amy E and Vesla M Weaver. 2014. Arresting citizenship: The democratic consequences of American crime control. University of Chicago Press.

Levy, Karen. 2015. "The Contexts of Control: Information, Power, and Truck-Driving Work." The Information Society 31(2):160-174. 
Levy, Karen. 2016. "Digital Surveillance in the Hypermasculine Workplace." Feminist media studies 16(2):361-365.

Lewandowsky, Stephan, Gilles E Gignac and Samuel Vaughan. 2013. "The Pivotal Role of Perceived Scientific Consensus in Acceptance of Science." Nature Climate Change 3(4):399.

Lichtenberg, Frank R. 2002. "The effects of Medicare on health care utilization and outcomes." Forum for Health Economics 83 Policy 5(1).

Lin, Winston et al. 2013. "Agnostic notes on regression adjustments to experimental data: Reexamining Freedman's critique." The Annals of Applied Statistics 7(1):295-318.

Lü, Xiaobo, Kenneth Scheve and Matthew J Slaughter. 2012. "Inequity Aversion and the International Distribution of Trade Protection." American Journal of Political Science $56(3): 638-654$.

Madrian, Brigitte C and Nancy Beaulieu. 1998. Does Medicare Eligibility Affect Retirement? In Inquiries in the Economics of Aging. University of Chicago Press pp. 109-131.

Mansfield, Edward D and Diana C Mutz. 2009. "Support for Free Trade: Self-Interest, Sociotropic Politics, and Out-Group Anxiety." International Organization 63(3):425-457.

Mansfield, Edward D and Diana C Mutz. 2013. "US Versus Them: Mass Attitudes Toward Offshore Outsourcing." World Politics 65(4):571-608.

Margalit, Yotam. 2013. "Explaining Social Policy Preferences: Evidence From the Great Recession." American Political Science Review 107(1):80-103.

Markus, Gregory B. 1988. "The Impact of Personal and National Economic Conditions on the Presidential Vote: A Pooled Cross-Sectional Analysis." American Journal of Political Science pp. 137-154.

Mazumder, Soumyajit. 2017. "Does Public Policy Make Citizens? Causal Estimates of the Impact of the Welfare State Participation on Democratic Citizenship." Working Paper.

URL: http://smazumder.me/files/mazumder_medicare_v2.pdf

Mettler, Suzanne. 2005. Soldiers to citizens: The GI Bill and the making of the greatest generation. Oxford, UK: Oxford University Press.

Mettler, Suzanne. 2011. The submerged state: How invisible government policies undermine American democracy. University of chicago Press.

Mettler, Suzanne. 2018. The government-citizen disconnect. New York: Russell Sage Foundation.

Mettler, Suzanne and Andrew Milstein. 2007. "American political development from citizens' perspective: Tracking federal government's presence in individual lives over time." Studies in American Political Development 21(1):110-130.

Michaels, Guy, Ashwini Natraj and John Van Reenen. 2014. "Has ICT Polarized Skill Demand? Evidence From Eleven Countries Over Twenty-Five Years." Review of Economics and Statistics 96(1):60-77. 
Mooney, Chris. 2006. The Republican war on science. New York: Basic Books.

Morgan, Kimberly J and Andrea Louise Campbell. 2011. The delegated welfare state: Medicare, markets, and the governance of social policy. Vol. 1 Oxford, UK: Oxford University Press.

Motta, Matthew. 2018. "The Polarizing Effect of the March for Science on Attitudes toward Scientists." PS: Political Science and Politics 51:782-788.

URL: https://doi.org/10.1017/S1049096518000938

Mutz, Diana C. 2018. "Status Threat, Not Economic Hardship, Explains the 2016 Presidential Vote." Proceedings of the National Academy of Sciences 115(19):E4330-E4339.

Nadeau, Richard and Michael S Lewis-Beck. 2001. "National Economic Voting in US Presidential Elections." Journal of Politics 63(1):159-181.

Nannestad, Peter and Martin Paldam. 1994. "The VP-Function: A Survey of the Literature on Vote and Popularity Functions After 25 Years." Public Choice 79(3-4):213-245.

Ndulue, Emily Boardman. 2019. How the US Media Covers the Future of Work. Technical report Media Cloud.

URL: $\quad$ https://mediacloud.org/news/2019/5/8/how-the-us-media-covers-the-future-ofwork

Nedelkoska, Ljubica and Glenda Quintini. 2018. Automation, Skills Use and Training. Technical report OECD iLibrary.

URL: https://doi.org/10.1787/2e2f4eea-en

Newman, Benjamin J and Neil Malhotra. 2019. "Economic Reasoning with a Racial Hue: Is the Immigration Consensus Purely Race Neutral?" The Journal of Politics 81(1):153166 .

Nyhan, Brendan, Ethan Porter, Jason Reifler and Thomas J Wood. 2019. "Taking FactChecks Literally but Not Seriously? The Effects of Journalistic Fact-Checking on Factual Beliefs and Candidate Favorability." Political Behavior .

URL: https://doi.org/10.1007/s11109-019-09528-x

Nyhan, Brendan and Jason Reifler. 2010. "When Corrections Fail: The Persistence of Political Misperceptions." Political Behavior 32(2):303-330.

Nyhan, Brendan and Jason Reifler. 2015. Estimating Fact-Checking's Effects. Technical report American Press Institute.

URL: https://www.americanpressinstitute.org/wp-content/uploads/2016/09/EstimatingFact-Checkings-Effect.pdf

Oreskes, Naomi and Erik M Conway. 2011. Merchants of Doubt: How a Handful of Scientists Obscured the Truth on Issues From Tobacco Smoke to Global Warming. New York: Bloomsbury Publishing USA.

Orr, Lilla V and Gregory A Huber. 2020. "The Policy Basis of Measured Partisan Animosity in the United States." American Journal of Political Science . 
O'Grady, Tom. 2019. "How do economic circumstances determine preferences? Evidence from long-run panel data." British Journal of Political Science 49(4):1381-1406.

Patashnik, Eric M and Julian E Zelizer. 2013. "The struggle to remake politics: Liberal reform and the limits of policy feedback in the contemporary American state." Perspectives on Politics 11(4):1071-1087.

Pierson, Paul. 1993. "When effect becomes cause: Policy feedback and political change." World politics 45(04):595-628.

Pierson, Paul. 1995. Dismantling the welfare state?: Reagan, Thatcher and the politics of retrenchment. Cambridge, UK: Cambridge University Press.

Pierson, Paul. 2017. "American Hybrid: Donald Trump and the Strange Merger of Populism and Plutocracy." The British Journal of Sociology 68:S105-S119.

Polsky, Daniel, Jalpa A Doshi, Jose Escarce, Willard Manning, Susan M Paddock, Liyi Cen and Jeannette Rogowski. 2009. "The health effects of medicare for the near-elderly uninsured." Health services research 44(3):926-945.

Prior, Markus. 2010. "You've either got it or you don't? The stability of political interest over the life cycle." The Journal of Politics 72(3):747-766.

Raj, Manav and Robert Seamans. 2018. AI, Labor, Productivity, and the Need for FirmLevel Data. In The Economics of Artificial Intelligence: An Agenda. Chicago, IL: University of Chicago Press.

Rho, Sungmin and Michael Tomz. 2017. "Why Don’t Trade Preferences Reflect Economic Self-interest?" International Organization 71(S1):S85-S108.

Rodrik, Dani. 2018. "Populism and the Economics of Globalization." Journal of International Business Policy 1(1-2):12-33.

Rose, Deondra. 2017. "Higher Education and the Transformation of American Citizenship." PS: Political Science \& Politics 50(2):403-407.

Rose, Deondra. 2018. Citizens by degree. Oxford,UK: Oxford University Press.

Roy, Siddhartha. 2016. "Engineers Shall Hold Paramount the Safety, Health and Welfare of the Public - But Not If It Threatens Our Research Funding?". Flint Water Study.

URL: $\quad h t t p: / / f l i n t w a t e r s t u d y . o r g / 2016 / 10 /$ engineers-shall-hold-paramount-the-safetyhealth-and-welfare-of-the-public-but-not-if-it-threatens-our-research-funding/

Ruggiero, Leonard F. 2010. "Scientific independence and credibility in sociopolitical processes." Journal of Wildlife Management 74(6):1179-1182.

Schaffner, Brian F, Matthew Macwilllams and Tatishe Nteta. 2018. "Understanding White Polarization in the 2016 Vote for President: The Sobering Role of Racism and Sexism." Political Science Quarterly 133(1):9-35.

Schneider, Stephen H. 2009. Science as a Contact Sport: Inside the battle to save Earth's climate. National Geographic Books. 
Sedlak, David. 2016. "Crossing The Imaginary Line." Env. Science and Tech. 50(18):98039804.

Smith, Aaron. 2016. Public Predictions for the Future of Workforce Automation. Technical report Pew Research Center.

URL: $\quad$ https://www.pewinternet.org/2016/03/10/public-predictions-for-the-future-ofworkforce-automation/

Smith, Aaron and Monica Anderson. 2017. Automation in Everyday Life. Technical report Pew Research Center.

URL: http://www.pewinternet.org/2017/10/04/automation-in-everyday-life/

Soss, Joe. 2002. Unwanted claims: The politics of participation in the US welfare system. University of Michigan Press.

Thewissen, Stefan and David Rueda. 2019. "Automation and the Welfare State: Technological Change as a Determinant of Redistribution Preferences." Comparative Political Studies 52(2):171-208.

Tonn, Bruce, Angela Hemrick and Fred Conrad. 2006. "Cognitive Representations of the Future: Survey Results." Futures 38(7):810-829.

Valentino, Nicholas A, Ted Brader and Ashley E Jardina. 2013. "Immigration Opposition Among US Whites: General Ethnocentrism or Media Priming of Attitudes About Latinos?" Political Psychology 34(2):149-166.

van der Linden, Sander L, Anthony A Leiserowitz, Geoffrey D Feinberg and Edward W Maibach. 2015. "The Scientific Consensus on Climate Change as a Gateway Belief: Experimental Evidence." PLOS One 10(2):e0118489.

West, Darrell M. 2018. The Future of Work: Robots, AI, and Automation. Washington, DC: Brookings Institution Press.

White, Ariel. 2019. "Misdemeanor Disenfranchisement? The demobilizing effects of brief jail spells on potential voters." American Political Science Review 113(2):311-324.

Williamson, Vanessa, Theda Skocpol and John Coggin. 2011. "The Tea Party and the Remaking of Republican Conservatism." Perspectives on Politics 9(1):25-43.

Wing, Coady and Thomas D fCook. 2013. "Strengthening the Regression Discontinuity Design Using Additional Design Elements: A Within-Study Comparison." Journal of Policy Analysis and Management 32(4):853-877.

Winick, Erin. 2018. Every Study We Could Find on What Automation Will Do to Jobs, in One Chart. Technical report MIT Technology Review.

URL: https://www.technologyreview.com/s/610005/every-study-we-could-find-on-whatautomation-will-do-to-jobs-in-one-chart/

Wood, Thomas and Ethan Porter. 2019. "The Elusive Backfire Effect: Mass Attitudes' Steadfast Factual Adherence." Political Behavior 41(1):135-163.

Wu, Nicole. 2019. "Misattributed Blame? Attitudes Towards Globalization in the Age of Automation." Working Paper. 
Young, Robert S. 2017. "A Scientists' March on Washington Is a Bad Idea." New York Times.

URL: $\quad$ https://www.nytimes.com/2017/01/31/opinion/a-scientists-march-onwashington-is-a-bad-idea.html?_r=0 